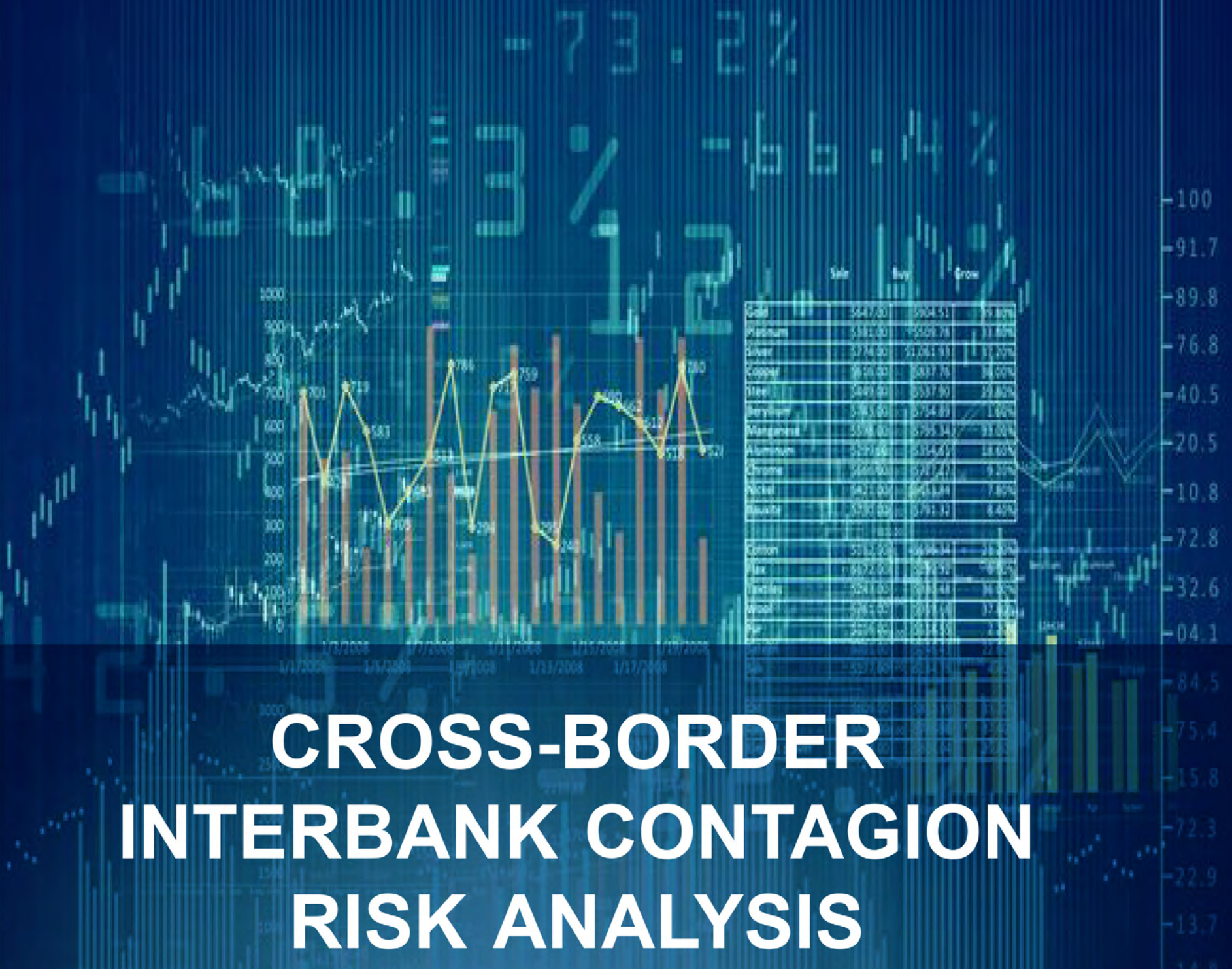

\title{
Roman Matousek
}

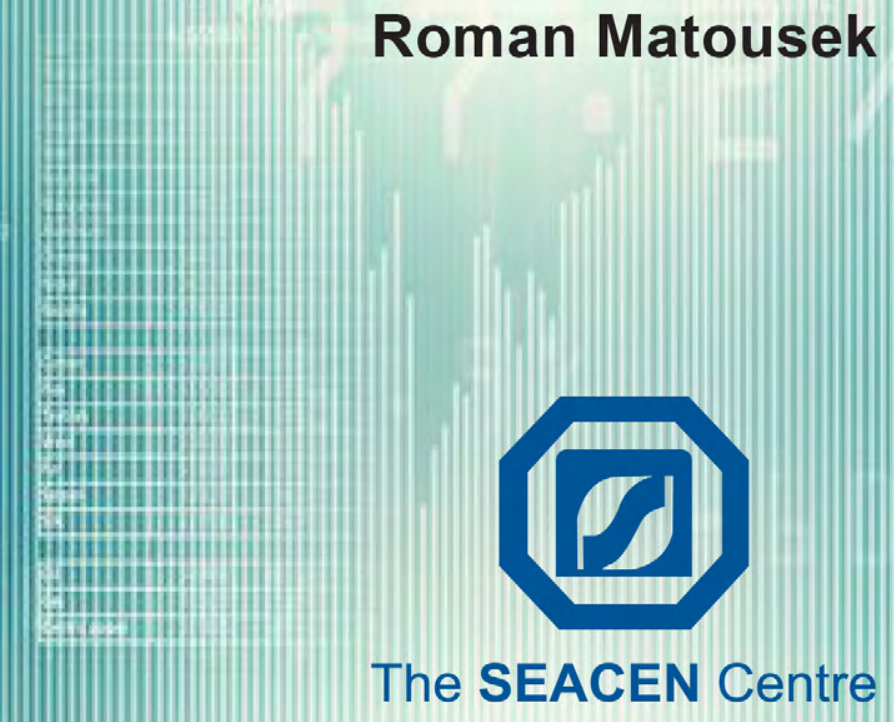

The South East Asian Central Banks (SEACEN)

Research and Training Centre 


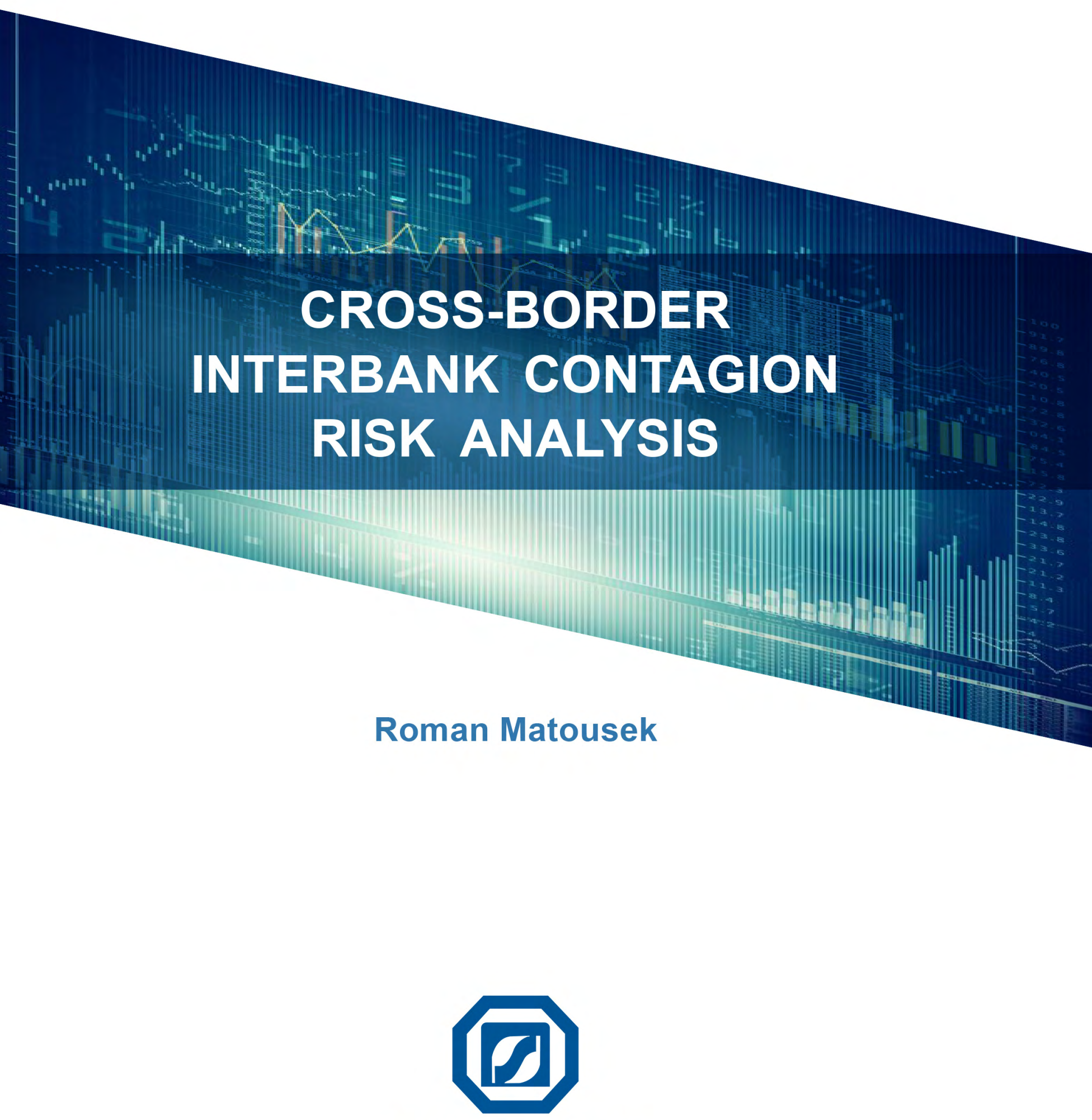

The SEACEN Centre

The South East Asian Central Banks (SEACEN)

Research and Training Centre 



\title{
FOREWORD
}

Since the early 1990s, we have observed unprecedented changes in the global financial architecture. In particular, international financial markets have become highly volatile and closely interconnected. It is evident that since 1997, cross-border financial integration in Asian emerging market economies has significantly accelerated and become rather complex. In this study, the project team members attempt to explore the effects of cross-border bank activites on contagion risk in the selected Asian-Pacific countries. The analysis then evaluates scenarios of potential triggers of cross-border interbank contagion risk in the Asia-Pacific region.

The project team comprised of representatives from the Reserve Bank of India, Bank Indonesia, Bank of Korea, Bank Negara Malaysia, Bank of Papua New Guinea, Bangko Sentral ng Pilipinas and State Bank of Vietnam. The SEACEN Centre wishes to express its sincere gratitude to the participating central banks for their support for this project.

The project was led by Roman Matousek, Professor of Finance and Director of the Global Centre for Banking and Financial Innovation for Nottingham University, Great Britain. Prof. Matousek was appointed as Visiting Research Economist at SEACEN in 2018. Sincere gratitude goes to Dr. Ole Rummel, Director of Macroeconomic and Monetary Policy Management (MMPM) at SEACEN, for his overall support, suggestions and lead role at all the stages of the project. The assistance of SEACEN staff members of MMPM, in particular Mrs. Jami'ah Jaffar, Dr. Victor Pontines and Dr. Rogelio Mercado is most gratefully acknowledged.

SEACEN is pleased to have been able to provide input for the project at a research workshop and seminar held at the SEACEN Centre where the findings of the project were presented and discussed. We would also like to acknowledge the helpful comments and suggestions from Professor Sushanta Mallick on the integrative report and summary chapter prepared by the project leader. The views expressed in this study are those of the authors and do not necessarily reflect those of the SEACEN Centre or the SEACEN member central banks/monetary authorities.

\author{
Hans Genberg \\ Executive Director \\ The SEACEN Centre
}

May 2019 


\section{EXECUTIVE SUMMARY}

A number of recent empirical studies by central banks and the academic literature have focused on the impact of the Great Financial Crisis (GFC) and on the systemic stability of the financial system as a whole. The complex financial cross-border interbank linkages conceal possible idiosyncratic shocks that may cause spillovers to other financial systems. It is imperative that financial regulators deploy models that allow them to monitor not only the soundness of SIBs but also the potential contagion risk caused by cross-country interbank linkages in Asian emerging market economies (AEME).

This collaborative research project on "Cross-border Interbank Contagion Risk Analysis" investigates cross-border interbank claims and liabilities of the individual countries located in the Asia-Pacific region. The study contributes to current research cross-border interbank contagion risk in the following ways: Firstly, this is the first study that is exclusively focused on Asian-Pacific countries, while taking into consideration the effect of the most developed economies and key financial centres. Secondly, the applied visual network analysis allows us to capture the flows of funds and highlight the financial linkages across the analyzed countries.

The analysis unambiguously shows that the volume of transactions has dramatically increased, particularly after 1997. There is also supportive evidence that the connectedness of economies in the Asia-Pacific region since 1997 has changed completely, specifically on the structure of how countries are connected now is significantly different. The links across the selected countries have become much closer and the volume of credit transactions has increased severalfold. The results further indicate that since 2016, there is the strong dominance of Hong Kong and China in the regional financial system. This type of structural change will necessarily have implications on system stability not only in terms of regional stability but also on a global scale. Yet, the dominance of Hong Kong and its extensive links with China while remarkable, is not surprising.

The study also concludes that a more comprehensive analysis of contagion risk with the help of more complex methodological frameworks can be conducted only if the reported statistics are improved, as studies capable of detecting possible triggers of systemic risk require much more disaggregated statistical information. 


\section{TABLE OF CONTENTS}

Foreword

Executive Summary

\section{Chapter 1}

INTRODUCTION

By Roman Matousek

References

\section{Chapter 2}

A CONTAGION RISK ANALYSIS THROUGH

VISUAL NETWORK: AN OVERVIEW OF THE

ASIA-PACIFIC REGION

By Roman Matousek, Seohyun Lee and Ole Rummel

1. Introduction

2. Financial Markets in the Asia-Pacific Region:

An Overview

2.1 Systemic Changes in the Asian Economies since $1997 \quad 11$

2.2 Cross border Activities in the Asia-Pacific Region 12

2.3 The Asia-Pacific Region after the Great Financial Crisis 13

3. Related Literature 14

3.1 Contagion Risk in the Financial Markets 14

3.2 Network Models: Theoretical Concepts 16

3.3 Empirical Research 17

4. Data and Methodology 17

4.1 Data Description 17

4.2 Network Settings 19

4.3 Network Measurements: Applied Indicators 20

5. Empirical Results 21

5.1 Network Connectivity Measurements 21

5.2 Visual Network Analysis $\quad 27$

6. Conclusions and Policy Implications 33

References $\quad 34$

$\begin{array}{ll}\text { Appendix } & 37\end{array}$ 


\section{Chapter 3}

CROSS-BORDER BANKING IN INDIAN CONTEXT

By Upasana Sharma

1. Introduction 39

2. Banking Sector in India: A Brief Overview 40

2.1 Brief History of Banking Sector 40

2.2 Present Scenario of the Banking Sector 41

2.3 Domestic Systemically Important Banks (D-SIBs) in India 42

2.4 Recent Developments and Challenges of the Indian Banking Sector 43

3. Literature Review 45

4. Data and Methodology 47

5. International Exposure of Banks in Indian Context 49

5.1 Some Stylised Facts 49

5.2 Indian Banking during Recent International
Crises

6. Network Analysis of Cross-border Banking in the Indian Context 55

7. Conclusion 58

References $\quad 60$

\section{Chapter 4}

UNDERSTANDING CROSS-BORDER CONTAGION RISKS IN INDONESIA

By Maulana Harris Muhajir; Arnanda H.F. Wibowo; and Irman Ramdhan

1. Introduction

2. Banking System and Cross-border Activities in Indonesia: An Overview

3. Literature Review

4. Data Collection and Applied Methodology 68

4.1 Identifying the D-SIB 68

4.2 Network Topology 70

4.3 Network Shock Simulation 71

5. Empirical Result 73

5.1 Identifying the D-SIB 73

5.2 Network Visualization $\quad 74$

5.3 Network Shock Simulation 78

6. Conclusion and Policy Implications 80

$\begin{array}{ll}\text { References } & 81\end{array}$ 


\section{Chapter 5}

GLOBAL NETWORK IN CROSS-BORDER INTERBANK FLOWS:

THE CASE OF SOUTH KOREA

By Seohyun Lee

1. Introduction 83

2. Banking Sector of South Korea 85

3. Data 88

4. Network Analysis 92

4.1 Methodology 92

4.2 Empirical Results 93

5. Conclusions 104

References 105

$\begin{array}{ll}\text { Appendices } & 106\end{array}$

\section{Chapter 6}

CROSS-BORDER INTERBANK CONTAGION RISK TO THE MALAYSIAN BANKING SYSTEM

By Harikumara Sababathy and Lim Sheng Ling

1. Introduction 109

2. Literature Review 110

2.1 Network Analysis $\quad 110$

2.2 Counterfactual Simulations $\quad 111$

3. Malaysian Banking System 113

4. Data 118

4.1 Network Analysis 118

4.2 Counterfactual Simulation Model 119

5. Methodology 119

5.1 Network indicators 119

5.2 Counterfactual Simulation Model 121

6. Results 123

6.1 Network Analysis 123

6.2 Counterfactual Simulation Analysis 129

7. Conclusion and Policy Implications 134

$\begin{array}{ll}\text { References } & 135\end{array}$

Appendices 138 


\section{Chapter 7}

CROSS-BORDER INTERBANK CONTAGION RISK ANALYSIS FOR PAPUA NEW GUINEA

By Ludwig Aur Aba

1. Introduction 143

2. Literature Review 144

3. An Overview of the Financial System in Papua New Guinea

3.1 Domestic Banking Activity 148

3.2 Early Warning Indicators 149

4. Data and Methodology 150

4.1 Data 151

4.2 Methodology 151

5. Empirical Analysis 153

5.1 Capital Adequacy 153

5.2 Credits and Asset Quality 155

5.3 Liquidity and Bank Failures 157

6. Cross-border Activities 159

6.1 Foreign Exchange Interbank Market in PNG 159

6.2 Domestic Banks' Foreign Exchange Holding 160

6.3 Cross-border Network Visualization 161

6.4 Foreign Liabilities 161

6.5 Foreign Claims 162

6.6 Cross-border Position Instrument, Sector and

7. Cross-border shocks through Interest Rates and Credit from Australia and Commodity Prices 165

7.1 Cross-border shocks through Interest Rates and Credit from Australia $\quad 165$

7.2 Commodity Prices 167

8. Conclusion 168

$\begin{array}{ll}\text { References } & 170\end{array}$

$\begin{array}{ll}\text { Appendix } 1 & 173\end{array}$ 


\section{Chapter 8}

PHILIPPINES: CONTAGION RISK ANALYSIS OF

CROSS-BORDER EXPOSURES OF BANKS

By Jenny T. Dizon, Jessica P. Hutalla and Jaime M. Rariza, Jr.

1. Introduction

2. Review of Related Literature

3. Overview of the Philippine Banking System (PBS)

3.1 Assessment of the Philippine Banking System's Cross-Border Exposures

3.2 Cross-Border Position of U/KBs by Region

3.3 Cross-Border Position of U/KBs by Country

4. Data and Methodology

5. Simulations and Results

5.1 Vulnerability Due to Credit Shock

5.2 Vulnerability Due to Funding Shock

5.3 Vulnerability Due to Funding Shock with Changes in Exchange Rate

6. Summary and Policy Implications

6.2 Policy Implications

\section{Chapter 9}

CROSS BORDER INTERBANK CONTAGION RISK

FROM VIETNAM'S BANKING SYSTEM

By Nguyen Ha Phuong, Phan Manh Cuong and

Ngo Thi Huyen Linh

1. Introduction

2. An Overview of the Financial Market - Banking System in Vietnam

2.1 Overview on the Structure of the Banking System

2.2 Main Challenges

2.3 Performance Indicators

3. Data and Methodology

3.1 Description of the Applied Methods

3.2 The Suitability of the Chosen Specific Methods 202

4. Empirical Part

4.1 Identification of D-SIBs 203

4.2 Stress Testing D-SIBs 206

5. Conclusions 211

References 



\title{
Chapter 1
}

\section{INTRODUCTION}

\author{
By \\ Roman Matousek ${ }^{1,2 *}$
}

This chapter serves as an introduction to the edited volume on "Cross-border Interbank Contagion Risk Analysis". We provide a brief summary of the research outputs that have been conducted by research teams from seven central banks located in the Asia-Pacific region, namely, the Reserve Bank of India, Bank Indonesia, Bank of Korea, Bank Negara Malaysia, Bank of Papua New Guinea, Bangko Sentral ng Pilipinas and State Bank of Vietnam. This unique research project includes eight comprehensive analytical studies that focus on cross-border contagion risk analysis.

Since 1997, we have observed unprecedented changes in terms of the financial architecture in the Asia-Pacific region. In particular, international financial markets have become highly volatile and closely interconnected. In a recent study, Genberg (2017) illustrated how financial integration in Asian emerging market economies (AEME) has not only been an important part of the global financial landscape, but has become more complex as a result. Cross-border interbank linkages in AEME form part of a true global network that resulted from elevated economic growth which was prevalently financed through banks. Similar arguments are presented by Seohyun Lee from the Bank of Korea in Chapter 5. Furthermore, financial products are more complex and the detection of possible systemic risk within the financial system and/or across financial systems is becoming increasingly difficult. As a direct reaction to these structural changes, the systemic stability of financial institutions and banks has become an important agenda for bank regulators. There has been extensive research on the so-called systematically important banks (SIBs). We also know that contagion risk through cross-border interbank activities is not easy to detect. The opaqueness of the linkages is even more pronounced when banks are mutually interconnected through off-balance sheet financial activities. Complex financial cross-border interbank linkages conceal possible idiosyncratic shocks that may cause spillovers to other financial systems. This project contributes to a number of studies that have been published by central banks, the International Monetary Fund (IMF) and the Bank for International Settlement (BIS). For more details see, for example, Von Peter (2007), Haldane and May (2011), Yellen (2013), Minoiu and Reyes (2013), Yilmaz (2017) and Korniyenko et al. (2018).

1. Global Centre for Banking and Financial Innovation (GCBFI), Nottingham University Business School, University of Nottingham, Nottingham NG8 1BB, Email: roman.matousek@nottingham.ac.uk

2. Othman Yeop Abdullah Graduate School of Business (OYAGSB), University Utara Malaysia, UUM Sintok, Kedah, Malaysia.

*. This project was conducted while I was a Visiting Research Economist at the SEACEN Centre as part of the SEACEN Research Project on "Cross-border Interbank Contagion Risk Analysis". I am grateful to the SEACEN Centre for its hospitality during my stay.

I thank participants of the Research Seminar at the SEACEN Centre, Dr. Ole Rummel and Professor Sushanta Mallick for their constructive comments and suggestions on an early version of this chapter. I also thank Mrs. Jami'ah Jaffar for her excellent administrative support. 
The objective of this research project is therefore several fold. First, the study provides a retrospective view of how financial systems have changed in the region, including structural changes in the seven countries. Next, individual studies map cross-border interbank money flows in and out of the countries under study. Each individual team project paper uses visual network analysis (VNA), which allows us to evaluate interbank exposures either for a specific country or for systematically important banks (SIBs). Through VNA, we may investigate 'hierarchical' crosscountry interbank contagion risk. Third, the analytical studies reveal and highlight potential weak links in cross-border interbank activities. Such an analysis evaluates interbank exposures to and from the individual countries. Finally, by creating a detailed mapping of cross-border interbank linkages in AEME, we can analyse the effect of an adverse credit event or liquidity contraction on SIBs through cross-border interbank linkages. This type of analysis may also identify triggers of contagion risk, which could be either market or idiosyncratic shocks. The findings may direct policymakers towards effective prudential management policies. An integral part of the outcomes of the individual country studies is to draw policy implications and recommendations for the particular countries and the region as a whole.

The common theme of the case studies in this volume is the importance of financial regulators imposing a prudent regulatory environment on banks' business behaviour.

In this chapter, we provide a summary of the individual case studies that are contained in this volume. Overall, emphasis is paid to the findings and policy implications. The first research paper by Roman Matousek, Seohyun Lee and Ole Rummel is related to the South-East Asian financial crisis (AFC) in 1997 and the Great Financial Crisis (GFC) in 2007-2008. The authors link common factors of both crises and show how the financial architecture and economic landscape have changed over the ten-year period between the two crises. The contribution of this chapter lies, among other things, in the discussion of the fundamental problems of financial crises in general and banking crises in particular. The analytical part includes an overview of the key issues related to cross-border contagion risk and describes extensively the underlying factors that may become potential triggers of a financial/banking crisis. The authors discuss broader issues that are relevant for this type of analysis, including a discussion of the consequences of the AFC that could be regarded as the starting point of the subsequent economic and financial development in the region. This discussion is further expanded by an analysis that explores cross-border (economy) activities and their structural changes over the last two decades. A final part includes a discussion of how the GFC affected the region, including the non-conventional monetary operations launched by the Federal Reserve in the US. The chapter contributes to current research by providing an overview of the recent contributions in the literature that include both theoretical and empirical research. The overall discussion starts with the clarification of how best to understand contagion risk. Once the authors establish the appropriate definition, they move on to the discussion of network analysis and its application to financial markets. This discussion is based on the seminal paper by Allen and Gale (2000). This subsection also provides a succinct summary of the key studies that should be consulted before any research project. Matousek et al. provide a detailed analysis of structural changes in the Asia-Pacific region based on the graphical presentation using visual network analysis (VNA). The analysis shows the changes in interbank activities in the decade from 1998 to 2018. 
The comprehensive analytical overview permits the authors to identify some of the key problems that specific economies could face. In particular, they find that economies within the region surpassed the importance of many of the G7 countries (Great Britain and Japan, in particular). Since 2016, Hong Kong and China dominate the regional financial system. This type of structural change will necessarily have implications on systemic stability not only in terms of regional stability, but also on a global scale. The dominance of Hong Kong and its extensive links with China may be remarkable, but perhaps not surprising. The authors argue that this extremely close link could have serious contagion effects if the Chinese economy were to face turbulence, mainly on account of the fact that international flows of money terminate in China and are not diversified further. This is very different from the 2000 s, when Japan played the key role in the network. At that time, the flows of money from Japan were directed mainly at Singapore, but Singapore in turn widely diversified the received financial resources. They conclude that there is a need to further explore economies' (banks') portfolio diversification in the region.

Chapter 3 is presented by Upasana Sharma from the Reserve Bank of India. The author analyses cross-border risks to the Indian banking sector. The study provides a detailed analysis of recent changes in Indian financial markets, with a special emphasis on the banking sector. The analytical part contains a thorough overview of the main challenges that the Indian central bank and government have been facing in maintaining stable financial markets. The author discusses the various evolving stages of financial needs in a country that has been undergoing fundamental structural changes. She argues that the banking sector has been the predominant player in the Indian financial system in terms of providing resources to the commercial sector, channelling household savings and, hence, playing an important role in financial intermediation. The discussion is supported by extensive statistical data showing how the regulator and government have contributed to making the sector more efficient, thus enabling it to play a crucial role in financial intermediation. An integral part of this analysis is the discussion of recent challenges that Indian banks face in terms of their asset quality.

The subsequent part of this case study explores the cross-border banking network. The author argues that cross-border banking activities in India remain somewhat muted. By using VNA's weighted degree measure, Sharma shows that India's major counter-parties in the case of crossborder liabilities are the US, the UK, France, Germany and Japan. Perhaps surprisingly, the results show that India's role in cross-border interbank activities is not that prominent.

Chapter 4 on "Understanding Cross-border Risks in Indonesia" was prepared by Maulana Muhajir, Arnanda Wibowo and Irman Ramdhani from Bank Indonesia, who analyse the network topology of cross-border interlinkages for systemically important banks from the Indonesian perspective, as well as their interconnectedness to global financial hubs. The authors also explore potential contagion risks within cross-border activity in the event of a credit and funding shock in the network system using a simulation method introduced by Espinosa-Vega and Sole (2010).

The authors commence their analysis with an overview of the international linkages of the Indonesian banking system. They show that cross-border interbank activities among banks that operate in Indonesia and those outside the country occur mostly in the regional financial hubs. They identify Singapore as a key financial centre that has the most transactions with banks from Indonesia. Furthermore, Hong Kong and UK banks are the second and third-largest contributors respectively. The study indicates that there are 30 banks which are mainly categorised as domestic 
systemicaly important banks (D-SIBs) in Indonesia. These Indonesian D-SIBs dominate the market. The authors also identify two state-owned banks as key players within the Indonesian banking system. In terms of the interconnectedness score, only three banks yield a significant result because of the high number of claims and liabilities held in the intra-financial system. By using VNA, the authors show that Indonesia's cross-border interbank money market was negatively impacted in the aftermath of the GFC. Evidence was found for 2007 and 2008, when there was a squeeze in the cross-border interbank money market. While there were many linkages in crossborder interbank money markets in 2007, that number had fallen one year later. Furthermore, the authors find that most of the important banks are domiciled in either Europe (France and Germany) or Asia (Singapore and Japan). Meanwhile, the domestic banking group that conducts the most cross-border transactions is a foreign-branch bank. An interesting finding shows that not all of the 30 D-SIBs were involved in cross-border interbank bank activites in 2017. Rather, the prominent linkages include only 15 D-SIB and 22 international banks.

The second part of their analysis focuses on network shock simulation. The results indicate that Indonesian SIBs have adequate capital to cover their losses even in the worst-case shock scenario. The authors conclude that the central bank should pay more attention to cross-border interlinkages as the interbank money market could be an early warning indicator for a banking crisis.

Chapter 5 explores global networks in cross-border interbank flows in South Korea. This chapter is prepared by Seohyun Lee from the Bank of Korea. The case study aims to explore the role of South Korea as an important financial intermediary in the Asian-Pacific region. The key focus of the analysis is put on the time period before and after the GFC. The author outlines common trends in the Asia-Pacific region since the AFC in 1997. Based on firm statistical evidence, Lee argues that financial markets have experienced remarkable growth that has attracted foreign capital inflows directly to these countries or to the regional financial centres, such as Hong Kong, Singapore and Macau. It is further shown that advanced economies in the region, such as Australia, South Korea and Chinese Taipei, have also expanded their international exposures in the region.

The author then provides a brief overview of the importance of the South Korean financial market in the region. She shows that the South Korean banking system has become more linked to international and regional financial markets. Banks' balance sheets have been more integrated globally than their asset side, with international liabilities equivalent up to $22 \%$ of the annual GDP. There have also been important changes in terms the role of South Korea within the financial markets after the GFC. More specifically, the country has become a net creditor to Asia-Pacific economies. The author also provides a brief, but very informative, discussion about the overall South Korean banking system, and argues that the banking sector has remained stable with sufficient capacity for withstanding domestic and external shocks. The analytical part is based on VNA and confirms the hypothesis that the financial network of cross-border banking activities in the Asia-Pacific region has become more interconnected and thus complex. The results further confirm that following the GFC, South Korea has become more active in serving as a financial intermediary for capital flows in and out of the Asia-Pacific region. The author identifies the triggers of these changes, which include stronger growth in AEME that in turn attracted capital flows from advanced countries and South Korea. Next, advanced economies' monetary policies have significant implications on cross-border bank activities and their network. A final push factor 
is the high demand for lending in emerging Asia. However, the author argues that this trend can be reversed as lending in advanced economies recovers in line with robust economic growth. The study concludes with a list of relevant policy recommendations that are strongly supported by empirical findings.

Chapter 6 is prepared by a research team from Bank Negara Malaysia that consists of Harikumara Sababathy and Lim Sheng Ling. This chapter focuses on the analysis of cross-border interbank contagion risk to the Malaysian banking sector. The research objective of this case study is twofold. First, they apply VNA and counterfactual simulation to analyse interconnectivity within the interbank market and solvency contagion risks of Malaysian banks. The analytical part on the Malaysian banking system indicates that domestic banks are more exposed to adverse market and geopolitical developments across different economies in Asia. The authors show that moderate spillover effects were observed in the domestic market during the period of the GFC in 2008 as a result of tightened US dollar conditions. They show that the extent of financial linkages of the Malaysian banking system has evolved and increased steadily since the GFC. The authors also explain that the rapid expansion of Malaysian banks' external exposures is driven by the sizeable presence of foreign banks in Malaysia, which include activities in the Labuan International Banking and Financial Centre (LIBFC) and regionalisation of domestic banks, particularly in the ASEAN region.

The next part of their research is based on the VNA's methodological framework of Minoiu and Reyes (2011). In turn, the counterfactual simulation analysis is based on Battiston et al. (2012). The authors' findings support the expectation that interconnectivity and solvency contagion risk in the Malaysian banking system to external shocks have declined since 2013. They further argue that SIBs are more prone to induce contagion within the network. The authors contribute to current research by evaluating potential losses that arise from two other channels of contagion, namely, valuation losses due to common asset exposures and mark-to-market losses resulting from credit quality deterioration or a loss of confidence (also known as the 'credit quality channel' (Fink et al. (2016)).

Finally, the authors outline directions for future research. One of their suggestions on how to improve the rigorousness of their findings is to assess contagion risk by taking into account other forms of interlinkages through which banks are interconnected with other financial institutions, such as a wider set of asset classes, e.g. cross holdings of securities or markets such as over-the counter (OTC) derivative markets.

Chapter 7 is written by Ludwig Aur Aba from the Bank of Papua New Guinea and assesses cross-border interbank contagion risk for the financial sector in Papua New Guinea (PNG). The author's aim is to highlight contagion risks faced by banks with respect to their cross-border dealings. Such an analysis should help to establish the networks through which potential contagion can spread from one country to another. An integral part of this analysis is the identification of sources of contagion risk, both domestic and external. Such an analysis should allow us to estimate the magnitude of those shocks on domestic banks through the banking network. The analysis has important policy implications for central bankers since they are able to fully recognise the sources of contagion and contagion transmission channels. In other words, the central bank could undertake proactive micro- and macroprudential measures to intervene and mitigate potential losses associated with the banks' exposures from their cross-border trading. 
The author starts the analysis by reviewing the main challenges facing the banking system in PNG. Aba argues that the key obstacles to the financial system's sound development are a lack of foreign currency and trading in the interbank foreign-exchange market. The available data show that banks are short of foreign exchange due to its growing demand. Moreover, existing liquidity is distributed unevenly across banks. The author states that despite these challenges, banks have been performing well and remain profitable. It is further argued that there has been a decline in bank credit, GDP growth, commodity prices, and interest and exchange rates which is seen as a potential trigger that can escalate contagion risk in the banking network.

The methodological framework that is applied to a stress test is based on Cihak (2007). It allows for the imposition, estimation and subsequent assessment of the impact of shocks on some key macroeconomic variables on bank activities. Shock from a credit default, non-performing loans (NPLs) and a bank's credit and funding difficulties that causes a liquidity squeeze on other banks are also captured. The second part of the analysis focuses on the mapping of cross-border interbank activities and is modelled by VNA. The third part of the analysis deploys ordinary least squares regressions to estimate the extent to which a shock affects domestic banking activity in PNG, especially credit, capital adequacy and liquidity.

The findings indicate that banks in PNG are capitalised over and above the minimum regulatory threshold. As a result, shocks that originate from NPLs, credit, interest rates, liquidity and the exchange rate should only have a minimal impact on the systemic stability of the banking sector. Nevertheless, unevenly distributed liquidity among the banks continues to remain a challenge. The findings on cross-border positions and risk transfers indicate that most of the claims against PNG are held by non-bank corporates from Australia, Japan, France, Hong Kong and Chinese Taipei. That could be a potential indication of where most of the risks are coming from. The empirical results thus support the argument that there are more inward than outward risk transfers. The study concludes that network visualisation provides a clear analytical view about the connectedness across the region. The author concludes that PNG banks have adequate capital buffers to withstand the shock. However, potential domestic and external shocks are real and present a number of risks for domestic banks.

A research group from Bangko Sentral ng Pilipinas, represented by Jessica Hutalla, Jenny Dizon and Jaime Rariza, analyse "Contagion Risk Analysis of Cross-border Exposures in the Philippines" in Chapter 8. The case study explores cross-border exposures of universal and commercial banks with their key cross-border counterparties. The study also includes the assessment of the effects of credit and liquidity shocks on domestic and foreign banks' capital. The authors assess the potential systemic implications of the cross-border linkages of Philippine banks with their counterpart countries, such as the US and the selected Asia-Pacific countries, by deploying an interbank exposure model along the lines of Espinosa-Vega and Sole (2010). As the authors discuss, the network model permits them to identify systemic and vulnerable institutions in terms of capital absorption within a network of banks. It also enables the monitoring of contagion chains resulting from different financial shocks. They propose two scenarios wherein Philippine banks' balance sheets are subjected to different shocks. The first scenario includes assessing vulnerability due to credit shocks, while the second scenario considers credit-plus-funding shocks to the banking system. 
The findings of their analysis show that foreign banks are mostly affected by the failure of US counterparty banks, even at the lowest possible credit shock scenario. When the authors increased shock parameters, foreign banks' capital was impaired by default in counterparty banks in three countries, namely, the US, Japan and Singapore. In the second type of simulation that uses a funding shock scenario, they observe that because of roll-over and asset sales, the impact was minimal relative to the first scenario. But, in general, foreign banks were greatly affected by capital reduction compared to domestic banks. An interesting finding also reveals a possible link with Indonesia. The results for funding risk indicate that Indonesian and Chinese counterparty banks have induced more capital reduction on domestic banks than on foreign banks. Hutalla et al. conclude that foreign banks are mostly affected when there are counterparty defaults, but risks to contagion will be minimal as most of the identified D-SIBs were classified as domestic banks.

Chapter 9 focuses on "Cross-border Interbank Analysis in Vietnam". The research group from the State Bank of Vietnam, which consists of Nguyen Ha Phuong, Phan Manh Cuong and Ngo Thi Huyen Linh, provides interesting insights into the connectedness of the Vietnamese banking sector with external financial institutions. This empirical study attempts to equip policy makers in Vietnam with alternative scenarios of potential risk triggers of cross-border interbank contagion.

The first part of the study identifies D-SIBs. The methodological concept is based on the standard methodologies applied by the BIS and/or the IMF that deploy static quantitative indicators. The systematic importance of banks is assessed in two steps. First, the authors define quantitative scores using a set of indicators of scale, degree of alignment and substitutability. That is followed by he qualitative assessments that support the quantitative findings. Second, the team imposes a stress test of a bank's resilience in terms of its capital or liquidity in the face of shocks to risk factors. The authors apply the stress test on a sample of 15 Vietnamese D-SIBs in 2017. They impose hypothetical shock scenarios that are based on real market and bank system conditions in Vietnam, such as bad debt, cross ownership rate, exchange rates, interest rates and real estate price.

The results for the $15 \mathrm{D}$-SIBs in Vietnam unambiguously show that there is a very low level of contagion risk emanating from one bank's default on its obligation to other banks through the interbank market. In terms of international linkages, the authors argue that the impact from other countries on Vietnamese banks are low and do not have much impact. That result could be partially explained by the relatively low degree of connectivity between the Vietnamese banking sector and other countries. 


\section{References}

Allen, F. and D. Gale, (2000), "Financial Contagion," Journal of Political Economy, Vol. 108, No.1, pp. 1-33.

Battiston, S.; D. Delli Gatti; M. Gallegati; B. Greenwald and J. Stiglitz, J., (2012), "Liaisons Dangereuses: Increasing Connectivity, Risk Sharing, and Systemic Risk," Journal of Economic Dynamics and Control, 36(8), pp. 1121-1141.

Cihak, M., (2007), "Introduction to Applied Stress Testing,” IMF Working Paper, WP/07/59.

Espinosa-Vega, M. and J. Solé, (2010), "Cross-Border Financial Surveillance: A Network Perspective," IMF Working Paper, 10/105.

Fink, K.; U. Krüger; B. Meller and L. Wong, (2016), "The Credit Quality Channel: Modeling Contagion in the Interbank Market," Journal of Financial Stability, 25, pp. 83-97.

Genberg, H., (2017), "Global Shocks and Risk to Financial Stability in Asia," Working Paper 25/2017, The South East Asian Central Banks (SEACEN) Research and Training Centre, Kuala Lumpur, Malaysia.

Haldane, A.G. and R.M. May, (2011), "Systemic Risk in Banking Ecosystems," Nature, Vol. 469, pp. $351-355$

Korniyenko, Y.; M. Patnam; R. M. del Rio-Chanon and M. A. Porter, (2018), "Evolution of the Global Financial Network and Contagion: A New Approach," IMF Working Papers, 18/113, International Monetary Fund.

Minoiu, C. and J. A.Reyes, (2013), “A Network Analysis of Global Banking: 19782010,” Journal of Financial Stability, Vol. 9, No. 2, pp.168-184.

Von Peter, G., (2007), “International Banking Centres: A Network Perspective,” BIS Quarterly Review Working Paper, Basel, Switzerland.

Yellen, J., (2013), "Interconnectedness and Systemic Risk: Lessons from the Financial Crisis and Policy Implications," Board of Governors of the Federal Reserve System, Washington, D.C.

Yilmaz, K., (2017), Bank Volatility Connectedness in the SEACEN Region, SEACEN, Kuala Lumpur, Malaysia. 


\title{
Chapter 2
}

\section{A CONTAGION RISK ANALYSIS THROUGH VISUAL NETWORK: AN OVERVIEW OF THE ASIA-PACIFIC REGION}

By

\author{
Roman Matousek ${ }^{1,2 *}$, Seohyun Lee ${ }^{3}$ and Ole Rummel ${ }^{4}$
}

\section{Introduction}

This study outlines a detailed overview of the structural changes in the Asia-Pacific region from the 1990s onwards, and we also review the most relevant literature on this important topic. The second part of the paper then provides the descriptive analysis of the financial structures in the region including the role of the G7 countries, Luxembourg and Switzerland. The following chapters in this volume then focus on the specific characteristics of the individual countries with deeper insights about their financial structures.

A number of recent empirical studies by central banks and the academic literature have focused on the impact of the Great Financial Crisis (GFC) and the role of systematically important banks (SIBs) on the systemic stability of the financial system as a whole. These studies unambiguously show that cross-border interbank exposures affect the systemic stability of individual banking systems through the transmission of shocks, see, for example, Haldane and May (2011), Allen and Gale (2000), Yellen (2013) and Cerutti (2015), among others.

This contagion risk through cross-border interbank activities has not been easy to detect. The opaqueness of the linkages is even more pronounced when banks are linked through off-balance sheet financial activities. The complex financial cross-border interbank linkages conceal possible idiosyncratic shocks that may cause spillovers to other financial systems.

1. Global Centre for Banking and Financial Innovation (GCBFI), Nottingham University Business School, University of Nottingham, Nottingham NG8 1BB, Email: roman.matousek@nottingham.ac.uk

2. Othman Yeop Abdullah Graduate School of Business (OYAGSB), University Utara Malaysia, UUM Sintok, Kedah, Malaysia.

3. The Bank of Korea, Email: shlee5@bok.or.kr. All views expressed are solely those of author and cannot be taken to represent those of the Bank of Korea.

4. The SEACEN Centre, Kuala Lumpur, Email : orummel@seacen.org

*. This project was conducted as part of the SEACEN Research Project on Cross-border Interbank Contagion Risk Analysis, while I was a Visiting Research Economist at the SEACEN Centre. I am grateful to the SEACEN Centre for its hospitality during my stay.

We thank participants of the Research Seminar at the SEACEN Centre and Professor Sushanta Mallick for the constructive comments and suggestions on an early version of the paper. We also thank Mrs. Jami'ah Jaffar for her excellent administrative support. 
As Genberg (2017) shows, cross-border financial integration in Asian emerging market economies (AEME) has become rather complex. Following a lengthy period of high economic growth, which has been primarily financed through bank lending, cross-border interbank linkages in the AEMA have a prominent global network component. On the one hand, this type of interconnectedness has a positive effect on the efficient allocation of funds in terms of innovation activities and competition. On the other hand, cross-border interconnectedness poses higher contagion risk in terms of systemic instability within the banking system and financial institutions. Glasserman and Young (2015) further show that strongly interconnected financial systems report higher losses due to, and caused by, this contagion risk.

So far empirical research on systematic stability of the banking sector in AEME has been rather limited. It is imperative that financial regulators deploy models that allow them to monitor not only the soundness of SIBs but also the potential contagion risk caused by cross-country interbank linkages in AEME. In this paper we predominantly focus on the following two research objectives. First, we propose to analyse cross-border interbank claims and liabilities of the individual countries located in the Asia-Pacific region by deploying visual network analysis (VNA). Such an analysis evaluates interbank exposure to SIBs within the specific market. VNA allows us to also explore the 'hierarchical' cross-country interbank contagion risk that seems to have been neglected in similar studies. In doing so, we evaluate the contagion risk of the individual countries emanating from the financial centres in Hong Kong, Singapore, Tokyo, New York and London. A number of studies have shown that the network analysis is a suitable method in analysing the links between financial institutions (countries). It allows us to unveil links and statistical factors that could be used as a key tool for detecting the potential triggers of systemic risk and contagion effects. Overall, the visual network analysis is able to capture the very complex and extensive interconnectedness of financial institutions (countries). The pros and cons of such a methodological approach have been extensively assessed in a number of studies published by academics and researchers from central banks, the International Monetary Fund (IMF) and the Bank for International Settlement (BIS), e.g., Allen and Gale (2000), Upper (2007), Chau-Lan et al. (2009), Espinosa-Vega and Sole, (2010) and Changmo et al. (2014), among others.

Second, by creating a detailed mapping of cross-border interbank linkages in AEME, we may uncover possible weak links of an adverse credit event or liquidity contraction. Since we do not have data on SIBs through cross-border interbank linkages, as was applied, for example, by Upper (2007), we will explore these links at the country level. The analysis should also provide some insights into potential idiosyncratic shocks, including the impact of 'home bias'. This type of analysis may identify whether the triggers of contagion risk are market shocks or country specific shocks. We also address an important question regarding solvency and liquidity contagion risks. This is of crucial importance and the findings may direct policy makers towards effective prudential management policies.

In doing so, we deploy bilateral data on cross-border bank lending for 28 countries. The sample includes nine global core countries, that is, the $G 7^{5}$ plus Switzerland and Luxembourg; as well as six core economies in South-East Asia and the Pacific region, namely Australia, Hong Kong, Chinese Taipei, South Korea, Macau and the Philippines. We further include 13 periphery economies. The detailed discussion can be found in Section 4 on data and methodology. The visual network analysis allows us to capture the dynamics and structural changes across these economies including the Great Financial Crisis. Our analysis spans from 2000 Q4:to 2018 Q1.

5. The G7 countries include Canada, France, Germany, Italy, Japan, the United Kingdom, and the United States. 
In this particular study, we adopt the methodological framework proposed by Minoiu and Reyes (2013). The adoption of this methodological framework allows us to compare the finding for AEME with previous research and detect commonalities of the issues across economies. In addition, the execution of the model is relatively feasible even for those who have little knowledge in the field of network simulations systems.

The study contributes to current research in the following ways. To begin with, this is the first study that is exclusively focused on the Asian-Pacific economies, while taking into consideration the effect of the most developed countries and key financial centres. Second, the visual network analysis allows us to capture the flows of funds. This is a particularly important issue in the case of the liquidity constraint to which the financial institutions in the region were exposed to during the financial crisis. A relatively long sample period of our analysis also helps to understand the significant structural changes that took place across the economies in our analysis. We further follow the weighted approach applied by Minoiu and Reyes (2013) to identify the potential intensity of capital flows across the selected economies.

Furthermore, our study provides both qualitive and quantitative analyses through VNA about cross-border contagion risk in the selected Asian-Pacific economies. The key objective of such an analysis is to equip policy makers with the alternative scenarios of potential triggers of cross-border interbank contagion risk. An integral part of this analytical study is to provide recommendations on how to mitigate possible contagion risk within the specific economies and the Asia-Pacific region as a whole.

This chapter is organised as follows. Section 2 overviews the financial markets in the Asia-Pacific region. Section 3 reviews related literature and Section 4 summarises the data and methodology used in our chapter. Section 5 reports and explains the empirical results and Section 6 concludes.

\section{Financial Markets in the Asia-Pacific Region: An Overview}

\subsection{Systemic Changes in the Asian Economies since 1997}

Since the late 1990s, we have observed significant structural changes in terms of the systemic stability of financial markets. In particular, the activities of financial institutions have become more closely linked and interconnected. In 1997, Asian countries experienced one of the most protracted crisis in their recent history, and the financial systems in many countries were almost brought to a complete standstill. The crisis revealed not only the significant structural problems in their domestic economies, but also showed the extensive interconnectedness with financial institutions in advanced economies and global financial centres. The lesson that financial markets learnt during the Asian financial crisis was that domestic and/or external shocks can significantly undermine the systemic stability of the banking system if financial institutions are undercapitalised and face liquidity problems.

Nevertheless, there was a remarkable revitalisation of the financial systems immediately after the crisis. That is in a sharp contrast with what we saw during the Great Financial Crisis (GFC) after 2007-2008. One of the possible explanations why the GFC was much more severe and lasted for such a prolonged period was that since 1997, global financial markets have become even more 'integrated'. Emerging and less developed economies have become extremely dependent not only on their own state of the economy but on the economic stability and the phase of the business 
cycles in the advanced economies as well. This link could easily undermine their economic and financial stability and thus affect their further development. The common lesson from the financial crises is that it is important to maintain sound macroeconomic fundamentals along with financial stability underpinned by appropriate financial regulations. These are the basic measures that have to be implemented by regulators and policy makers. Nevertheless, as we argue later, it is not sufficient that these measures focus only on the soundness of purely domestic markets. Bank or even systemic failures can be 'imported' through contagion effects from other countries. Anecdotal evidence further shows that these effects are not necessarily limited to geographically neighbouring countries but can actually be transmitted across continents.

The international bank lending market, which has substantially expanded in the last two decades, has become more vulnerable to external shocks. For example, in 2007, net cross-border bank lending stood at US\$4.3 trillion. One year later, the same net cross-border lending was reduced to minus US\$1 trillion. This was a consequence of the financial market turbulences and uncertainty when the GFC fully unfolded. Such unprecedented volatility clearly indicates how financial liquidity can suddenly go into reverse. Because of the complexity and extensive linkages across global financial markets, changes in one dominant financial market can have a significant knock-on effect on even relatively sound banking systems. This problem is more pronounced in emerging and less developed economies that are more vulnerable to sudden inflows/outflows of short-term capital including speculative capital. Furthermore, countries' extreme dependence on external finances combined with an underdeveloped financial infrastructure and insufficient financial regulations may lead to unfavourable conditions and an inability to withstand different forms of adverse effects. Such adverse effects can be further reinforced by the higher complexity of financial products. It has become more difficult to detect possible systemic risks within the financial system and/or across the financial systems. The systemic stability of the banking system has therefore become an imperative task for bank regulators.

\subsection{Cross border Activities in the Asia-Pacific Region}

As Genberg (2017) shows, cross-border financial integration has become rather complex in Asian emerging market economies (AEME). Following many years of relatively high economic growth that was predominantly financed by banks, cross-border interbank linkages in the AEME now contain a strong global network component. We have witnessed a dramatic expansion of cross-border activities, predominantly in the form of cross-border bank lending. This acceleration of cross-border activities was driven particularly by international banks from the more advanced economies, including the G7 countries and both global as well as regional financial centres Singapore, Hong Kong and Kuala Lumpur. Von Peter (2007) provides a detailed analysis of how international banking activity has changed since 1990s. His analysis unambiguously shows that international lending activities are dominated by only a handful of global banks from advanced economies. For example, in [period], the United Kingdom held 20.4\% of international bank assets and $22.8 \%$ of international bank liabilities. With a share of $12.6(9.2) \%$ in terms of bank liabilities (assets), the United States constituted the second largest financial centre. Japan, by contrast, has seen a contraction in terms of international lending activities, most likely on account of the long-standing banking restructuring process. It is also of interest to note that Japanese banks do not provide lending directly to less developed economies, but rather allocate their assets to the financial centres in Hong Kong and Singapore (see Section 5 for a broader discussion). The other G7 countries, such as Germany, France and Switzerland, have significantly lowered their exposures to international lending activities to single-digit percentages. 
The current global economic and political uncertainty could undermine the fragile stability in emerging and less developed economies. In particular, the recent interest rate increases by the Federal Reserve, as well as the termination of quantitative easing in the USA and Europe, could put extra pressure on the financial liquidity position of financial institutions in Southeast-Asian economies. A resulting capital outflow combined with currency depreciation could have an adverse effect on systemic stability. The recent global outflow of funds from the emerging economies to the tune of US\$12.3 billion has undermined the stability of domestic currencies. And a global economic slowdown could aggravate the situation even more. Furthermore, countries also face the problem of political and economic uncertainty. The current trade disputes between the USA and China could have adverse consequences for Asian economies as a whole. It is well documented that a reduction of China's export could negatively affect supply chains across Southeast Asia, as regional trade with China is based on the trade of intermediate goods, which accounts for more than $50 \%$ of overall trade. In terms of internal economic and political issues, many Southeast Asian economies exhibit a high share of household debt that is linked to aggressive competition among the retail banks and non-financial institutions expanding their business activities into the retail banking sector.

On the other hand, countries are better equipped to withstand shocks coming from contagion effects. Asian-Pacific economies have put a lot of effort into the key factors that should alleviate potential contagion effect compared to the Asian financial crisis in 1998, including changes to exchange rate regimes. Many economies have abandoned the fixed currency pegs that prevented a devaluation of their currencies in the case of sudden financial market turbulence. That should prevent the sharp, crisis-led devaluations that we witnessed in 1998 when, for example, the Indonesian rupiah devaluated by more than $75 \%$ against the US dollar and the Malaysian ringgit devalued by more than $50 \%$. The current setting of the exchange rate regime, such as a managed float that Southeast Asian economies have consequently adopted, should considerably reduce the problem of sudden and rapid devaluations of their currencies.

A further important step that should significantly contribute to the reduction of possible contagion effects is the fact that most economies in the region have substantially boosted their foreign exchange reserves. In fact, some economies have increased their foreign exchange reserves tenfold since 1998. That should help to protect them from short-term speculative attacks on their domestic currencies. Moreover, many economies have addressed the problematic aspects of fiscal deficits, and fiscal discipline has been documented in a number of emerging and less developed economies in the region. This goes hand in hand with curbing inflationary pressures that might undermine overall financial and economic stability and cause unwanted contagion damage if financial market turbulences were to materialise.

\subsection{The Asia-Pacific Region after the Great Financial Crisis}

The emerging and less developed economies in Southeast Asia have undergone significant structural changes in terms of their cross-border activities and financial exposures. Although they still rank rather low in terms of the volume of transferred funds, linkages with countries have changed. A general expansion of the volume of transactions is mostly due to the increased number of international banks that have established operations in these economies. Undoubtedly, these stylised facts can be regarded as an early benefit of the extensive linkages across banks in the Asia-Pacific region. These activities also reflect the banks' business strategy of diversifying their portfolio to limit potential risks. But increased cross-border financial linkages may have potential 
negative externalities in terms of systemic stability, including the case of sudden capital outflows that many countries have recently faced as a reaction to the phasing out of quantitative easing in the USA and Europe.

A number of studies have recently tried to identify the links between quantitative easing (QE) and capital flows to Asia. The outcomes are rather inconclusive. For example, Cho and Rhee (2013) argue that the first round of QE (QE1) substantially contributed to capital inflows to Southeast Asian economies after the GFC. Their argument is based on the notion that QE1 lowered US yields, which 'helped' to redirect capital flow to Asia. The authors do not share the view that QE2 and QE3 had similar effects to QE1. They also point to the housing market in some Asian economies and the fact that many residential house prices have risen sharply. It appears that housing prices went up in those economies where the domestic currency has not appreciated. These observations might be also be ascribed to the prolonged QE policies and the resulting effects on global capital flows.

Overall, the turbulence in international financial markets during the GFC disrupted the flows of credit from advanced countries to emerging and less developed economies in Asia and Latin America. Based on the data from the BIS Banking Statistics, we may observe a decline in crossborder claims, which undoubtedly had an adverse effect. This was mainly caused by a retrenchment by global and multinational financial institutions. The structural changes that financial institutions and financial markets have undergone in the last three decades or so caused financial markets at different stages of their development to react differently to external shocks.

\section{Related Literature}

There has been an extensive number of empirical research studies that analyse potential systemic crises and contagion risk using VNA, which has become a well-recognised tool for mapping potential risk within the financial system. The key advantage is that financial linkages can be mapped on a truly global scale. A number of studies have been published by central bankers, financial regulators, practitioners and academics that focus on the factors that may trigger contagion risk. In particular, special attention has been given to the issues of systemic risk, intra- and cross-border contagion risk and the role of systematically important banks (SIBs). These studies unambiguously show the vulnerability of systemic banking stability to the transmission of shocks, see, for example, Allen and Gale (2000), Haldane and May (2011), Yellen (2013), Cerutti (2015), Minoiu and Reyes (2013) and Yilmaz (2017), among others.

\subsection{Contagion Risk in the Financial Markets}

Prior to starting the discussion about contagion risk and bank cross-border interconnectedness, it is important to look at how the term systemic risk is established and positioned within the economic literature that deals with contagion risk. Undoubtedly, the term systemic risk is broadly applied and its definition varies. We adopt the definition that is used by the Group of Ten (G10, 2001, p. 126). They propose the following definition:

"Systemic financial risk is the risk that an event will trigger a loss of economic value or confidence in, and attendant increases in uncertainty about, a substantial portion of the financial system that is serious enough to quite probably have significant adverse effects on the real economy. 
Systemic risk events can be sudden and unexpected, or the likelihood of their occurrence can build up through time in the absence of appropriate policy responses. The adverse real economic effects from systemic problems are generally seen as arising from disruptions to the payment system, to credit flows, and from the destruction of asset values. Two related assumptions underlie this definition. First, economic shocks may become systemic because of the existence of negative externalities associated with severe disruptions in the financial system. If there were no spillover effects, or negative externalities, there would be, arguably, no role for public policy. [...]

Gerlach (2009) shows that this definition provides three key factors that provide important characteristics of systemic risk. First, it must impact on a "substantial portion" of the financial system. Thus, it is risk to the financial system as a whole. Second, systemic risk has multiple spillover effects, i.e., a single bank facing severe financial distress can undermine the financial stability and soundness of other banks that are connected to it. Such a situation requires that the effects of this risk are somehow measured and the potential impact is quantified if possible. It is important to mention that systemic risk could be triggered by adverse macroeconomic conditions as well.

Degryse and Nguyen (2004) provide an additional way of detecting potential triggers of interbank contagion risk. They use the following three fundamental explanations. First, interbank contagion attains its momentum in the case of insufficient financial liquidity for a specific financial market. They correctly underline the fact that domestic and cross-border interbank markets provides liquidity only through the redistribution channel, which on its own fails to create new financial assets (liquidity). It is commonly observed from a number of financial crises that the key element that causes a liquidity crisis is the fact that an individual bank, or even the entire banking system, relies too much on the liquidity provided within domestic or cross-border markets. This can also be a reflection of the adopted business model by the bank in question. A further factor that often causes a liquidity constraint occurs when banks suddenly change their exposure to the interbank market due to their own liquidity problems or business activities. It is important to note that the withdrawal from the interbank market is a much easier and cheaper option for a bank than the liquidation of its long-term position. Hoggarth et al. (2010) show that large international banks respond to a liquidity problem by reducing their exposure on the interbank market rather than reshuffling their liquidity across their branches and subsidiaries.

The next factor that can contribute to systemic turbulences within the banking system is a change in market expectations. This can cause contagion and have spillover effects across the entire market and/or the cross-border interbank market. Such a situation occurred during the Asian financial crisis in 1997, for example, when banks faced unprecedented asset-liability mismatches. The latter became even more pronounced when the currencies of those countries depreciated, which led to runs on banks in some countries. The interbank market almost froze overnight, aggravating the problem. Finally, the third way in which systemic contagion can occur is through the failure of systematic important banks (SIB). The failure of a SIB may cause not only a systemic crisis of the banking system in the specific country, but an ensuing spillover effect can be contagious for the banking systems of neighbouring countries. The degree of contagion depends on the linkages across banks through domestic (cross-border) interbank markets. The main area of our concern is therefore to evaluate the linkages of those SIBs within the domestic and cross-border interbank markets that are key players in terms of both liquidity provision and asset activities. 


\subsection{Network Models: Theoretical Concepts}

The seminal paper by Allen and Gale (2000) derived a contagion model within a financial market equilibrium framework, where financial contagion is modelled as an equilibrium phenomenon. They show that because liquidity preference shocks are imperfectly correlated across regions, financial institution hold precautionary claims on other regional financial institutions. Such a mechanism is perceived to reduce risk against liquidity preference shocks. Allen and Gale (2000) further argue that the key factor that triggers contagion across the financial institutions (markets) is determined by the structure of the claims within the financial market system. It is then evident that systemic changes within the financial (banking) market can affect systemic changes within both the core-periphery and the core-core network. It is then further shown that such interconnectedness can have a positive effect on the efficient allocation of financial funds by improving financial innovation and competition.

In the economics literature, there is prevailing empirical support that a well-developed global financial network contributes to accelerated economic growth. Anecdotal evidence indicates that economic growth in emerging and less developed economies depends significantly on bank lending. Undoubtedly, competitive pressures within a global network of financial institutions can have a favourable effect on how capital is allocated. At the same time, a number of financial (banking) crises demonstrate that the network across global and multinational financial (banking) institutions undermines the stability of an individual banking system through adverse contagion risk. The latter occurs through systemic instability within the banking system and financial institutions. Glasserman and Young (2015) indicate that strongly interconnected financial systems report higher losses caused by contagion risk. The threat of contagion risk has multidimensional effects on emerging and less developed economies that have rather limited economic stabilisers to withstand the adverse effects of contagion risk, which can be escalated via cross-border interbank activities. Glasserman and Young (2015) further show that this is even more reinforced in cases where bank activities are linked through off balance sheet financial activities. In this regard, possible turbulences in terms of lending disruptions involving quite complex cross-border interbank linkages may contribute to a spillover effect on other financial institutions.

Frexias et al. (2000) model systemic risk in an interbank market. Their research question is on how the banking system is capable of withstanding the insolvency of one bank. They also explore whether or not the closure of one bank could cause a knock-on effect on the rest of the system. An integral part of their model is the investigation of how the central bank can coordinate to avoid the negative consequences on the payment system, including the doctrine of too-big-to-fail. Mirroring Allan and Gale (2000), Leitner (2005) also argues that an interconnectedness of financial institutions improves the allocation of scarce resources through innovation and competitiveness. Leitner (2005) shows that interconnectedness across banks is beneficial if it can push banks in a crisis to provide financial support for one another (bailing them out). This effect is, however, subject to their ability to coordinate such events. Gai and Kapadia (2010) argue that models with endogenous network formation, such as Leitner (2005), impose strong assumptions. They also state that the existing literature fails to differentiate between the probability of contagious default and the potential way it is propagated. Gai and Kapadia (2010) expanded existing analytical models of contagion in financial networks by allowing an arbitrary structure. In particular, they assessed two key channels of contagion in financial systems through which default may spread from one institution to another. The primary focus is on how losses can potentially spread via a complex network of direct counterparty exposures, following an initial default. They argue that the probability of contagion is generally low, but that the effect, once contagion occur, tends to be widespread. 


\subsection{Empirical Research}

The empirical research on interbank linkages and contagion risk is rather voluminous. Representative studies include Sheldon and Maurer (1998), Furfine (1999) and Wells (2002). While Boss et al. (2004) focus on case studies in European countries, Upper and Worms (2004) analyse contagion risk in the USA. Undoubtedly, they help policy makers to better understand the complexity of the financial network, although they fall short on providing general policy recommendations and policy actions needed to deal with an eventual manifestation of contagion risk. A further notable study involving VNA was published by Nier et al. (2007). The study is underpinned by the seminal paper by Allen and Gale (2000). However, Nier et al. (2007) provide much deeper insights into the area of contagion risk by exploring possible financial contagion effects. They show that banks that are well capitalised compared to their peers, are more resilient against possible contagious effects. They also show that a relatively marginal change in bank connectivity can trigger disproportional contagion effects. At the same time, if connectivity reaches a threshold value, bank connectivity can help banks that are mutually connected to withstand possible shocks. Nier et al. (2007) also find that the size of interbank liabilities can have a negative impact on bank stability through domino effects. That can occur despite sufficient capital reserves. In terms of competition, they provide evidence that a higher degree of concentration within the banking system can trigger larger systemic risk.

Minoiu and Reyes (2013) provide a comprehensive analysis of the global banking network using data on cross-border banking flows for 184 countries over the period from 1978 to 2010 . They show that the density of the global banking network is pro-cyclical. They also provide interesting evidence that country connectedness increases before financial crises and drops afterwards. In the paper, they further argue that the network density in 2007 was comparable to earlier peaks. A more recent study by Korniyenko et al. (2018) further explores the global financial network.

\section{Data and Methodology}

\subsection{Data Description}

As Fender and McGuine (2010) argued, the GFC ably demonstrated that the type of available information that would be needed by regulators to identify international funding risks is inadequate. Cerutti et al. (2012) pointed out that the quality of data is an important issue in the analysis about systemic risk. McGuire and Wooldridge (2005) review the currently available data sources for research on contagion effects and systemic risk. As highlighted in McGuire and Wooldridge (2005), the BIS currently provides three types of statistics on international banking activity: locational banking statistics (LBS), consolidated banking statistics (CBS) and syndicated loan statistics (SLS). LBS provides information on the external debt measures that use national accounts or balance of payments. LBS are generally used by national statistical offices for the construction and evaluation of balance of payments statistics, while CBS and SLS contain information regarding cross-border borrowing sourced from individual banks.

It is important at this stage to point out the differences of how the data are reported. McGuire and Wooldridge (2002) provide a detailed explanation of how these two sets of statistics differ from conventionally applied measures of external debt. The locational statistics cover cross-border positions of all banks domiciled in the reporting area, including positions vis-à-vis their foreign affiliates. But the consolidated statistics report the nationality of the reporting bank as well as their net out intragroup positions (McGuire and Wooldridge, 2005). Minoiu and Reyes (2013) advocate the use of LBS as the appropriate statistics if the aim is to explore linkages across countries. 
The focus of our analysis is an exploration and capture of the global financial network structure as it pertains to the Asia-Pacific region. In doing so, we use the LBS data set that is available from the BIS. We should note that LBS data are unconsolidated, which means the data sample includes positions vis-à-vis affiliates of foreign banks that reside in different countries. We only use data on loans and deposits on banks' balance sheet.

The sample period runs from 1998 Q1 to 2018 Q1 for nine core countries (Australia, Canada, France, Germany, Japan, Luxembourg, Switzerland, the United Kingdom, and the United States). Six other economies, namely Hong Kong, Italy, Macau, South Korea, Chinese Taipei and the Philippines, started reporting their banking flow statistics to the BIS after 1998. Therefore, the number of core and periphery economies varies over time. ${ }^{6}$

The different types of claims on reporting economies include loans and investments to counterparty economies (borrowers). Liabilities of a reporting economy include deposits, and borrowings from counterparty economies (lenders). As we may observe from Figure 1, both total claims and liabilities increased over time, reaching a peak in 2008 Q1 before plummeting during the financial crisis. Cross-border banking flows have gradually recovered since 2009 Q1. We find similar trends for total claims and liabilities of the G7 countries, Switzerland and Luxembourg. However, they exhibit different development after the GFC. Both total claims and liabilities stagnated and have not yet recovered to their pre-crisis level.

Figure 1. Total Amounts of Cross-border Bank Flows

(a) Total Claims

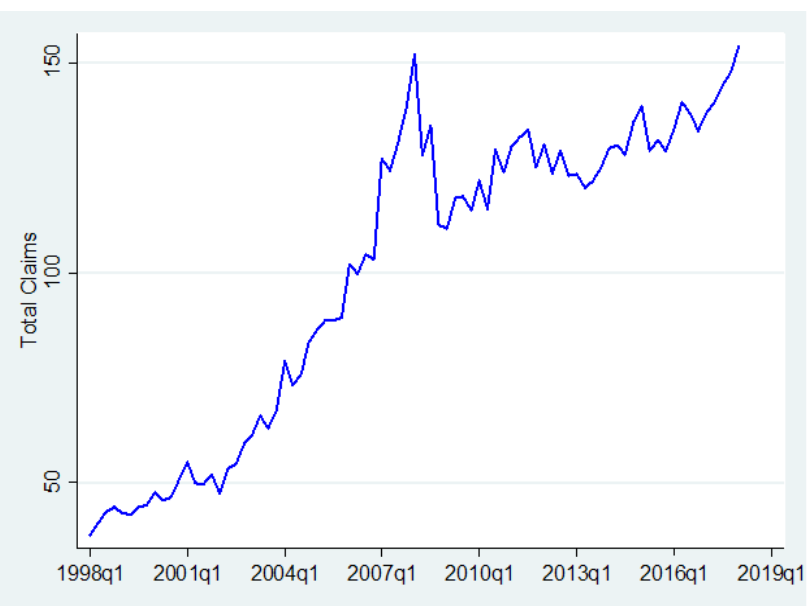

(b) Total Liabilities

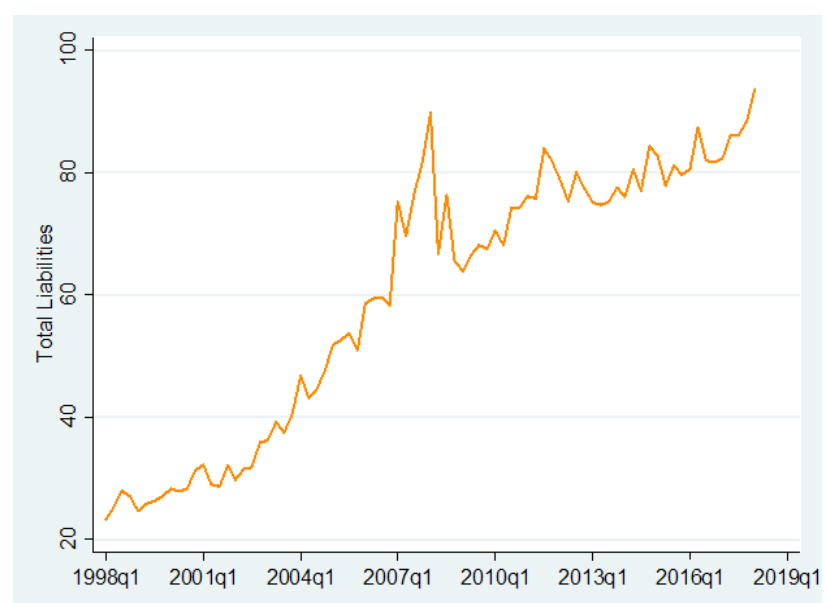

Source: BIS Locational Banking Statistics.

Notes: Total claims (liabilities) is the sum of all cross-border banking claims (liabilities) between reporting and counterparty countries. The data is modified using exchange rate and break adjusted changes based on BIS calculation. Total claims and liabilities are in 100 billion USD.

6. The number of each category is as follows: [1998q1-2000q3]: Core (10), Periphery (18), [2000q4-2003q3]: Core (11), Periphery (17), [2003q1-2005q3]: Core (12), Periphery (16), [2005q4-2014q3]: Core (13), Periphery (15), [2014q4-2016q3]: Core (14), Periphery (14), [2016q4-]: Core (15), Periphery (13). 
Figure 2a provides a comparison of the volume of cross-border flows by taking into consideration the full network and contrasting it with Figure $2 b$, which shows the flows when bilateral transactions between the G7 countries, Luxembourg and Switzerland are excluded.

Figure 2

\section{Cross-border Bank Flows (Claims)}

(a) Full network

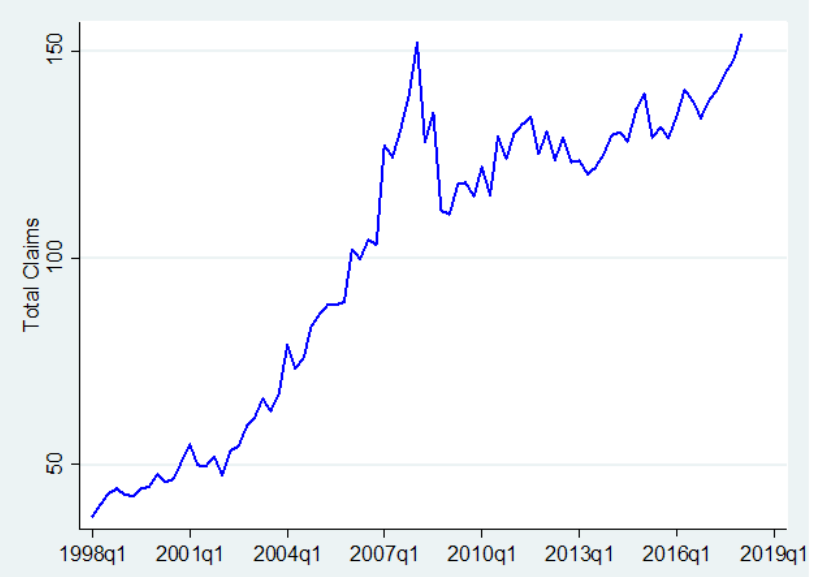

(b) Excluding bilateral transactions of G7+2

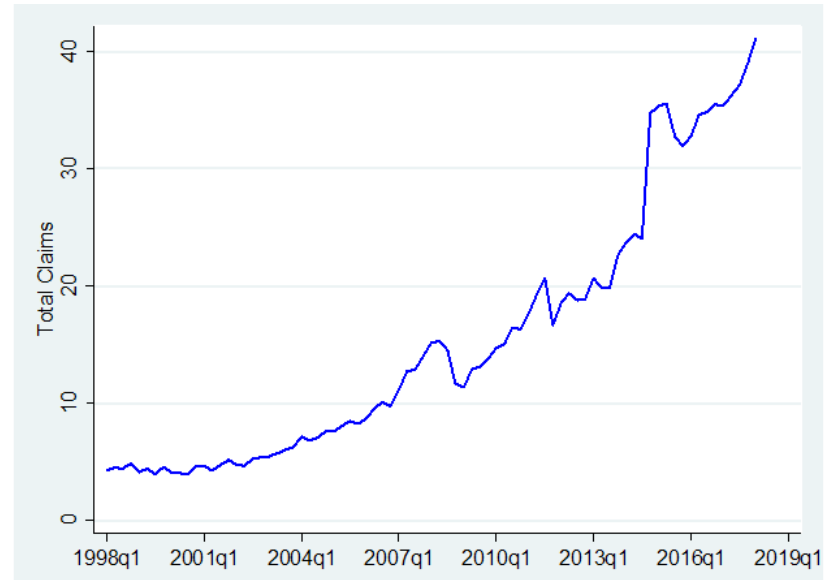

Source: BIS Locational Banking Statistics.

Notes: Total claims is the sum of all cross-border banking claims between reporting and counterparty countries. The data is modified using exchange rate and break adjusted changes based on BIS calculation. Total claims and liabilities are in 100 billion USD.

\subsection{Network Settings}

Our sample includes major economies in the Asia-Pacific region and other globally systemically important economies. In total, we collected data for 28 economies. We have nine global core countries (the G7countries as well as Switzerland and Luxembourg), six regional core economies (AU, HK, TW, KR, MO and $\mathrm{PH}$ ) and the remaining 13 have been designated as periphery economies (BD, CN, IN, ID, MY, MM, NP, NZ, PK, SG, LK, TH, VN). ${ }^{7}$ Core economies are defined as reporting economies to the BIS Locational Banking Statistics. As mentioned above, the available data set imposes certain restrictions that have to be taken into consideration. We need to map the network structure of core economies. However, some economies do not report these data so these are treated as periphery economies.

As Chan-Lau et al. (2007) show, by using the network simulation approach, we may assess direct and indirect cross-border interbank contagion risk caused by liquidity and/or solvency problems. In order to establish cross-country interbank linkages, we have to project a matrix that captures the exposures of individual banks. Working with central banks would allow us to collect data on bilateral exposures that provide a more detailed understanding of the potential contagion risks.

7. See Table A1 in Appendix for the complete list of economies and their abbreviations. 
Our network consists of a set of nodes that are represented by the 28 economies in our sample. Thus, each node represents an individual economy. A link to another economy then represents financial claims on the total banking system in that economy. The proposed network is constructed as follows: economies represent nodes and edges capture the flows of money. The orientation of links runs from source to target economies. Our network structure is a directed network that includes both in-coming and out-going links. Specifically, the evidence based on the links from sources to targets provides valuable information about which economy holds claims (liabilities) of other economies (through nodes). In our network structure some nodes (economies) are positioned as a source, but also as a target of bank flows. Other nodes (economies) represent a target only.

The individual linkages contain numerical values that capture the volume of claims (liabilities) across the entire network. The weights of edges represent the amount of bank flows for each edge. In our VNA, we can also define the size of nodes, the colour of nodes and the thickness of arrows to reflect different network features. The pattern and size of linkages in our VNA contain a wealth of information and provide a comprehensive picture that may help to fully understand the complexity of the captured linkages. The resulting structure also allows us to identify the key economies that dominate the system in terms of the flows of money to periphery economies.

\subsection{Network Measurements: Applied Indicators}

The next part of our discussion focuses on the fundamental network indicators that are vital for our analysis.

The node degree provides fundamental information about the number of links associated with a given node. As Kolaczyk (2009) explains, we can easily calculate the number of in-coming (in-degree) and out-coming links (out-degree) in a directed network structure. In other words, indegree captures claims and out-degree liabilities. The concept of node degree indicates the number of edges connected to a node (economy). An economy with a high node degree has a large number of cross-banking contracts among the region. For a directed network, in-degree can be defined as the number of bilateral links to a target economy, while out-degree refers to those from a source (reporting) economy. We can further obtain information about the total amount of cross-border flows by using the weighted node degree (node strength), giving rise to the weighted out-degree and/or weighted in-degree for a given node (economy). The latter two capture the intensity of financial flows for a particular economy (node). We should note that in our network, out-degree and weighted out-degree for periphery economies, is equal to zero. We may interpret the node degree as follows: a higher node degree refers to the number of bilateral cross-border bank transactions. In the case of the complete network, the decrease in weighted out-degree reflects the reduced bilateral transactions among advanced countries.

A further important network indicator is connectivity, which is measured as the ratio of the total number of links (edges) that exist in the network to the number of total possible links (edges). In other words, connectivity measures network density or, alternatively, it can be interpreted as the likelihood of a connection between two economies (Minoiu and Reyes, 2013). 
Betweenness centrality is a measure for the relative frequency of a node appearing in the shortest paths between every other pair of nodes in the network. This measure is intended to show the place of a node in the network and reflects how influential an economy is as an intermediary of flows in the network. A higher centrality value of an individual node (economies) indicates a higher importance of an economy in the network. This measure captures the transmission of contagion effects: nodes with higher centrality values have a larger influence on other nodes (economies).

Two additional summary statistics include closeness centrality and eccentricity. The former is defined as the average distance from a given starting node to all other nodes in the network. Closeness centrality therefore measures the mean distance from a node to other nodes. This quantity has a low value for nodes that are separated from others by only a short distance on average. Such nodes could have better access to information at other nodes or a more direct influence on other nodes. Newman (2010) shows that this indicator is a natural measure of centrality and is often used in social and other network studies. There is one issues with this indicator that is related to the fact that its values tend to span a rather small dynamic range from largest to smallest. As Newman (2010) further shows, this problem has practical implications, because it is difficult to distinguish between central and less central nodes using this measure. The second summary statistic, Eccentricity, measures the distance from a node to the farthest node from it.

Fagiolo (2007) expands the standard clustering coefficient of Watts and Strogatz (1998) for unweighted and undirected networks to binary directed networks and weighted directed networks. Tabak et al. (2011) show in the case of the Brazilian banking system that the directed clustering coefficient is a suitable indicator for measuring systemic risk in complex networks. The clustering coefficient measures the completeness of a neighbouring node. In our analysis, we apply the binary clustering coefficient, the value for which ranges from 0 to 1 . This coefficient is calculated as the ratio between the total number of complete triangles to the total possible number of such triangles.

\section{Empirical Results}

\subsection{Network Connectivity Measurements}

In this section, we try to capture the dynamics of lending relationships in the selected economies over the observed period. Such a detailed analysis will disclose the potential for partially hidden problems that might trigger a banking crisis through contagion effects.

Table 1 provides a basic overview of the various network indicators. We can see that the selected economies in our sample borrow from 7.3 lenders on average and up to 15 lenders in total. In each quarter, the borrowed volume is on average equal to US\$54.4 billion, with a range from zero (minimum) to US\$934 billion (maximum). Core economies lend on average to 18.29 economies and the maximum number of the economies that receive loans is 28 . The volume of flows in core economies ranges from US $\$ 0.79$ billion to US $\$ 1,378$ billion. The bottom panel of Table 1 provides information regarding network density. We observe that the likelihood of two economies being connected through cross-border flows falls in the interval from 59.5 to $71.9 \%$. As for the binary clustering coefficient, we find that two economies having a connection with one another if they both have a relationship with a third economy is on average $36.0 \%$ for all economies and $21.6 \%$ for reporting economies. Betweenness centrality, i.e., the relative frequency of a node appearing in the shortest path between every other pair of nodes in the network, is on average 8.96. The indicator of closeness centrality varies from 0.692 to 0.813 . 
Table 1

Summary Statistics of Network Indicators

\section{Claims}

\begin{tabular}{|c|c|c|c|c|c|}
\hline & Obs & Mean & SD & Min & Max \\
\hline \multicolumn{6}{|l|}{ Measures of country centrality } \\
\hline \multicolumn{6}{|c|}{ Network excluding transactions among advanced economies } \\
\hline In-degree & 2268 & 7.308 & 3.697 & 0 & 15 \\
\hline Weighted in-degree & 2268 & 54460.7 & 104178.5 & 0 & 934564.8 \\
\hline Out-degree & 906 & 18.295 & 4.694 & 4 & 27 \\
\hline Weighted out-degree & 906 & 136332.2 & 177590.3 & 709 & 1378037.0 \\
\hline \multicolumn{6}{|l|}{ Measures of network density } \\
\hline \multicolumn{6}{|c|}{ Network excluding transactions among advanced economies } \\
\hline Connectivity & 81 & 0.659 & 0.031 & 0.595 & 0.719 \\
\hline Clustering coefficient (all) & 81 & 0.366 & 0.132 & 0.064 & 0.480 \\
\hline Clustering coefficient (reporting) & 81 & 0.216 & 0.087 & 0.050 & 0.352 \\
\hline Betweenness & 81 & 8.967 & 1.287 & 6.867 & 12.667 \\
\hline Closeness & 81 & 0.761 & 0.033 & 0.692 & 0.813 \\
\hline
\end{tabular}

Source: Authors' calculations.

Figure 3 provides information about cross-banking contracts. Figure 3 a captures the changes in bilateral links to a target economy. We observe that the average number of links to target economies increased steadily since the early 2000s. Over this period, we observe several significant adjustments in terms of the quantity of bilateral cross-border activities, which may reflect structural changes after the dot-com bubble and the period before the GFC. However, a significant change can be seen shortly after the peak of the GFC. The number of cross-border in-coming links has increased from 2013Q2 and has continued to grow. We observe that the volume of cross-border lending has increased consistently over the entire period, which is reflected in node strength, which captures total flows (orange line in Figure 3a). We find a structural break shortly after the GFC in 2008.

By contrast, cross-border links from source to target economies display a steady pattern with a brief drop during the period of the GFC (Figure 3b). The strength of the nodes, however, increased from the relatively low values observed in 1998 and reached US\$1,137 billion shortly after the GFC. 


\section{Figure 3}

Time Series Graphs of Network Metrics (Claims; full network)

(a) In-degree

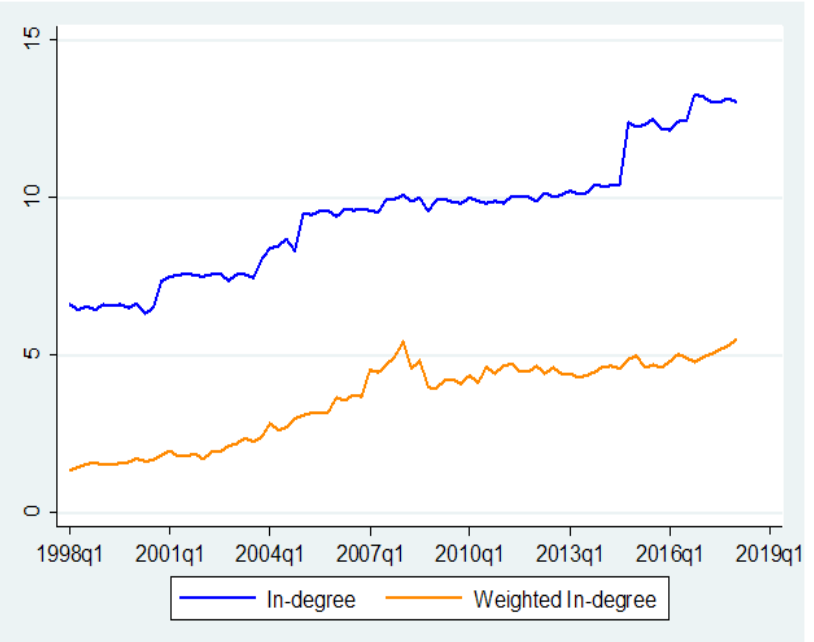

(b) Out-degree

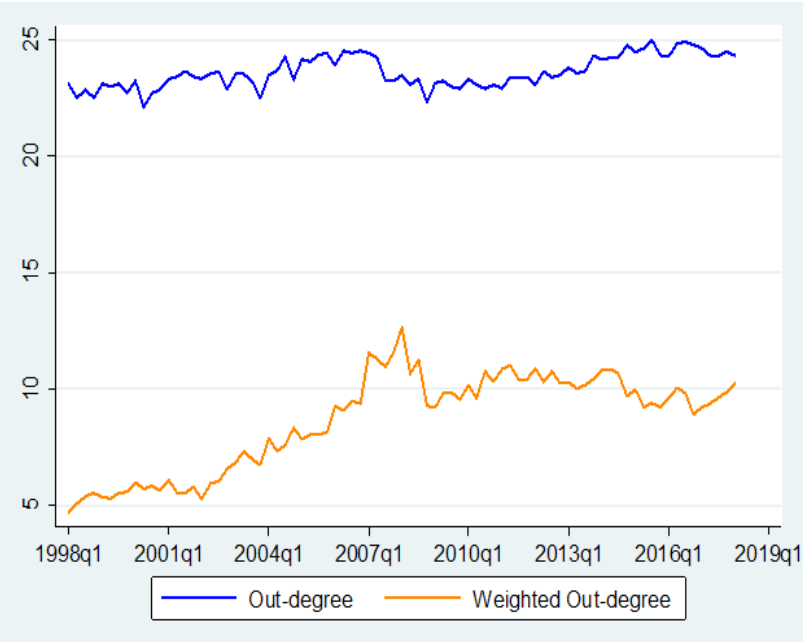

Notes: The unit of cross-border banking transactions is 100 billion USD.

In order to provide information about cross-border banking transactions in selected AsiaPacific economies, we plot two panels in Figure 4. Figure 4a shows the strength of nodes for our full network. We observe that there has been a clear drop in the volume of cross-border activities shortly after 2007, which most likely reflects credit contractions faced by individual financial systems, predominantly in the USA and Europe. However, Figure $4 \mathrm{~b}$ demonstrates that once we exclude the bilateral links within the G7 countries, Luxembourg and Switzerland, regional economies in Asia have not been significantly affected by the crisis. We can see a gradual growth in terms of the volume of bank loans, with only a partial adjustment shortly after the GFC. Nevertheless, this fall was reversed very quickly. We may argue that financial markets in advanced economies have shifted to emerging markets and less developed economies as a consequence of the increased uncertainty in the USA, UK and the rest of Europe. We might also speculate whether QE could have contributed to the increased liquidity in those economies. So far, the evidence of empirical research studies is rather inconclusive. A more intuitive explanation and discussion is provided by visual network graphs below. 


\section{Figure 4 \\ Node Strength}

(a) Full network

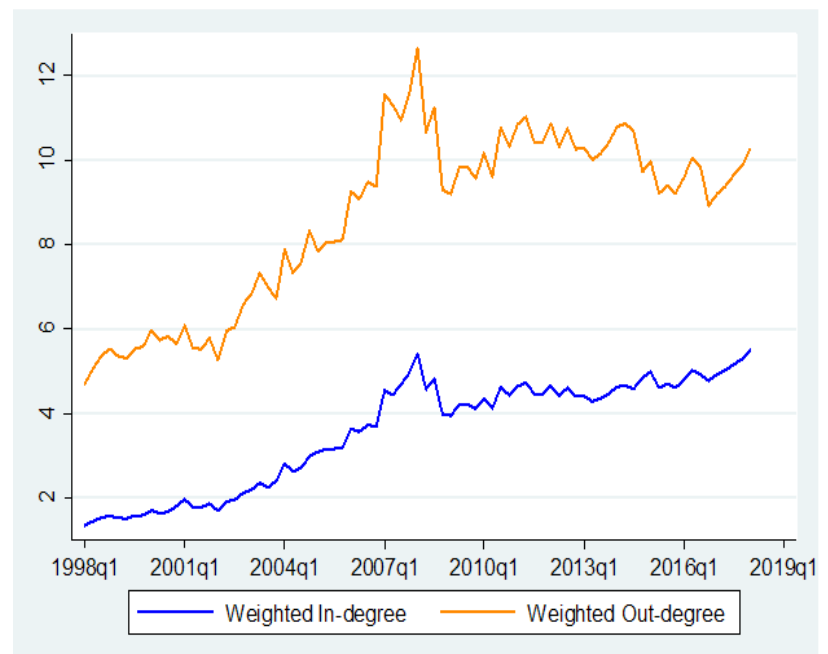

(b) Network excl. bilateral links of G7+2

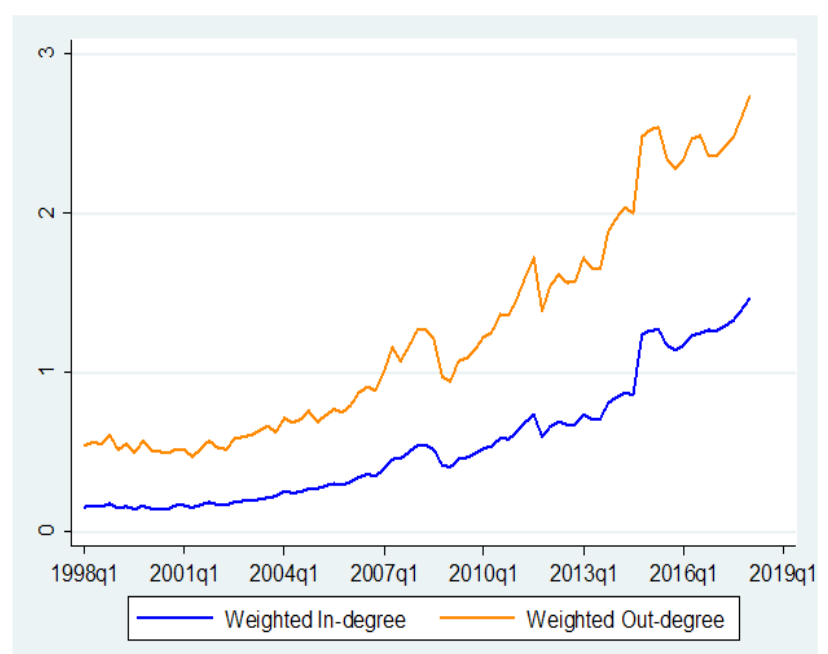

Notes: The unit of cross-border banking transactions is 100 billion USD.

In Figure 5, we turn our attention to the clustering coefficient. As we have discussed earlier, the clustering coefficient is a possible indicator for providing valuable information about systemic risk in complex networks. From Figure 5b, we observe a structural change in the early 2000s, when the value of the coefficient jumped up over the subsequent periods, indicating a higher probability that two economies are connected through a third economy. In other words, increased values of the coefficient indicate that there has been a tendency for higher clustering in the network over the period. Since we observe that increase from early 2000 , i.e., before the GFC, we may surmise that there has been a tendency for the financial markets to create regional clusters and that financial markets have become more connected.

\section{Figure 5}

\section{Clustering Coefficient}

(a) Full network

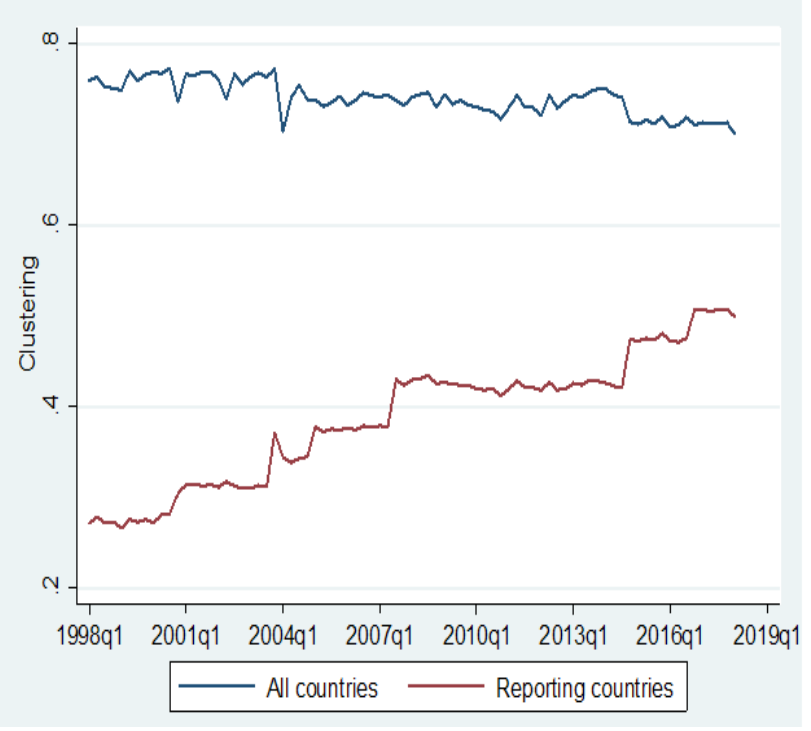

(b) Network excl. bilateral links of G7+2

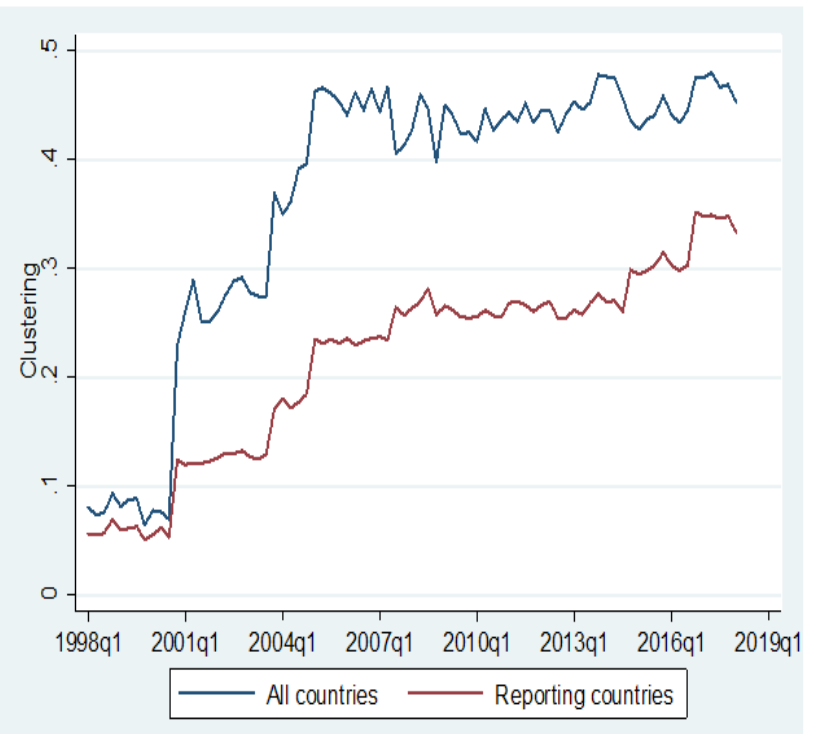


We can further explore the issue of how the network is mutually linked - connected by using the network connectivity coefficient. Let us recall that connectivity measures network density. If we focus just on Figure 6a, we observe that the coefficient has increased over the analysed period, which suggests that cross-border activities within the region have increased. This lends support to our earlier conclusions based on changes in the clustering coefficient.

\section{Figure 6 \\ Connectivity}

(a) Full network

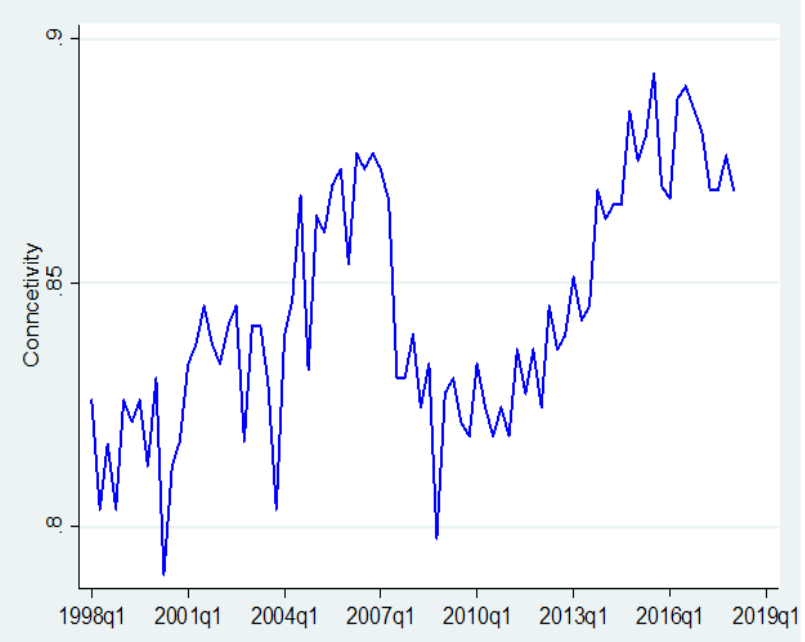

(b) Network excl. bilateral links of G7+2

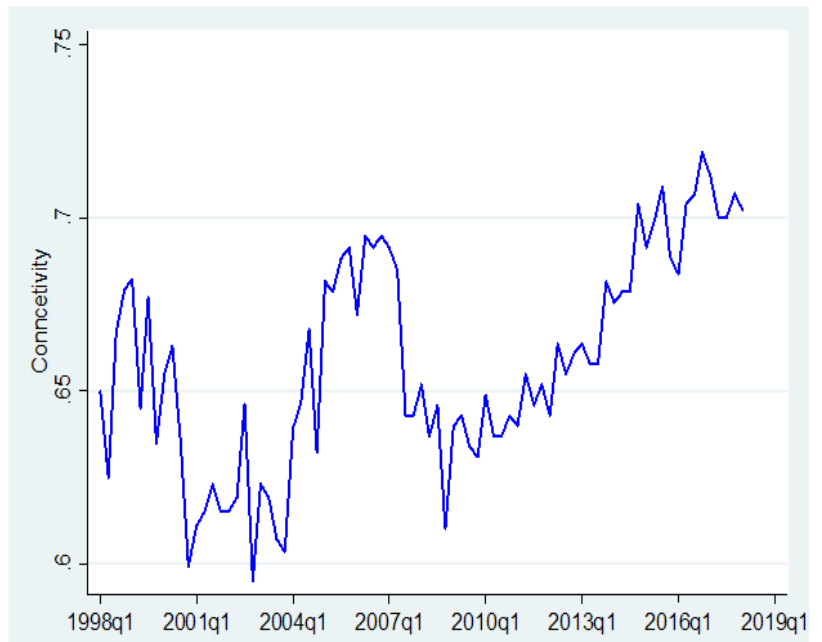

In Figure 7, we look at the closeness centrality network coefficient. We again provide two panels, that is, the full network and the full network without the bilateral links of the G7 countries, Luxembourg and Switzerland. There is strong evidence that the coefficient that measures closeness dropped sharply at the outset of the GFC. We can observe a similar sharp decrease in 2000-2001 during the dot-com crisis. While Figure $7 \mathrm{~b}$ provides a similar pattern, the drop in the coefficient values over the period is less pronounced than in Figure 7a. By contrast, we find an increasing trend. We recall that low values for nodes that are separated from others by only a short geodesic distance on average indicate that such nodes may have better access to information at other nodes or more direct influence on other nodes. Thus, the low value of the coefficient indicates that the distance of individual (economy) node has increased, which can be interpreted as large financial centres playing a key role in the network. However, Newman (2010) argues that there is a problem with this practical implication since it is difficult to distinguish between central and less central nodes using this measure. 


\section{Figure 7}

\section{Closeness Centrality}

(a) Full network

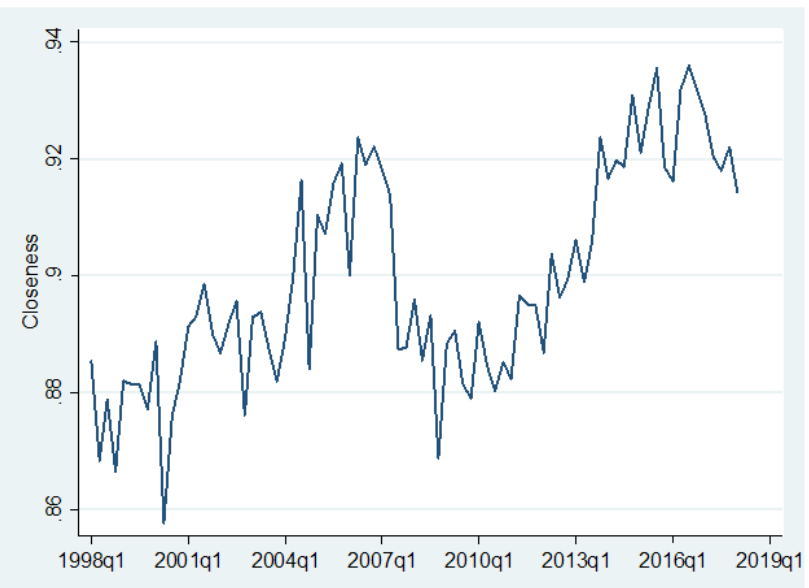

(b) Network excl. bilateral links of G7+2

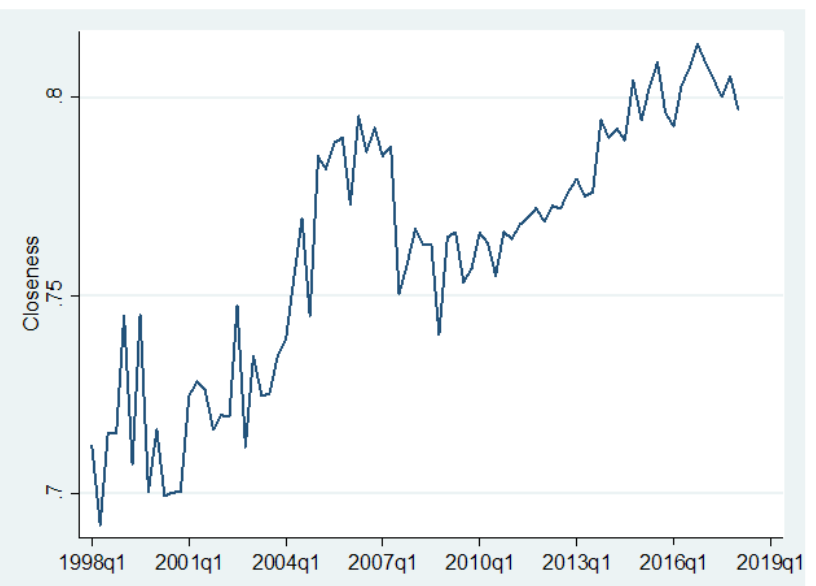

Last but not least, the final network coefficient is the betweenness centrality, which provides information about the influence of an individual economy as an intermediary of flows in the network. A closer look at Figure 8 indicates that coefficient values have gradually declined. This corresponds to our previous discussion that the system has become more clustered and none of the economies maintain a dominant position within the market compared to the period of the late 1990 s and early 2000s. We can further observe some degree of volatility of the coefficient during the GFC, but since 2010 there has been a clear tendency of a diminishing role for a few key players. This outcome will also be observable in the network graphs that we discuss later. This trend is further supported by Figure 9, which focuses on the influence of advanced economies (the G7, Luxembourg, and Switzerland) on regional network only. Based on the presented figures, we conclude that financial markets have been undergoing substantial changes that were further reinforced or amplified by the GFC.

Figure 8

\section{Betweenness Centrality}

(a) Full network

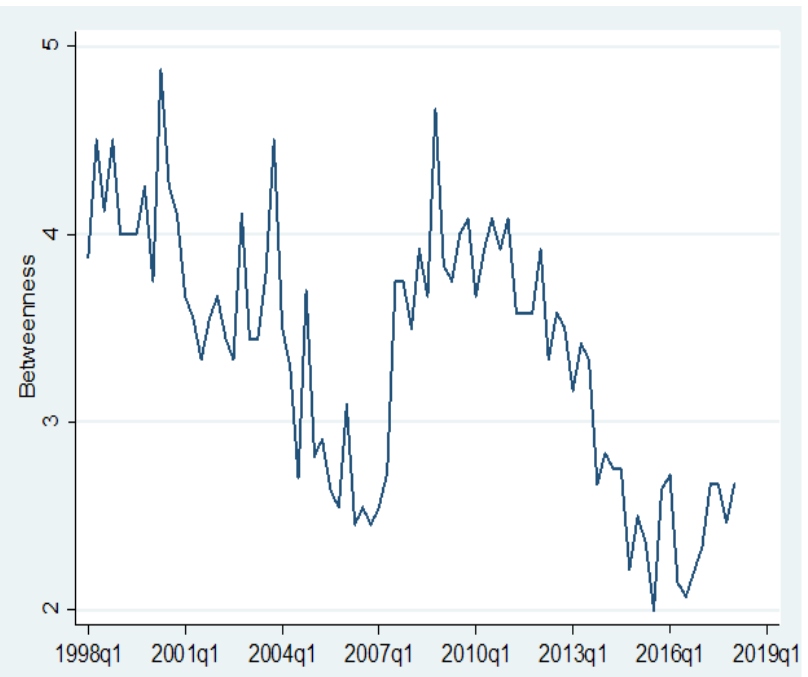

(b) Network excl. bilateral links of G7+2

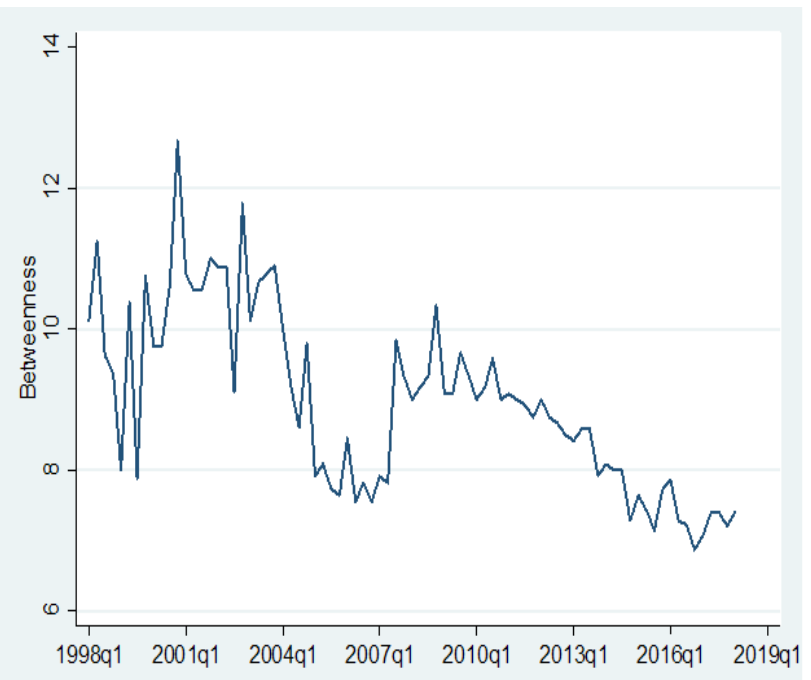




\section{Figure 9}

\section{Betweenness Centrality of Advanced Economies in Regional Network}

\section{Regional Network}

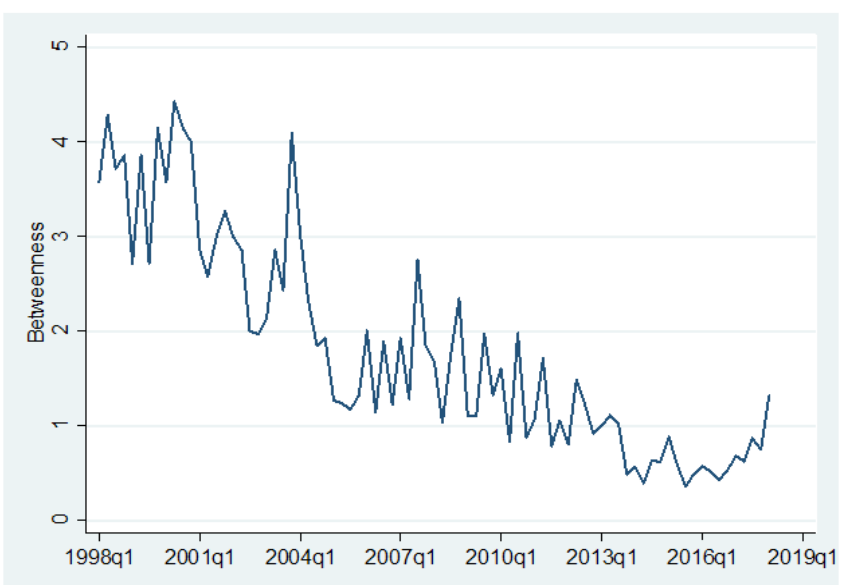

\subsection{Visual Network Analysis}

In this section, we extend our discussion by providing a visual presentation of network analysis. The graphs were obtained by using Gephi, which is a publicly available visualisation software (https://gephi.org/). Our results are presented in the following way. First, we plot graphs that provide information about the network structure for the complete network. Then, we analyse the regional network, which means that we exclude the bilateral links between the G7 countries, Luxembourg and Switzerland. Finally, we present the ranking of network measures by focusing on in- and out-weighted summary statistics.

Graph 1 provides a detailed analysis of how the flows of money have changed during the entire period. It highlights the complete picture of bank flows in the Asia-Pacific region including bilateral transactions between advanced economies (the G7, Luxembourg and Switzerland). In addition, Graph 1 provides information about the weighted out-degree, which is represented by the size of a node. The colour of nodes indicates the betweenness centrality coefficient and the size of bilateral bank flows is reflected in the thickness of the edges. We analyse each period from 1998 Q1 to 2018 Q1 and show graphs for the first quarter of selected years. ${ }^{8}$ What we can observe from Graph 1 is that, based on the betweenness centrality measure and the thickness of edges, Great Britain and Japan played a key role in terms of money flows over the period from 1998 to 2014. Since then, however, Hong Kong has taken the lead along with Japan and Australia, while Great Britain's dominance in the network has fallen significantly. South Korea also plays an important role in cross-border banking activities, while Chinese Taipei's position in that market has remained more or less unchanged. The colour of nodes, which represent betweenness centrality, become brighter over time, reflecting the growing importance of economies like Chinese Taipei, South Korea, Macau and China.

8. We show graphs for the first quarter of every fourth year between 1998 and 2006. To highlight the changes during the GFC period, we show network graphs of the first quarter of 2008, 2009, 2010. Then, we present graphs biennially from 2012 up to 2018. 
In Graph 2, we focus exclusively on the regional network, excluding the bilateral transactions between advanced economies (the G7, Luxembourg, and Switzerland). We present measures of weighted out-degree (the size of nodes), betweenness centrality (the colour of nodes) and the size of bilateral bank flows (the thickness of the edges). The Graph reveals that Japan played an important role from 1998 to 2002, attaining a dominant position in terms of overall money flows as well as bilateral bank flows. It is worth noting that money from Japan went above all to Singapore and, to lesser extent, to Australia. The same links can be observed for Great Britain, which was also connected with Singapore, Australia and Hong Kong. The betweenness centrality metric, which provides information about the influence of an economy in the region, indicates that Chinese Taipei took the lead, followed by Singapore. Graphs after 2006 indicate that the regional network has undergone some significant changes. Great Britain became the key country in terms of the flows of money, still followed by Japan. At the same time, Australia, Chinese Taipei and South Korea became the most influential economies in the region. ${ }^{9}$ In 2016, Hong Kong and Australia overtook Japan and Great Britain in terms of the flows of money (out-degree). Hong Kong also increased its influence in the region with its extensive links to China, as can be clearly observed during 2016. South Korea (dark green colour) also strengthened its position within the region. In 2018, the Philippines also became an influential economy in the region based on the betweenness centrality coefficient, the overall flows of money and bilateral bank flows. Hong Kong has a dominant position in the market by having the largest flows of money, the largest amount of bilateral flows and an influential position in the region based on the betweenness centrality coefficient. More specifically, it increased the number of bilateral bank flows with Great Britain and Japan. The most notable phenomenon is that the activities between Hong Kong and China strengthened. Hong Kong's position in the region significantly increased along with other financial hubs.

Graph 3 maps the regional network in terms of incoming links. In this regard, Singapore plays a pivotal role in the system not only with the largest volume of flows of money but also in terms of the size of bilateral bank flows. The position of Singapore remained unchanged until 2012. There is also a fair number of other economies with the relatively low coefficient of betweenness centrality, indicating their influence in the region. These economies include Singapore, Hong Kong, New Zealand, Australia, South Korea, China, Chinese Taipei, India and Thailand. However, there have been later structural changes similar to those we discussed for Graph 2. In 2004, China overtook Singapore as the largest economy in terms of flows of money, followed by Hong Kong. We can also observe from 2014 onwards that a number of economies in the region have become more influential in terms of the betweenness centrality measure. These economies include, among others, Vietnam, Myanmar, Bangladesh, India and Thailand.

The changes in the importance of individual economies find further support in Tables 3 and 4. Table 3 shows the ranking in terms of the weighted out-degree measure. Table 4 presents the ranking of the weighted in-degree. Table 3 shows a marked a shift in positions since 2014. In particular, Great Britain is only the fourth-ranked economy measured on the basis of overall flows of money in 2018 Q1. Hong Kong, Japan and Australia remain the key centres in the regional network. Table 4 ranks the top ten economies measured by weighted out-degree metric. Singapore was overtaken by China in 2014, and remains in second rank, followed by Hong Kong and Australia.

9. Out-going bilateral bank flows data for Hong Kong is only available from 2014 Q1 and the same data for Singapore is unavailable throughout the sample period. Therefore, it should be noted that our analysis is based on the data with limited availability. See Table A1 in Appendix for the sample period of individual economy. 


\section{Graph 1}

\section{Complete Network}

$1998 q 1$

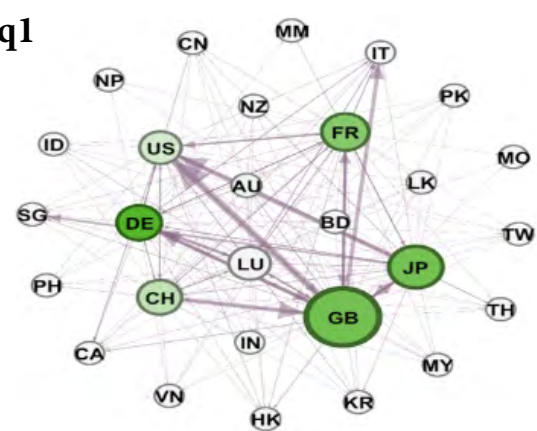

2006q1

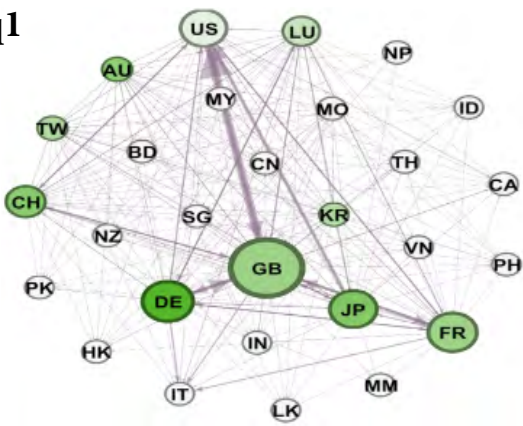

2009q1

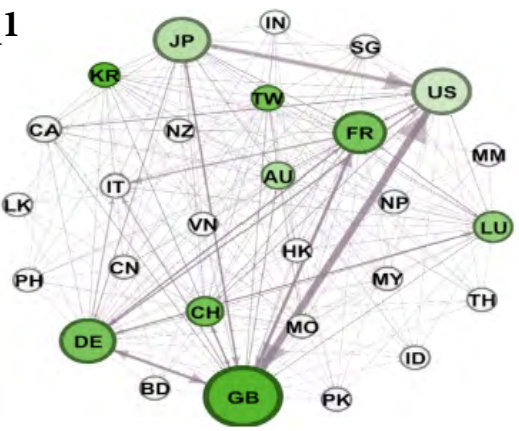

2012q1
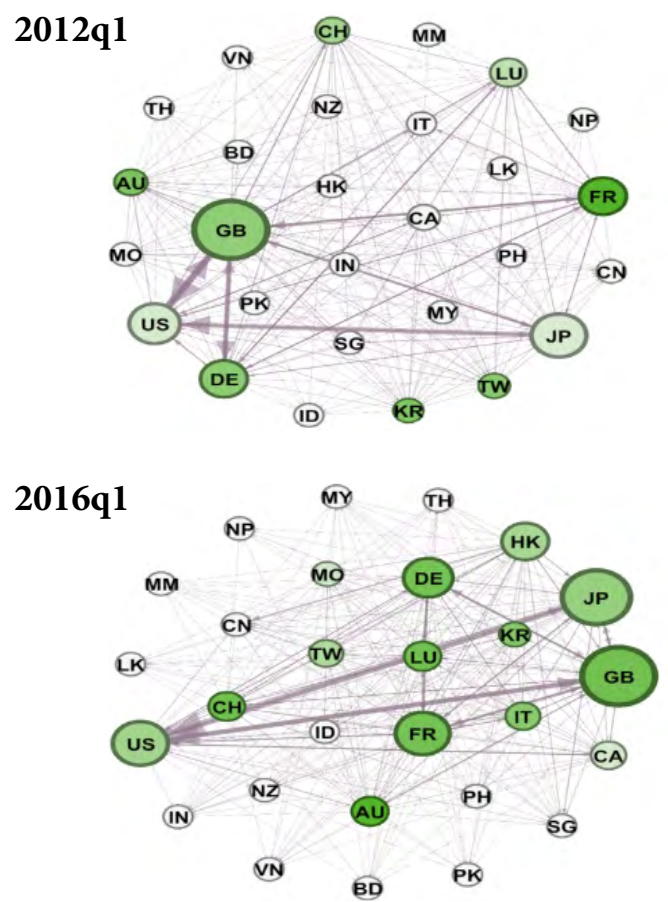

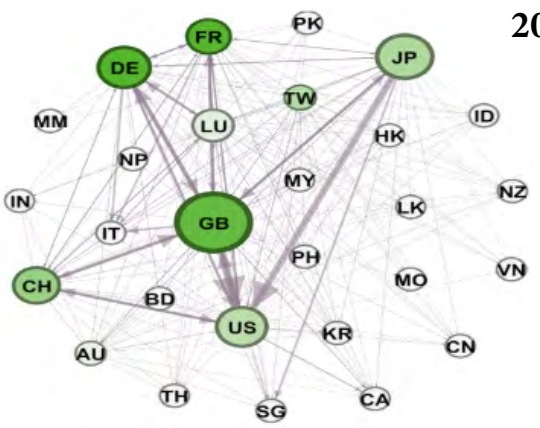

$2002 q 1$

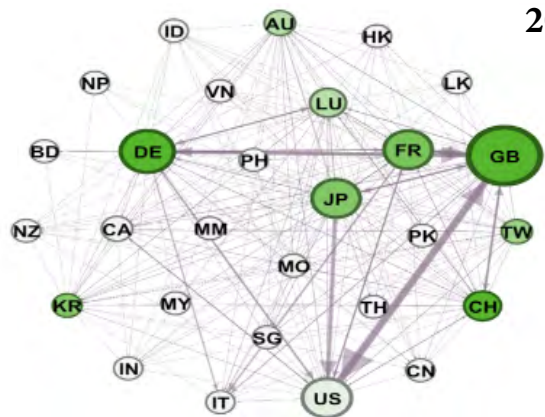

2008q1
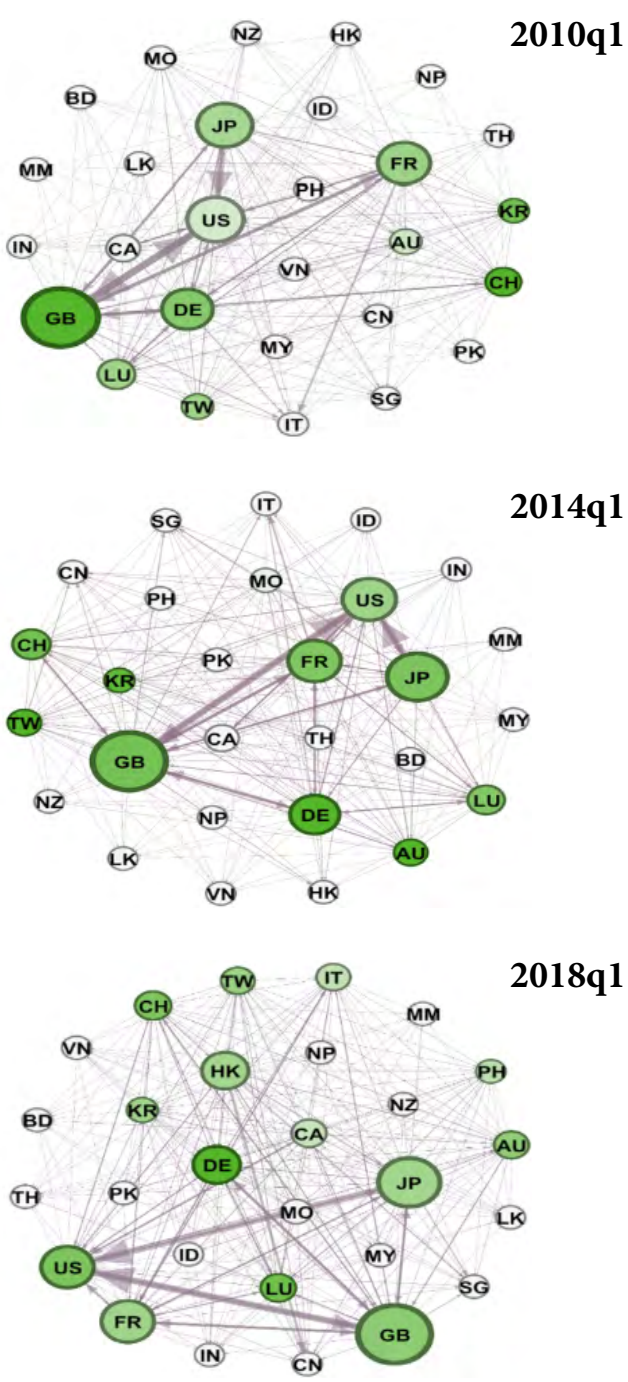
Graph 2

Regional Network (Weighted Out-going Links)

$1998 q 1$

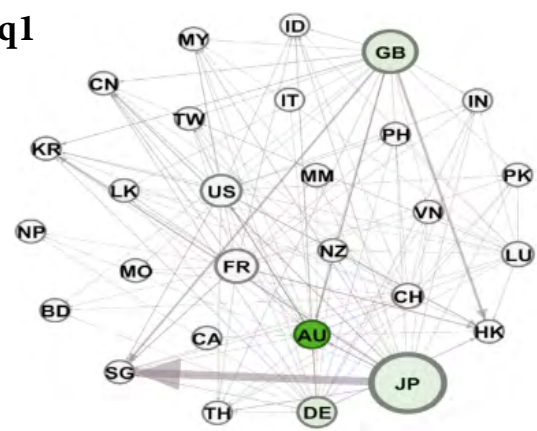

2006q1

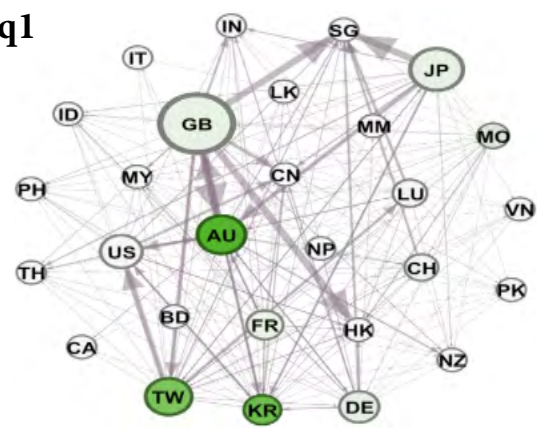

$2009 q 1$

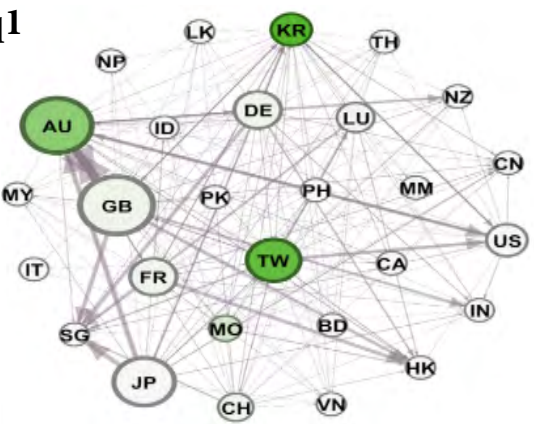

2012q1
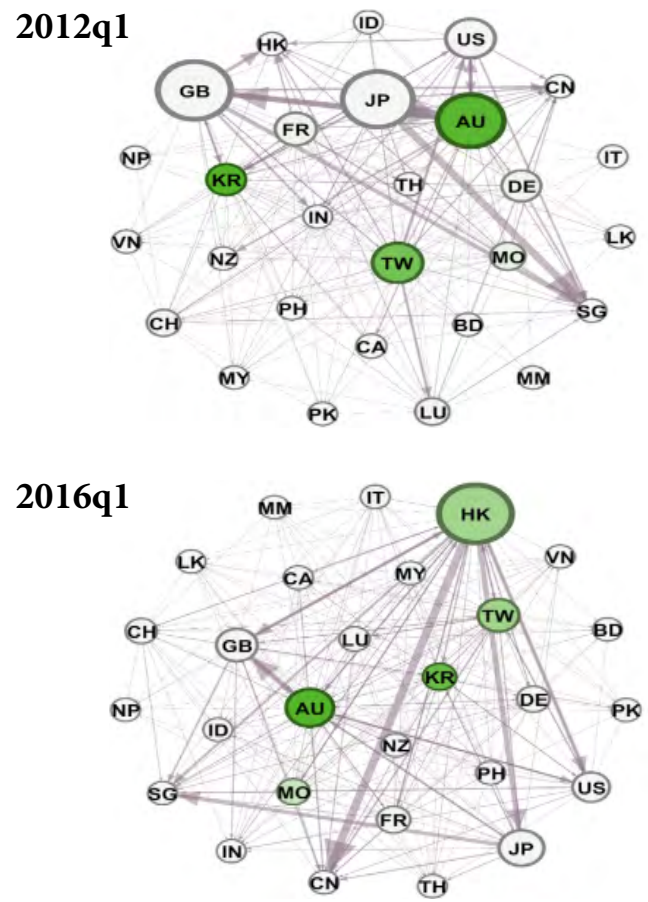

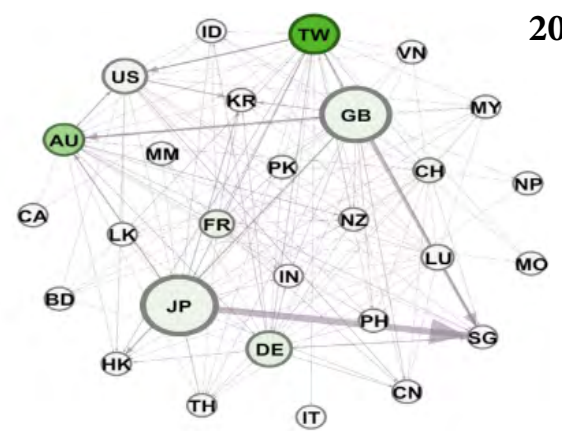

2002q1
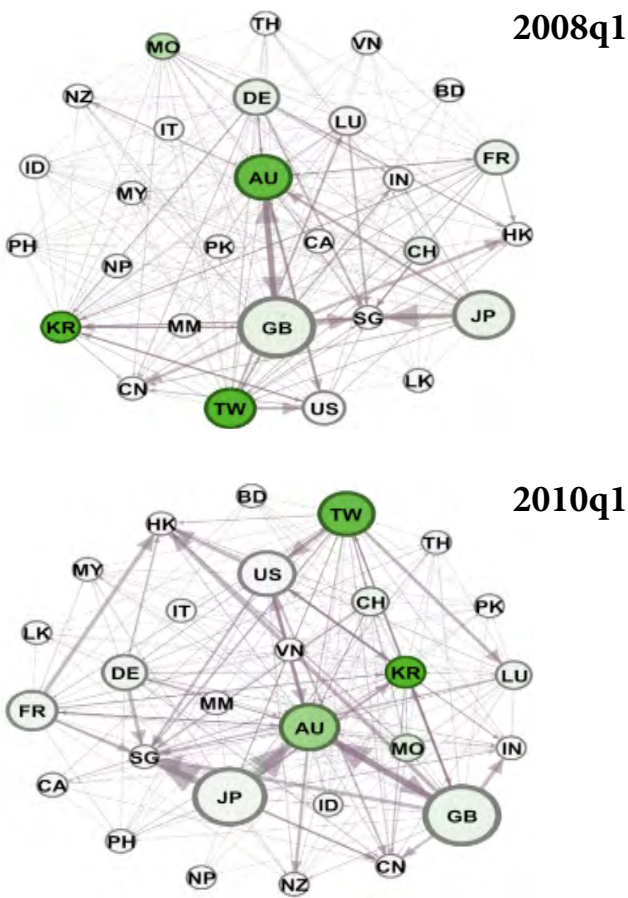

2010q1
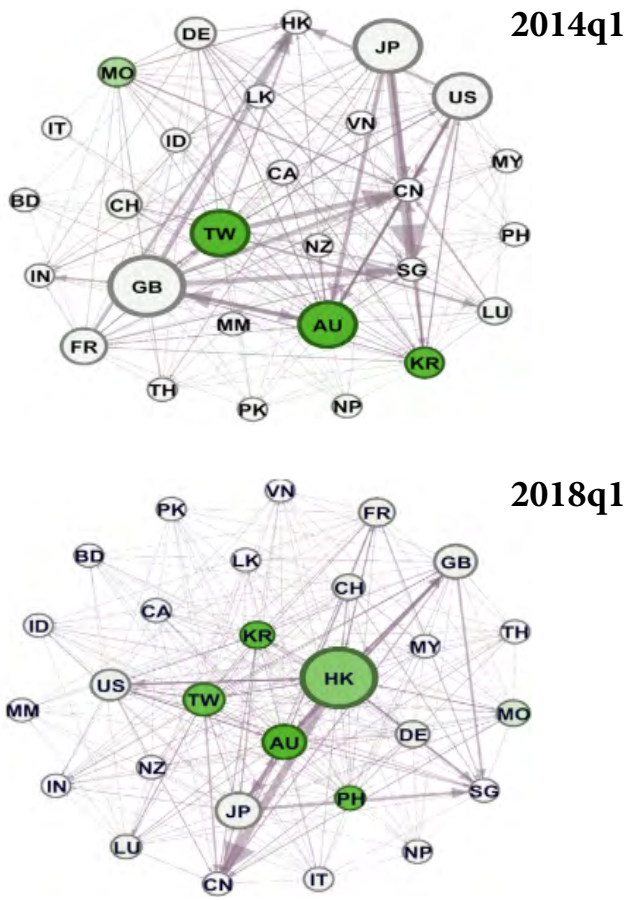


\section{Graphs 3}

Regional Network (Weighted In-coming Links)

$1998 q 1$

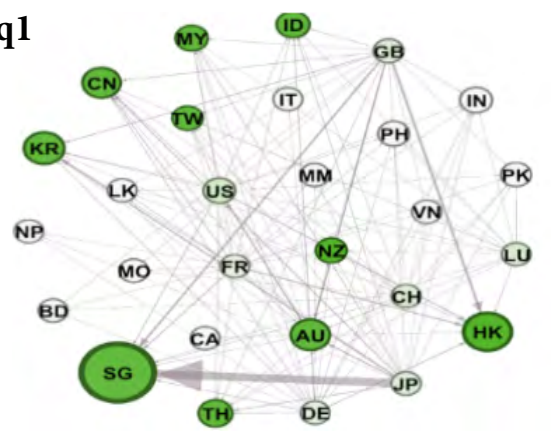

2006q1

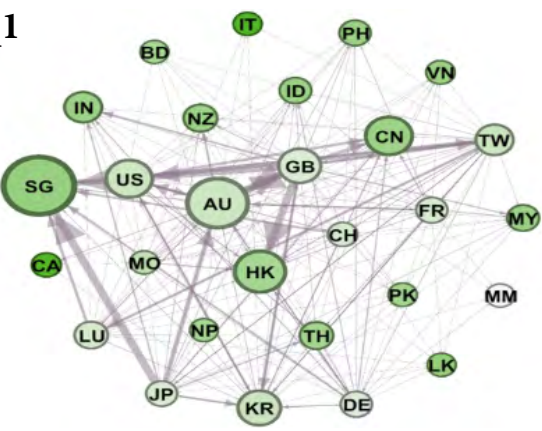

$2009 q 1$

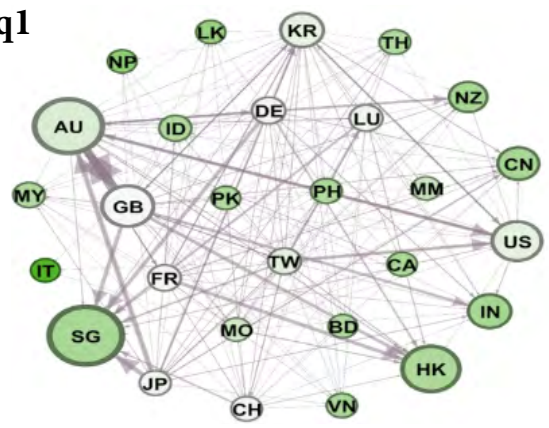

$2012 q 1$

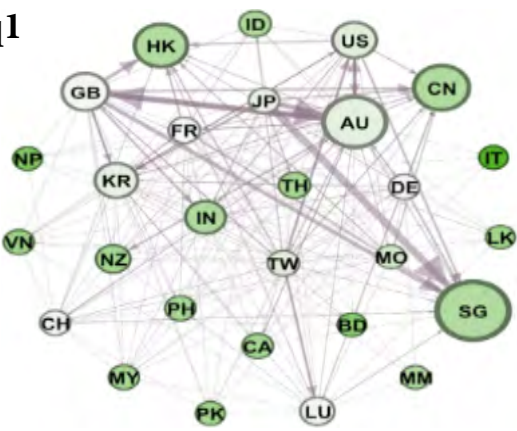

2016q1

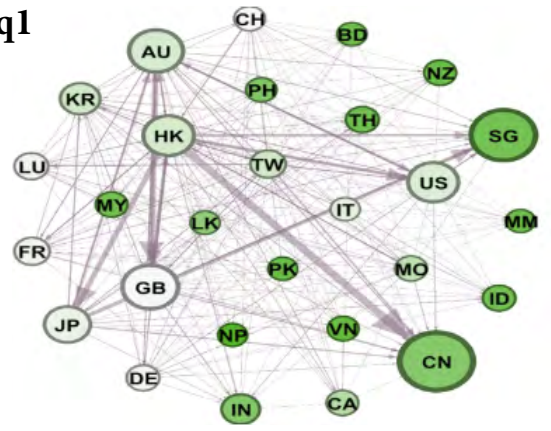

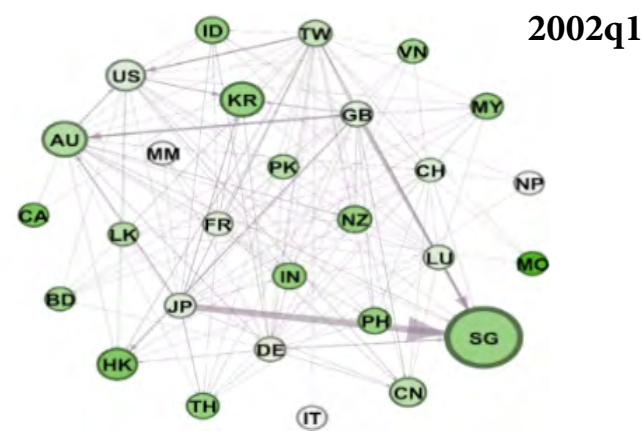
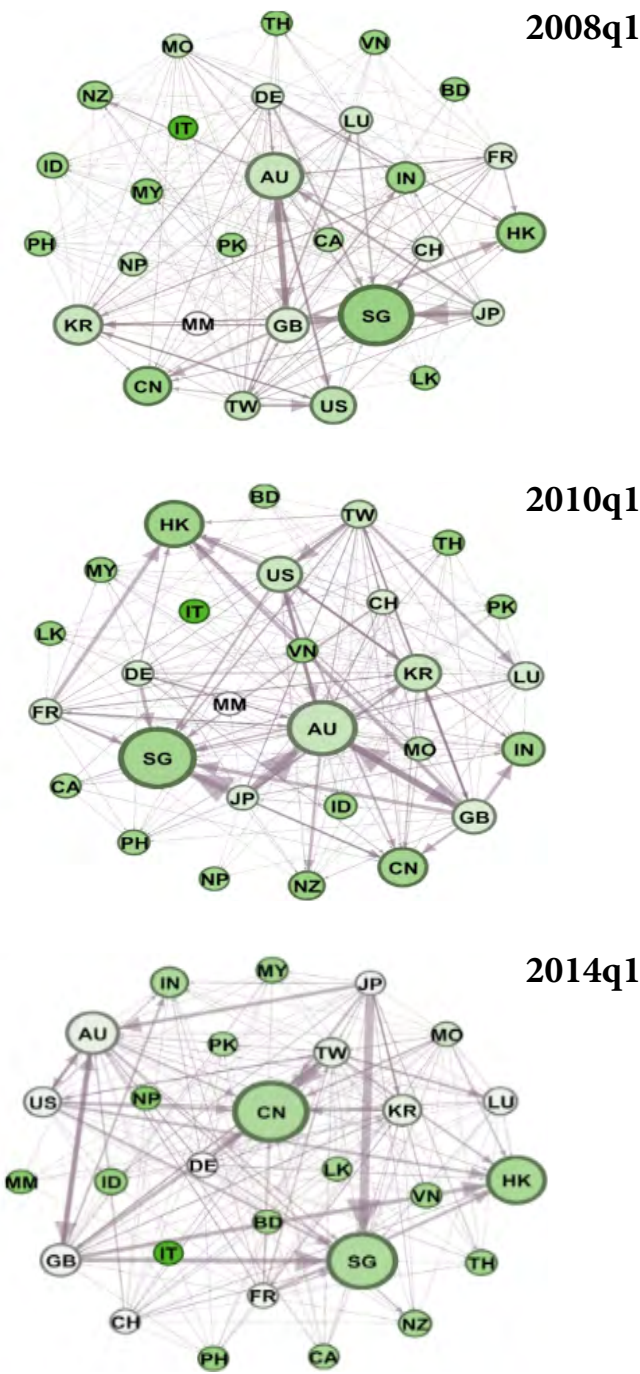

$2014 q 1$

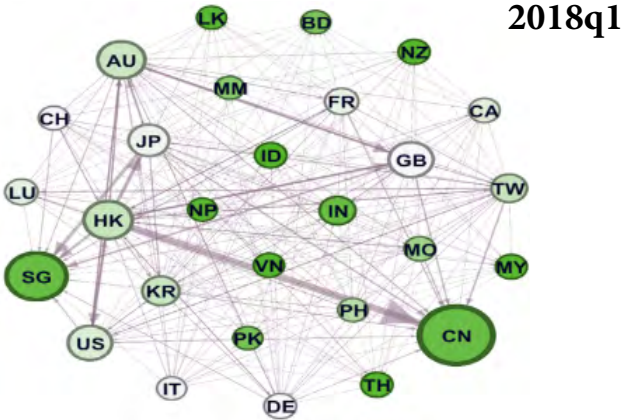


Table 3

Ranking of Network Measures (Weighted Out-degrees)

\begin{tabular}{ccccccccccc}
\hline 1998 & 2000 & 2002 & 2004 & 2006 & 2008 & 2010 & 2012 & 2014 & 2016 & 2018 \\
\hline SG & SG & SG & SG & SG & SG & SG & SG & CN & CN & CN \\
HK & AU & AU & AU & AU & AU & AU & AU & SG & SG & SG \\
KR & KR & KR & KR & HK & KR & HK & CN & HK & GB & HK \\
AU & HK & HK & HK & CN & HK & CN & HK & AU & AU & AU \\
CN & CN & US & US & US & CN & KR & GB & GB & HK & GB \\
TH & TH & CN & CN & KR & US & US & US & KR & US & US \\
ID & ID & NZ & TW & GB & GB & GB & KR & IN & JP & JP \\
IN & IN & IN & GB & TW & IN & IN & IN & US & KR & KR \\
MY & NZ & ID & NZ & IN & TW & NZ & NZ & TW & IN & IN \\
US & GB & TW & IN & NZ & NZ & LU & LU & LU & TW & TW \\
\hline
\end{tabular}

Table 4

Ranking of Network Measures (Weighted In-degrees)

\begin{tabular}{ccccccccccc}
\hline 1998 & 2000 & 2002 & 2004 & 2006 & 2008 & 2010 & 2012 & 2014 & 2016 & 2018 \\
\hline JP & JP & JP & GB & GB & GB & GB & GB & GB & HK & HK \\
GB & GB & GB & JP & JP & JP & JP & JP & JP & AU & JP \\
FR & DE & TW & AU & AU & AU & AU & AU & US & JP & AU \\
US & US & DE & US & TW & TW & US & TW & TW & TW & GB \\
DE & AU & US & TW & US & DE & TW & US & AU & GB & TW \\
AU & FR & AU & DE & DE & FR & FR & FR & FR & US & US \\
LU & LU & FR & FR & KR & US & DE & DE & DE & FR & FR \\
CH & CH & LU & LU & FR & KR & KR & KR & KR & KR & KR \\
IN & PH & CH & CH & LU & LU & CH & MO & MO & DE & DE \\
IT & CA & SG & MO & CH & CH & LU & LU & CH & MO & MO \\
\hline
\end{tabular}




\section{Conclusions and Policy Implications}

This study provides a comprehensive analysis of development in cross-border banking activities over the last 20 years. The analysis is based on the BIS' Locational Banking Statistics. In order to provide an overall picture of how banking systems are interconnected, we deploy the visual network analysis (VNA). We explain in great detail how this methodological framework can contribute to a better understanding of the issues under investigation. This technique clearly demonstrates not only the complexity of cross-border bank activities within the Asia-Pacific region but also the connectedness with advanced economies.

The data sample from 1998 to 2018 allows us to trace the structural changes that have occurred, particularly during the financial turbulences that occurred either in the region or in the advanced economies. The analysis investigates the characteristics of cross-border activities in the Asia-Pacific region. Reported network summary statistics include measures such as closeness centrality, betweenness centrality, connectivity and clustering. The analysis of these coefficients over the sample period help us to better understand structural changes over time. We have also evaluated the role of individual economies in our network over time. Our network analysis shows that the volume of transactions has dramatically increased, particularly after 1997. This change was accompanied by an increased number of bilateral links across banks. We note that many of the periphery economies became increasingly influential in the overall network. We also show that the connectedness of economies in the Asia-Pacific region since 1997 has changed completely, specifically that the structure of how economies are connected now is significantly different. There is evidence that the links have become much closer and the volume of credit transactions has increased severalfold.

The economies within the region surpassed the importance of many of the G7 countries (Great Britain and Japan, in particular). Since 2016, we observe the dominance of Hong Kong and China in the system. This type of structural change will necessarily have implication on system stability not only in terms of regional stability but also on a global scale. The dominance of Hong Kong and its extensive links with China are remarkable, but not surprising. Nevertheless, this extremely close link could have serious contagion effects if the Chinese economy faces turbulence. Our network analysis shows that the flows of money terminates in China and is not diversified further. This is very different from the $2000 \mathrm{~s}$, when Japan played the key role in the network. At that time, the flows of money from Japan were directed mainly at Singapore, but Singapore widely diversified the received financial resources. Based on our results, there is a need to further explore economies' (banks) portfolio diversification in the region.

We also conclude that a more comprehensive analysis of contagion risk with the help of more complex methodological frameworks can be conducted only if the reported statistics are improved, as studies capable of detecting possible triggers of systemic risk require much more disaggregated statistical information. 


\section{References}

Allen, F. and D. Gale, (2000), "Financial Contagion," Journal of Political Economy, Vol. 108, No.1, pp.1-33.

Bardoscia, M.; P. Barucca, C. A. Brinley and J. Hill, (2017), "The Decline of Solvency Contagion Risk," Bank of England Staff Working Paper, 662.

Boss, Michael; Helmut Elsinger; Martin Summer and Stefan Thurner, (2004), "Network Topology of the Interbank Market," Quantitative Finance, Vol. 4, No. 6, pp. 677 - 684.

Cerutti, E., (2015), "Drivers of Cross-border Banking Exposures During the Crisis," Journal of Banking and Finance, Vol. 55, pp. 340-375.

Cerutti, E.; S. Claessens and P. McGuire, (2012), "Systemic Risks in Global Banking: What Available Data Can Tell Us and What More Data are Needed?" NBER Working Paper, No. 18531.

Changmo, A.; G. Lee and D. Chang, (2014), "The Global Financial Crisis and Transmission Channels: An International Network Analysis," Working Paper 7/2014, The South East Asian Central Banks (SEACEN) Research and Training Centre, Kuala Lumpur, Malaysia.

Chan-Lau, J.; M. Espinosa; K. Giesecke and J. Solé, (2009), “Assessing the Systemic Implications of Financial Linkages,” IMF Global Financial Stability Report, 2.

Cho, D. and Changyong R., (2013), "Effects of Quantitative Easing on Asia: Capital Flows and Financial Markets," ADB Economics Working Paper Series, No. 350.

Degryse, H. and G. Nguyen, (2004), "Interbank Exposures: An Empirical Examination of Systemic Risk in the Belgian Interbank Market," NBB Working Paper, No. 43.

Espinosa-Vega, M. and J. Solé, (2010), "Cross-Border Financial Surveillance: A Network Perspective," IMF Working Paper, 10/105.

Fagiolo, G., (2007), “Clustering in Complex Directed Networks,” Physical Review E, 76, 026107.

Freixas, X.; B. Parigi and J.-C Rochet, (2000), "Systemic Risk, Interbank Relations and Liquidity Provision by the Central Bank," Journal of Money Credit and Banking. Vol. 32, pp. 611-638.

Furfine, C.H., (2003), "Interbank Exposures: Quantifying the Risk of Contagion," Journal of Money, Credit and Banking, Vol. 35, No. 1, pp. 111-128.

Gai, P. and S. Kapadia, (2010), "Contagion in Financial Networks," Proceedings of the Royal Statistical Society - Series A: Mathematical, Physical and Engineering Sciences, Vol. 466, No. 2120, pp. 2401-23. 
Genberg, H., (2017), "Global Shocks and Risk to Financial Stability in Asia," Working Paper 25/2017, The South East Asian Central Banks (SEACEN) Research and Training Centre, Kuala Lumpur, Malaysia.

Glasserman, P. and H.P. Young, (2014), "How Likely is Contagion in Financial Networks?” Journal of Banking and Finance, Vol. 50, pp. 383-399.

Group of Ten, Task Force on the Impact of Financial Consolidation on Monetary Policy, (2001), Report on Consolidation in the Financial Sector, Basel: Bank for International Settlements.

Haldane, A.G. and R.M. May, (2011), "Systemic Risk in Banking Ecosystems,” Nature, Vol. 469, pp. 351-355.

Hoggarth, G.; L. Mahadeva and J. Martin, (2010), "Understanding International Bank Capital Flows during the Recent Financial Crisis," Financial Stability Paper, No. 8, Bank of England.

Hoggarth, G.; R. Reis and V. Saporta, (2001), “Costs of Banking System Instability: Some Empirical Evidence," Journal of Banking and Finance, Vol. 26, pp 825-55.

Korniyenko, Y.; M. Patnam; R. M. del Rio-Chanon and M. A. Porter, (2018), "Evolution of the Global Financial Network and Contagion: A New Approach," IMF Working Papers, 18/113, International Monetary Fund.

Leitner, Y., (2005), "Financial Networks: Contagion, Commitment, and Private Sector Bailouts," Journal of Finance, Vol. 60, pp. 2925-2953.

McGuire, P. and P. Wooldridge, (2005), “The BIS Consolidated Banking Statistics: Structure, Uses and Recent Enhancements," BIS Quarterly Review.

Minoiu, C. and J. A.Reyes, (2013), “A Network Analysis of Global Banking: 19782010,” Journal of Financial Stability, Vol. 9, No. 2, pp.168-184.

Newman, M., (2010), Networks: An Introduction, Oxford University Press, Oxford.

Nier, E.; J. Yang; T. Yorulmazer and A. Alentorn, (2008), "Network Models and Financial Stability," Bank of England Working Paper, No. 346.

Sheldon, G. and M. Maurer, et al., (1998), "Interbank Lending and Systemic Risk: An Empirical Analysis for Switzerland," Swiss Journal of Economics and Statistics, Vol. 134, pp. 685-704.

Tabak, B. M.; M. Takami; J. M. C. Rocha and D. O. Cajueiro, (2011), "Directed Clustering Coefficient as a Measure of Systemic Risk in Complex Banking Networks," WP 249, Banco Central do Brasil.

Upper, C., (2007), "Using Counterfactual Simulations to Assess the Danger of Contagion in Interbank Markets," BIS Working Paper, No. 234. 
Upper, C. and A. Worms, (2004), "Estimating Bilateral Exposures in the German Interbank Market: Is There a Danger of Contagion?" European Economic Review, Vol. 48, No. 4, pp 827-49.

Von Peter, G., (2007), “International Banking Centres: A Network Perspective," BIS Quarterly Review Working Paper, Basel, Switzerland.

Wells, S., (2004), "Financial Interlinkages in the United Kingdom's Interbank Market and the Risk of Contagion," Working Paper, No. 230. Bank of England.

Yang, J.; T. Yorulmazer and A. Alentorn, (2008), "Network Models and Financial Stability,” Bank of England Working Paper, No.346.

Yellen, J., (2013), "Interconnectedness and Systemic Risk: Lessons from the Financial Crisis and Policy Implications,” Board of Governors of the Federal Reserve System, Washington, D.C.

Yilmaz, K., (2017), Bank Volatility Connectedness in the SEACEN Region, SEACEN, Kuala Lumpur, Malaysia. 
Table A1

List of Economies

\begin{tabular}{|c|c|c|c|}
\hline Economy & Abbreviation & $\begin{array}{c}\text { Type } \\
\text { (Core/Periphery) }\end{array}$ & $\begin{array}{l}\text { Sample period } \\
\text { (Core economy) }\end{array}$ \\
\hline Australia & $\mathrm{AU}$ & $\mathrm{C}$ & 1998 Q1 - 2018 Q1 \\
\hline Bangladesh & $\mathrm{BD}$ & $\mathrm{P}$ & - \\
\hline Canada & CA & $\mathrm{C}$ & 2007 Q3 - 2018 Q1 \\
\hline China & $\mathrm{CN}$ & $\mathrm{P}$ & - \\
\hline Hong Kong, SAR & $\mathrm{HK}$ & $\mathrm{C}$ & 2014 Q4 - 2018 Q1 \\
\hline India & IN & $\mathrm{P}$ & - \\
\hline Indonesia & ID & $\mathrm{P}$ & - \\
\hline Japan & $\mathrm{JP}$ & $\mathrm{C}$ & 1998 Q1 - 2018 Q1 \\
\hline Macau, SAR & MO & $\mathrm{C}$ & 2004 Q1 - 2018q1 \\
\hline Malaysia & MY & $\mathrm{P}$ & - \\
\hline Myanmar & MM & $\mathrm{P}$ & - \\
\hline Nepal & NP & $\mathrm{P}$ & - \\
\hline New Zealand & NZ & $\mathrm{P}$ & - \\
\hline Pakistan & PK & $\mathrm{P}$ & - \\
\hline Philippines & $\mathrm{PH}$ & $\mathrm{C}$ & 2016 Q4 - 2018 Q1 \\
\hline Singapore & $\mathrm{SG}$ & $\mathrm{P}$ & - \\
\hline South Korea & KR & $\mathrm{C}$ & 2005 Q1 - 2018 Q1 \\
\hline Sri Lanka & LK & $\mathrm{P}$ & - \\
\hline Chinese Taipei & TW & $\mathrm{C}$ & 2000 Q4 - 2018 Q1 \\
\hline Thailand & $\mathrm{TH}$ & $\mathrm{P}$ & - \\
\hline UK & GB & $\mathrm{C}$ & 1998 Q1 - 2018 Q1 \\
\hline US & US & $\mathrm{C}$ & 1998 Q1 - 2018 Q1 \\
\hline Vietnam & $\mathrm{VN}$ & $\mathrm{P}$ & - \\
\hline Germany & $\mathrm{DE}$ & $\mathrm{C}$ & 1998 Q1 - 2018 Q1 \\
\hline France & FR & $\mathrm{C}$ & $\mathrm{v}$ \\
\hline Italy & IT & $\mathrm{C}$ & 2014 Q4 - 2018 Q1 \\
\hline Switzerland & $\mathrm{CH}$ & $\mathrm{C}$ & 1998 Q1 - 2018 Q1 \\
\hline Luxembourg & LU & $\mathrm{C}$ & 1998 Q1 - 2018 Q1 \\
\hline
\end{tabular}

Notes: $\mathrm{C}$ denotes core (reporting) economies of which the data for individual counterparty economies are available, $\mathrm{P}$ denotes periphery (non-reporting) economies. 



\title{
Chapter 3
}

\section{CROSS-BORDER BANKING IN INDIAN CONTEXT}

\author{
By \\ Upasana Sharma ${ }^{1}$
}

\section{Introduction}

From a relatively isolated economy in a global context with somewhat muted economic performance to finding itself placed among the fastest growing countries in terms of output and aspiring to become an economic powerhouse, the Indian economy has made a remarkable transition in the past three decades. The liberalization wave which surged in 1991 paved way for globalization of the Indian economy and the reforms undertaken in the early nineties and beyond led to the integration of India with global markets in terms of trade, finance, knowledge flow, labour among others. The banking sector was also reformed drastically during this period as will be detailed later in the paper. As the Indian economy continues to become integrated with the international financial system, its exposure to cross-border risks is certainly increasing. The crisis of recent times including the Great Recession of 2008 has brought to the fore the risks that arise in the backdrop of the global integration of financial markets (Prasad, 2010). In this scenario, it has become ever important that vigilant and pro-active monitoring of risks is to be done on a continuous basis. The banks play a very crucial role in the Indian economy. It is important to note that the Indian financial system is largely bank dominated (RBI, 2017b). Further, the banking sector is the biggest absorber of household financial savings in the country as well as the largest contributor to the household sector's financial liabilities (Prakash et al., 2018). The banking sector has a crucial role in the financial system network in India too, as it accounted for around $46 \%$ of the bilateral exposures as of March 2018, more than any other financial entities and almost three times of the next biggest contributor (RBI, 2018b). Hence, the Indian banking sector is one of the most important pillars of its economy and any risk materializing from this sector can have widespread ramifications on the economy's multiple actors and sectors alike. The regulation and supervision of the banking sector in India is vested with its central bank, i.e., the Reserve Bank of India under the Reserve Bank of India Act, 1934 and the Banking Regulation Act, 1949. This paper is an attempt to analyse the integration of the banking sector in India with the countries across its border. The international operations of the banking sector in India are regulated by the Reserve Bank under the Foreign Exchange Management Act (FEMA) Act. As we shall discuss in detail later, owing to regulations, cross-border banking in India is comparatively small in size.

Cross-border banking is expected to bring about positive effects for the lending as well as borrowing countries through newer investment opportunities, higher returns on assets, risk diversification and increased efficiency owing to higher competition among others. However, these benefits are not free of costs. The more integrated banking channels become, the probability of

1. The author is currently working as Research Officer, Department of Economic and Policy Research in the Reserve Bank of India, Hyderabad Office. The views expressed in the paper are strictly those of the author and not of the Reserve Bank of India or the SEACEN Centre or its member central banks/monetary authorities. The author extends her gratitude to the Reserve Bank of India for giving her opportunity to work on this project and Professor Roman Matousek, the project team leader, for his continued guidance and encouragement. All errors or omissions are the responsibility of the author. 
risks spilling over from one country to another increases. The recent great financial crisis of 200708 and its aftermath was the realization of such risks at a massive scale which put the entire global economy into jeopardy. The objective of this paper is to understand cross-border banking in the Indian context. Owing to India's calibrated and partial opening of its capital account, the banking sector's cross-border activities are subject to prudential regulations. We will try to understand the international exposure in the context of Indian banks by analysing the data on the same. Specifically, we will study the breakdown of international assets and liabilities of India, the geographical origin of the same, the currency-wise break down among others such features of international banking. We will also apply the technique of network analysis to understand the India's position vis-à-vis its major banking partner countries. This will be done for both liabilities as well as claims.

In the present analysis, an attempt has been made to study the cross-border risks to the Indian banking sector. Using secondary data consolidated by the Bank of International Settlement (BIS) and the Reserve Bank, the robustness of the banking sector in context of its international banking operation will be assessed. The succeeding section discusses the evolution of the banking sector in India, the current scenario, along with a discussion on the recent developments and challenges facing the sector. Section 3 briefly reviews the available literature on the issue. This is followed by the discussion of the data and methodology in Section 4. Cross-border banking in the Indian context along with the presentation of some stylised facts and the experience of the Indian banking sector in recent crises is discussed in Section 5. Section 6 discusses the results of the network analysis of a sample of countries, with India being the focus. The paper is concluded in Section 7.

\section{Banking Sector in India: A Brief Overview}

As mentioned earlier, the Indian financial landscape is mostly dominated by the banks (RBI, 2017b). The number of domestic banks in India stands at 117 (21 public sector (universal) banks, 21 private sectors (universal) banks, 3 local area bank, 10 small finance banks, 6 payment banks, 56 regional rural banks) ${ }^{2}$. In addition, there are 45 foreign sector banks (FSBs) in India ${ }^{3}$. However, the majority of the banking activity remains dominated by public and private sector universal banks (thereafter PSBs and PvSBs). Before discussing the salient features of the Indian banking system, a very brief historical account of Indian banking follows.

\subsection{Brief History of Banking Sector}

The banking sector in India has undergone a plethora of changes since independence. Borrowing from RBI, 2008 which presents detailed information on the evolution of the sector in India, it may be mentioned that after independence of the country in 1947, the banking sector saw two major transformations viz. nationalisation in late 1960s (followed by another such exercise in 1980) and liberalisation ushering in the era of reforms in 1991 and beyond. The two decades of the banking sector were completely dominated by the private sector which saw a major overhaul in form of nationalisation in the late 1960s and beyond, which led to almost absolute government control over the sector till 1990. One of main premises of the nationalisation was the extension of

2. The information accessed from https://rbi.org.in/commonman/english/scripts/banksinindia.aspx\#SBI as of September 21, 2018 at 2000 IST.

3. Apart from these, there are number of credit co-operatives, comprising of urban co-operative banks (UCBs) and rural co-operative credit institutions operating in the country. However, their share is small in India's financial system (RBI, 2017b). 
banking services to sectors like agriculture, small industry and exports which may be ignored by the banks working purely with profit motives (Banerjee et al., 2004). The liberalisation of Indian economy in 1991 had profound impact on the banking sector as well. The reforms of the 1990s later brought in sweeping changes including changes in the ownership structure of public sector banks with the government being the major owner in these banks rather than the only owner as in the past, opening up the sector for private players, operational freedom, phased deregulation of administered interest rates, removal of automatic monetisation of fiscal debt, signification reduction of financial repression inter alia through phased reduction in cash reserve ratio and statutory liquidity ratio and many others (Acharya, 2000; Shirai, 2000; RBI, 2008; Mohan and Ray, 2017). The other major reforms in the money market, payment systems and external sector also contributed to modernizing of the banking sector (Mohan and Ray, 2017). Against the backdrop of this evolution, the banking sector in India grew tremendously and the same is indicated in the increase of credit and deposit as ratios of GDP in the country (Chart 1).

\section{Chart 1 \\ Credit and Deposit as Ratio of GDP in India (in \%)}

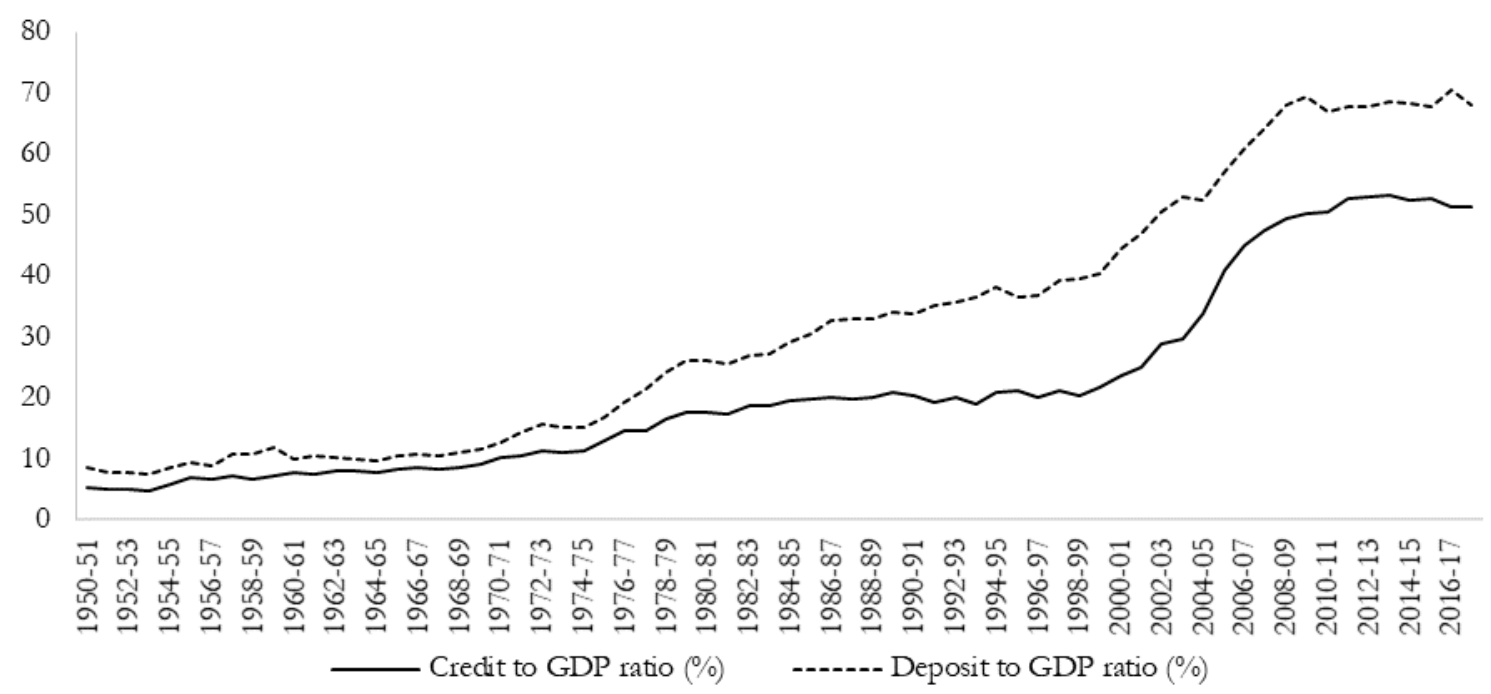

Source: Author's calculation based on Database on Indian Economy, Reserve Bank of India.

\subsection{Present Scenario of the Banking Sector}

With this brief historical background, we now reorient our discussion towards the present landscape of the sector. As discussed earlier, the banking sector in India plays an instrumental role, being the one major contributor to flows to the commercial sector as well as being the biggest absorber of household saving in the country (RBI, 2017b; Prakash et al., 2018). However, in spite of opening up of the sector for private players in liberalisation reforms, the Indian banking sector continues to be dominated by 21 PSBs in which the Indian government holds the majority stake, although the share of private sector banks has shown gradual improvement (Chart 2). The public sector banks account for the majority of deposits and advances showing their overall significance in the economy. The role of the FSBs is very limited compared to their public and private sector counterparts. The capital to risk weighted ratio for the scheduled commercial banks stood at $13.8 \%$ as of March 2018 (RBI, 2018b). The net interest margin for the sector was $2.7 \%$ as of March 2018 (RBI, 2018b). 


\title{
Chart 2
}

Public and Private Sector Banks' in India - A Comparison

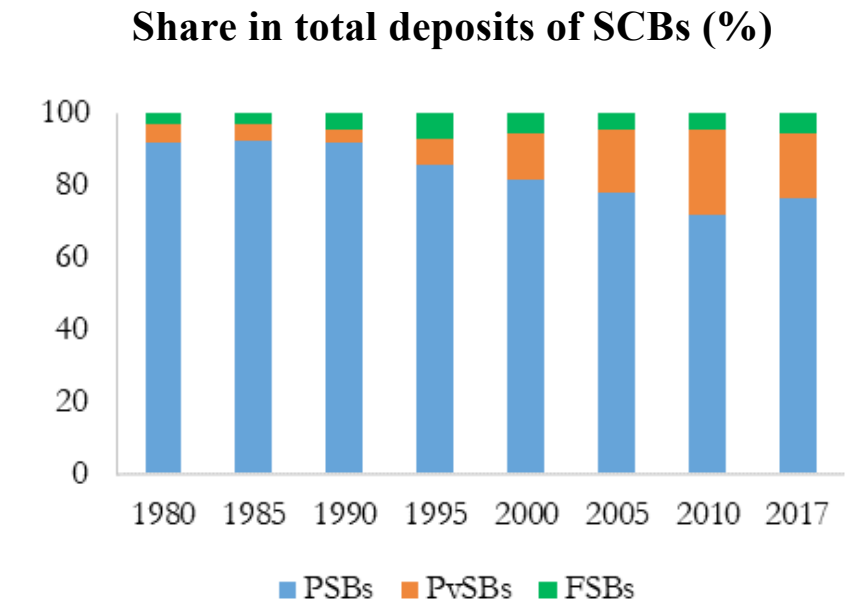

\begin{abstract}
Share in total advances of SCBs $(\%)$
\end{abstract}

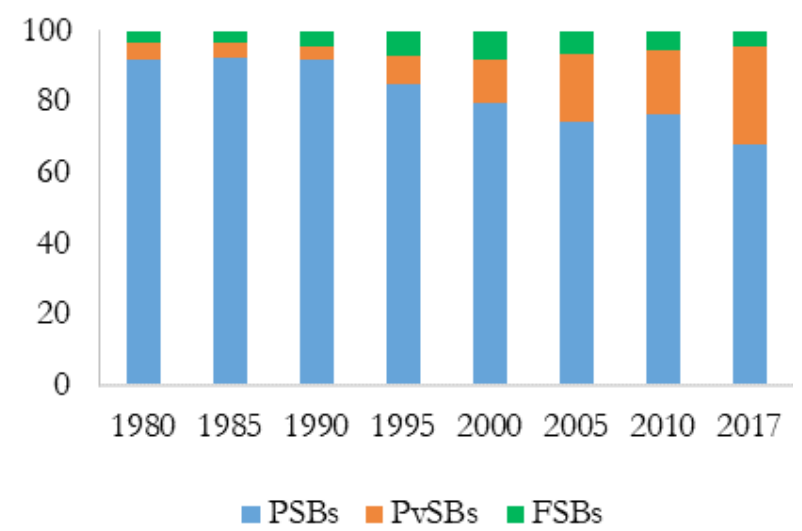

Source: Ramasastri and Samuel (2006); Author's calculation based on Statistical Tables Relating to Banks in India (accessed from Database on Indian Economy, RBI's Data Warehouse).

\subsection{Domestic Systemically Important Banks (D-SIBs) in India}

The unfolding of the global financial crisis in the previous decade was an evidence of the risk posed by large and inter-connected financial institutions, spilling over and spreading to entities within and outside national borders, negatively impacting the growth in many countries as well as global economic expansion. In the aftermath of the crisis, the Basel Committee on Banking Supervision (BCBS) developed a framework 2011 for identifying the Global Systemically Important Banks (G-SIBs). It also advocated additional loss absorbency capital requirements applicable to these G-SIBs. Further, other member countries were required to put in place a regulatory framework to deal with Domestic Systemically Important Banks (D-SIBs) ${ }^{4}$. Consequently, the Reserve Bank developed a framework to identify the DSIBs and also prescribed additional capital requirements for these banks. Further, an additional common equity requirement is applied based on the bucket in which a D-SIB is placed ${ }^{5}$. Based largely on the framework of BCBS to identify G-SIBs, the indicatorbased approach and methodology is being used in India for DSIBs' identification. The indicators used to assess domestic systemic importance of the banks are their size; their interconnectedness; their lack of readily available substitutes or financial institution infrastructure; and their complexity (RBI, 2014). The banks having a size of more than 2\% of GDP are considered for this exercise. Currently three banks, viz. the State Bank of India (a PSB and the largest bank in India), the ICICI and the HDFC (both PvSBs) have been identified as DSIBs in India ${ }^{6}$.

4. Source: https://www.rbi.org.in/scripts/bs_viewcontent.aspx?Id=2861

5. In case a foreign bank having branch presence in India is a G-SIB, it has to maintain additional capital surcharge in India as applicable to it as a G-SIB, proportionate to its Risk Weighted Assets (RWAs) in India. (https://rbi.org. in/Scripts/BS_PressReleaseDisplay.aspx?prid=41556).

6. Source: https://rbi.org.in/Scripts/BS_PressReleaseDisplay.aspx?prid=41556 accessed on September 23, 2018. 


\subsection{Recent Developments and Challenges of the Indian Banking Sector}

\subsubsection{Introduction of Differentiated Banks}

The Indian banks were, till very recently, universal in their activities. However, the sector has now been opened for differentiated banks which serve niche clients/segments and the beginning was made in this direction by issuing the licences to the small finance banks ${ }^{7}$ and the payment banks ${ }^{8}$ which commenced their operations during last two years. The idea is being mooted to set up wholesale and long-term finance (WLTF) banks which will be entrusted with task of meeting the credit needs of the infrastructure sector and small, medium and corporate businesses. It is envisaged that differentiated banks will contribute to the economic development by furthering the cause of financial inclusion and catering to varied credit needs in the country (RBI, 2017b).

\subsubsection{Asset Quality Concerns}

In the most recent times, the banking sector in India is facing challenges of asset quality concerns and banks' weak balance sheets (RBI, 2015, 2016, 2017a, 2017b; GoI, 2018). The ratio of gross non-performing assets as a percentage of gross advances has increased in recent years with the ratio of gross non-performing assets (NPAs) being much higher in PSBs as compared to PvSBs. Further, the concentration of NPAs remains proportionally higher in industrial sector vis$\grave{a}$-vis agriculture and service sectors (Chart $3 \mathrm{a}$ and $3 \mathrm{~b}$ ). The current NPA issue has been attributed to excessive credit growth in the preceding period, long-term infrastructure financing by the banks leading to asset-liabilities mismatch, unfavourable economic conditions, structural issues negatively impacting the funded projects among others (Sengupta and Harsh Vardhan, 2017; Samantaraya, 2016). The capital to risk weighted assets ratio for PSBs was $11.7 \%$, whereas for PvSBs it was registered at 16.4\% as of March 2018 (RBI, 2018b). The Insolvency and Bankruptcy code, as will be discussed later, is one of the most important steps taken by policy makers to not only tackle the present episode but also ensure that the resolution process becomes efficient to minimise the risk of such incidences occurring in the future.

\subsubsection{Insolvency and Bankruptcy Code}

The problem of worsening asset quality in India was compounded by the multiplicity of legal acts and processes, and their complexity as well as their improper utilisation by the banks which made the recovery and resolution process difficult in case of bad loans (RBI, 2017b). A landmark development was the introduction of the Insolvency and Bankruptcy Code in 2016, which has now become a single law for insolvency and bankruptcy in a time-bound manner and envisages the speedy resolution of bad assets, bringing much needed efficiency in the process.

7. The objectives of these banks are to provide savings vehicles and supply credit to small business units; small and marginal farmers; micro and small industries; and other unorganised sector entities, through high technology-low cost operations (https://www.rbi.org.in/Scripts/BS_PressReleaseDisplay.aspx?prid=32614).

8. These banks have been set with an aim of providing small savings accounts and payments/remittance services to migrant labour workforce, low income households, small businesses, other unorganised sector entities and other users (https://rbi.org.in/scripts/BS_PressReleaseDisplay.aspx?prid=32615). 


\section{Chart 3 \\ Rising NPAs in India - Bank-group and Sectoral Trends}

1a: Trend in GNPA ratio across bank-group types

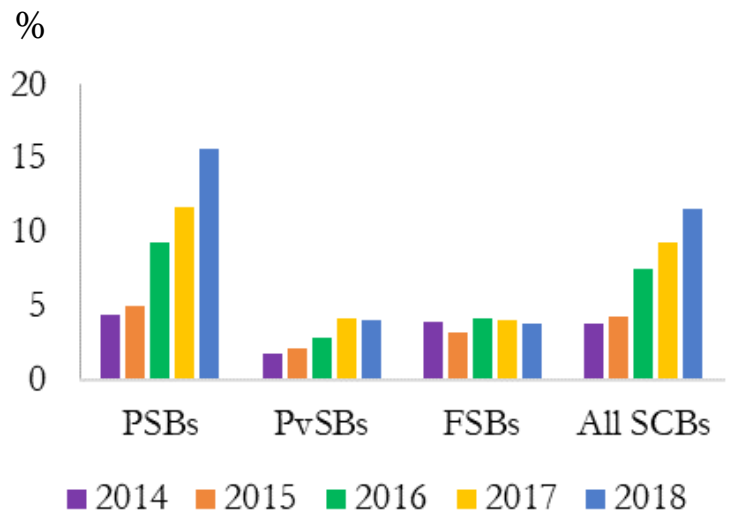

1b: Trend in GNPA ratio across major sectors in 2018

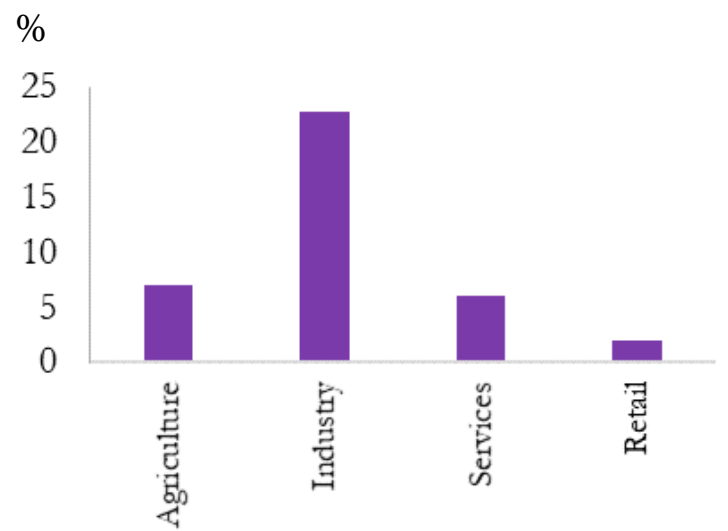

GNPA: Gross non-performing assets; SCBs: Scheduled commercial banks;

Notes:

1. GNPA ratio refer to the GNPA as Percentage of Gross Advances.

2. SCBs here refer to PSBs, PvSBs and FSBs taken together.

Source: Handbook on Indian Economy, 2018, RBI and Financial Stability Report, June 2018, RBI and the RBI.

\subsubsection{Recapitalization and Consolidation of Public Sector Banks}

Recapitalization of PSBs is one of the important step in solving the ongoing problem of asset quality in view of their weak balance sheets and impact on fresh credit creation. The majority ownership of the government in these banks, however, limit their access to market resources for raising capital (Sengupta R. and Harsh Vardhan, 2017). At the same time, recapitalisation by the government imposes huge costs on the public exchequer. Keeping these trade-offs in mind, the Indian Government recently introduced a recapitalization package named the Indradhanush programme.

Further, the consolidation in the banking sector of public sector banks has long been an issue in the policy discourse with the various committees formed by the policy makers arguing for the same (Narasimham Committee Report, 1991 and 1998). The same was reiterated in the budget speech 2016-17 of the Finance Minister ${ }^{9}$. The Government of India has since embarked on the route of consolidation of the public sector banks. As the first step, the merging of the State Bank of India (the largest bank in India) and its associates was undertaken. There is a proposal to merge three more PSBs together to form the second largest bank in the near future.

\subsubsection{Efforts to Step-up Financial Inclusion}

The Indian banks, serving an emerging nation, are also entrusted with a multitude of developmental activities. Financial inclusion is one such goal which has been pursued continuously over the years to bring hitherto unbanked population under the ambit of the formal banking sector. The banks play an instrumental role towards the goal with both the Reserve Bank and the

9. Accessed from https://www.indiabudget.gov.in/budget2016-2017/ub2016-17/bs/bs.pdf 
government making overarching guiding policies and initiatives in the direction. Consequently, a number of initiatives has been taken in recent years, including the opening of specialized banks in form of the small finance banks and payment banks, liberalisation of the branch opening norms ${ }^{10}$, the massive account opening scheme in the form of Pradhan Mantri Jan Dhan Yojna ${ }^{11}$, the Pradhan Mantri Mudra Yojana scheme with the major aim of providing small loans to small and micro units/ entrepreneurs, employment of technology to encourage digital modes of payment by lowering cost, improving their ease of use, increase adoptability among many others. Further, the existing schemes like the priority sector lending ${ }^{12}$, Kisan Credit $\mathrm{Card}^{13}$ scheme, financial literacy drives, business correspondent model to encourage banking at the doorsteps in the rural areas of the country, the lead bank scheme ${ }^{14}$ among others are fine-tuned on a continuous basis to improve their efficiency in furthering the cause of financial inclusion.

Notwithstanding the challenges facing the sector, the ever changing and evolving banking landscape in India continues to give impetus to India's growth story. With this brief background of the Indian banking sector, we know that presently, the literature review focuses on the increasing integration of financial systems across the countries, their repercussions including the studies which have analysed these international networks and the possible contagion that this integration brings along.

\section{Literature Review}

The increasing connectedness among the financial systems of different countries with each other is one of the most prominent features of globalization. The opening of capital accounts in developing economies contributed to this rising integration (Agenor, 2013). As discussed in Agenor (2013), this international financial integration can benefit countries through multiple potential channels viz. smoothing of consumption through international risk sharing, improvement in domestic investment and growth, increased discipline at macroeconomic level and increased efficiency and stability of the domestic financial system. However, this integration does not come

10. The Reserve Bank rationalised branch opening in May, 2017 (refer to https://rbi.org.in/Scripts/NotificationUser. aspx?Id=10972\&Mode=0 for details) with an objective of defining 'banking outlet' and harmonising the treatment of different forms of bank presence for the purpose of opening outlets in underserved areas.

11. The Pradhan Mantri Jan Dhan Yojana is the massive, flagship initiative of the Government of India to extend financial services to the masses. It was launched on August 28, 2014 (RBI, 2015). So far, 327.5 accounts have been opened under the scheme (as of September 19, 2018) (accessed from https://pmjdy.gov.in/account on September, 2018).

12. The objective of priority sector lending (PSL) is developmental in nature which is aimed to provide vulnerable sections of the society access to credit and ensure flow to sectors with high employment potential (RBI, 2015a). The priority sector includes agriculture, micro, small and medium enterprises, export credit, education, housing, social infrastructure, renewable energy and others (https://m.rbi.org.in/Scripts/FAQView.aspx?Id=87). As per current norms, $40 \%$ of Adjusted Net Bank Credit or Credit Equivalent Amount of Off-Balance Sheet Exposure, whichever is higher needs to be allocated for priority sector by domestic SCBs and FBs with 20 more or branches (https://m.rbi.org.in/Scripts/FAQView.aspx?Id=87).

13. Kisan Credit Card Scheme is an innovation which has an objective of providing adequate and timely credit support from the banking system under a single window to the farmers for their cultivation \& other needs (https:// rbidocs.rbi.org.in/rdocs/content/pdfs/CRB5100512AN.pdf).

14. Refer https://www.rbi.org.in/Scripts/NotificationUser.aspx?Id=11321\&Mode=0 for details. The scheme's objective is to coordinate activities of banks and other developmental agencies to increase priority sector lending and promote the role of banks in rural sector development. 
without the costs. With the increased globalization and integration of financial channels across the countries, the risk of contagion spreading from shock in one country to other connected countries has only been rising. In fact, it has been argued that these networks can contribute to the amplification of financial booms and boost, which in turn causes crises (Borio and Disyatat, 2011; Borio, 2014) making them not only a factor for the spread of the crisis but also the reason for crisis in the first place. Borio et al. (2015) found that the international monetary and financial system raise the risk of financial crises which have significant macroeconomics costs. In fact, Dungey and Gajurel (2015) argued that the crises which are transmitted across the borders are difficult to be tackled by domestic policy makers. Cerutti et al. 2014, also discussed that global financial linkages and channels of spread of spillovers are more complex. Tonzer (2015) also argued that international banking which can have positive effects during the periods of stability are to be treated cautiously during the periods of turmoil as they may affect the entire network. The great recession of 2007-08 and its aftermath has once again brought these issues to the fore. There is also evidence that those emerging economies which had direct or indirect exposure to banks in crisis-affected countries, also experienced higher capital outflows during the crisis of 2007 (Park and Shin, 2017). This shows that banking integration can also have impact on other sectors of financial systems as well.

The increasing interconnectedness of financial systems and the associated risks has been of the interest to researchers. Alan and Gale (2000) in their seminal work modelled contagion to understand how a small shock in one region of an economy can translate into economy wide crisis and found that a complete network of banks with every bank connected to another are more resilient to risks rather than an incomplete network. Upper (2011) based on his review of the existing research on contagion, found that there are many possible channels of contagion through the liability side (bank runs, common liquidity pool, asset quality concerns, portfolio rebalancing, fear of direct effects, protentional lenders' behaviour) and asset liability side (interbank lending, payment system, security and forex settlement, direct exposure, equity holdings, asset prices). There have been studies which have tried to identify the relative importance of these channels in the crises of the recent past. OECD (2012) also highlighted the role of cross-border banking contagion in the great financial crisis of later 2000s and mentioned that bank balance-sheet contagion can be of a direct nature through "lending-country spillovers" and indirect banking contagion through "common-creditor contagion". It further discussed that crisis risk have been bigger for commoncreditor contagion. Forbes (2012) discussed that shock arising in one country in form of increased stressed assets and lowering of bank deposits can spread to other countries because of the reduction in bank credit in other countries to restore capital adequacy.

Methodologically, a number of techniques have been used to study the status of network and contagion risks among banking sectors across the borders. The network analysis based on the graph theory has been applied in number of studies to study the banking network existing among a large number of countries across continents (Minoiu and Reyes, 2013; see Huser, 2015 for detailed review). Minoiu and Reyes, 2013 using data from 1978 to 2010 found that the density of international banking network is pro-cyclical and country connectedness rose before crises and then rapidly falling after the occurrences. Further, they found that the recession of 2007 was comparable to earlier periods in terms of increase in aggregate flows, suggesting the location of origin of shock in the network's core was responsible for the crisis' severity. There are also studies which used simulation exercises on the matrix of bilateral credit relationships among domestic and foreign banks for specific countries on bank level data (Degryse et al., 2009; Degryse and Nguyen, 2009; Upar and Worms, 2004; Gabrieli et al., 2015 and see Upper, 2011 for review). Gropss et al. (2009) relied on econometrics exercises in the form of a multinomial logit model to find that there existed significant cross-border contagion in a sample of European banks from 1994 to 2003. 
They also mentioned that contagion may have heightened with the Euro's introduction. Gabrieli et al. 2015 found that contagion is most closely associated with the bank's position in the network and exposure to counterparties which are the riskiest in nature. Degryse et al. 2009 also found that for the period 1999-2006, the shock impacting liabilities of one country has the potential to affect the complete financial system and contagion was more prevalent in countries sharing close geographical distance.

There are number of studies which included India in their cross-border banking network and contagion analysis. Dungey and Gajurel (2015) in their study of banking contagion in 54 countries during 2007-09 employing the Capital Asset Pricing Style Framework found that India exhibited all three channels of contagion via systematic, idiosyncratic and volatility. However, only idiosyncratic increased the likelihood of systemic crisis in the country. Minoiu and Reyes (2013) used the network analysis on confidential location-based flow data provided the BIS and defined global banking network with a core-periphery structure. They found that in the run-up to crisis of 2008, the BRIC (Brazil, Russia, India, and China) were among the most integrated borrowers alongside countries of emerging Europe. The Reserve Bank of India also conducts network analysis and contagion analysis in its half yearly Financial Stability Reports at the national level to identify the dominant banks in the sector as well as the dominant sectors in the overall financial system. RBI (2018b) found the number of dominant banks on basis of their network analysis to be 4 . Further in the network analysis of the Indian financial system, the banking sector was identified to be the most significant compared to other financial entities in terms of bilateral flows.

\section{Data and Methodology}

As far as data is concerned, the current paper relies on the Locational Banking Statistics (LBS) and Consolidated Banking Statistics provided by the Bank of International Settlement (BIS). Additionally, the data on International Banking Statistics as compiled by the Reserve Bank of India has also been used for the analysis to supplement the data provided by BIS. The methodology can be broadly divided into two parts. In first part, we discuss the main components of international assets and liabilities of Indian banks in the backdrop of the regulations under which they operate. This section will also include the other stylised facts related to counter-countries, currency denomination and also comparison of India with its peers in terms of their participation in crossborder banking operations. This will then be followed by the application of the network analysis to understand India's position vis-à-vis other countries with which the country shares cross-border banking relationships in terms of liabilities as well as assets.

The network analysis has emerged as an important tool to understand networks in recent times with applications in varied fields. The tool is also important in the economics and financial analysis to gain insights into networks operating in these sectors. As explained in the preceding section, there is a strand of the literature which has employed this tool to understand cross-border banking transactions. We will also apply this methodology to understand international banking in the Indian context. The network analysis is based on the graph theory, the branch of mathematics devoted to study pairwise associations between objects. The network in our analysis, in non-mathematical terms, consists of a set of vertices (also known as nodes, points) which represent the countries and edges (also known as line, arcs) showing the claims or liabilities between the country pairs. Since the focus of this paper is on India, the countries in our analysis are restricted to those with which India is involved in terms of cross-border banking transactions. Specifically, we have combined the information from BIS's Locational Banking Statistics and the Reserve Bank's International Banking Statistics to draw our sample. The Reserve Bank's database include information on the 
top 14 and 13 countries with which India has the topmost liabilities and claims, respectively. For these countries, the data was then drawn from BIS's LBS database to find these countries' major banking counter-countries and the data wherever available, was included in our analysis to form the network and gain insights into the position of India. Apart from data on these major countries, we also included the countries and their major counter countries from the BIS database for which the counterparty-country was India. The flows under consideration in our analysis are international claim and liabilities. Since the Reserve Bank also compiles data on basis of LBS statements of BIS, we are assuming the data to be comparable with BIS's LBS. The data for network analysis pertains to Q1 of 2018. In our analysis, the total number of countries in the analysis of liabilities is 38 and in case of claims is 58 .

To formalise our analysis, we are borrowing the Matrix Approach to the network analysis as adopted by Minoiu and Reyes (2013). Following them, we define the Matrix X with rows showing the lenders and the column representing borrowers. The cell $\mathrm{x}_{\mathrm{ij}}$, hence, represents, the weighted liabilities (or claim, as the case may be) of country $i$ towards country $j$. The corresponding adjacent matrix is defined as $\mathrm{A}_{\mathrm{t}}$, where an element $\mathrm{a}_{\mathrm{ij}}$ takes a value of 1 if $\mathrm{x}_{\mathrm{ij}}$ is non-zero, and 0 otherwise. We used total flow from country $i$ to country $j$ as weights in our analysis and rescaled them for charting purpose using in-built algorithm in Gephi 0.9.2, an open source software for network analysis. We will be finding out the following for our sample:

a. Node degree (in-degree and out-degree) and Weighted Node degree (weighted in-degree and weighted out-degree)

This measure gives the number of links for each node in a network. In the present analysis, we have a directed network (liabilities or claims of country $i$ towards country $j$ ), therefore, the network has links which are outgoing as well as incoming. Hence, we also define out-degree and in-degree which are the number of outgoing and incoming links, respectively. However, since the information in BIS is not complete as not all the countries are reporting the detailed data, these measures may not reflect actual reality. Hence, we will give the weighted outdegree and weighted in-degree measure where the weights of edges are used. Further, the weight degree which is the sum of weight in-degree and weighted out-degree will also be calculated. These measures capture the centrality of the nodes as gauged by the level of their connectivity with the other nodes in a network.

b. Connectivity

It is one of the measures to capture the density of the network under observation. It is defined as the ratio of number of edges which exist in a network to the total number of edges which are possible between the nodes of the give network.

\section{c. Betweenness Centrality}

For a given node in a network, betweenness centrality may be defined as the relative frequency of its appearance in the shortest paths that exists between other pairs of nodes. This is also reflective of the importance of a country in the flows in a network. 


\section{International Exposure of Banks in Indian Context}

The Indian banks have been engaged in international operations for the past many decades. However, as Kulkarni (1980) put it, the Indian banks were involved more in operations related to retail banking and foreign exchange business opportunities overseas rather than in international banking in the real sense and the same was reiterated in Verghese (1988). The reforms in Indian banking in the post-liberalisation era gave some impetus to the international operations of the Indian banks. However, the Indian banks operating cross-borders are still subjected to a number of regulations and restrictions. The international banking transactions are regulated by the Reserve Bank of India under the Foreign Exchange Management Act, 1999 (FEMA). The Act empowers the central bank to frame regulations to prohibit, restrict and regulate the opening, holding and maintaining of foreign currency accounts and the limits up to which amounts can be held in such accounts by a person resident in India. Further, the maintenance of deposits/accounts between a resident in India and a person outside is also regulated by the Reserve Bank under the same Act. The Reserve Bank under the FEMA Act, 1999 also frames the regulation for foreign exchange business conducted by the banks with their customers/constituents and issues directions for laying down the modalities with a view to implementing these regulations. Broadly speaking, the international banking transactions in India remain regulated under the overall partial capital account convertibility framework prevalent in India.

\subsection{Some Stylised Facts}

The statement on international liabilities/claims of banks classified according to type of instrument is presented in Table 1 . As can be clearly seen, around one-third of the liabilities are in form of loans and deposits and even within this category, the money deposited under various accounts and schemes offered to the non-resident Indians (NRIs) is the major contributor. These NRIs deposits have been found to be positively related to relative interest rates, LIBOR and negatively related to political and geopolitical risks as well as external events like financial crises (Gordon and Gupta, 2004).

As far as claims are concerned, owing to regulations on international banking lending activities, the claims of Indian banks are, on the majority, loans to non-resident and foreign currency loans to residents. NOSTRO Balances and Placements Abroad form the major part of the claims. The other major category is outstanding export bills. The international liability to claim ratio for India is 2.1 showing the dominance of deposits in the international banking activities in the country. The overview of India's international liabilities and claims clearly show that cross-border banking in India is mostly restricted to catering the needs of the NRIs, exporters and foreign currency loans to the residents. 
Table 1

International Liabilities/Claims of Banks Classified According to Type of Instruments (Based on LBS Statements)

Amount in US\$ Million

\begin{tabular}{|c|c|c|c|}
\hline Liabilities Category & March - 2018 & Claims Category & March - 2018 \\
\hline 1. Loan \& Deposits & $153747.1(77.8)$ & 1. Loans \& Deposits & $89572.6(97.6)$ \\
\hline $\begin{array}{l}\text { Foreign Currency Non-resident Bank } \\
\text { [FCNR (B)] Scheme }\end{array}$ & $22036.3(11.2)$ & Loans to Non-residents & $30150.4(32.9)$ \\
\hline Resident Foreign Currency (RFC) A/Cs & $265.5(0.1)$ & $\begin{array}{l}\text { Foreign Currency Loan to } \\
\text { Residents }\end{array}$ & $23583.6(25.7)$ \\
\hline $\begin{array}{l}\text { Exchange Earners Foreign Currency } \\
\text { (EEFC) A/Cs }\end{array}$ & $4054.4(2.1)$ & Outstanding Export Bills & $13695.9(14.9)$ \\
\hline $\begin{array}{l}\text { Other Foreign Currency Deposits } \\
\text { (including Inter-bank foreign currency } \\
\text { deposits) }\end{array}$ & $1193.3(0.6)$ & $\begin{array}{l}\text { Foreign Currency in hand, } \\
\text { Travelers Cheques, etc. }\end{array}$ & $150.6(0.2)$ \\
\hline $\begin{array}{l}\text { Foreign Currency Borrowing } \\
\text { (Inter-bank borrowing in India and } \\
\text { from abroad, external commercial } \\
\text { borrowings of banks) }\end{array}$ & $23073.3(11.7)$ & $\begin{array}{l}\text { NOSTRO Balances and } \\
\text { Placements Abroad }\end{array}$ & $21992.1(24.0)$ \\
\hline $\begin{array}{l}\text { VOSTRO Balances and Balances in } \\
\text { Exchange Houses and in Term Deposits }\end{array}$ & $988.5(0.5)$ & & \\
\hline $\begin{array}{l}\text { Non-Resident External Rupee (NRE) } \\
\text { Accounts }\end{array}$ & $84643.5(42.9)$ & & \\
\hline $\begin{array}{l}\text { Non-Resident Ordinary (NRO) Rupee } \\
\text { Accounts }\end{array}$ & $12117.0(6.1)$ & & \\
\hline Embassy Accounts & $150.9(0.1)$ & & \\
\hline $\begin{array}{l}\text { Foreign Institutional Investors (FII) } \\
\text { Accounts }\end{array}$ & $5145.1(2.6)$ & & \\
\hline ESCROW A/Cs & $79.2(0.0)$ & & \\
\hline $\begin{array}{l}\text { 2. Own Issues of International } \\
\text { Securities }\end{array}$ & $177.88(0.1)$ & $\begin{array}{l}\text { 2. Holdings of Debt } \\
\text { Securities }\end{array}$ & $1416.50(1.5)$ \\
\hline Bonds & $177.9(0.1)$ & $\begin{array}{l}\text { Investment in Foreign } \\
\text { Government Securities }\end{array}$ & $1416.5(1.5)$ \\
\hline $\begin{array}{l}\text { Other Own Issues of International Debt } \\
\text { Securities }\end{array}$ & - & $\begin{array}{l}\text { Investment in Other Debt } \\
\text { Securities Abroad }\end{array}$ & - \\
\hline
\end{tabular}




\begin{tabular}{|c|c|c|c|}
\hline Liabilities Category & March - 2018 & Claims Category & March - 2018 \\
\hline 3. Other International Liabilities & $43591.4(22.1)$ & 3. Other International Assets & $768.5(0.8)$ \\
\hline ADRs/GDRs & $6942.2(3.5)$ & $\begin{array}{l}\text { Investments in Equities } \\
\text { Abroad }\end{array}$ & $172.9(0.2)$ \\
\hline $\begin{array}{l}\text { Equities of Banks Held by Non- } \\
\text { residents }\end{array}$ & $21416.7(10.8)$ & $\begin{array}{l}\text { Capital supplied to and } \\
\text { receivable profits from foreign } \\
\text { branches of Indian banks and } \\
\text { other unclassified intl. assets }\end{array}$ & $595.6(0.6)$ \\
\hline $\begin{array}{l}\text { Capital/Remittable Profits of Foreign } \\
\text { Banks in India and Other Unclassified } \\
\text { International Liabilities }\end{array}$ & $15232.5(7.7)$ & & \\
\hline Total International Liability & 197516.36 & Total International Asset + & 91757.66 \\
\hline
\end{tabular}

+ : In view of the incomplete data coverage from all the branches, the data reported under the LBS are not strictly comparable with those capturing data from all the branches.

'-': nil or negligible.

Figures in parentheses are percentages to total.

Source: International Banking Statistics, Database on Indian Economy, RBI’s Data Warehouse.

\subsubsection{Currency Denomination of International Liabilities/Claims}

Around $65 \%$ of international liabilities as well as international claims are denominated in Indian rupees (Chart $4 \mathrm{a}$ and $4 \mathrm{~b}$ ). As far as liabilities are concerned as we discussed earlier, various accounts and schemes offered to the NRIs form its major share and most of these are denominated in Indian rupee only. This higher proportion of Indian rupee in international liabilities and claims translates into lower currency risks for the Indian banks.

\section{Chart 4}

Share of Currencies of International Liabilities/Claims (Based on LBS Statements)

a: Share in International Liabilities

$(\%)$ b: Share in International Claims

$(\%)$

65.1

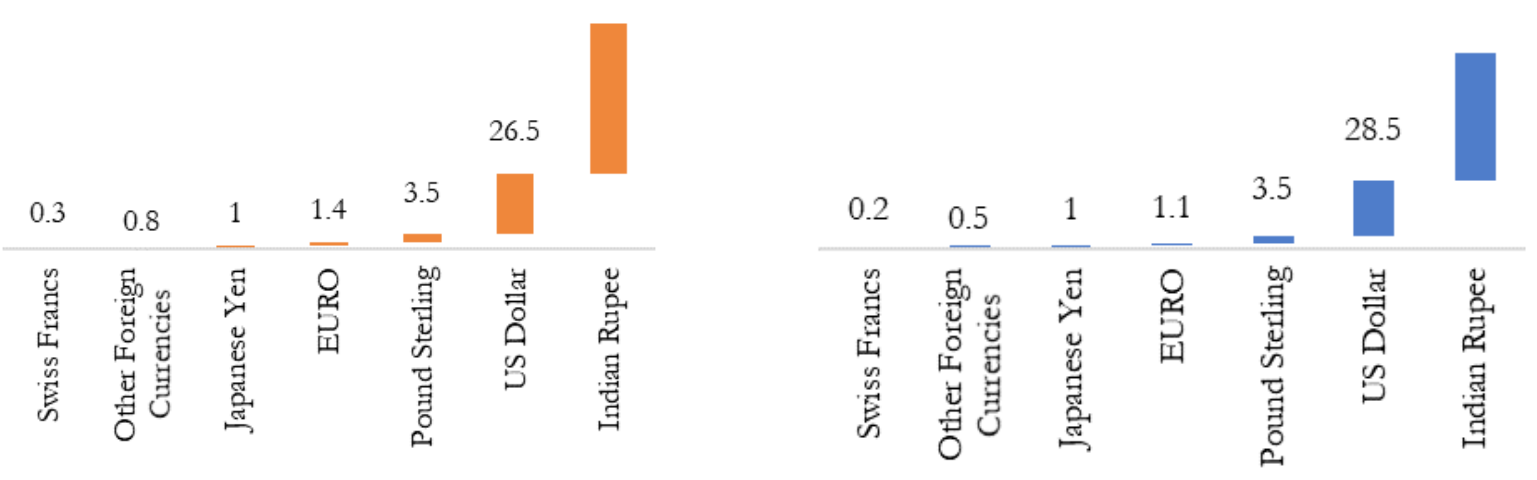

Source: Author's calculation based on International Banking Statistics, Database on Indian Economy, RBI's Data Warehouse. 


\subsubsection{Country of Residence in International Liabilities}

The top three country of residence with the highest share in the international liabilities is the UAE, USA and United Kingdom. Many of these countries host significant part of Indian diaspora abroad and hence, are major source for NRI deposits in India (Chart 5).

\section{Chart 5}

\section{Country of Residence in International Liabilities of India (Based on LBS Statements)}

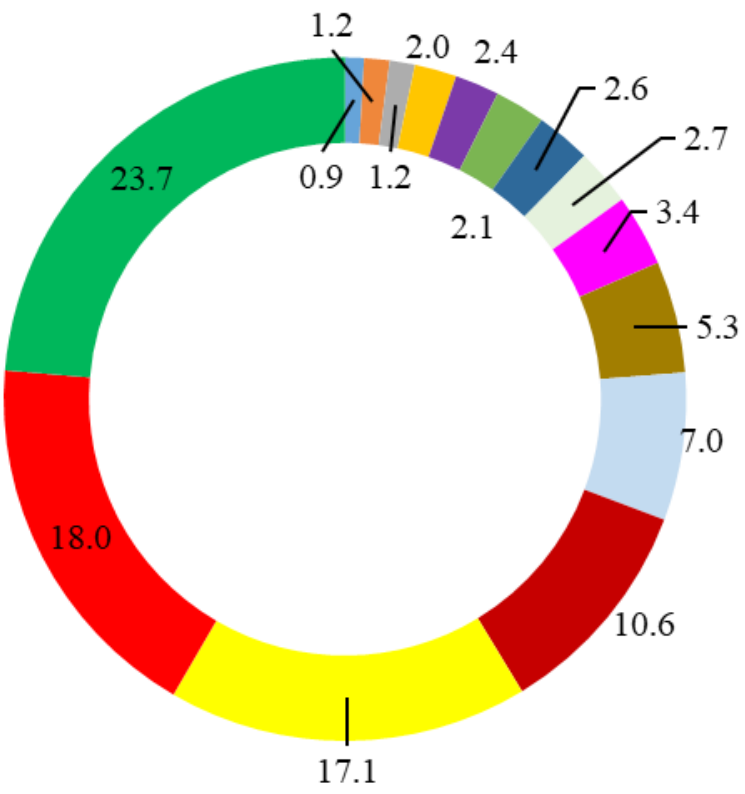

$$
\begin{aligned}
& \text { France } \\
& \text { Mauritius } \\
& \text { Bahrain } \\
& \text { Canada } \\
& \text { - Hong Kong } \\
& \text { Oman } \\
& \text { - Germany* } \\
& \text { Kuwait } \\
& \text { - Saudi Arabia } \\
& \text { - Singapore } \\
& \text { India } \\
& \text { - UK } \\
& \text { Others } \\
& \text {-UAE } \\
& \text { - US }
\end{aligned}
$$

Source: Author's calculation based on International Banking Statistics, Database on Indian Economy, RBI's Data Warehouse.

\subsubsection{Consolidated International Claims}

The data shows that in the case of consolidated international claims of banks on immediate country risk basis, the highest proportion is that of the USA, followed by UAE, Singapore, UK and Hong Kong (Chart 6). While USA and UK are important international financial centres, Singapore and Hong Kong are important offshore financial centres. Hence, the risk materializing in these economies in general and banking sector in particular, may have potential spill over effects on India. 


\section{Chart 6 \\ Share of Country of Transacting Units in Consolidated International Claims of Banks (Based on CBS Statements) in \% - on Immediate Country Risk Basis}

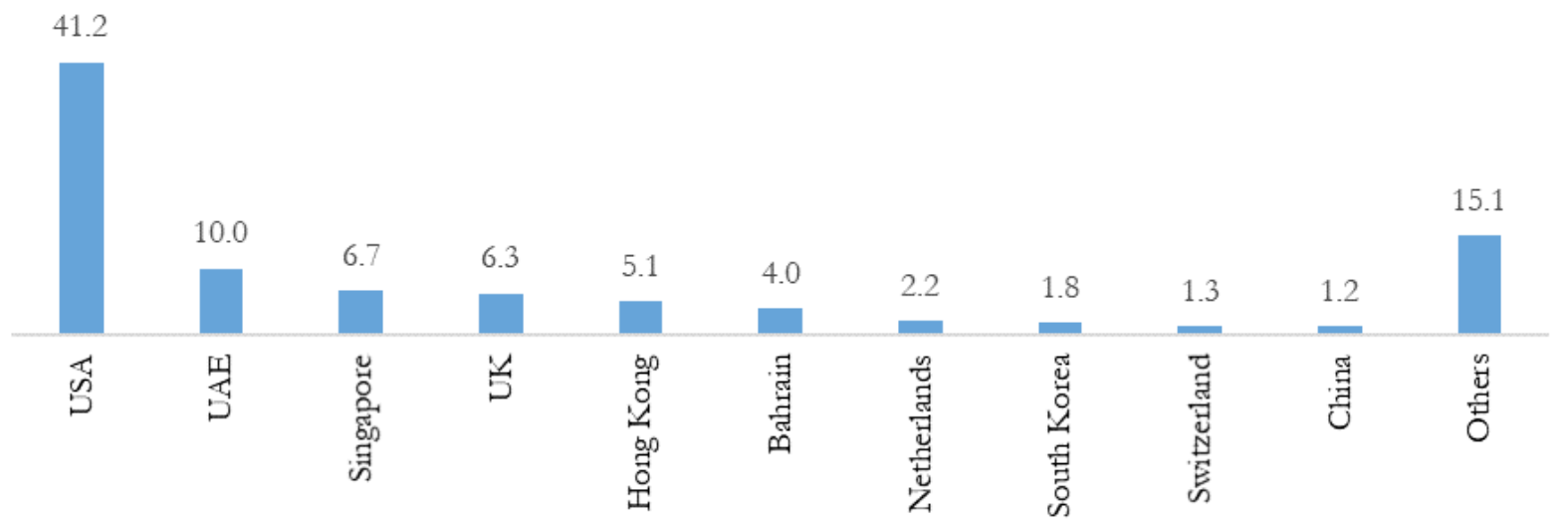

Source: Author's calculation based on International Banking Statistics, Database on Indian Economy, RBI's Data Warehouse.

\subsubsection{Indian Cross-border Banking: An International Comparison}

Despite the increasing share of India in global cross-border banking activity, its share remains very low (Chart 7). This may be attributed to the regulations on borrowing and lending across borders. In fact, among BRICS (Brazil, Russia, India, China and South Africa) the share of India is also not very significant (Chart 8). In fact, the share of India in cross-border claims has been more or less the same for the preceding period, during and after the great financial crisis of 2008. Hence, in context of global international banking scenario, the role of India is limited.

\subsection{Indian Banking during Recent International Crises}

Owing to the regulations on international banking activities in the country, Indian banking remained shielded during international crises of the recent past. The Indian banks continued to operate normally in the aftermath of the global financial crisis as outlined in Kumar and Vashisht (2009) and Sinha (2011). The main reasons cited for the normal functioning was the limited exposure of Indian banks to troubled assets, the prudential regulations by the regulator and limited presence of foreign banks in India (Sinha, 2011). However, indirect effects of the crises impacted Indian banks by putting pressure on domestic liquidity on the back of sudden reversals of foreign capital (Kumar and Vashisht, 2009). The Reserve Bank took a number of measures to ease liquidity conditions to ensure normalcy (see Sinha, 2011 for details). 


\section{Chart 7}

Shares Pertaining to India and Developing Asia and Pacific in Total Cross-border Positions in \% (Based on LBS Statements)

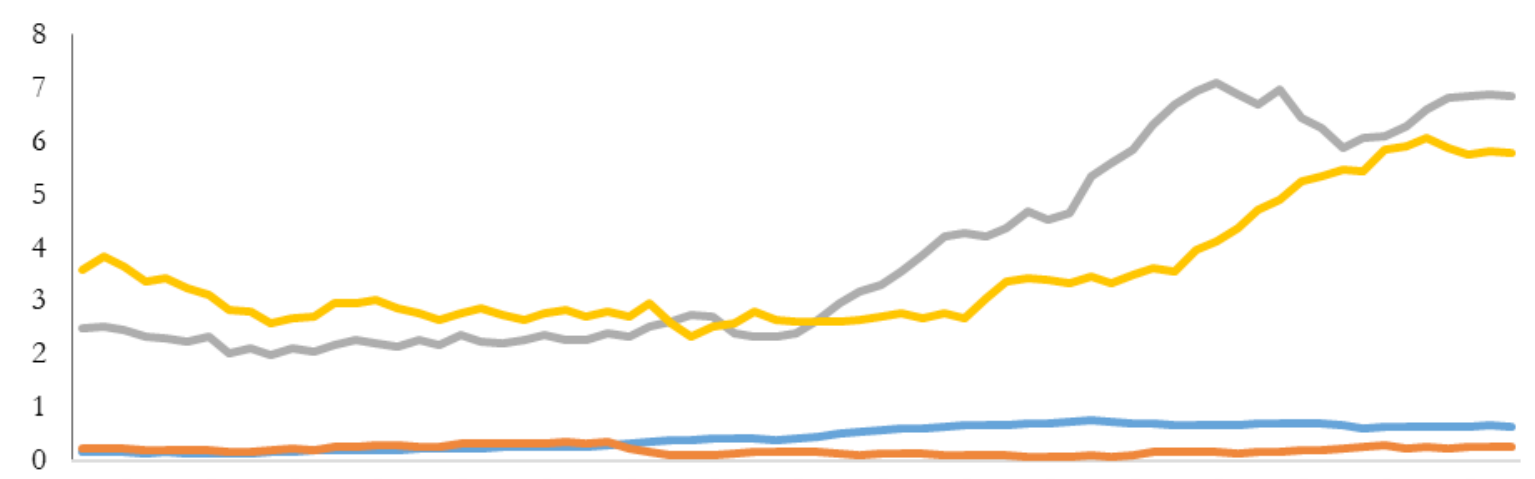

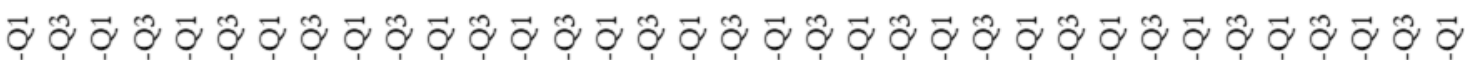
范

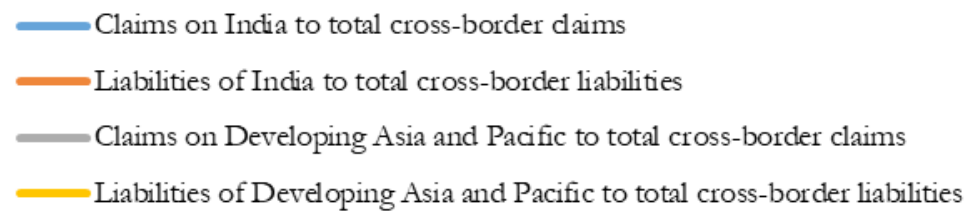

Source: Author's calculation based on Locational Banking Statistics, BIS.

\section{Chart 8}

\section{Cross-border Claims on BRICs Countries}

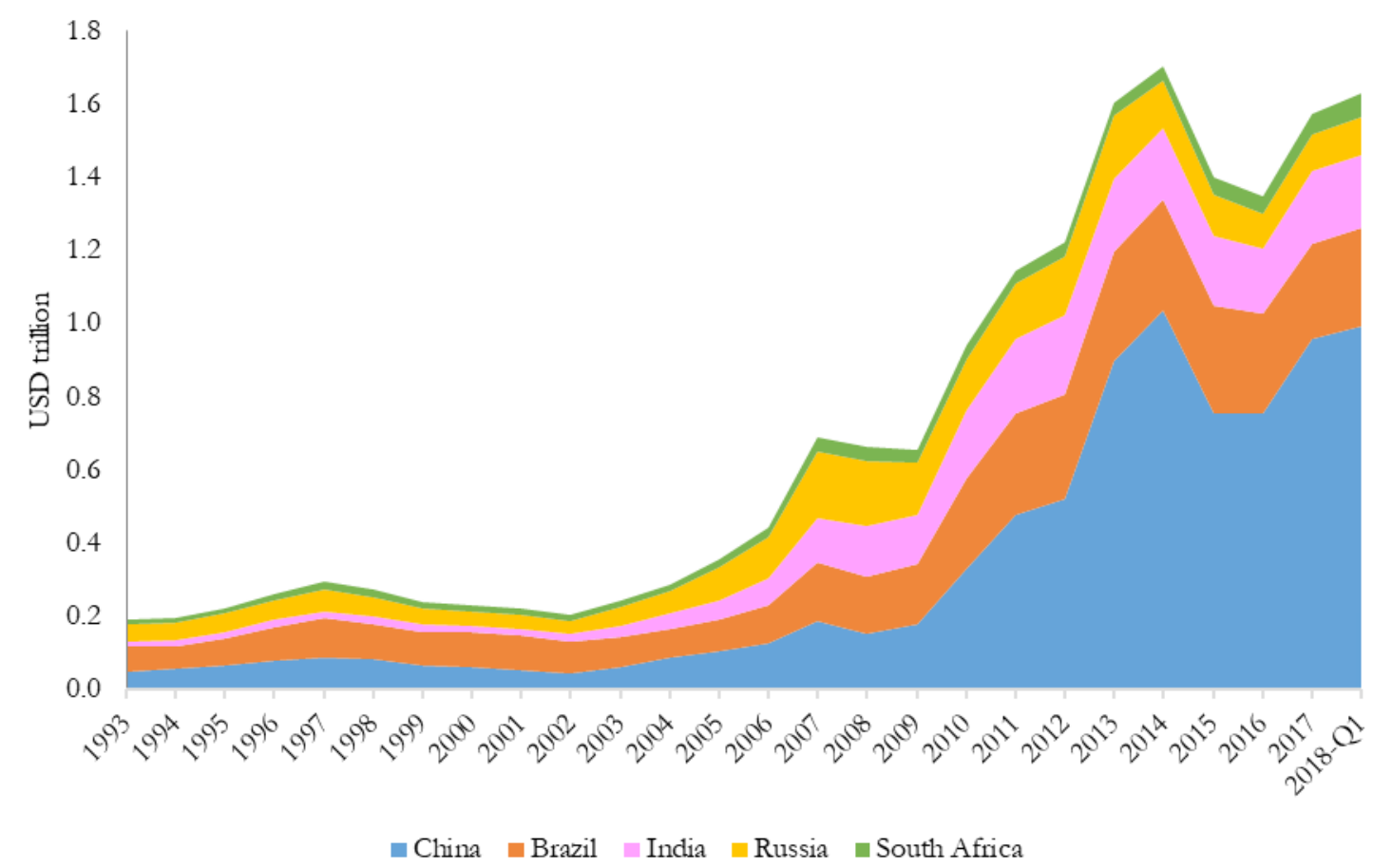

Source: Author's calculation based on Locational Banking Statistics, BIS. 


\section{Network Analysis of Cross-border Banking in the Indian Context}

Following the methodology described in Section 4, we now discuss the cross-border banking network keeping India in focus. As discussed in the preceding section, cross-border banking in India remains somewhat muted. We first discuss the network analysis in context of cross-border liabilities, followed by a discussion on cross-border claims. The network created, using the data as described in Section 4, the network for our sample is indicated in Chart 9. Among India's major counter-parties in case of cross-border liabilities, United States, United Kingdom, France, Germany and Japan are the most connected, as indicated by their weighted degrees. The ranking of the top ten countries along with the ranking of India is presented in Table 2. The network connectivity is 0.07 for this case. The network pertaining to cross-border claims is presented in Chart 10, followed by the ranking of major countries and India on different network measures in Table 2. The results as tabulated show that role of India is not that prominent, in spite of the fact that our data was focused on India. The network connectivity is computed to be 0.11 . The highest rank of India in case of between centrality is because of the nature of our sample as we have included countries focusing on India. In case of cross-country claims as well, the role of India is depicted in terms of ranks. However, the results of this data come with the caveat that the analysis has been done on a limited number of countries. In the analysis of the entire set of countries, the results may differ from the current results. Overall, countries like United States, United Kingdom, France, Germany and Japan are among the most important players in the cross-border banking network pertaining to India.

Table 2

\section{Network Measures for Cross-country Liabilitie}

\begin{tabular}{l|l|l|l}
\hline Weighted In-Degree & Weighted Out-Degree & Weighted Degree & Betweenness Centrality \\
\hline United Kingdom & France & United Kingdom & India \\
\hline United States & United Kingdom & United States & United Kingdom \\
\hline Cayman Islands & United States & France & Jersey \\
\hline Germany & Japan & Germany & Germany \\
\hline Luxembourg & Hong Kong SAR & Japan & Hong Kong \\
\hline Japan & Germany & Hong Kong & France \\
\hline Netherlands & Australia & Cayman Islands & South Africa \\
\hline France & Switzerland & Switzerland & Switzerland \\
\hline China & Canada & Luxembourg & United States \\
\hline Ireland & Belgium & Netherlands & Denmark \\
\hline \multicolumn{2}{|c|}{ India's Rank } & \\
\hline \multicolumn{2}{|c|}{15} & & \\
\hline
\end{tabular}

Source: Author's calculation based on data taken from Locational Banking Statistics, BIS and International Banking Statistics, Database on Indian Economy, RBI's Data Warehouse. The total number of countries in the analysis is 58. 


\section{Chart 9}

Network Analysis of Cross-border Liabilities in the Indian Context

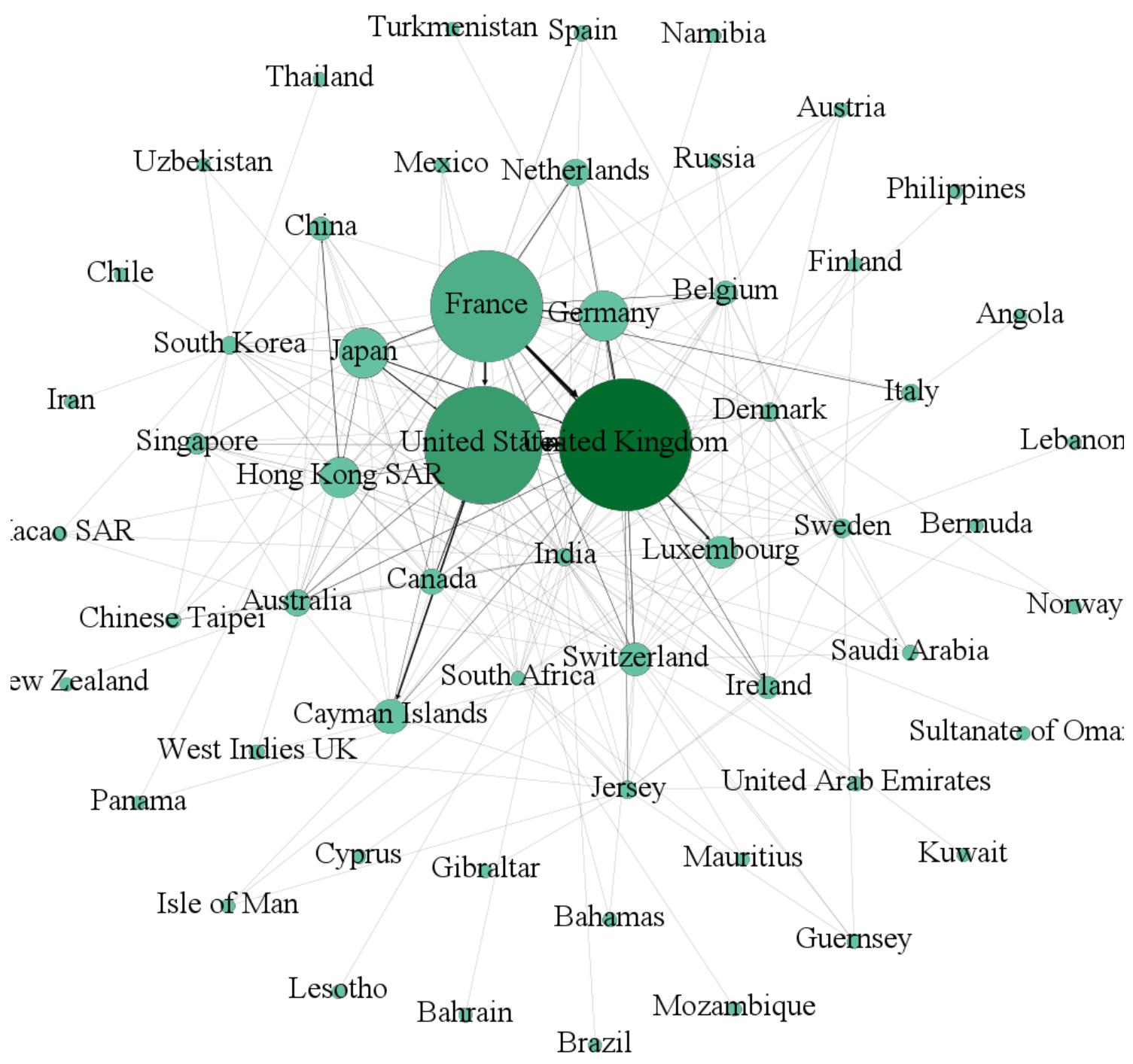

Source: Author's calculation based on data taken from Locational Banking Statistics, BIS and International Banking Statistics, Database on Indian Economy, RBI's Data Warehouse.

Note: The sizes of the nodes are representing weighted degree. The width of the edges represents the scaled weights. Nephi 0.9.2 has been used for the creation of the chart. 


\section{Chart 10 \\ Network Analysis of Cross-border Claims in Indian Context}

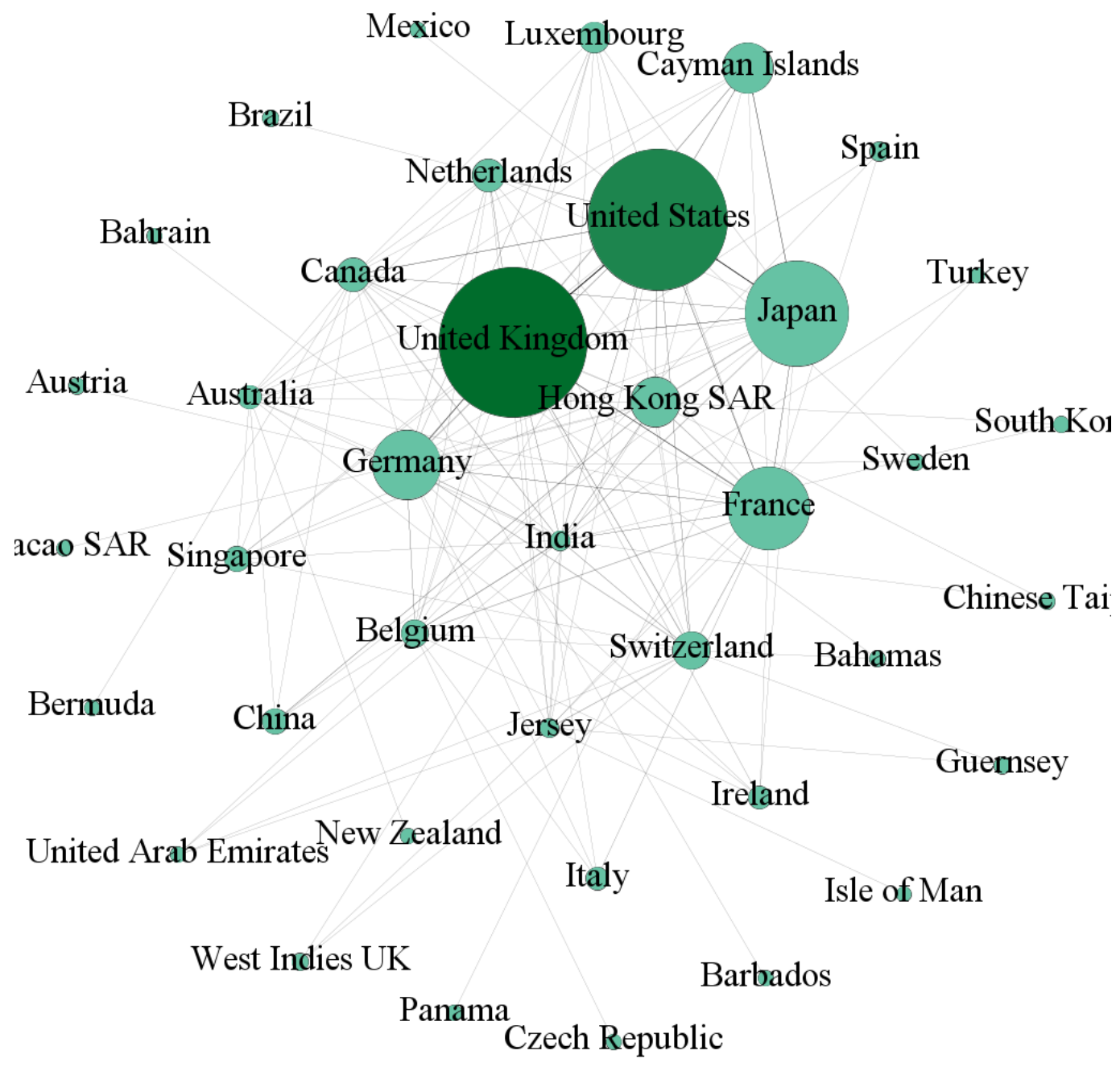

Source: Author's calculation based on data taken from Locational Banking Statistics, BIS and International Banking Statistics, Database on Indian Economy, RBI's Data Warehouse.

Note: The sizes and shades of the nodes are representing weighted degree. The width and shade of the edges represent the scaled weights. Gephi 0.9 .2 has been used for the creation of the chart. 
Table 3

Network Measures for Cross-country Claims

\begin{tabular}{|c|c|c|c|}
\hline Weighted In-degree & Weighted Out-degree & Weighted Degree & Betweenness Centrality \\
\hline United States & United Kingdom & United Kingdom & India \\
\hline United Kingdom & Japan & United States & Switzerland \\
\hline Cayman Islands & United States & Japan & Germany \\
\hline France & France & France & United States \\
\hline Japan & Germany & Germany & Hong Kong SAR \\
\hline Germany & Hong Kong SAR & Cayman Islands & France \\
\hline Netherlands & Switzerland & Hong Kong & Canada \\
\hline Luxembourg & Canada & Switzerland & United Kingdom \\
\hline China & Australia & Canada & Belgium \\
\hline Singapore & Belgium & Netherlands & Japan \\
\hline \multicolumn{4}{|c|}{ India’s Rank } \\
\hline 18 & 13 & 19 & 1 \\
\hline
\end{tabular}

Source: Author's calculation based on data taken from Locational Banking Statistics, BIS and International Banking Statistics, Database on Indian Economy, RBI's Data Warehouse. The total number of countries in the analysis is 38.

\section{Conclusion}

The banking sector has evolved through various stages in the country reflecting the financial needs of a growing economy. The banks in India continue to play a very important role in the country's economic process. The banking sector in the country is the most predominant player in the Indian financial system in terms of resources provided to the commercial sector, channelling household savings and hence, playing an important role of financial intermediation. Further, its share in the financial sector network in India is the most significant in terms of bilateral flows. The continued efforts by the regulator and government have contributed to making the sector more efficient, enabling it to play a crucial role in financial intermediation. The recent challenges facing the Indian banks in the form of asset quality are also being managed with new policies to ensure their speedy resolution. At the same time, regulations and supervision ensure that the sector remains robust against the various risks.

With liberalisation, the pace of globalisation of the Indian economy has also increased. In the context of global cross-border banking scenario, the Indian banking sector's international operations are subject to regulations prescribed by the central bank in the purview of the existing legal framework under the overarching partial capital account convertibility. Most of the international operations of the banking sector in India are devoted to catering to the needs of NRIs, exporters and foreign currency credit needs of residents. Further, most of the international liabilities and claims are denominated in Indian rupees lowering the currency risks. The cross-border banking activities 
for banks operating in India are subject to prudential regulations which translate to lower exposure for these entities to cross-border risks. Further, the presence and operations of foreign banks in India is also limited. In this scenario, cross-border contagion risks remain limited for the country as seen by the India's banking sector's experience in the wake of the global and regional financial crises of the recent past. The results from our observations and analysis using the BIS global datasets and the Reserve Bank's data also point towards the same and show that the role of India is not that significant in the global banking network. The results from the network analysis corroborated these findings where the ranking of India in the network measures among the major countries with which it shares cross-border banking relations is not very high. The prudential approach of the country in terms of cross-border banking operations has shielded the banking sector from the effects of the crisis that originated in foreign countries. 


\section{References}

Acharya, Shankar, (2001), "India's Macroeconomic Management in the Nineties," Working Paper, ICRIER, New Delhi, Available at: https://www.imf.org/external/pubs/ft/wp/2004/wp0448.pdf

Agenor, Pierre-Richard, (2003), "Benefits and Costs of International Financial Integration: Theory and Facts," The World Economy, Volume 26, Issue 8, pp. 1089-1118.

Allen F. and D. Gale, (2000), "Financial Contagion," Journal of Political Economy, 108(1), pp. $1-33$.

Banerjee A.V.; S. Cole and E. Duflo, (2004), "Banking Reform in India," in India Policy Forum 2004, Volume 1, (Eds.) S. Bery, P. S. Bosworth and A. Panagariya.

Borio, C., (2014), “The International Monetary and Financial System: Its Achilles Heel and What To Do About It," BIS Working Papers, No. 456, September.

Borio, C. and P. Disyatat, (2011), "Global Imbalances and the Financial Crisis: Link or No Link?" BIS Working Papers, No. 346, May, Revised and Extended Version of "Global Imbalances and the Financial Crisis: Reassessing the Role of International Finance," Asian Economic Policy Review, 5, 2010, pp. 198-216.

Borio, Claudio; Harold James and Hyun Song Shin, (2014), "The International Monetary and Financial System: A Capital Account Historical Perspective," BIS Working Papers, 457, Bank for International Settlements, Available at: https://www.bis.org/publ/work457.pdf

Cerutti, Eugenio; Stijn Claessens and Patrick McGuire, (2014), "Systemic Risks in Global Banking: What Available Data Can Tell Us and What More Data Are Needed?" in Risk Topography: Systemic Risk and Macro Modeling, (Eds.) Markus Brunnermeier and Arvind Krishnamurthy, National Bureau of Economic Research.

Degryse, Hans and M. A. Elahi. and María Fabiana Penas, (2009), "Cross-Border Exposures and Financial Contagion,” TILEC Discussion Paper, No. 2009-008, March 19, Available at: https:// ssrn.com/abstract=1365115 or http://dx.doi.org/10.2139/ssrn.1365115

Degryse, Hans and Grégory Nguyen, (2007), "Interbank Exposures: An Empirical Examination of Contagion Risk in the Belgian Banking System," International Journal of Central Banking, 3, Issue 2, pp. 123-171.

Dungey, M. and D. Gajurel, (2015), "Contagion and Banking Crisis - International Evidence for 2007-2009,” Journal of Banking \& Finance, 60, pp. 271-283.

Forbes, Kristin, (2012), “The 'Big C': Identifying and Mitigating Contagion,” 36th Jackson Hole Symposium.

Gabrieli, S.; D. Salakhova and G. Vuillemey, (2015), "Cross-border Interbank Contagion in the European Banking Sector," Banque de France Working Paper, 545, Available at: https://www. banque-france.fr/sites/default/files/medias/documents/working-paper_545_2015.pdf 
Gordon, James P. and Poonam Gupta, (2004), "Nonresident Deposits in India: In Search of Return?" IMF Working Paper, 04/48, International Monetary Fund

Government of India, (2018), Economic Survey 2017-18.

Gropp R.; M. Lo Duca and J. Vesala, (2009), Cross-border Bank Contagion in Europe, International Journal of Central Banking, March, pp. 97-139.

Hüser, Anne-Caroline, (2015), "Too Interconnected to Fail: A Survey of the Interbank Networks Literature," SAFE Working Paper, No. 91, Available at: https://ssrn.com/abstract=2577241 or http://dx.doi.org/10.2139/ssrn.2577241

Kulkarni G. R., (1980), “International Dimensions of Indian Banking,” Economic and Political Weekly, 15(48), pp. M127-M146.

Kumar, R. and P. Vashisht, (2009), "The Global Economic Crisis: Impact on India and Policy Responses,” ADBI Working Paper, 164, Tokyo: Asian Development Bank Institute. Available at: http://www.adbi.org/working-paper/2009/11/12/3367.global.economic.crisis.india/

Minoiu C. and J. A. Reyes, (2013), “A Network Analysis of Global Banking: 1978-2010,” Journal of Financial Stability, 9 (2013), pp. 168-184.

Mohan, R. and P. Ray, (2017), Indian Financial Sector: Structure, Trends and Turns, IMF working paper, WP/17/7

OECD (2012), "Financial Contagion in the Era of Globalised Banking?" OECD Economics Department Policy Notes, No. 14, June.

Park, Cyn-Young and Kwanho Shin, (2017), "A Contagion Through Exposure to Foreign Banks During the Global Financial Crisis," Asian Development Bank Economics Working Paper Series, No. 516, July, Available at: https://ssrn.com/abstract=3187781 or http://dx.doi.org/10.2139/ ssrn. 3187781

Prakash A.; A. K. Shukla; A. P. Ekka and K. Priyadarsh, (2018), Quarterly Estimates of Households' Financial Assets and Liabilities, RBI Bulletin, March, pp. $11-18$.

Prasad E. S., (2010), "Financial Sector Regulation and Reforms in Emerging Markets: An Overview," IZA Discussion Paper, No. 5233, Institute for the Study of Labor, Switzerland.

Ramasastri A. and A. Samuel, (2006), "Banking Sector Developments in India, 1980-2005: What the Annual Accounts Speak?" Reserve Bank of India Occasional Papers, 27 (1 and 2), pp. 177205.

Reserve Bank of India, (2008), Report on Currency and Finance, 2006-08, Volume-I.

Reserve Bank of India, (2014), Framework for Dealing with Domestic Systemically Important Banks (D-SIBs).

Reserve Bank of India, (2015), Annual Report 2014-2015. 
Reserve Bank of India, (2015a), Report of the Internal Working Group (IWG) to Revisit the Existing Priority Sector Lending Guidelines.

Reserve Bank of India, (2016), Annual Report 2015-2016.

Reserve Bank of India, (2016a), Master Direction - Deposits and Accounts, Available at: https:// rbidocs.rbi.org.in/rdocs/notification/PDFs/09MDD593B2F2D48648C8AB3D37625C9F245D. PDF

Reserve Bank of India, (2017a), Annual Report 2016-2017.

Reserve Bank of India, (2017b), Report on Trend and Progress of Banking in India for the year ended June 30, 2017.

Reserve Bank of India, (2018a,) Annual Report 2017-18.

Reserve Bank of India, (2018b), Financial Stability Report, Issue No. 17.

Samantaraya, A., (2016) "Procyclical Credit Growth and Bank NPAs in India," Economic and Political Weekly, Money, Banking and Finance, 51(12), pp. 112 - 119.

Sengupta R. and Harsh Vardhan, (2017), This Time it is Different Non-performing Assets in Indian Banks," Economic and Political Weekly, 52(12), pp. 85 - 95.

Sinha A., (2011), Impact of the International Banking Crisis on the Indian financial System, in the Global Crisis and Financial Intermediation in Emerging Market Economies, Bank for International Settlements, 2011, Vol. 54, pp. 225-234.

Shirai S., (2002), "Banking Sector Reforms in India and China: Does India's Experience Offer Lessons for China's Future Reform Agenda?" Asia-Pacific Development Journal, 9(2), pp. 51-82.

Tonzer, Lena, (2015), “Cross-border Interbank Networks, Banking Risk and Contagion,” Journal of Financial Stability, Vol. 18, Issue C, pp. 19-32.

Upper, C., (2011), "Simulation Methods to Assess the Danger of Contagion in Interbank Markets," Journal of Financial Stability, 7 (3), pp. 111-125.

Upper, C. and A. Worms, (2004), "Estimating Bilateral Exposures in the German Interbank Market: Is there a Danger of Contagion?" European Economic Review, 48(4), pp. 827-849.

Verghese, S. K., (1988), 'Developments in International Banking and Prospects of Indian Banks' Overseas Business," Economic and Political Weekly, 23(18), pp. 899-908. 


\title{
Chapter 4
}

\section{UNDERSTANDING CROSS-BORDER CONTAGION RISKS IN INDONESIA ${ }^{1}$}

\author{
By \\ Maulana Harris Muhajir; Arnanda H.F. Wibowo; and Irman Ramdhani
}

\section{Introduction}

The international bank lending market that substantially expanded in the last two decades has become more akin to external shocks. The extreme change caused by the global financial crisis (GFC), i.e. in 2007 net cross-border bank lending was at the level of $\$ 4.3$ trillion but one year later, the net cross-border bank lending was reduced to minus \$ 1 trillion in 2008.

As one of the countries affected by GFC, Indonesia realises the potential risk of foreign exposure to the banking system in Indonesia. Indeed, in the case of Indonesia, this country has uniqueness because of its volatility of capital flow compared to peer-countries in emerging Asia. It makes Indonesia more vulnerable to sudden changes in the global financial condition. Hence, the financial regulator, Bank Indonesia, has implemented structural reforms, such as well-monitoring private sector external debts, including banks.

More complexity and extensive linkages across global financial markets can have a significant knock-on effect on even relatively sound banking systems. Regarding that fact, complexity and interconnectedness are becoming essential factors to consider whether the bank is systemic or not. Indeed, most of the banks that have interlinkages on cross-border are systemically important banks (SIB).

Indonesia itself has already implemented G-SIB guidelines from BCBS to identify D-SIB. However, this calculation method has not included cross-border interlinkages. In particular, the issues of systemic risk have been analysed by several empirical studies, intra-cross-border and contagion risk and the role of systematically important banks (SIBs), i.e., by Haldane and May (2011), Allen and Gale (2000), Yellen (2013) and Cerutti (2015). Genberg (2017) in his recent study further shows that the cross-border financial integration has become more complicated in emerging market economies in Asia.

Glasserman and Young (2015) explain that the strongly interconnected financial systems report higher losses caused by contagion risk. On the other hand, interconnectedness also has a positive effect on the allocation of funds regarding innovation activities and competition, (see Tabak (2014) and Surjaningsih et al. (2016)).

Concerning previous studies and facts, the aim of our research is to try fill in the gap since there are no studies yet analysing the network topology of cross-border interlinkages for systemically important banks from Indonesian perspectives as well as its interconnectedness to global financial hub.

1. The views expressed herein are those of the authors; they do not necessarily reflect the views of the Bank Indonesia. 
The second objective is to analyse the potential contagion risk within cross-border activity in the event of a credit shock and funding shock in the network system using a simulation method introduced by Espinosa-Vega and Sole (2010).

The rest of the paper is organised as follows: Section 2 explains the overview in the banking system and cross-border activities in Indonesia while Section 3 describes the sample, data variables and methodology. Section 4 presents the empirical results and Section 5 provides the conclusion and policy recommendation.

\section{Banking System and Cross-border Activities in Indonesia: An Overview}

The financial system in Indonesia is mostly dominated by banks, compared to other financial institutions. Banks control around $90 \%$ of the national loan market share. The Indonesian banking system has 115 commercial banks (as of May 2018), comprising state-owned banks, private banks, development banks, and foreign branch banks. Besides these, there are also 1,607 rural banks which function as economic drivers for the SME segment.

Despite the numbers of banks, ironically, the banking market in Indonesia is concentrated in some of the large banks, a fact that is becoming an issue for institutions that are Too-Big-To-Fail (TBTF).

Taking this into account and also as one of the G-20 member countries, the financial regulator in Indonesia has conducted financial reform by addressing the Too-Big-To-Fail (TBTF) issue and strengthening the resilience of financial institutions. One of them is by adopting the Global Systemically Important Bank (G-SIB) methodology assessment recommended by BCBS (2011) into the domestic level of Domestic Important Bank (DSIB).

The stipulations concerning Systemic Banks are stated in the Financial System Prevention and Crisis Management Act in Article 1. Systemic Banks are banks due to the size of assets, capital and liabilities; broad network or transaction complexity of banking services; and any linkages with other financial sectors or some other banks or financial services sectors, would have impact whether operational or financial if the banks are impaired or fails. In these rules, especially regarding interconnectedness, calculations for cross-border activity are not included. Interconnection is calculated only for the level of the domestic banking system.

On the other hand, the interbank money market between cross-border banks in Indonesia faced a significant decline after the GFC. The net cross-border interbank transactions reached its lowest level in 2008, to about to US\$21.23 mil., compared to the previous year which reached US\$23.78 mil. Squeezing cross-border activity at that time was very much felt in the Asian region. Figure 1 describes the decrease in net transaction volume in the cross-border interbank money market. 
Figure 1

Net Transaction Volume of Cross-Border Interbank Market

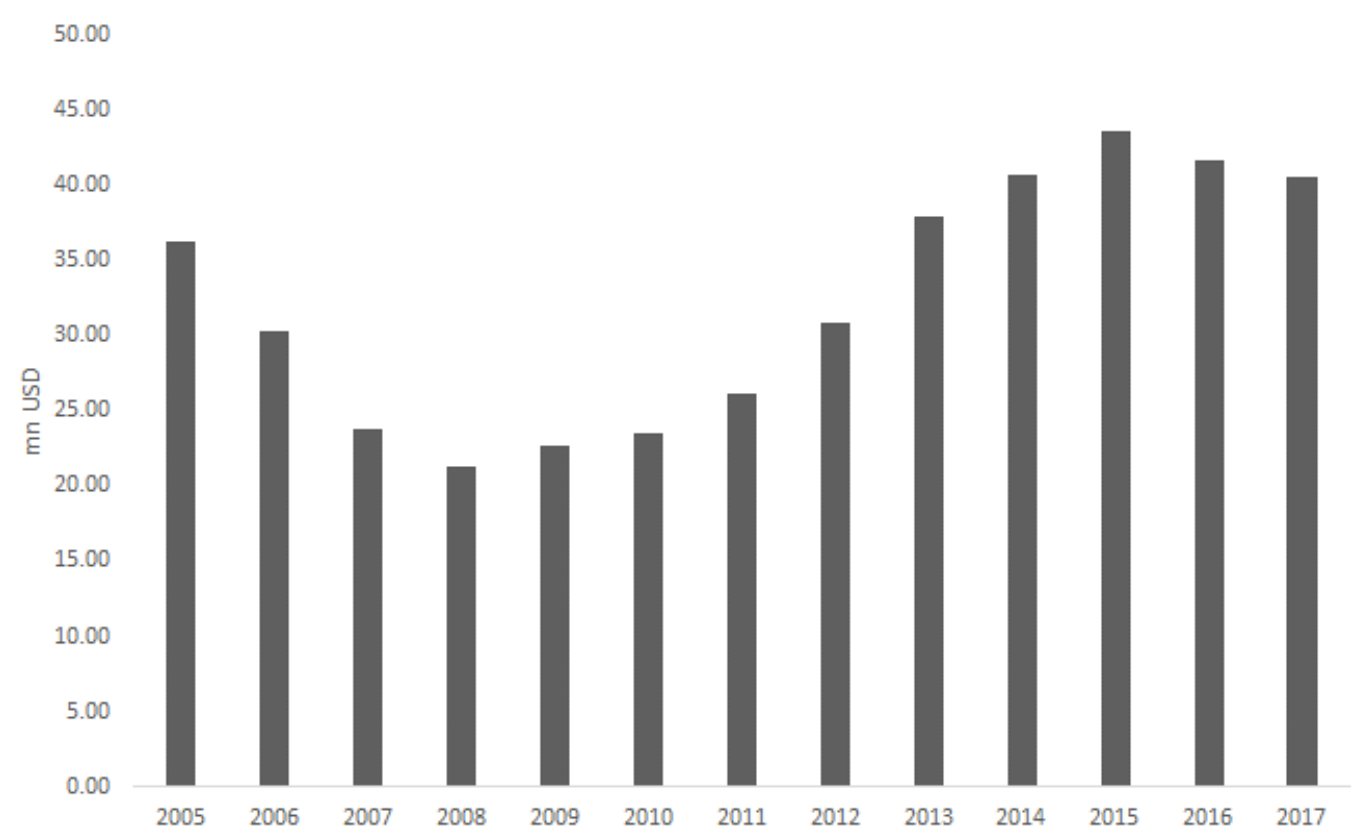

Source: Bank Indonesia Daily report, author calculation.

Whereas regarding the financial crisis, especially for emerging countries like Indonesia, the transmission of external factors such as spillover risk from other countries can happen due to the linkage of cross-border financial institutions. The international banks could have a contagion risk to the Indonesian banking system and should be anticipated early on.

As of the year 2017, the growth of the cross-border interbank money market began to revive. Figure 2 shows that the growth of cross-border interbank money market in 2017 was the highest since the last ten years. This fact is motivated by increasing liquidity flow from emerging countries to advanced countries as a result of growing export-import trading activity in recent years. The evidence of money flows is also supported by data on claims and liabilities originating from Indonesia based on BIS data. (Figure 3). 
Figure 2: The Growth of Cross-border Interbank Money Market (\%)

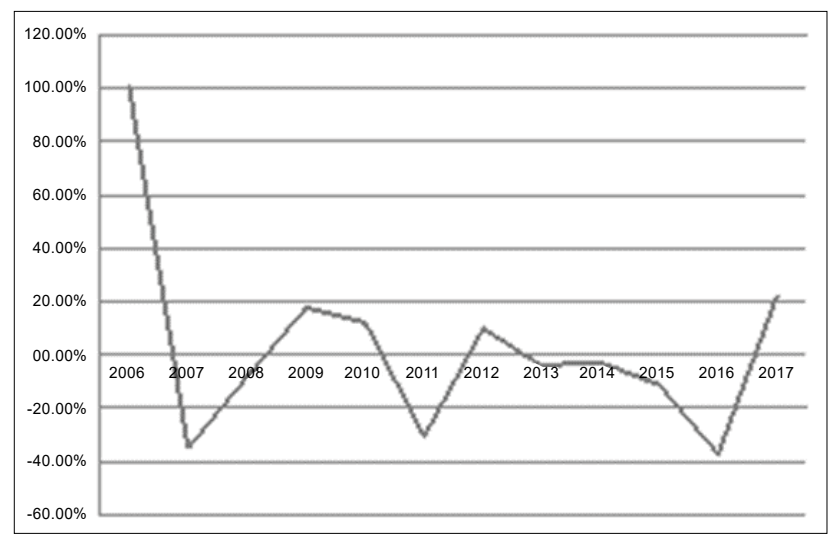

Source: Bank Indonesia Daily Report, author calculation.
Figure 3: Indonesia Claims and Liabilities (US\$ bn)

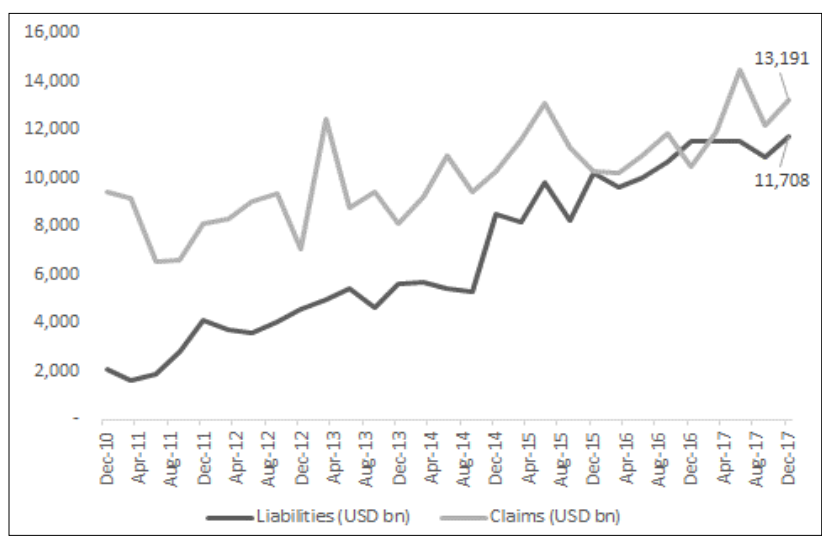

Source: Bank International Settlement, author calculation.

For the cross-border interbank money market, the interconnection of banks in Indonesia and other banking systems occurs mostly with countries known as financial hubs in the region. In Figure 4, we can see that Singapore dominates the proportion of the interbank money market as the country that has the most transactions with banks from Indonesia. Furthermore, there are Hong Kong and the UK banks which are the second and third largest consecutively. Nonetheless, this data does not yet assume the origin of the bank or the home country, for instance, the Singapore branch of Sumitomo is assumed to represent Bank Sumitomo Japan, or Deutsche Bank Singapore branch is assumed to represent Bank Deutsche Germany and so on.

\section{Figure 4 \\ IMM Volume by Countries (\%)}
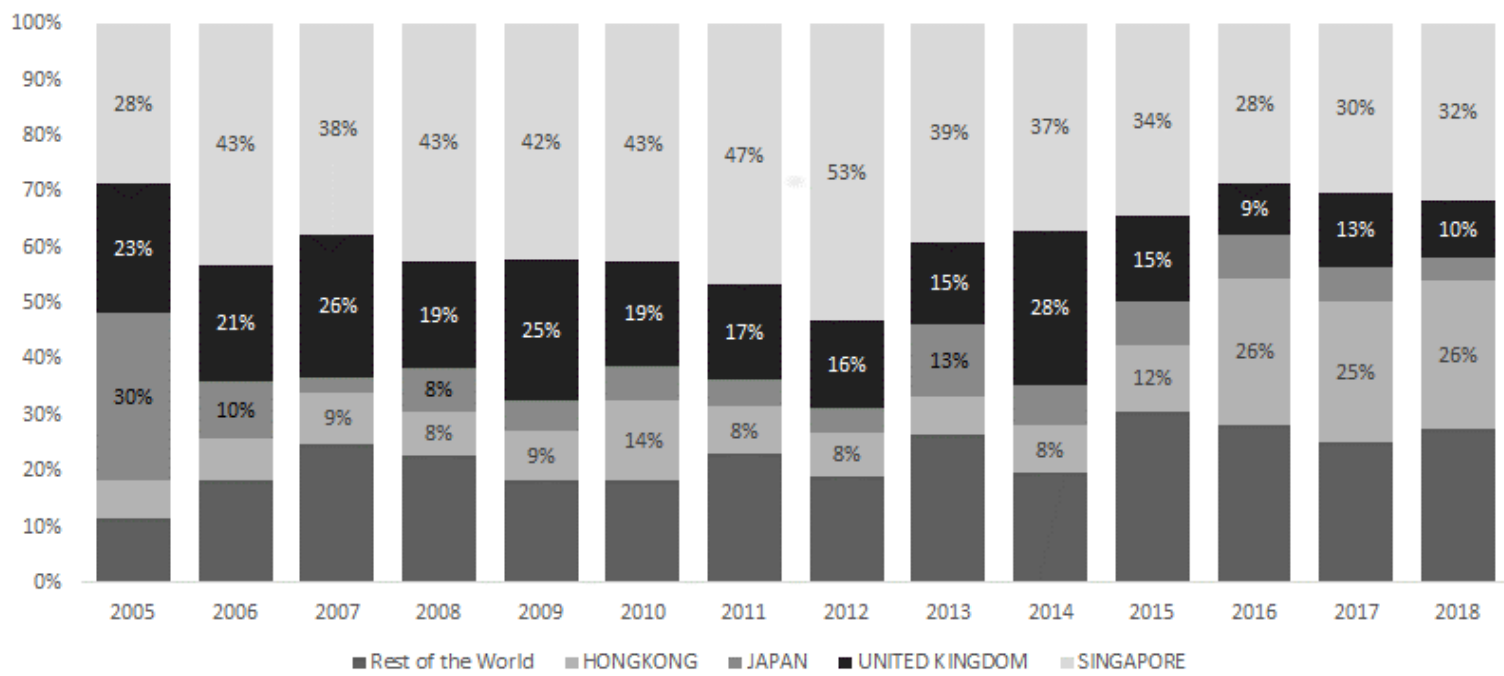

Source: Bank Indonesia Daily Report, author calculation.

This paper assumes that international banks act as representations of the parent bank in its home jurisdiction. Based on these assumptions, we would like to see which origin countries conduct inter-bank cross-border money market transactions and are the primary source of crossborder contagion risk for Indonesia. 


\section{Literature Review}

Our paper relates to the literature on the potential of contagion or spillovers risk due to crossborder interlinkages. Regarding the Asian financial crisis and the Global Financial Crisis, crossborder interlinkages has caused the effect of the crises to spread faster in a number of countries. This shows the need for studies on measures of cross-country contagion between emerging economies and their counterparts including their linkages to advanced economies.

The financial linkage that is originating from the interbank money market relationship is one of the channels that can create contagion risk and spillovers. The interbank money market relationship, especially in liquidity management, could be a particular vulnerability, i.e., squeezing or default can be contagious to the financial system as a whole. Our paper could make a significant contribution because it looks at the individual level, making it possible to analyse which entities are influential in bringing about contagion risk in the Indonesian interbank money market.

So far there has been no research in Indonesia related to cross-border interlinkages. However, Surjaningsih et al. (2016) have looked at a related topic on interconnectedness which used interbank money market data from $2010 \mathrm{q} 3$ to $2015 \mathrm{q} 4$ to measure the impact of interconnectedness on individual bank efficiency. This study found that the closer the proximity of a bank to another bank, this can increase the efficiency of the bank with regard to its profitability.

Our paper attempts to link contagion risk and spillover caused by a systemic bank in Indonesia. The systemic banks chosen are according to BCBS (2014) which states that the interconnected nature of the global economy has contributed to the potential failure of a single large institution to have a broader effect on the global economy. Krause and Giansante (2012) suggested that a network of interbank lending can be a transmission mechanism for the failure of banks through the system. In line with this, Drehmann and Tarashev (2013) also stated that interconnection between banks could propagate shocks across the system and it is vulnerable to propagated shocks. Moreover, to identify systemic banks in Indonesia, our study uses the BCBS (2014) approach based on the balance-sheet approach that will be explained in the methodology sub-section.

On crisis spillovers and contagion risk, we rely on actual data of interlinkages rather than those that rely on market data and implicit interlinkages. Potential contagion risk caused by crossborder linkages has been studied in Gropp et al. (2006) which carried out cross-border analysis in a sample of European banks from January 1994 to January 2003. They used the multinomial logit model to estimate that there is a large shock on co-exceedances as a function of variables measuring common shocks and lagged co-exceedances in other countries. The findings of this paper show the existence of significant cross-border contagion, and this condition also occurred when the euro was introduced in Europe.

The latest research comes from Choi et al. (2018), which uses cross-country data from 120 countries from the period of 1970 to 2014 to prove the incidence of banking crises. The results of the study found that the coordinated implementation of the macroprudential policies across highly linked countries could pose risks of widespread banking crises, although this effect may take some time to materialize. 
The main reference paper of this study is based on what was done by Espinosa-Vega and Solé (2010) which typically consider spillovers due to actual bilateral exposures. Their paper utilises BIS banking data to simulate the transmission of a country 's banking system's "failure" on other countries' banking systems as a result of an explicit (predetermined) interbank credit or funding shocks.

\section{Data Collection and Applied Methodology}

This paper uses data from various sources. To obtain interconnectedness data that describes the relationship on individual levels, Bank Indonesia as the central bank has quite valuable data because it has reporting data from banks on a daily basis. This report requires banks in Indonesia to report their Interbank Money Market (IMM) transactions including counterparts and their origin countries.

\section{Data}

As mentioned above, data sources for this research rely on the Bank Indonesia Daily Report. Furthermore, to identify SIB in Indonesia, we are using data that comes from the Bank Indonesia Monthly Report (LBBU), Bankscope, Data for International Settlements (BIS) and Financial Stability Board (FSB).

As a period sample for network analysis, we are using the cumulative period of 2017, which are then annualised ${ }^{2}$. Capital exposure was derived from Bankscope and cross-checked with the annual report from each bank respectively.

We chose year 2017 as a sample period because it had the highest growth of cross-border interbank money since the last ten years.

\section{Methodology}

Answering the research question, this paper uses three steps. The first step is identifying the Domestic Systematically Important Banks (D-SIB), while the second step is using network analysis to map the network topology of the cross-border interbank money market from the Indonesian perspective. Finally, the third step is applying network shock simulation to see how contagious the relationships are that occur in the cross-border interbank money market.

\subsection{Identifying the D-SIB}

BCBS already stipulates the guidance of the G-SIB assessment methodology based on key indicators and ancillary indicators. The primary indicators used in the G-SIB assessment methodology are size, interconnectedness, substitutability, complexity, and cross-border activity. In the context of Indonesia, cross-border activity does not take into account in the calculation of domestic systematically important banks (D-SIB). Therefore, this research becomes substantial as a supplementary information in the context of DSIB that are connected with other countries. Besides, to accommodate the characteristics of the domestic financial system, additional sub-indicators of country-specific were added. This additional sub-indicator was incorporated into the complexity indicator.

2. Interbank money market data is on daily basis report, we annualized it by dividing the total transaction volume by 250 , assuming there are 250 workdays in a year-period. 
On the other hand, some other sub-indicators are irrelevant to Indonesian bank contexts, such as underwritten transactions in debt and equity markets, which are not included. Countryspecific sub-indicators are Letter of Credit (L / C), bank guarantee, total SBN (AFS and trading) ownership, number of domestic and overseas branches, number of credit facilities and deposits. The size indicator represents the size of the financial services to the financial system and the real sector. In the GSIB framework, BCBS specifies the size as measured as total exposure calculated from i) total assets; ii) administrative accounts; and iii) on-balance sheet and future exposure derivatives.

$$
\text { Size }_{j}=\frac{{\text { Size } \text { Value }_{j}}^{n}}{\sum_{j=1}^{n} \text { Size Value }_{j}}
$$

The interconnectedness factor is calculated from the assets and liabilities of the financial institutions. The methodology used in SIB in Indonesia uses three sub-indicators of interconnectedness, namely: i) intra-financial system assets, i.e. calculation of bank assets placed in other financial institutions; ii) intra-financial system liabilities is the opposite of intra-financial system assets that are the liabilities of a domestic bank placed in another domestic financial institution; and iii) securities outstanding are securities issued by domestic banks.

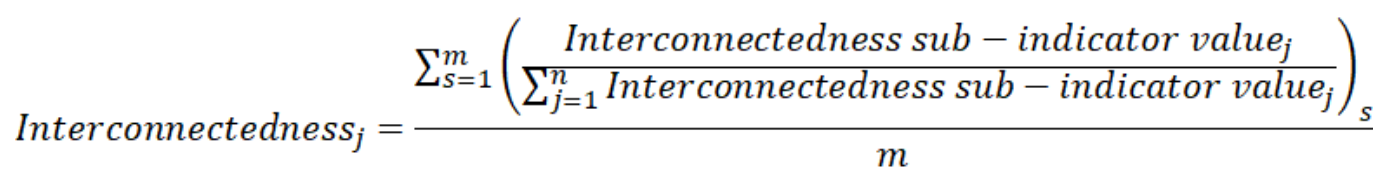

The complexity indicator is an indication of the complexity of a bank's business which is calculated based on the amount of business activity as well as the complexities and business operational structure. In the calculation of the indicator of this complexity, many adjustments are made to include possible components of substitutability. It also incorporated country-specific factors. Here are the details: i) the complexity of two indicators: OTC derivatives notional value and value of securities held for trading and AFS. The average value of the two sub-indicators becomes a representation of the value of complexity; ii) indicators of country-specific factors. It is a discretion of Indonesia to include this factor consisting of L / C, bank guarantee, total ownership of SBN (AFS and trading), number of branch offices, number of credit facilities, and number of deposit facilities; and iii) for substitutability divided into a) payment system amount; b) payment volume system; and c) assets under custody.

$$
\text { Complexity }_{j}=\frac{\sum_{t=1}^{l} \text { Share of Complexity }}{t}
$$

Furthermore, the formula of a systemic bank score as follows:

$$
\text { Systemic Score }=10,000 * \frac{\sum_{i=1}^{n} \text { Indicator }}{n}
$$




\subsection{Network Topology}

We used the Gephi software to visualise the network of the cross-border interbank money market. In order to have a proper interpretation, we used the total volume of the cross-border interbank money market. Using this data will show the actual relationship between lenders and borrowers compared to if we were to use the net transaction data that could be biased.

Interconnectedness measures the network link between contractual obligation held by financial institutions which can have an impact on interlinkage distress (spread distress) in a financial system and conglomerate group - the contractual obligations measured by the size of the assets and liabilities of an institution. This interconnectedness will also affect the banking characteristic.

In the literature, interconnectedness can be represented by the network theory. A network $(\mathrm{N}, \mathrm{g})$ consists of a collection of nodes and a collection of edges. Nodes here are in the form of financial institutions and edges are contractual obligations between banks. A network can be directed and undirected. Undirected network happens when two nodes are connected or not at all. Connectedness is when the first node is related to the second node and the second node is also related to the first node. In other words, there are mutual relationships in the undirected network. This model, in general, is like economic relations such as partnerships, friendships, and alliances commonly found in social media today.

On the other hand, directed networks occur when a node is related to the second node but the second node does not have a relationship with the first node, so it does not have to be a mutual relationship. This model can be either citation by writers or web pages that are linked to other web pages. In this paper, we use the directed network assumption. In an interbank market, a bank does not have to have mutual relationships with other banks.

Degree from node $i$ is the number of edges that start and end in node $i$. Indegree from node $i$ is the number of edges that end in the node $i$. Outdegree from nodes $i$ is the number of edges starting from node $i$. In other words, the number of indegree and outdegree is the same as the degree of a node. This degree measurement shows that a higher degree of a bank means more connectivity to other banks. The higher the indegree of a bank, the more the bank gets a loan from another bank (and vice versa for outdegree).

Centrality measures how important a node is in a network. Centrality measurement is usually done by dividing a particular node relationship by the maximum possible relationship. Degree centrality describes the importance of a node in a network with a degree size. In other words, this indicator can also be used to figure out how connected a node is. The formula $D_{c}$ degree centrality of node $i$ is as follows:

$$
D_{c}(i)=\frac{|E i|}{|V|-1}
$$


Closeness Centrality describes the capacity that can be achieved by other nodes in a network. Closeness can also be described as an indicator to measure how close a node is to other nodes. Closeness is calculated by the inverse of the average distance between particular nodes and other nodes. The formula for $C_{c}$ closeness centrality of node $i$ is as follows:

$$
C_{c}(i)=\frac{|n|-1}{\sum_{i \neq j} d(i, j)}
$$

Betweenness Centrality describes the capacity of a node to be intermediary for one node with another node in a network. Betweenness Centrality measures how the shortest path passes through a particular node. Suppose that $P_{i}(k j)$ describes the number of geodesics (shortest paths) between $i$ and $j$ which have nodes $i$ and $P(k j)$ is the total geodesics between nodes $k$ and $j$. We can estimate how important node $i$ is in connecting between nodes $k$ and $j$ by looking at the results of the ratio $P_{i}(k j) / P(k j)$. If the ratio is close to 1 , then the node exists between many geodesics that connect $k$ and $j$. With the average of all nodes, the formula betweenness centrality of node $i$ is:

$$
B_{c}(i)=\sum_{k \neq j: i \notin)(k, j)} \frac{P_{i}(k j) / P(k j)}{(n-1)(n-2) / 2}
$$

\subsection{Network Shock Simulation}

Conducting an assessment of cross-border interbank contagion risk analysis, we use the network analysis method conducted by Espinosa and Sole (2010). We followed this methodology as it can represent contagion risk in a system, and also because this method emphasises the shortterm loan which is the data we are using for the model. This network analysis based on the bank's balance sheet has the following assumptions:

$$
\sum_{j} x_{j i}+a_{i}=k_{i}+b_{i}+d_{i}+\sum_{j} x_{i j}
$$

where $x_{j i}$ stands for bank $i$ loans to bank $j, a_{i}$ for bank $i$ 's other assets, $k_{i}$ for bank $i^{\prime}$ s capital, $b_{i}$ are long term and short-term borrowing (excluding interbank loans), $d_{i}$ for deposits, and $x_{i j}$ for bank $i$ borrowing from bank $j$. 
This methodology simulates the case of a shock from credit using the assumption of loss given default (LGD) which is represented by $\lambda$. It is assumed that the banking system $i$ 's capital absorbs the losses on impact, and it also tracks the sequence of defaults triggered by this event. For instance, after taking into account the initial credit loss stemming from the default of $h$ institution, the baseline balance sheet identity of bank $i$ becomes:

$$
a_{i}+\sum_{j \neq h} x_{j i}+(1-\lambda) x_{h i}=\left(k_{i}-\lambda x_{h i}\right)+b_{i}+d_{i}+\sum_{j} x_{i j}
$$

so bank $i$ is said to fail if its capital is insufficient to fully cover its losses (i.e., if $k_{i}-\lambda x_{h i}<0$ ). These losses are depicted in light gray in Figure 5. ${ }^{3}$

\section{Figure 5}

\section{Effect of a Credit Shock on a Bank's Balance Sheet}

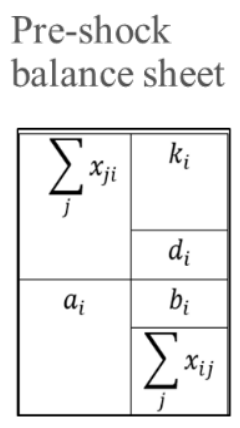

Post-shock

balance sheet

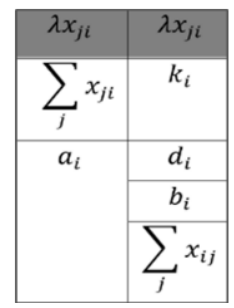

It is assumed that institutions are unable to replace all the funding previously granted by the defaulted institutions, which, in turn, triggers a fire-sale of assets. Thus, bank $i$ is able to replace only a fraction $(1-\rho)$ of the lost funding from bank $h$, and its assets trade at a discount, so that bank $i$ is forced to make a fire-sale of their assets worth $(1+\delta) p x_{i h}$ in book value terms. The funding shortfalls induced loss, $\delta \rho x_{i h}$, is absorbed by bank $i^{\prime} s$ capital (Figure 6.), and thus the new balance sheet identity for institution $i$ is given by:

$$
a_{i}+\sum_{j} x_{j i}-(1+\delta) \rho x_{i h}=\left(k_{i}-\delta \rho x_{i h}\right)+b_{i}+d_{i}+\sum_{j} x_{i j}-\rho x_{i h}
$$

Figure 6

\section{Effect of a Funding Shock on a Bank's Balance Sheet}

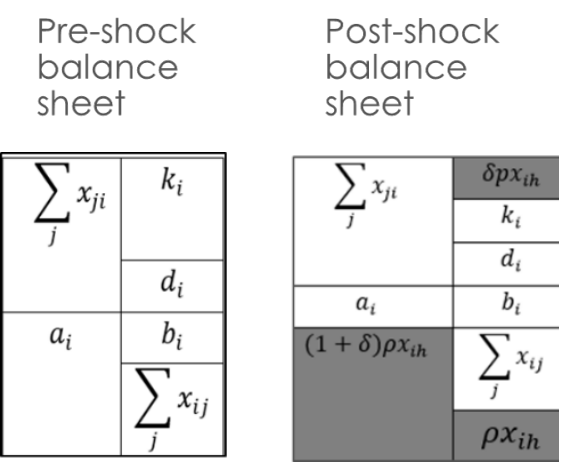

3. Subsequent rounds in the algorithm do not take into account the losses stemming from all failed institutions up to that point. 


\section{Empirical Result}

Due to the confidentiality of systemically important banks in Indonesia, this study will be disguising bank name/code. However, in order not to subtract from the value of our research, we denote the types of banks as follows: SOB (state-owned bank); PLB (private-local bank); and FBB (foreign-branch bank). The confidentiality would help to avert people's misperceptions about systemic banks particularly. Some people think that they must avoid systemic banks because they have a higher possibility of loss and this misperception could lead to a bank-run or deposit flight to a non-systemic bank. Instead, the systemic banks should be perceived as banks that have more cushion in order to be more resilient than the non-systemic banks.

Furthermore, in the case of non-domestic banks which have a relationship with D-SIB, we decided not to reveal the bank's name since there is no relevant issue about those banks, primarily related to confidentiality matters. The international banks which are related within the cross-border interbank money market in Indonesia have status as global systematically important banks (G-SIB). The list released by the Financial Stability Board (FSB) can be accessed publicly.

\subsection{Identifying the D-SIB}

As stipulated in the act of the Financial System Prevention and Crisis Management, the decision of whether a bank is systemic or not is made by the Financial Supervisory Authority (OJK) and Bank Indonesia. The review is made twice in a year to monitor and evaluate the existence of D-SIB and to impose a capital surcharge on each bank. When considering the decision regarding D-SIB, the OJK and Bank Indonesia impose a weight proportion in estimating D-SIB as follows:

Figure 7

\section{Weight Proportion of D-SIB Calculation}

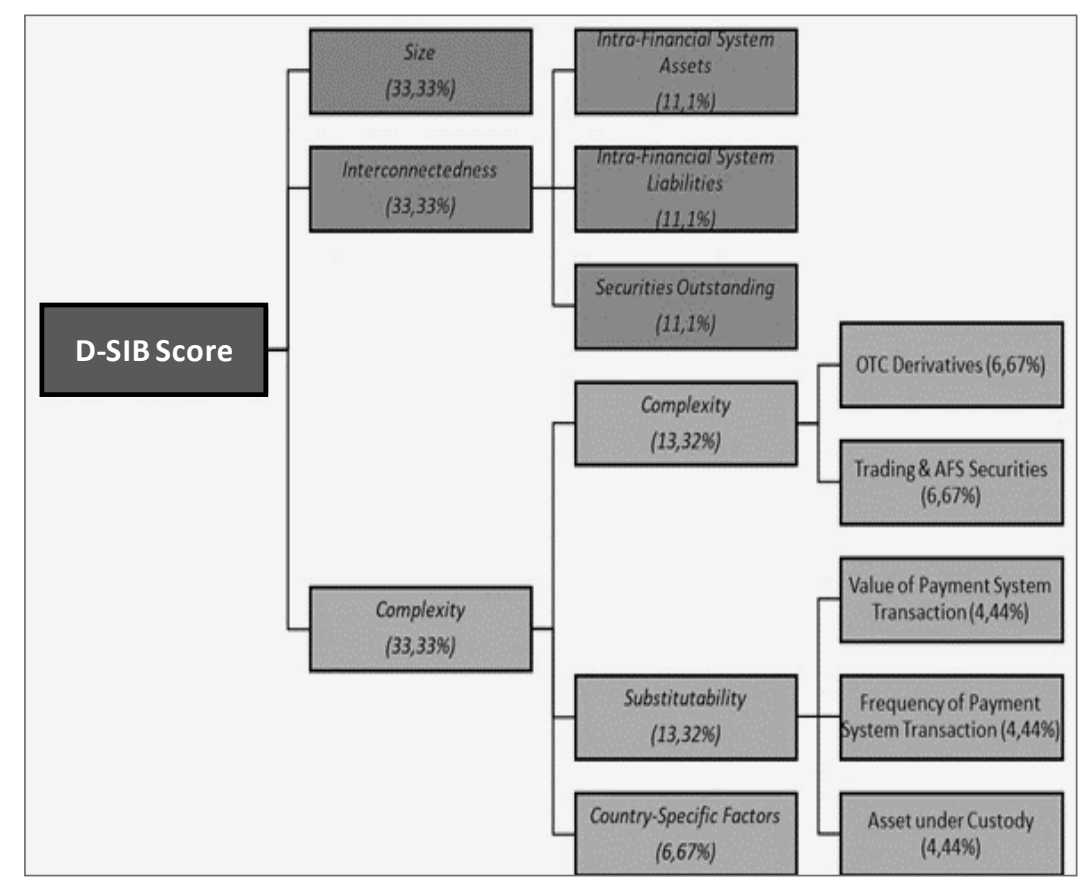

Using the proportion above, we find that there are 30 banks which are mainly categorised as systemic banks in Indonesia. The list and the descriptive statistics are shown in Table 1 and Table 2 respectively. 


\section{Table 1: List of D-SIB in Indonesia}

This table reports each measure and its score in D-SIB decision making. The data in column 1 are number based on the highest total score; column 2 shows the bank code that has already been decoded for confidentiality. Column 4 to 6 consist of each score which is Size, Interconnectedness and Complexity respectively. The data is for month June 2018.

\begin{tabular}{|c|c|c|c|c|c|}
\hline No & $\begin{array}{l}\text { Bank } \\
\text { Code }\end{array}$ & $\begin{array}{l}\text { Total } \\
\text { Score }\end{array}$ & $\begin{array}{l}\text { Size } \\
\text { Score }\end{array}$ & $\begin{array}{l}\text { Interconnectedness } \\
\text { Score }\end{array}$ & $\begin{array}{l}\text { Complexity } \\
\text { Score }\end{array}$ \\
\hline & & Jun-18 & Jun-18 & Jun-18 & Jun-18 \\
\hline 1 & $508 B$ & 1,221 & 1.315 & 1,176 & 1,173 \\
\hline 2 & SOBA & 1,134 & 1,307 & 1.283 & 811 \\
\hline 3 & PLBC & 1,122 & 1,046 & 1,310 & 1,009 \\
\hline 4 & $508 \mathrm{C}$ & 780 & 845 & 706 & 789 \\
\hline 5 & PLBF & 366 & 356 & 237 & 506 \\
\hline 6 & FaBC & 308 & 292 & 294 & 337 \\
\hline 7 & SOBD & 277 & 304 & 422 & 104 \\
\hline 8 & PLBI & 267 & 225 & 128 & 449 \\
\hline 9 & PLBA & 247 & 206 & 291 & 243 \\
\hline 10 & FBBA & 244 & 171 & 139 & 422 \\
\hline 11 & $\mathrm{FBBH}$ & 234 & 53 & 65 & 583 \\
\hline 12 & PLBH & 220 & 232 & 183 & 246 \\
\hline 13 & FDBG & 214 & 135 & 103 & 403 \\
\hline 14 & PLBD & 206 & 210 & 177 & 230 \\
\hline 15 & PLBE & 201 & 242 & 232 & 130 \\
\hline 16 & PLBB & 189 & 215 & 152 & 200 \\
\hline 17 & FABD & 162 & 177 & 217 & 91 \\
\hline 18 & FBBE & 153 & 156 & 86 & 217 \\
\hline 19 & DBRA & 149 & 121 & 267 & 59 \\
\hline 20 & PLBM & 144 & 112 & 138 & 181 \\
\hline 21 & PLBG & 100 & 144 & 51 & 106 \\
\hline 22 & PL8L & 100 & 102 & 142 & 56 \\
\hline 23 & PLEN & 86 & 104 & 104 & 51 \\
\hline 24 & FBBF & 85 & 110 & 85 & 61 \\
\hline 25 & SYBA & 72 & 100 & 35 & 81 \\
\hline 26 & FasB & 71 & 31 & 57 & 125 \\
\hline 27 & DBRB & 70 & 52 & 53 & 106 \\
\hline 28 & PLBJ & 64 & 87 & 78 & 29 \\
\hline 29 & DBRC & 61 & 68 & 87 & 30 \\
\hline 30 & PLAK & 59 & 80 & 68 & 28 \\
\hline
\end{tabular}

\section{Table 2: Descriptive Statistic of D-SIB}

This table reports descriptive statistic from each measurement in deciding D-SIB of Table 1. There are four segments which are Size, Interconnectedness and Complexity measurement. The total score is given and we also report the mean, standard error, median, standard deviation, minimum, maximum and sum.

\begin{tabular}{|c|c|}
\hline Size & Volue \\
\hline Mean & 287 \\
\hline Standard Error & $6 \div$ \\
\hline Median & 163 \\
\hline Standard Deviation & 352 \\
\hline Minimum & 31 \\
\hline Maximum & 1,315 \\
\hline Sum & 8,597 \\
\hline Interconmectediness & Volue \\
\hline Mean & 279 \\
\hline Standard Error & 65 \\
\hline Median & 141 \\
\hline Standard Deviation & 358 \\
\hline Minimum & 35 \\
\hline Maximum & 1,310 \\
\hline Sum & $8,36-4$ \\
\hline Complexity & Volue \\
\hline Mean & 295 \\
\hline Standard Error & 56 \\
\hline Median & 190 \\
\hline Standard Deviation & 305 \\
\hline Minimum & 28 \\
\hline Maximum & 1,173 \\
\hline Sum & 8.856 \\
\hline Total & Value \\
\hline Mean & 287 \\
\hline Standard Error & 60 \\
\hline Median & 195 \\
\hline Standard Deviation & 327 \\
\hline Minimum & 59 \\
\hline Maximum & 1,221 \\
\hline Sum & 8,606 \\
\hline
\end{tabular}

From the descriptive statistics, we can see that systemic banks in Indonesia have dominated the market share. Each measurement shows around $80 \%$ in sum value respectively which includes the total score which is about $86 \%$ of the total banking system. The ranking top two are state-owned banks as we can see from the SOB code. The biggest three banks have a distant score that are larger by far compared to other banks in the list. Regarding the interconnectedness score, these three banks yield a significant result because of the high number of claims and liabilities in the intrafinancial system. The numbers of linkages are not presented in this calculation; we will visualize it when we run the network visualization.

\subsection{Network Visualization}

Indonesia's cross-border interbank money market had experienced a negative impact in the aftermath of the GFC. Evidence was found for the relevant years of 2007 and 2008 when there was a squeeze in the cross-border interbank money market. In Figure 8, we can see that in 2007, there were many linkages in cross-border interbank money markets according to the density derived from the many arrows found, but in 2008 the density became less than 2007. 


\section{Figure 8}

\section{Cross-border Interbank Money Market in GFC Aftermath}

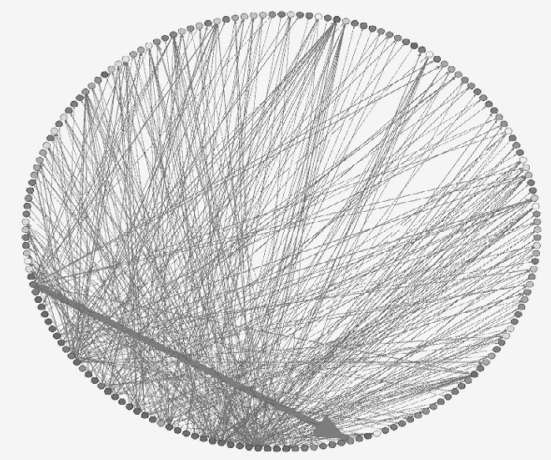

2007

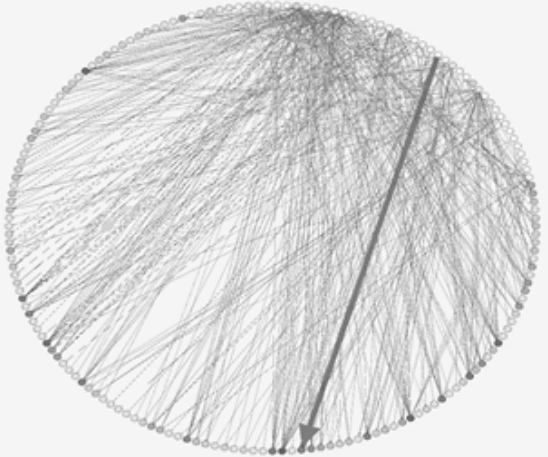

2008

Having identified D-SIB, we next tried to visualize the cross-border interbank money market from Indonesia's perspectives. Identifying D-SIB is essential because, in case of Indonesia, there are 115 commercial banks which may have a relationship to the cross-border interbank, therefore focusing on D-SIB will make this paper more relevant since the D-SIB may represent the Indonesian banking system.

Using the Gephi software, we found that not all the D-SIB banks are involved in the cross-border interbank money market at a sample period of 2017. Figure 9 depicts the network visualization.

Figure 9

Network Visualization of Cross-border Interbank Money Market

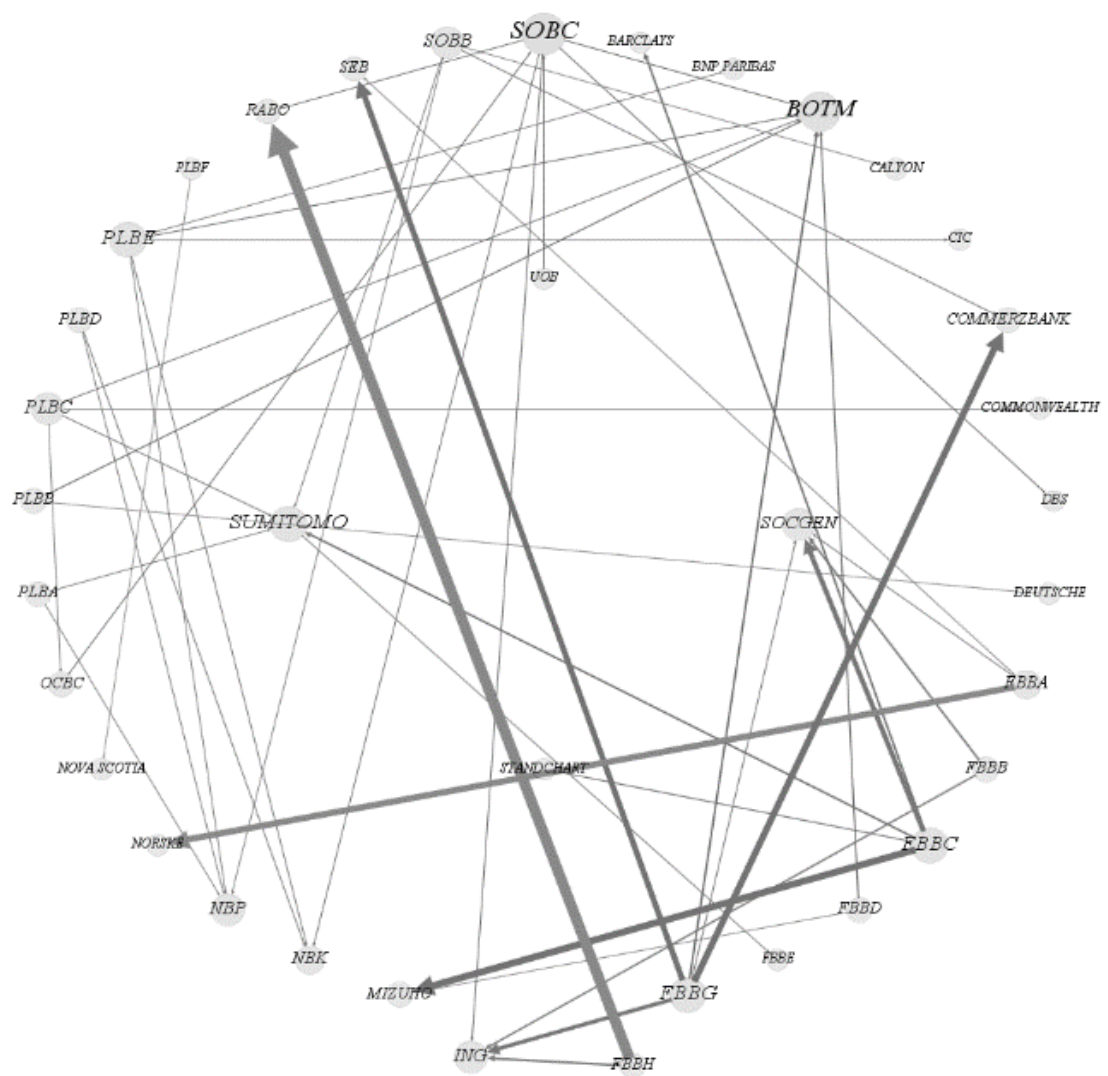


Based on visualization, regarding the home country of the international banks which interact with Indonesia SIBs, we found that most of the bank origins are from Europe (France and Germany) and Asia (Singapore and Japan). Meanwhile, the domestic bank group that conducts the most crossborder transactions is a foreign-branch bank (FBB). In the period data sample of 2017, we found that not all the 30 DSIBs were involved in cross-border IMM. It only consists of 15 D-SIB and 22 international banks.

Furthermore, we calculate the network statistics based on cross-border interlinkages. Some basic network measures like indegree, outdegree, and centrality measures can also be solved using the Gephi software.

Figure 10: Indegree and Outdegree

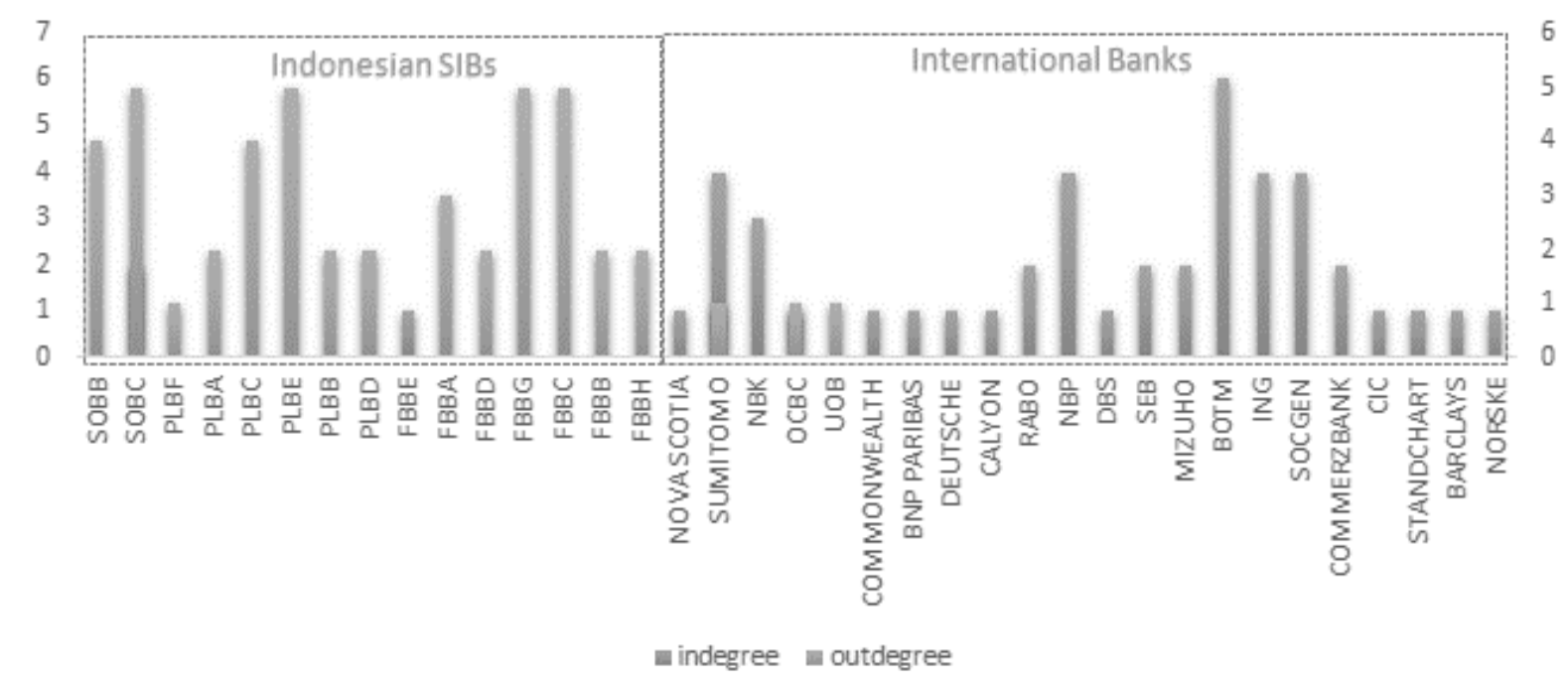

Figure 11: Weighted Indegree and Weighted Outdegree

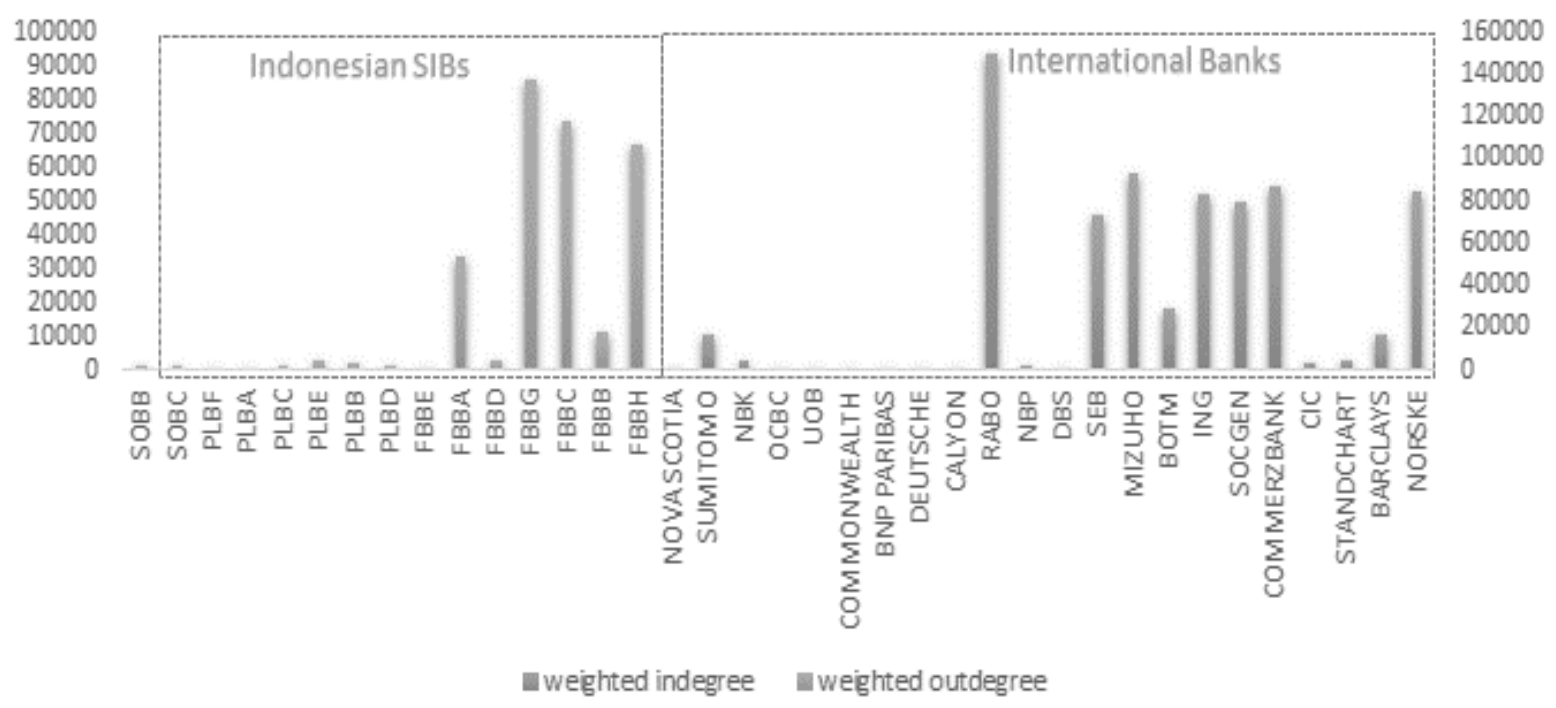


Regarding indegree and outdegree measurements, Indonesian SIBs act as the net lender to international banks, reflecting the ample condition of banks' liquidity during that period. Furthermore, from the weighted degree measure, the graph shows that FBBG which is a foreign bank branch in Indonesia is the one that has the most significant loans in the cross-border interbank money market. Rabobank whose home country is Netherlands appear to be the biggest borrower for Indonesian SIBs during the sample period.

Regarding centrality measures, this paper uses closeness and betweenness centrality. The Closeness indicator is used to see the average length of the shortest path between the node and other nodes. With this measure, we will know which bank had the closest relationship to any other banks in the system. The smaller the score means the closer the banks are to the others. Betweenness appears as a measure to indicate whether the bank has a role as a middle-man to another bank. The higher the score means more linkages across the bank given the role as the bridging bank.

Figure 11: Closeness Centrality

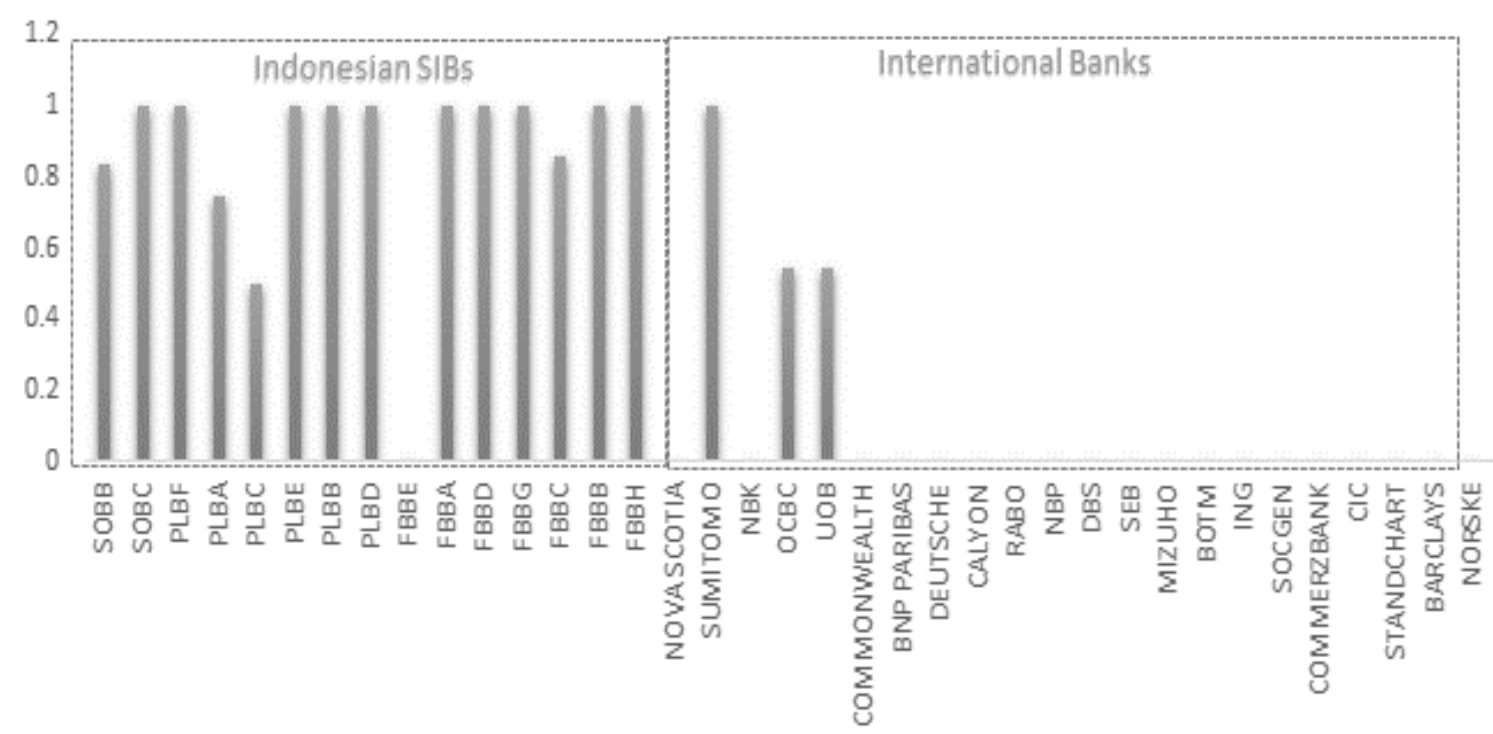

Figure 12: Betweenness Centrality

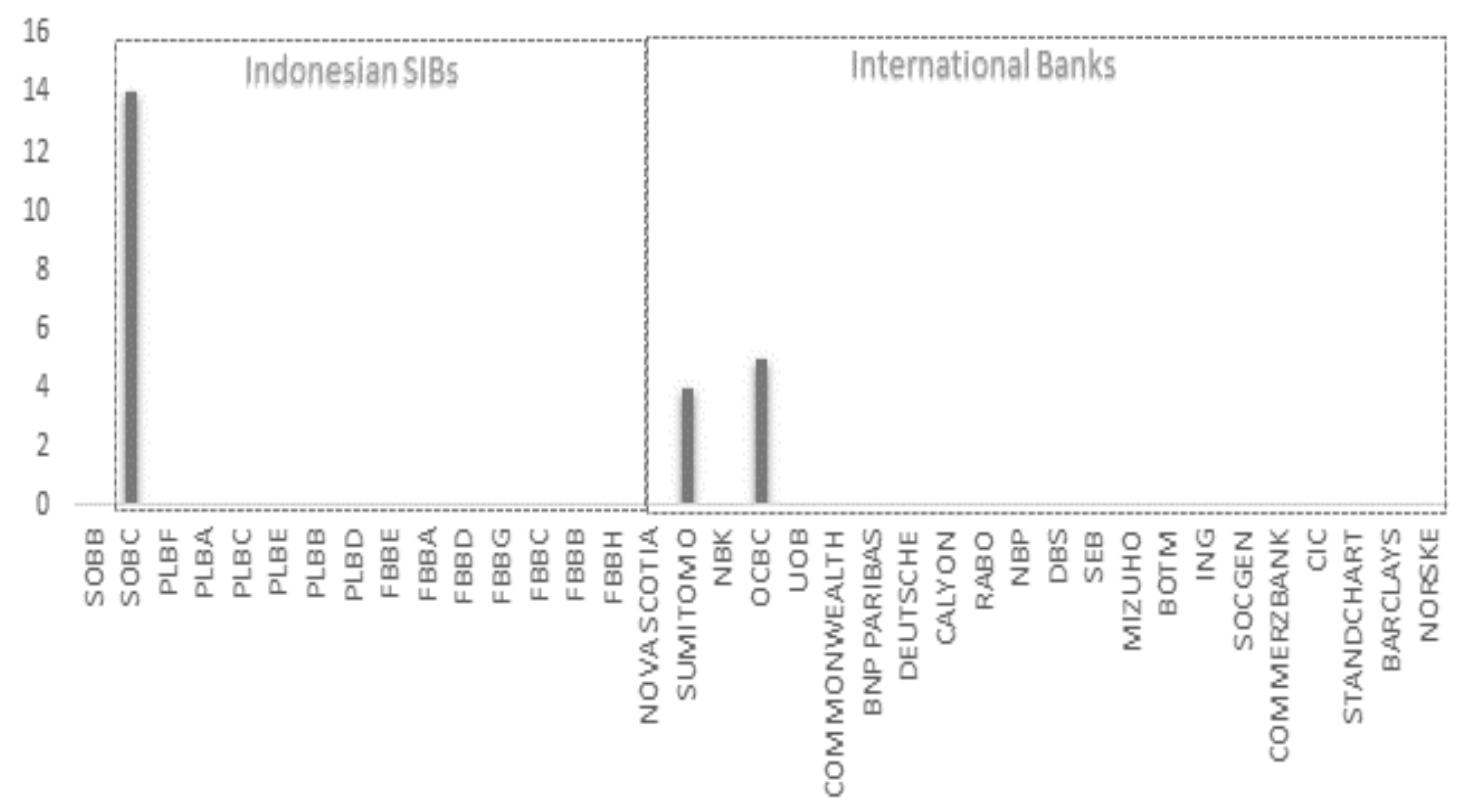




\subsection{Network Shock Simulation}

In this simulation, as we mentioned above, we are following a methodology that was introduced by Espinosa-Vega and Sole (2010). With this method, we define some terms that are relevant to interbank contagion risk. First, there is induced failures which represent the number of bank failures induced by the failure of a bank. Next, contagion rounds as the number of contagion rounds until no more bank fails due to the failure of a bank. Moreover, there is a hazard that explains the number of banks whose failure will result in the failure of this bank, also known as the vulnerability level and then a hazard rate which is described as the percentage of other banks whose failure will result in the failure of this bank.

Moreover, there will be two indices, one which is an index of contagion and an index of vulnerability that represents the average of loss percentage of other banks due to the failure of this bank, and represents the percentage of loss due to the default of all other banks, respectively.

In this network simulation, we are imposing three shock scenarios. These shock scenarios arevdetermined arbitrarily and do not refer to an actual condition which can be derived with a macroeconomic credit risk model since this will be out of the scope of this paper.

In the first scenario, a shock given to the system is a credit shock. A credit shock means there a default of a bank's loan in the interbank money market. It highlights the loss-resulting from one or some banks defaulting their debt obligations. In the first scenario, it is modelled on a default of a banking system's debt to other banks and how this default would affect other banks in the network hypothetically. The scenario given is bank's loss given default (LGD $=\lambda$ ) is $50 \%$. It is assumed that banks can roll over their funding sources and do not need to resort to fire sales of assets.

Next, the second scenario is funding shock scenario as an addition to the credit shock that we have imposed in the first scenario. In this scenario, we are pointing out that the institutions are unable to replace the funding previously granted by the defaulted institutions. If in the first scenario, the LGD is $50 \%$, for this scenario we are imposing that the LGD is $100 \%$, and banks are unable to recover the lost funding given to its borrower in the same exposure $(\rho=100 \%)$. It is still assumed that banks do not need to undertake fire sales of its assets.

Furthermore, the last scenario is to give the system two of the scenarios before and adding a fire sales of assets scenario. The fire sales scenario means that banks are forced to sell their assets at a discount or a haircut scenario. The action had to be taken because banks are forced to roll-over their funding to meet their obligations. In the third scenario, it is modelled that loss given default (LGD) or $\lambda=100 \%$ and banks are unable to recover the lost funding given to its borrower in the same exposure $(\rho=100 \%)$. Also, banks have to face haircut selling of their assets $(\delta=75 \%)$.

The result of the shock simulation is seen in Figure 13. 
Figure 13

Percent Failed Capital

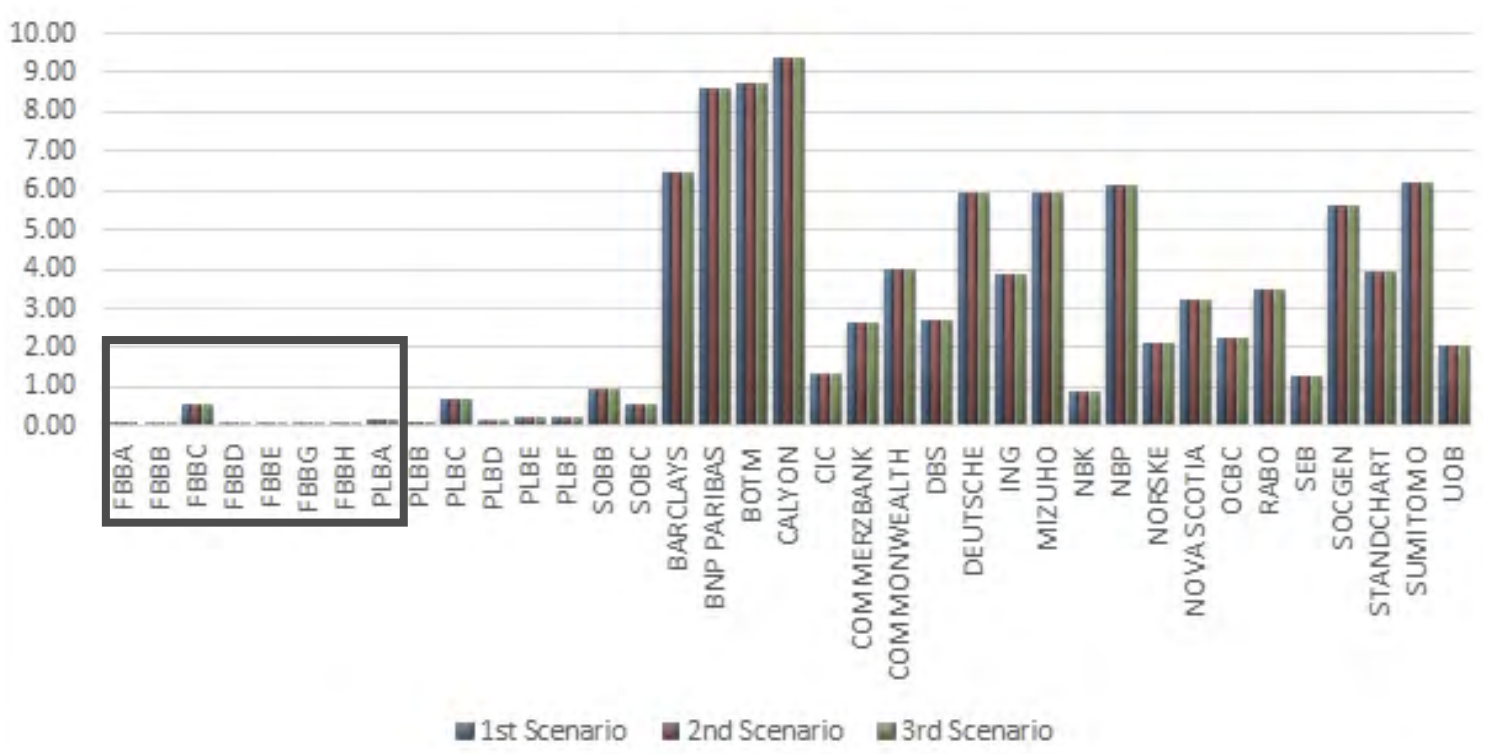

From the three scenarios, we found that none of the banks in the system caused failure of other banks. The result is supported by the fact that banks' capital in the system is adequate to mitigate the interbank risk. Nevertheless, we found that capitals of the foreign bank group are relatively small compared to other bank groups such as state-owned and private-owned banks. This is also related to the fact that the foreign bank group is more active in the interbank money market than other bank groups. From these three scenarios, we can also derive that there no banks are in a hazardous condition.

Moreover, for an index of contagion, in Figure 14, we can see that the second and third scenarios show us that FBBC and FBBG are relatively contagious because of their activeness in the cross-border interbank money market. However, this contagiousness is still in a manner that is not a threat to the whole system.

\section{Figure 14 \\ Index of Contagion}

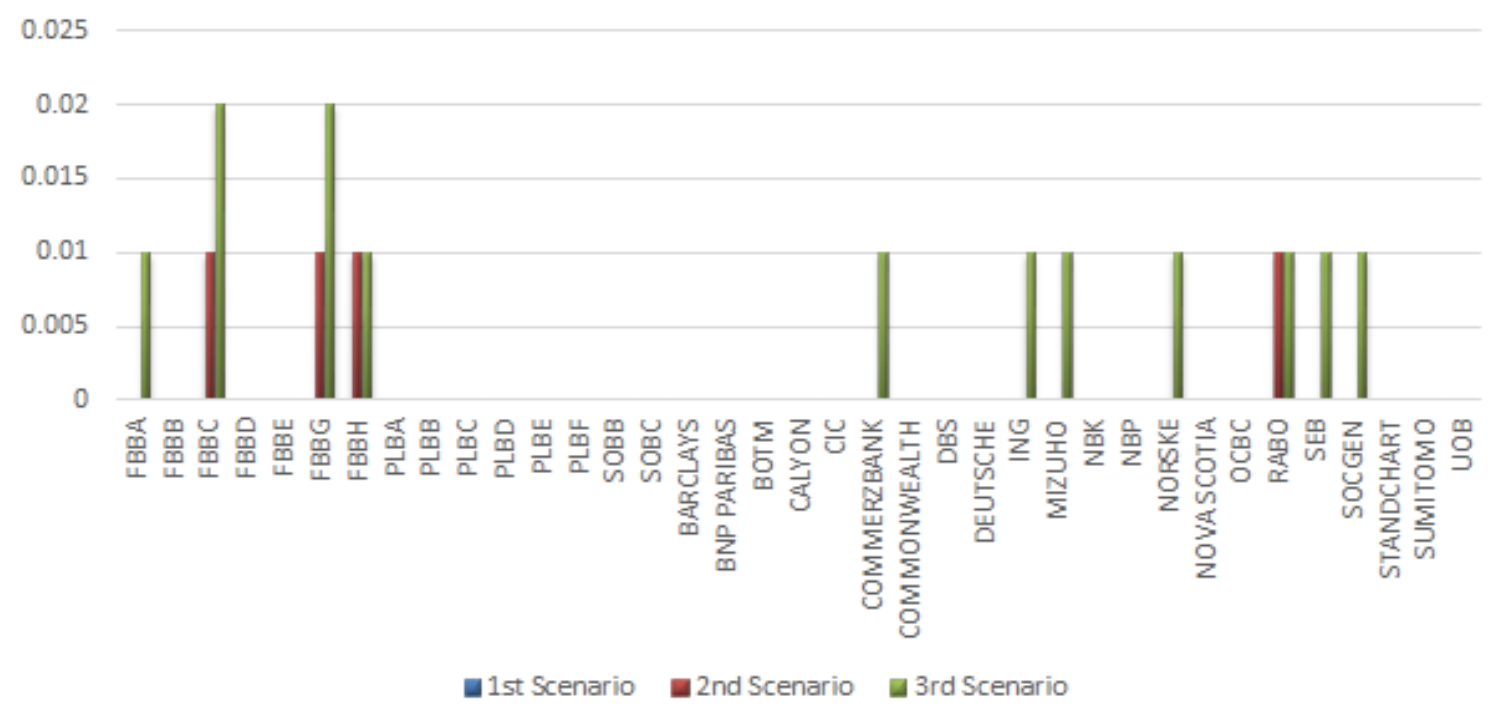


On the other hand, FBBG also comes up being the most vulnerable bank in the system because it has simultaneously higher exposures than other banks in the cross-border interbank money market (Figure 15).

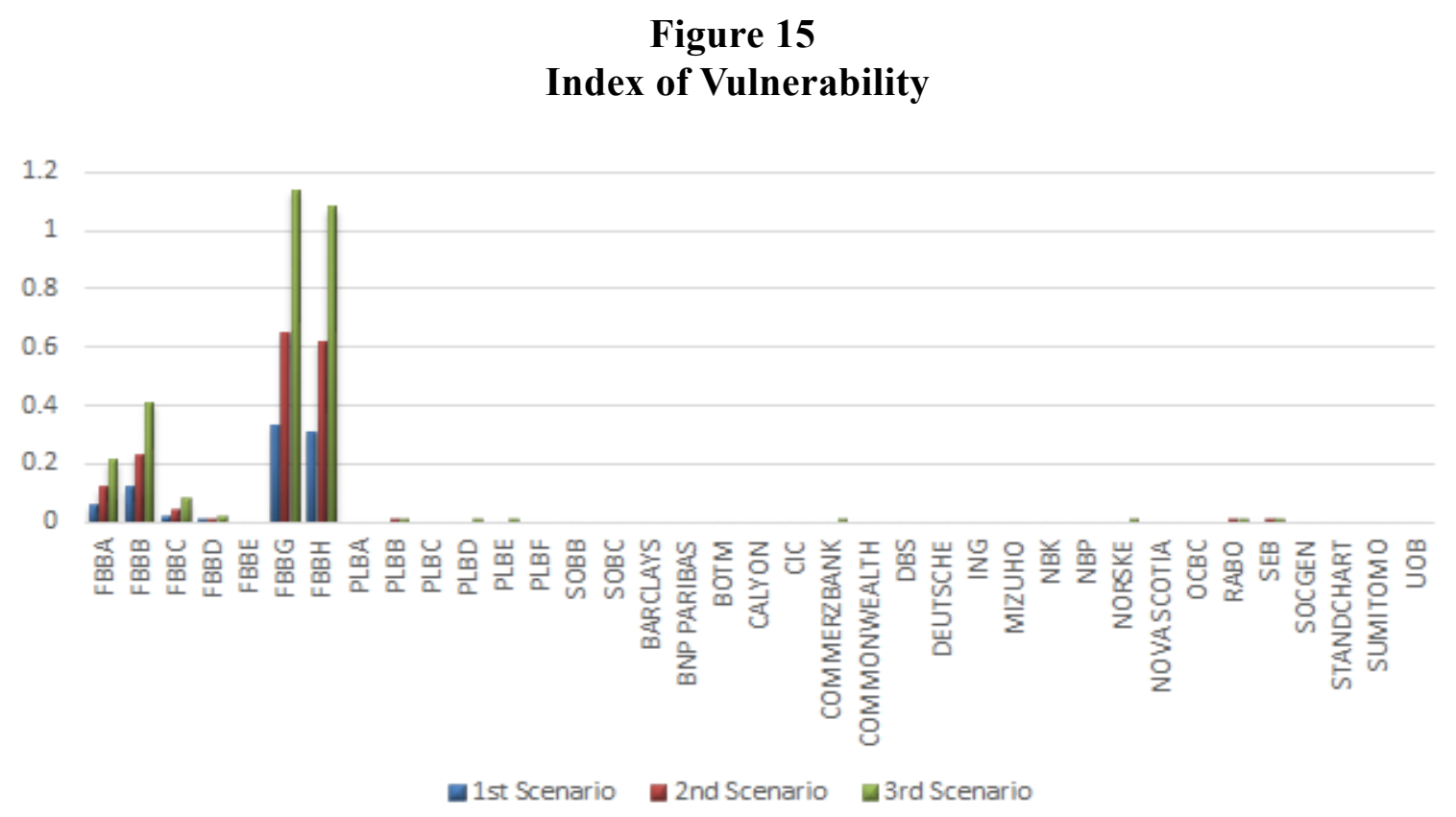

\section{Conclusion and Policy Implications}

Even though Indonesian SIBs are connected to other cross-border banks in the interbank money market, the exposures of their lending-borrowing activity are not large compared to other portfolios in their assets and liabilities. In the sample period, Indonesian SIBs were more involved as lenders than borrowers. This is due to the ample liquidity condition in Indonesia during the sample period.

Most of the active banks in the system belong to the foreign bank group. Based on network visualization, the borrowera come from banks in Europe. Meanwhile, Japan and Singapore banks act more as middle-banks.

The result of the network shock simulation shows that Indonesian SIBs have adequate capital to cover their losses even in the worst case shock scenario. FBBG comes up as the most contagious bank in the cross-border interbank money market from Indonesia's perspectives, while simultaneously, FBBG is also the most vulnerable because of their activeness in the cross-border interbank money market.

Nevertheless, the central bank as regulator should pay more attention to cross-border interlinkages as the interbank money market could be an early warning indicator for crisis. This can be managed through the D-SIB calculation because most of the banks involved in cross-border interlinkage are D-SIB.

The network shock simulation method in this paper can be considered as one of the measurement tools to gauge the contagious risk that can occur in cross-border interlinkages of banks internationally. 


\section{References}

Allen, F. and D. Gale, (2000), "Financial Contagion," The Journal Of Political Economy, Volume 108 , Issue I.

Bank for International Settlement, (2011), Global Systematically Important Banks: Assessment Methodology and the Additional Loss Absorbency Requirement Rules, Available at: https:// www.bis.org/publ/bcbs207.pdf.

Cerutti, E.S.; Claessens and P. McGuire, (2012), "Systemic Risks in Global Banking: What Available Data Can Tell Us and What More Dataare Needed?" NBER Working Paper, No. 18531.

Choi, Seung Mo; Laura Kodres and Jing Lu, (2018), "Friend or Foe? Cross-Border Linkages, Contagious Banking Crises, and "Coordinated" Macroprudential Policies," IMF Working Paper, WP/18/9.

Drehmann, Matias and Nikola Tarashev, (2013), "Measuring the Systemic Importance of Interconnected Banks," Journal of Financial Intermediation, Volume 22, Issue 4.

Espinosa, Marco A Vega and Juan Sole, (2010), "Cross-border Financial Surveillance A Network Perspective," IMF Working Paper, WP/10/105.

Freeman, Linton C., (2004), The Development of Social Network Analysis, Empirical Press, Vancouver, Canada.

Genberg, H., (2017), "Global Shocks and Risk to Financial Stability in Asia," Working Paper, 25/2017, The South East Asian Central Banks (SEACEN) Research and Training Centre, Kuala Lumpur, Malaysia.

Glasserman, P. and H.P. Young, (2014), "How Likely is Contagion in Financial Networks?” Journal of Banking and Finance, 50, pp. 383-399.

Gropp, Reint; Marco Lo Duca. and Jukka M. Vesala, (2006), "Cross-Border Bank Contagion in Europe," ECB Working Paper, No. 662.

Haldane, A.G. and R. M (2011), “Systemic Risk in Banking Ecosystems,” Nature, 469, pp.351 355.

Krause, Andreas and Simone Giansante, (2012), "Interbank Lending and the Spread of Bank Failures: A Network Model Of Systemic Risk," Journal of Economic Behavior \& Organization, Volume 83, Issue 3.

Moghadam., R. and J. Vinals, (2010), “Understanding Financial Interconnectedness,” International Monetary Fund Working Paper.

Surjaningsih, Ndari; Januar Hafidz; Justina Adamanti; Maulana Harris Muhajir and Muhammad Sahirul Alim, (2016), "The Impact of Interbank Market Interconnections to Indonesian Banking Efficiency,” Bank Indonesia Working Paper. 
Tabak, B.; S. M. Guera and R. C. Miranda, (2014), "Do Interconnections Matter for Bank Efficiency?" Working Paper, WP 374, Banco Central Do Brasil.

Yellen, J., (2013), "Interconnectedness and Systemic Risk: Lesson from the Financial Crisis and Policy Implications," Board of Governors of the Federal Reserve System, Washington, D.C. 


\title{
Chapter 5
}

\section{GLOBAL NETWORK IN CROSS-BORDER INTERBANK FLOWS: THE CASE OF SOUTH KOREA}

\author{
By \\ Seohyun Lee ${ }^{1}$
}

\section{Introduction}

The globalisation and integration of financial markets have strengthened the degree of economic and financial interlinkages among countries. Global mutual funds actively enter into international bond and equity markets and their collective behaviour becomes crucial in shaping asset prices. In addition, cross-border banking flows have grown substantially. Domestic banks' exposures to foreign assets and liabilities have increased steadily in the recent two decades. Also, foreign branches and subsidiaries of global banks have extended their operations widely in the advanced and emerging economies alike.

The consequences of the high level of international linkages in the banking sector can be summarised under three headings: macroeconomic, financial and policy-related consequences. First, to some extent, the higher cross-border integration in the banking sector may have positive effects on macroeconomic activities. For instance, through efficient allocation of global funds, it supports output growth of the less developed countries. A higher level of bank linkages can also promote international trade as the banking sector becomes more effective and plays an important role as a financial intermediary for firms that produce tradable goods (Caballero, Candelaria, and Hale, 2018).

Second, an increase in cross-border interbank transactions has significant financial consequences. International banking can increase banking sector competition and help improve domestic banks' efficiency. Moreover, a higher level of banking integration enables investors to diversify idiosyncratic risks and thus facilitate risk-sharing among banks. On the other hand, however, a complex financial network can easily propagate financial stress from banks' home country to any host country with sound banking system. As we had seen during the Asian financial crisis (AFC), the global financial crisis (GFC) and the European debt crisis, those countries can suffer from a sudden reversal of capital flows and severe financial instability. Battiston, et al. (2012) demonstrate that a financial network can be most resilient for intermediate levels of integration, but not at its maximal.

Due to their macroeconomic and financial effects, the complex and extensive interlinkages in the banking sector have become a paramount concern for policymakers and regulators. To ensure financial stability, policymakers pay more attention to changes in the conditions of global financial markets and monitor the sources and channels of systemic risk that may have significant knockon effects on their own economies. Furthermore, a complex global financial network can intensify

1. Economist, Bank of Korea, Email: shlee5@bok.or.kr. All views expressed are solely those of the author and cannot be taken to represent the views of the Bank of Korea. 
monetary policy spillovers across countries. Due to the highly connected global financial market, the quantitative easing of the advanced economies caused global co-movements in short- and longterm interest rates and capital inflows towards the emerging economies in search of higher yields. Analogously, the monetary policy normalisation of the U.S. since 2015 has significantly affected global money flows, posing risks of a sudden reversal of capital flows.

The high complexity in the financial network is also evident in the Asia-Pacific region. Since the AFC in 1997, the financial markets in the region have experienced a remarkable growth. A robust economic growth of the emerging countries, such as China, India and Vietnam, has attracted foreign capital inflows directly to these countries or to the regional financial centres, such as Hong Kong, Singapore, and Macau. ${ }^{2}$ Furthermore, the advanced economies in the region, such as Australia, South Korea, and Taiwan, have actively expanded their international exposure in the region to benefit from the growing trade and investment flows between these economies and the rest of Asia.

Clearly, South Korea is one of the key players in the Asia-Pacific financial network. The South Korean banking system has become more linked to international and regional financial markets. Before the GFC, Korean banks were less internationally active on the asset side of their balance sheets: their international assets amount to less than $8 \%$ of its annual GDP. However, the assets of Korean banks have expanded noticeably to $16 \%$ of annual GDP at the end of 2017 . On the funding side of banks' balance sheets, they have been more integrated globally than their asset side, having international liabilities equivalent up to $22 \%$ of annual GDP. What is more interesting is that Korea becomes a net creditor to Asia and the Pacific countries after the GFC. The amount of assets to the major Asia-Pacific countries has been growing tremendously from 2013 while the amount of liabilities to these economies has not changed much since $2007 .{ }^{3}$

The active participation of Korean banks in international operations provides benefits to the Korean economy, but it also poses greater risks. External shocks - financial crises, monetary policy shocks in the large advanced economy, and macroeconomic shocks to countries to which Korean banks have large exposures - can be transmitted to the Korean financial system and adversely affect the economy. A common creditor, a global bank that dominates cross-border banking activities, can create systemic risk via various channels. Because it is difficult to identify such common creditors and assess the complexity of cross-border financial interconnectedness and its impact, it may obscure the potential risks of contagion effects stemming from the global financial network.

In light of these pressing issues, the paper focuses on the cross-border network analysis of banking flows. In particular, we would like to answer how the global network has developed in the Asia-Pacific region and how important is South Korea as a financial intermediary in the region. We construct a dataset for cross-border interbank flows of South Korea between 2005Q2 and 2018Q1 and examine the network structure before, during and after the GFC. The aim of this chapter is to identify potential roles of financial network on cross-border interbank flows and to draw important policy implications.

2. See Remolona and Shim (2015) for the analysis of the changing role of banks in Singapore and Hong Kong after the GFC.

3. As of the end of 2017, the total amount of assets of Asia-Pacific economies held by Korean banks is equivalent to $40 \%$ of total international assets they own. These economies include Australia, Bangladesh, China, Hong Kong, India, Indonesia, Macau, Malaysia, Myanmar, Nepal, New Zealand, Pakistan, Philippines, Singapore, Sri Lanka, Chinese Taipei, Thailand, and Vietnam. 
The paper is organised as follows. Section 2 overviews the banking sector of South Korea. Section 3 explains the dataset and examines the trends in aggregate cross-border bank flows. Section 4 defines the key measures of network analysis and explores the network structure using these measures and network graphs. Finally, Section 5 concludes.

\section{Banking Sector of South Korea}

Banks in South Korea can be classified into two categories: commercial banks and specialised banks (see Table 1 for the number of banks in each category). Commercial banks consist of nationwide and local banks and branches of foreign banks. ${ }^{4}$ The number of branches of foreign banks is 38 as of February 2018 and the ratio of total assets of foreign bank branches to those of domestic banks has decreasing from $13.1 \%$ in 2013 to $9.6 \%$ in $2017 .{ }^{5}$

Special banks are banks established under special act rather than the universal Banking Act. Those include the Korea Development Bank, Industrial Bank of Korea, Korea Eximbank, Nonghyup Bank and Suhyup Bank. Their main business models can be different from those of commercial banks because they were founded to finance and manage special projects of the sectors that could suffer from insufficient access to funding by commercial banks only.

Table 1

Number of Banks (as of end February 2018)

\begin{tabular}{c|c|c}
\hline \multirow{2}{*}{ Classification } & Number \\
\hline \multirow{3}{*}{ Commercial Banks } & Nationwide Banks & 8 \\
\cline { 2 - 3 } & Local Banks & 6 \\
\cline { 2 - 3 } & Branches of Foreign Banks & 38 \\
\hline \multicolumn{2}{c}{ Specialised Banks } & 5 \\
\hline
\end{tabular}

As of end of first quarter of 2018, commercial banks' total assets amount to 1,561 trillion won, increased by $6.8 \%$ from the previous year (see Figure 1). The profitability of commercial banks in terms of Return on Assets (ROA) slightly improved from the last quarter of 2017 (see Figure 2). Net interest margin remained low due to the persistently low policy rate (see Figure 2 ).

4. Two internet-only banks (K-Bank and Kakao Bank) are included among nationwide banks.

5. The ratios are computed based on the fiscal year average (Source: Financial Supervisory Service). 
Figure 1. Total Assets

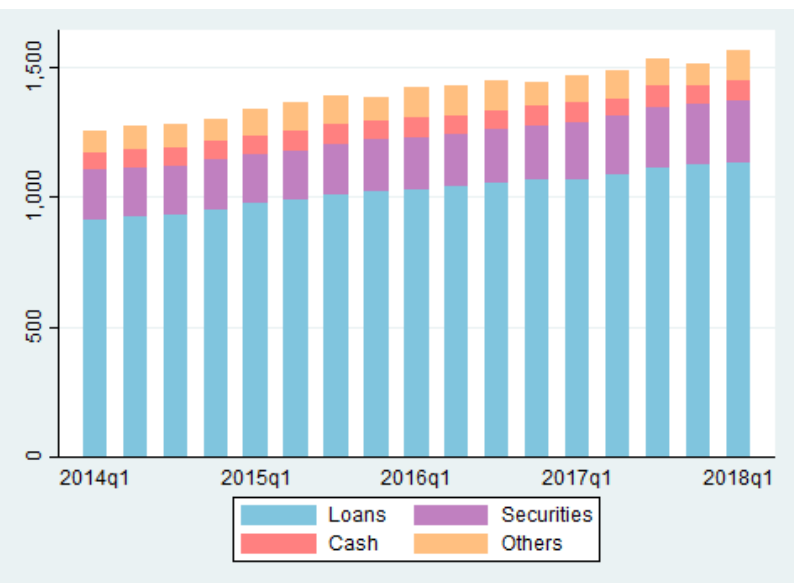

Notes: End period banking account balance basis (Trillion Won).

Sources: Commercial banks' business reports.
Figure 2. Profitability

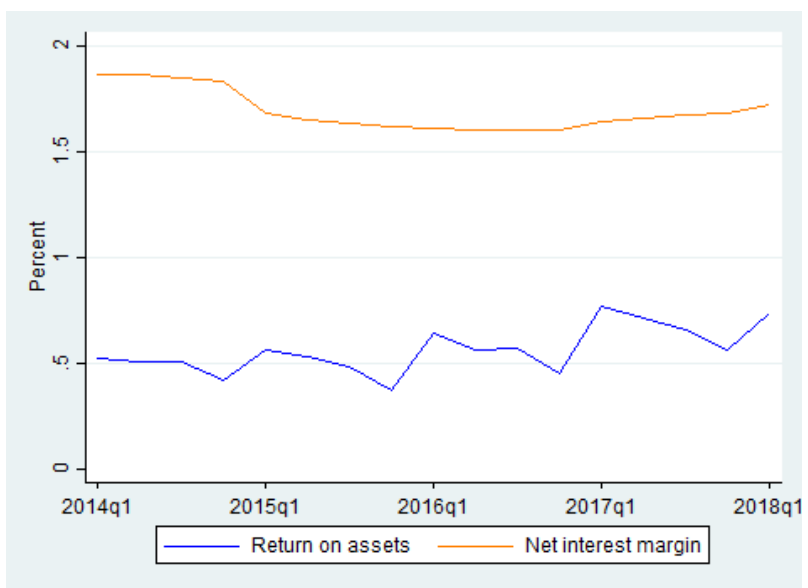

Notes: Accumulated quarterly incomes are annualised to compute the ratio.

Sources: Commercial banks' business reports.

The Korean banking sector is currently facing favourable overseas funding conditions with relatively low level of CDS premium (See Figure 3). In terms of asset soundness, commercial banks' average substandard-or-below loan ratio is $0.70 \%$ at the end of the first quarter of 2018 . There was only a mild pick-up in the ratio for large corporations in the last quarter of 2017 while the loans to Small and Medium Enterprises and households remain sound (see Figure 4). This was partly due to the commercial banks' efforts to improve risk management.

Figure 3. CDS Premium

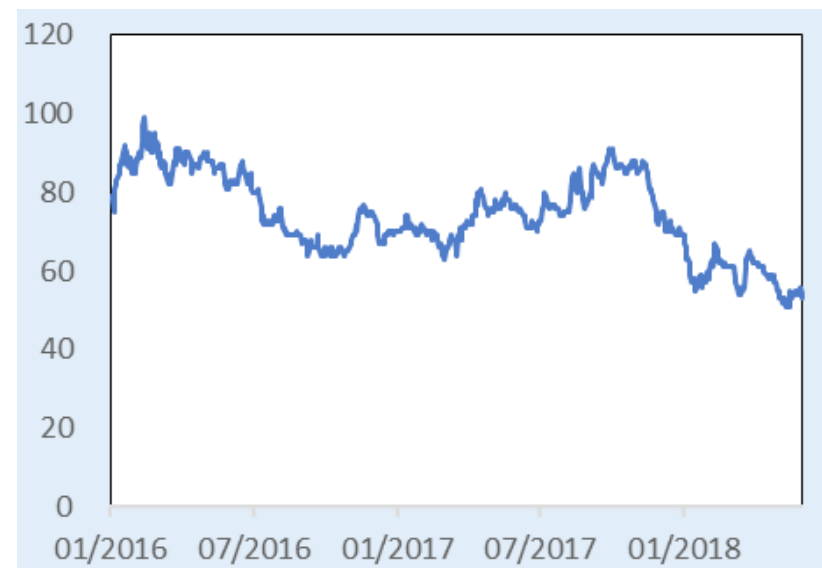

Notes: The average of four major commercial banks (5-year maturity basis).

Sources: Markit.

\section{Figure 4. Substandard Loan Rates}

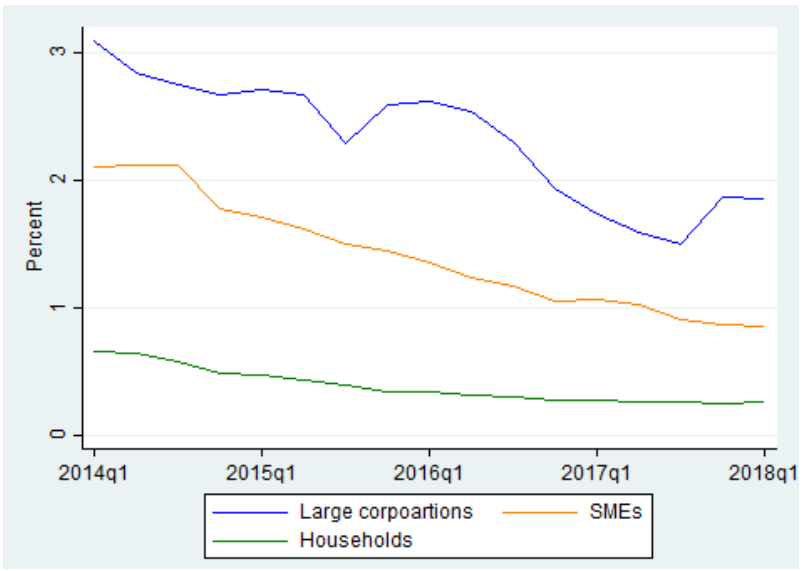

Notes: Commercial bank, substandard-or-below loan.

Sources: Commercial banks' business reports.

The amount of transactions among financial institutions has increased by $7.6 \%$ from the end of 2017 to 2,120 trillion won. The composition of the transactions among non-bank financial institutions are the largest (58.6\%) followed by the transactions between bank and non-bank (37.2 $\%$ ) and those among banks (4.2\%). To have a closer look at the network structure of the financial sector and banking sector, the interconnectedness graphs are examined (see Figure 5 and 6). 
The four largest-ranked financial institutions in terms of bilateral transaction volumes are domestic banks, securities companies, investment funds, and trusts. While branches of foreign banks have connections with other sectors, domestic banks are playing an important role within the Korean financial sectors. Figure 6 shows the interconnectedness of the banking sector based on mutual transactions among domestic banks. It includes 19 domestic banks: nationwide and local commercial banks and special banks. It identifies six Domestically Systemically Important Banks (D-SIBs). The D-SIBs for 2019 identified by Financial Services Commission are four bank holding companies (Shinhan Financial Group, Hana Financial Group, KB Financial Group, NH financial Group) and one bank (Woori Bank). ${ }^{6}$

Figure 5

\section{Interconnectedness of Financial Sector (as of end-2017)}

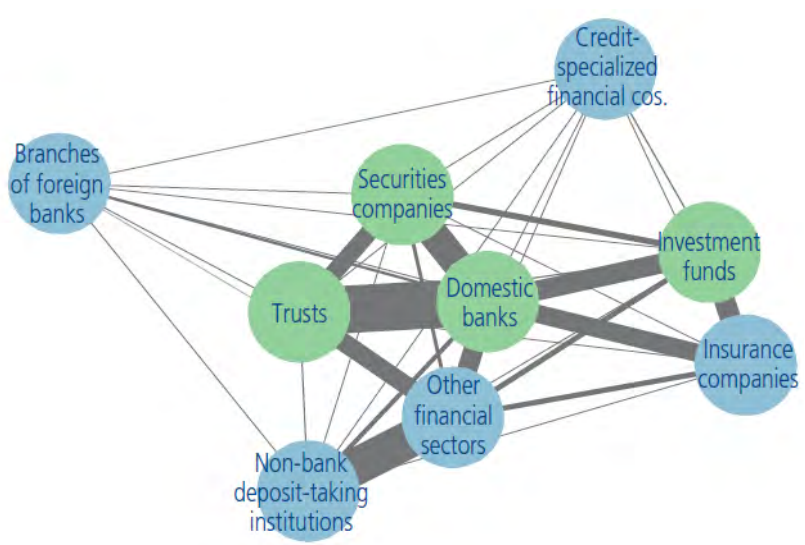

Notes: Green colour indicates the four highest-ranked financial sectors in terms of the volumes of mutual transactions. The line thickness is proportion to the mutual transaction volumes. Trusts refer to trust accounts of banks, securities and insurance companies. Non-bank deposit-taking institutions are community credit cooperatives, Credit Unions, savings banks. Other financial sectors refer to public financial institutions and financial holding companies.

Sources: The Bank of Korea Financial Stability Report, 2018.6 .
Figure 6

Interconnectedness of Banking Sector (as of end-2017)

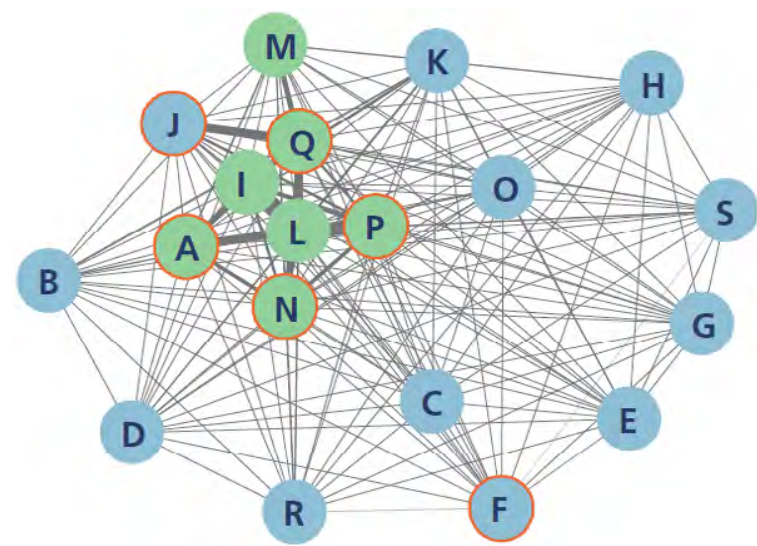

Notes: Green colour indicates the seven highest-ranked banks in terms of the volumes of mutual transactions. Circles (nodes) with orange borders indicate D-SIBs.

Sources: The Bank of Korea Financial Stability Report, 2018.6

Overall, the banking sector has remained stable with sufficient capacity for withstanding domestic and external shocks. However, there are considerable uncertainties that can put pressure on the Korean economy and financial sector. In particular, the monetary policy normalisation of central banks in the major countries and protectionism can be detrimental factors heightening uncertainties. Therefore, it is necessary to focus on the potential external risks that may threaten financial stability and how cross-border financial network affects the transmission of such risks to the domestic banking system.

6. Figure 6 shows six D-SIBs because it includes Jeju Bank which is a subsidiary of Shinhan Financial Group. 


\section{Data}

In order to examine the global financial network structure of the Asia-Pacific region, we construct a dataset of cross-border interbank transactions using the Locational Banking Statistics data obtained from the Bank for International Settlement (BIS). BIS provides three types of statistics: Locational Banking Statistics (LBS), Consolidated Banking Statistics (CBS), and Syndicated Loan Statistics (SLS). LBS data is collected on gross (unconsolidated) basis and therefore, includes positions vis-à-vis affiliates of foreign banks residing in different countries. It covers international lending and borrowing of banks in the narrow sense as it focuses on loans and deposits of banks' balance sheet. On contrary, CBS focuses on the assets side of balance sheet and covers financial claims on consolidated basis where inter-office positions are netted out.

One of the advantages of using LBS data over CBS data is that it is compatible with other official statistics, such as external debt and Balance of Payment (BOP) data. In addition, LBS provides foreign exchange rate and breaks adjusted data whereas CBS does not. As LBS reports bilateral bank flows of total claims and total liabilities, it is consistent with the recent approaches in academic papers that emphasise the analysis of gross capital flows rather than net capital flows. ${ }^{7}$

LBS data reports the bilateral banking activities, borrowing and lending, and the scope of counterparty countries to include is important for data preparation. To examine the external exposures of banking flows to the rest of the world, the total claims and liabilities to all other counterparty countries are retrieved from the BIS statistics (see Figure 7). South Korea's banking sector was at net liability position to the rest of the world until most recently. Cross-border liabilities of Korean banks increased dramatically from the end of 2005 until the first quarter of 2008. After the GFC, liabilities declined for about a year and recovered to approximately US $\$ 220$ million. Liabilities remained stable in the subsequent years until it reached US\$260 million in the third quarter of 2014. Total amount of claims to the rest of the world continuously increased from US\$50 million in 2005 to just above US\$250 million in 2017. There were two episodes of deleveraging in 2008 and 2012 and a rapid increase from 2013 to 2015.

For our main analysis, we consider bilateral banking transactions with major countries in the Asia-Pacific region and the other globally systemically important countries, such as the G7, Switzerland and Luxembourg (see Table 2 for the complete list of countries). The total number of countries for the analyses is 27 , excluding South Korea. Core countries are defined as reporting countries in the BIS Locational Banking Statistics. In order to track the network structure of core countries, the cross-border banking flows data for the reporting countries need to have bilateral bank flows data, i.e. bank flows to individual counterparty. Therefore, some of the reporting countries without such data are categorised as periphery countries. ${ }^{8}$

7. See, for example, Forbes and Warnock (2012); Broner, et al. (2013); and Milesi-Ferretti and Tille (2011).

8. Note that our analyses may have limitations due to the data availability. For most of the reporting economies, banks' total assets and liabilities to the rest of the world are available from 1998. However, in some cases, bank's total assets and liabilities to individual economy (bilateral transactions data) are not available for the same sample period. For example, South Korea started to report bilateral bank flows from the first quarter of 2005, while Hong Kong did so from the fourth quarter of 2014. 
Table 2

\section{List of Economies}

\begin{tabular}{|c|c|c|c|}
\hline Country & Abbreviation & Type & Sample period \\
\hline Australia & $\mathrm{AU}$ & $\mathrm{C}$ & $1998 q 1-2018 q 1$ \\
\hline Canada & $\mathrm{CA}$ & $\mathrm{C}$ & $2007 q 3-2018 q 1$ \\
\hline Chinese Taipei & TW & $\mathrm{C}$ & $2000 q 4-2018 q 1$ \\
\hline France & FR & $\mathrm{C}$ & $1998 q 1-2018 q 1$ \\
\hline Germany & $\mathrm{DE}$ & $\mathrm{C}$ & $1998 q 1-2018 q 1$ \\
\hline Hong Kong, SAR & HK & $\mathrm{C}$ & $2014 q 4-2018 q 1$ \\
\hline Italy & IT & $\mathrm{C}$ & $2014 q 4-2018 q 1$ \\
\hline Japan & JP & $\mathrm{C}$ & $1998 q 1-2018 q 1$ \\
\hline Luxembourg & LU & $\mathrm{C}$ & $1998 q 1-2018 q 1$ \\
\hline Macau, SAR & MO & $\mathrm{C}$ & $2004 q 1-2018 q 1$ \\
\hline Philippines & $\mathrm{PH}$ & $\mathrm{C}$ & $2016 q 4-2018 q 1$ \\
\hline South Korea & $\mathrm{KR}$ & $\mathrm{C}$ & $2005 q 1-2018 q 1$ \\
\hline Switzerland & $\mathrm{CH}$ & $\mathrm{C}$ & $1998 q 1-2018 q 1$ \\
\hline UK & GB & $\mathrm{C}$ & $1998 q 1-2018 q 1$ \\
\hline US & US & $\mathrm{C}$ & $1998 \mathrm{q} 1-2018 \mathrm{q} 1$ \\
\hline Bangladesh & $\mathrm{BD}$ & $\mathrm{P}$ & - \\
\hline China & $\mathrm{CN}$ & $\mathrm{P}$ & - \\
\hline India & IN & $\mathrm{P}$ & - \\
\hline Indonesia & ID & $\mathrm{P}$ & - \\
\hline Malaysia & MY & $\mathrm{P}$ & - \\
\hline Myanmar & MM & $\mathrm{P}$ & - \\
\hline Nepal & NP & $\mathrm{P}$ & - \\
\hline New Zealand & $\mathrm{NZ}$ & $\mathrm{P}$ & - \\
\hline Pakistan & $\mathrm{PK}$ & $\mathrm{P}$ & - \\
\hline Singapore & SG & $\mathrm{P}$ & - \\
\hline Sri Lanka & LK & $\mathrm{P}$ & - \\
\hline Thailand & $\mathrm{TH}$ & $\mathrm{P}$ & - \\
\hline Vietnam & $\mathrm{VN}$ & $\mathrm{P}$ & - \\
\hline
\end{tabular}

Notes: $\mathrm{C}$ denotes core (reporting) economies of which the data for individual counterparty countries are available, $\mathrm{P}$ denotes periphery (non-reporting) countries. 
Figure 8 shows the total amounts of cross-border exposures of Korean banking sector to 27 economies. Total liabilities exhibit similar trends as in Figure 7 with exception that the deposits from these 27 economies (liabilities) flatted out after 2013 while the total liabilities further increased since 2013. Total claims to these economies have shown robust increase since 2005 but milder than the claims to the rest of the world.

Figure 7

Total Amounts of Cross-border Bank Flows: All Economies

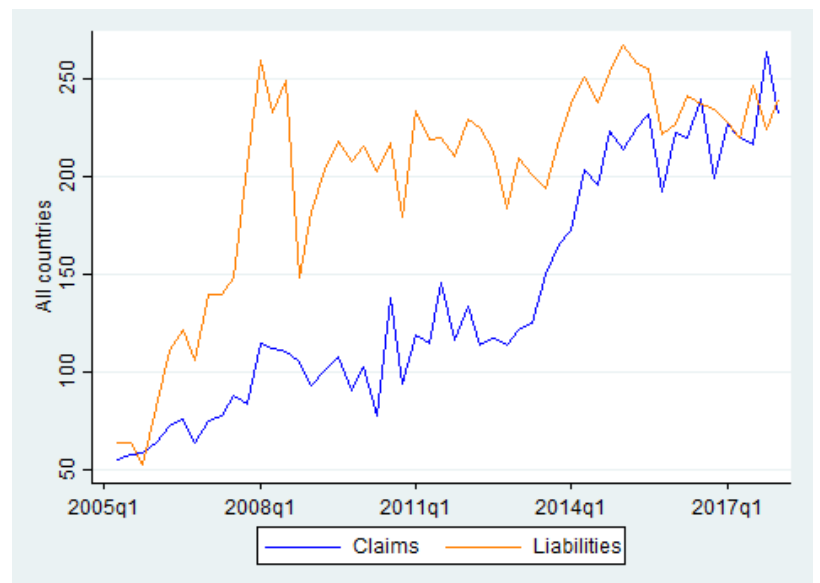

Notes: Total claims and liabilities are in billion US dollars.

Sources: BIS Locational Banking Statistics.
Figure 8

Total Amounts of Cross-border Bank Flows: 27 Economies

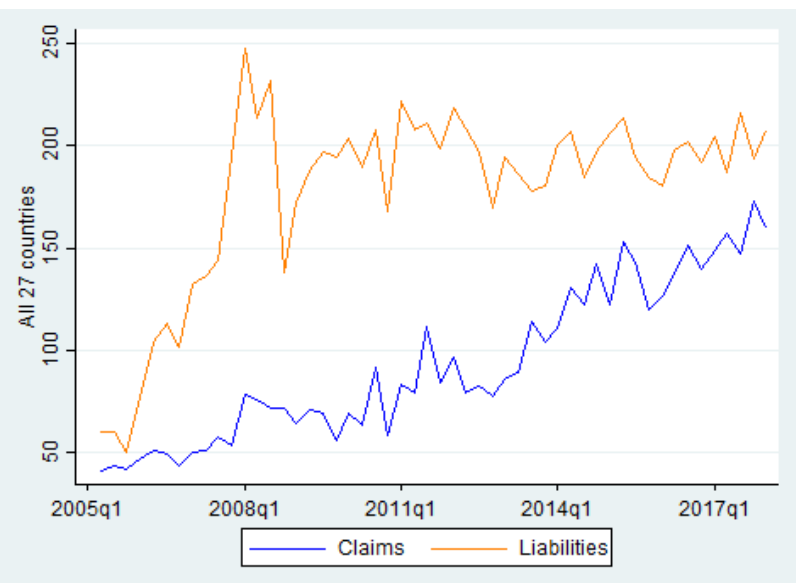

Notes: Total claims and liabilities are in billion US dollars.

Sources: BIS Locational Banking Statistics.

We investigated whether these cross-border bank flows from and to South Korea differ with respect to the counterparty country. Figure 9 demonstrates the bank flows between South Korea and the G7 countries (United States, United Kingdom, Canada, Japan, Germany, France, Italy), Luxembourg and Switzerland. ${ }^{9}$ South Korean banks have net liabilities to the banks of those countries. Total borrowings from these selected advanced economies reached its peak in 2008 but dropped in the aftermath of the financial crisis. It recovered its previous peak in 2011 but the level of claims slightly fell afterwards. Total claims (lending) have remained stable around US\$40 million with a slight pick-up at the end of 2017.

Figure 10 shows the trend of cross-border bank flows between South Korea and other periphery countries in the Asia-Pacific region. It includes Bangladesh, China, India, Indonesia, Malaysia, Myanmar, Nepal, New Zealand, Pakistan, Singapore, Sri Lanka, Thailand and Vietnam. Unlike the claims on assets of advanced countries in Figure 9, there was a substantial increase in the claims on assets of Asia-Pacific periphery countries from 2011. Due to this remarkable increase, the amount of loans of Korean banks to the region has exceeded that of deposits from the region since 2013 .

9. We include Luxembourg and Switzerland because they have a globalised banking sector. 
Figure 9

Total Amounts of Cross-border Bank Flows: G7+2

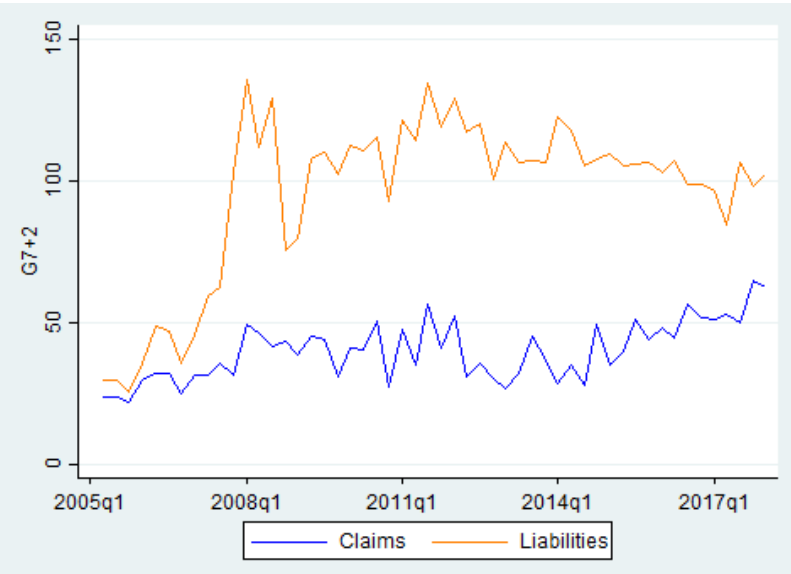

Notes: Total claims and liabilities are in billion US dollars.

Sources: BIS Locational Banking Statistics.
Figure 10

Total Amounts of Cross-border Bank Flows: Regional Periphery

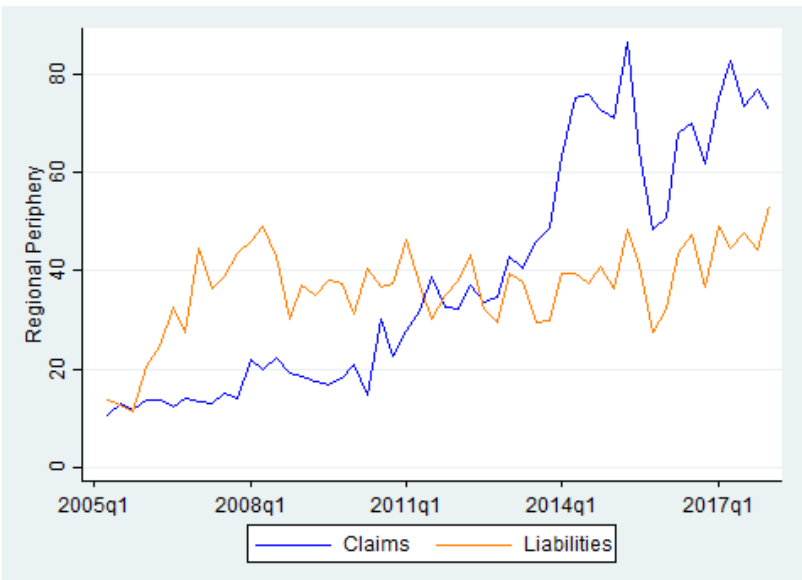

Notes: Total claims and liabilities are in billion US dollars.

Sources: BIS Locational Banking Statistics.

We investigate trends in the subset of the Asia-Pacific region to examine the different dynamics in the trends. Figure 11 exhibits the banking flows between Korea and three regional financial centres, Hong Kong, Singapore and Macau. These financial centres can serve as intermediaries of international funding to the Asia-Pacific region. Korean banks have more liabilities than claims with the regional financial centres. The trend of total liabilities tends to track that of total liabilities to the advanced economies (Figure 9) as the money flows in these countries would follow international investors' risk appetite.

\section{Figure 11}

Total Amounts of Cross-border Bank Flows: Regional Financial Centres

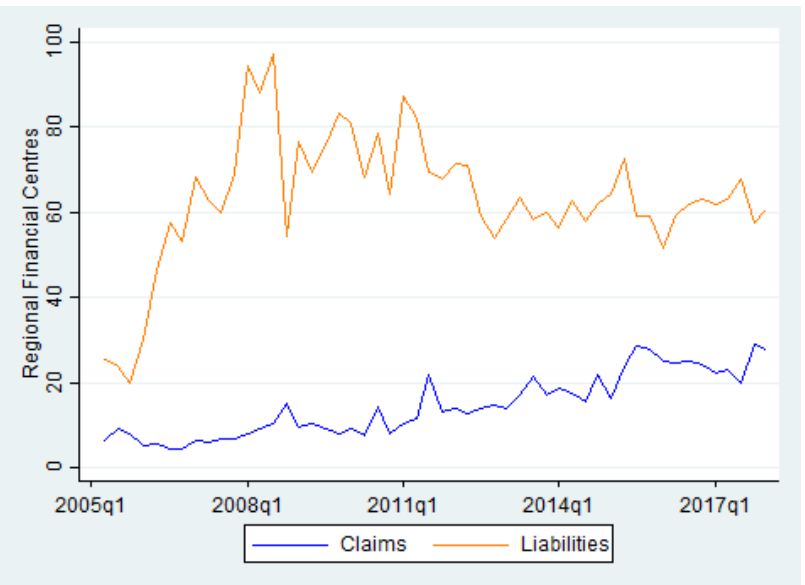

Notes: Total claims and liabilities are in billion US dollars.

Sources: BIS Locational Banking Statistics.

\section{Figure 12}

Total Amounts of Cross-border Bank Flows: China, India

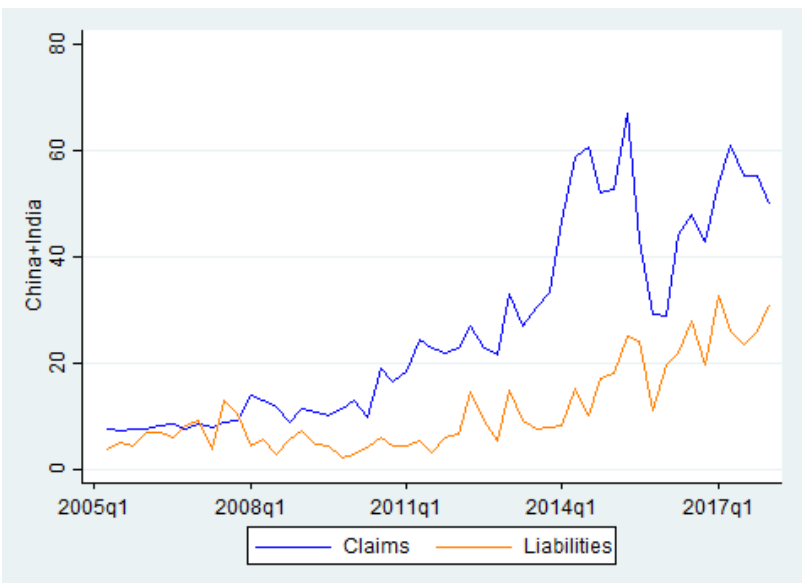

Notes: Total claims and liabilities are in billion US dollars.

Sources: BIS Locational Banking Statistics. 
Figure 12 identifies the trends in bank flows with two large economies that has been experienced a rapid economic growth recently, China and India. The Korean banks' lending to these two countries increased exponentially after the GFC. Reflecting the recent slowdown in these economies, total claims declined in 2015-16 substantially but recovered since then.

On the whole, South Korean banks' cross-border exposures in both asset and liability side have expanded considerably. The expansion of claims (lending) to foreign countries has been driven by the lending to developing countries in the Asia-Pacific region. The fluctuations in total liabilities (borrowing) largely depend on the economic conditions and monetary policy of advanced economies.

\section{Network Analysis}

\subsection{Methodology}

To define a network, two elements are required: nodes and edges. In our context of crossborder banking flows, a node refers to a country and an edge the amount of cross-border financial positions. Since we have both incoming and outgoing links, the cross-border bank flows network can be described as a directed network. For the claims data, nodes with outgoing links are reporting countries and lenders. For the liabilities data, nodes with outgoing links are also reporting countries but, in this case, borrowers.

Node degree indicates the number of bilateral links for a country (node). In other words, the degree of a node is the number of edges that are adjacent to the node. A country with higher node degree implies that the country has many cross-banking contracts among the other countries in the region. For a directed network, in-degree can be defined as the number of bilateral links to a target country while out-degree as those from a source (reporting) country.

Weighted node degree (node strength) is the total amount of cross-border banking flows from (weighted out-degree) or to (weighted in-degree) a given node. This metric reflects the intensity of financial flows for a given country. By definition, out-degree and weighted out-degree for periphery (non-reporting) countries equal to zero.

Clustering coefficient indicates how nodes are embedded in their neighbourhood or how complete the neighbourhood of a node is. It ranges from 0 to 1 . If every node in the neighbourhood of a given node is all connected, the clustering coefficient is 1 . If no nodes in the neighbourhood is linked, the clustering coefficient is 0 . The average clustering coefficient gives an overall clustering of a network. Reporting countries tend to have smaller clustering coefficients because they lend to or borrow from wide range of countries including both other reporting and periphery countries, but the neighbours are not necessarily connected to each other. However, a country whose cross-border financial transactions are limited to global financial centres that are likely to be interconnected, tend to have larger clustering coefficients. 
Betweenness centrality is the measure for the relative frequency of a node appearing in the shortest paths between every other pairs of nodes in the network. The betweenness centrality for node $v$ is computed as follows:

$$
B C(v)=\sum_{s, t \in N} \frac{\sigma_{s, t}(v)}{\sigma_{s, t}}
$$

where $\sigma_{s, t}$ is the total number of the shortest paths between node s and node $\mathrm{t}, \sigma_{s, t}(v)$ is the number of the shortest paths between $\mathrm{s}$ and $\mathrm{t}$ that contains node $v$. The betweenness centrality reflects how influential a country is as an intermediary of money flows in the network.

Distance between two nodes can be defined as the length of the shortest path between them. Closeness centrality is the average distance from a given starting node to all other nodes in the network. In particular, closeness is computed as the reciprocal of the sum of distance between a given node and all others. ${ }^{10}$

$$
C(v)=\sum_{s \in N} \frac{1}{\mathrm{~d}(\mathrm{~s}, v)}
$$

where $d(s, v)$ is the distance between the nodes, s and $v$. Therefore, the more central the node is in a network, the closer the node is to all other nodes.

\subsection{Empirical Results}

\subsubsection{Network Measures}

Based on the definition of the various network metrics, we compute these measures and analyse the trends of network measures for total claims and liabilities, respectively. Figure 13 shows in- and out-degree for claims data. The number of out-links are larger than that of in-links for South Korea. The in-degree represent the number of out-links from the reporting countries to South Korea among the entire sample countries. The average out-degree slightly increased after 2013, implying that the Korean banks' asset holdings became more diversified in terms of the destination of loans.

Figure 14 illustrates weighted in- and out-degree of South Korean cross-border bank flows. The level of weighted in-degree is higher than that of weighted out-degree, indicating that the amount of bank loans to South Korea is larger than the amount that Korean banks lend to other countries in the network. This is because the network includes advanced countries which South Korea rely on for funding. Weighted in-degree plummeted immediately after the GFC and gradually recovered from 2009. There was a strong increase in weighted in-degree in 2015 and it flattened out afterwards. Weighted out-degree have shown a steady increase, implying the expansion of crossborder lending of South Korean banks.

10. To compare the measure across different network, closeness centrality can be normalised by multiplying the reciprocal by the number of nodes, $\mathrm{N}$. 


\section{Figure 13 \\ Degrees}

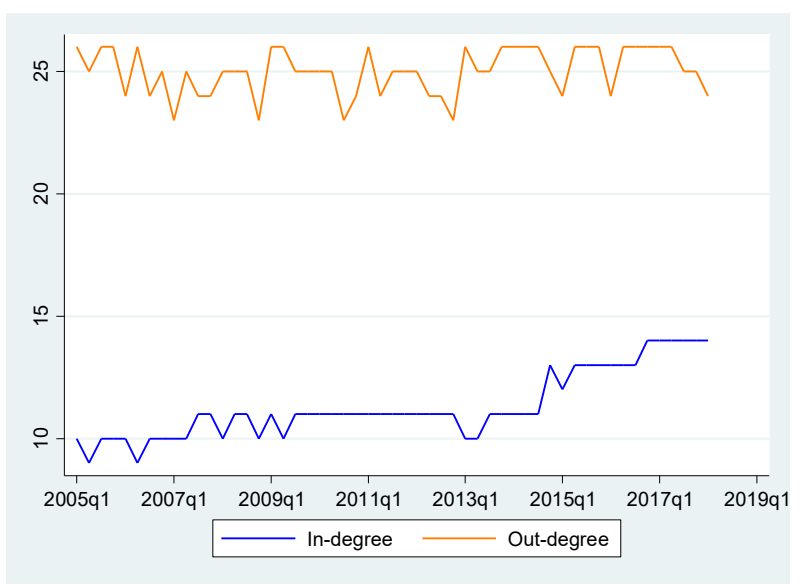

Notes: The measures are computed using total claims data.

Sources: BIS Locational Banking Statistics.
Figure 14 Weighted Degrees

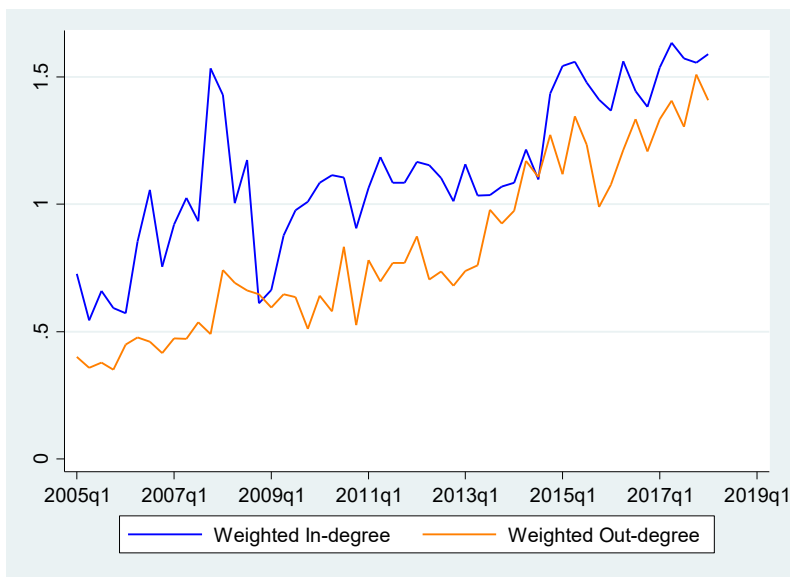

Notes: The measures are computed using total claims data. The unit of cross-border banking flows is US\$100 billion.

Sources: BIS Locational Banking Statistics.

The clustering coefficient for South Korea has risen substantially after 2015 (see Figure 15). This implies that the neighbouring countries of Korea are more interconnected in the network. ${ }^{11}$

Figure 15

\section{Clustering Coefficient}

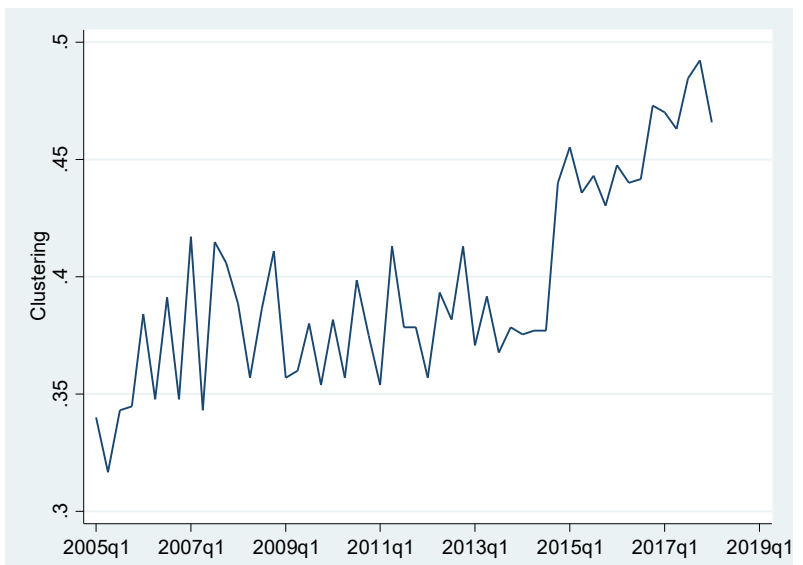

Notes: The measures are computed using total claims data.

Sources: BIS Locational Banking Statistics.
Figure 16 Betweenness Centrality

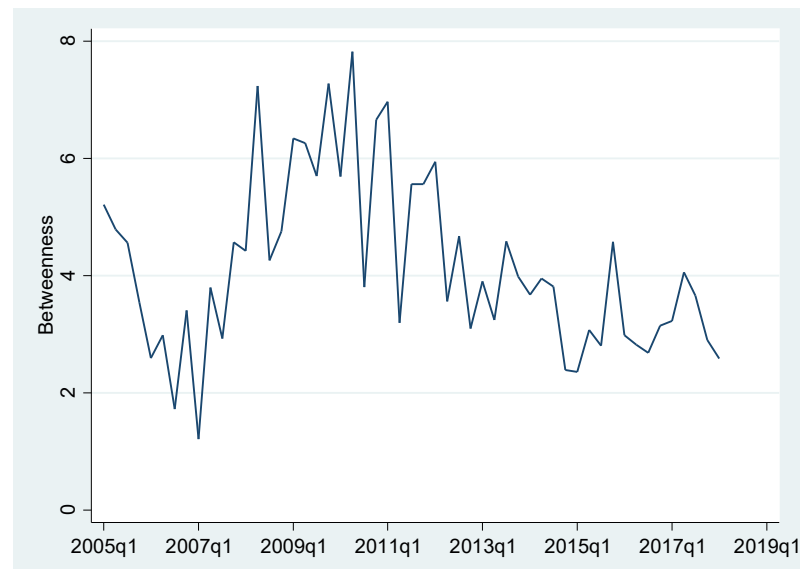

Notes: The measures are computed using total claims data.

Sources: BIS Locational Banking Statistics.

Betweenness centrality in Figure 16 shows how influential South Korea is in the network. It increased during the GFC periods, suggesting that Korea played an important role to provide funding to the region as the other advanced economies were severely hit by the crisis. However,

11. It should be noted that sharp increases in the clustering coefficient in $2014 \mathrm{q} 4$ and $2016 \mathrm{q} 4$ may be due to the inclusion of Hong Kong, Italy and Philippines as BIS reporting countries. However, the upward trend is robust regardless of the inclusion. 
betweenness steadily dropped since 2011 as the troubled advanced countries recovered and the financial intermediation function that Korea had served during the crisis weakened.

Closeness centrality decreased during the GFC period and recovered its level approximately after 2013 on average. This indicates that South Korea became closer to each nodes of the network as a lender and thus more central to the network. This is consistent with the previous findings that emphasise the increasing role of South Korea as a funding source in the cross-border banking flows network.

\section{Figure 17}

\section{Closeness Centrality}

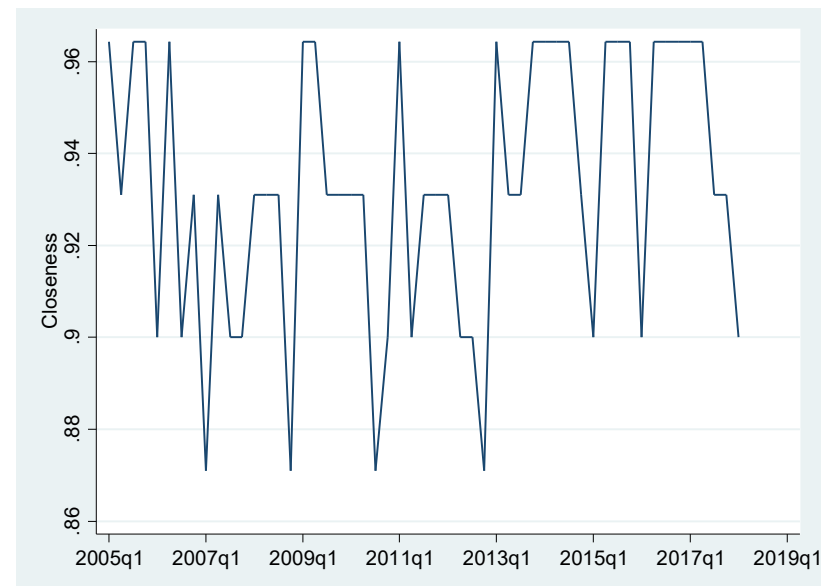

Notes: The measures are computed using total claims data.

Sources: BIS Locational Banking Statistics.

In the following, we examine the network measures for total liabilities, banks' deposits. With liabilities data, an out-link of South Korea means that Korean banks (borrowers) have deposits from non-residents (lenders). Analogous to this, an incoming link from a country to South Korea implies that Koreans (lenders) have deposit at foreign banks (borrowers).

Figure 18 shows in- and out-degree of liability. Similar to the claims result, out-degree clearly exceeds in-degree, meaning that the number of countries to which Korean banks owe liabilities is larger than the number of countries which owe liabilities to Korean depositors. Over time, both inand out-degree have increased slightly, suggesting that the liability side of bank flows has become more diversified.

As seen in Figure 19, the level of weighted out-degree is much higher than that of weighted in-degree. This implies that the amount of deposits from non-residents into Korean banks is larger than the amount of residents' deposits into the rest of the countries. In the first half of 2007, both weighted in- and out-degree rose steeply. This may reflect improved financial integration in the regional banking sector. However, it seems that the GFC discouraged the development of financial integration. There were strong signs of retrenchments (a decrease in residents' deposit in foreign banks) and stops (a decrease in non-residents' deposit in Korean banks) during the crisis period. 
After the financial crisis, weighted out-degree levelled off while weighted in-degree increased substantially from 2014. This increase in weighted in-degree was mainly due to the entrance of Hong Kong's bilateral banking flows data from the fourth quarter of $2014 .{ }^{12}$ In addition, an increase in Korean residents' deposits into the US banks is one of the crucial reason for the trend. Since the US monetary policy normalisation, markets have had a strong expectation of hikes in interest rates and appreciation of the US dollar. This expectation with motives of searching for higher yields led to such increase in deposits in the US banks.

\section{Figure 18 \\ Degrees}

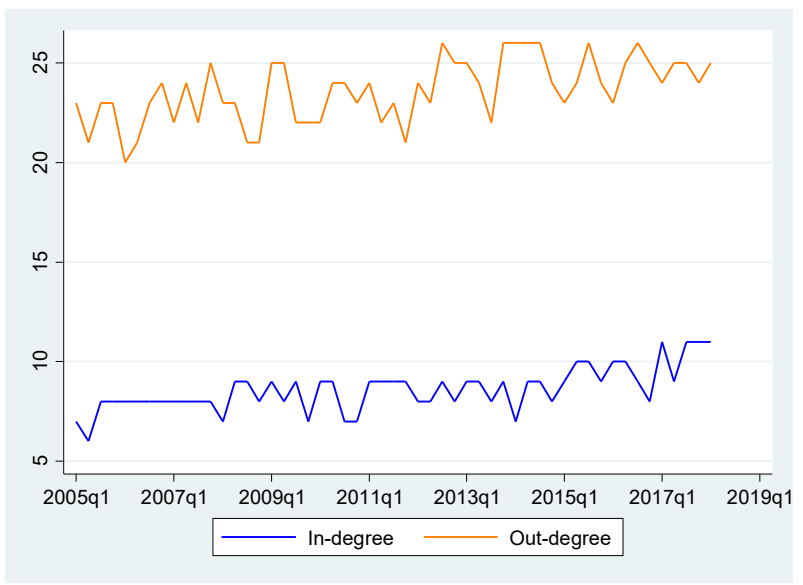

Notes: The measures are computed using total liabilities data.

Sources: BIS Locational Banking Statistics.

\section{Figure 19 \\ Weighted Degrees}

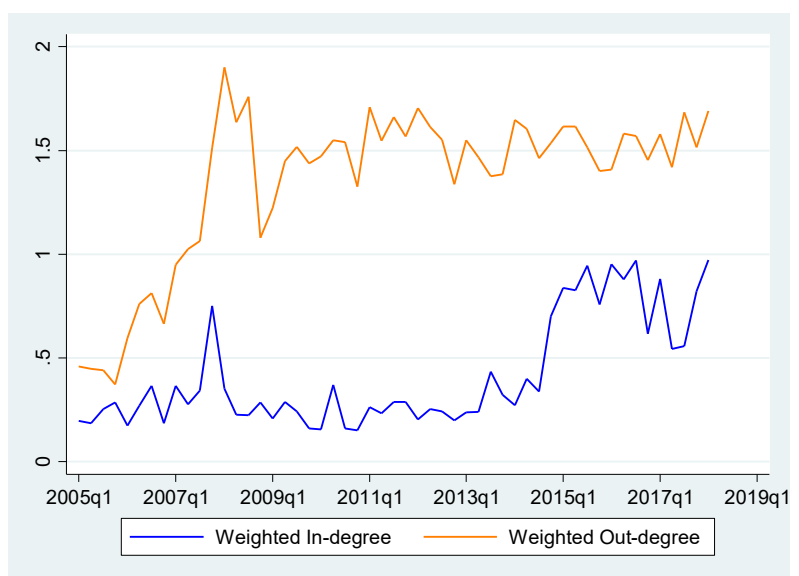

Notes: The measures are computed using total liabilities data. The unit of cross-border banking flows is US\$100 billion.

Sources: BIS Locational Banking Statistics.

Measures of connectivity in terms of liability are shown in Figure 20-22. The trends in clustering coefficient and betweenness are somewhat similar to that of claims data. Both graphs provide evidence of a highly connected regional financial network. As the network becomes denser, financially neighbouring countries of South Korea are getting more interlinked and Korea's influence as an intermediary of banking flows has become less significant.

12. The amount of liability of banks in Hong Kong to South Korea is approximately US\$32 billion in $2014 \mathrm{q} 4$. 
Figure 20

Clustering Coefficient

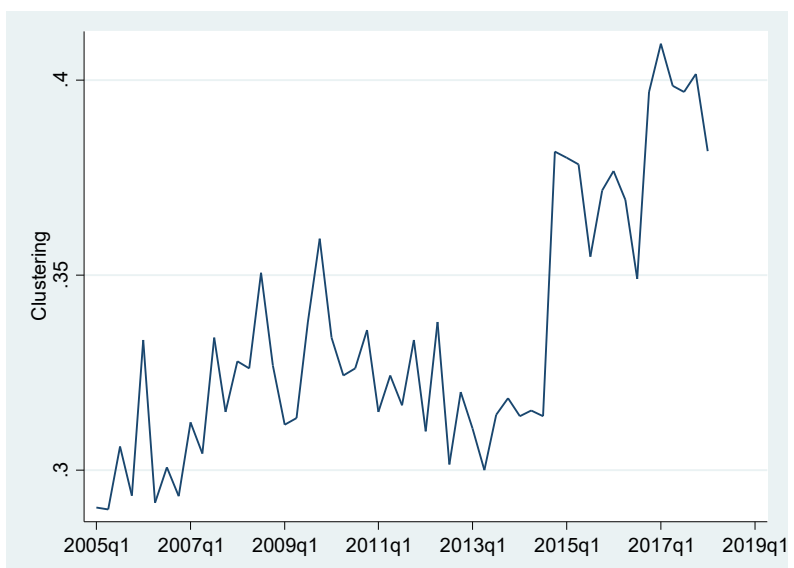

Notes: The measures are computed using total liabilities data.

Sources: BIS Locational Banking Statistics.
Figure 21

Betweenness Centrality

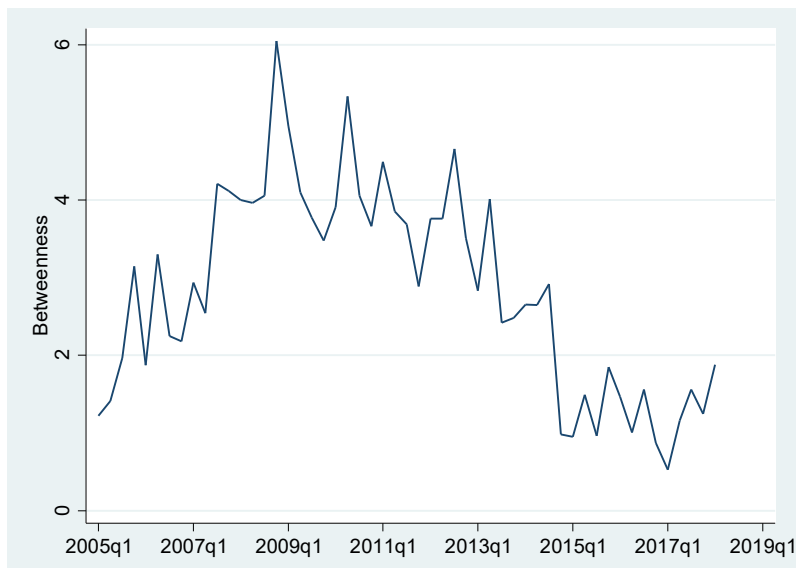

Notes: The measures are computed using total liabilities data.

Sources: BIS Locational Banking Statistics.

Closeness centrality in Figure 22 indicates that the measure is slightly lower than the claims data. However, an upward trend since 2012 is more noticeable than that in the claims data.

Figure 22

\section{Closeness Centrality}

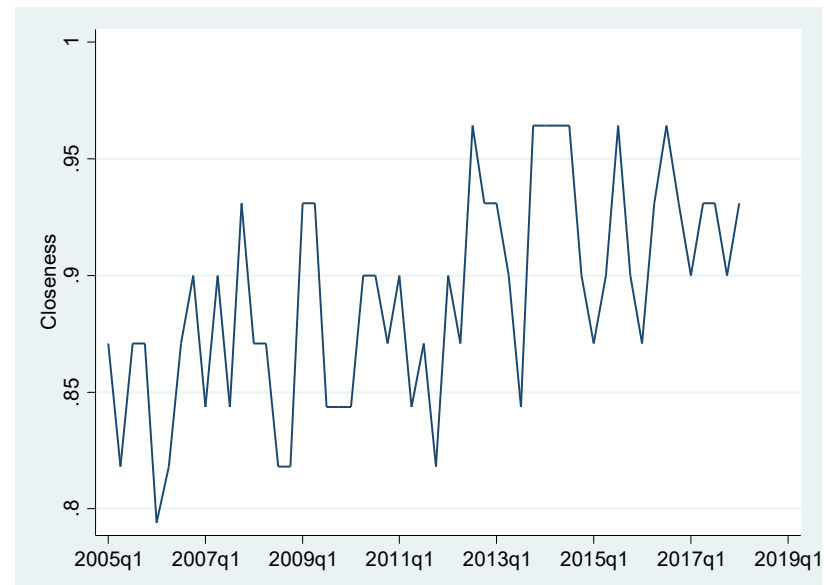

Notes: The measures are computed using total liabilities data.

Sources: BIS Locational Banking Statistics. 


\subsubsection{Network Graphs}

Next, we plot network graphs for claims and liability data using a software, Gephi. ${ }^{13}$ In order to highlight the bank flows in the Asia-Pacific region, bilateral transactions between advanced economies (the G7, Luxembourg and Switzerland) are excluded in the network graphs. This is because the amount of bank flows among these advanced economies tend to be much larger than the amount of flows between advanced and other Asia-Pacific countries or among the Asia-Pacific countries.

Three features of graph - the size of nodes, and the colour of the nodes, and the thickness of edges - can represent different aspects of a network structure. In the following network graphs, the node size indicates weighted out-degree, the colour of node betweenness connectivity, and the thickness of arrows the amount of bank flows.

Figure 23-31 show the network graph of total claims data for nine selected periods: 1998, $2000,2005,2007,2008,2009,2013,2015,2018$. All are the graphs for the first quarter of selected years to avoid capturing undesirable differences due to seasonality. The right panels of each figure show the same network graph but highlighting only the countries that have financial linkages with South Korea.

For the period from 1998 to 2004, South Korea was not reporting the LBS data to the BIS. Thus, Korea is considered as a periphery country which receives funding from foreign banks and does not lend to the rest of the world. As seen in Figures 23 and 24, it borrowed from only eight advanced economies, the US, the UK, Japan, Germany, France, Luxembourg, Switzerland and Australia.

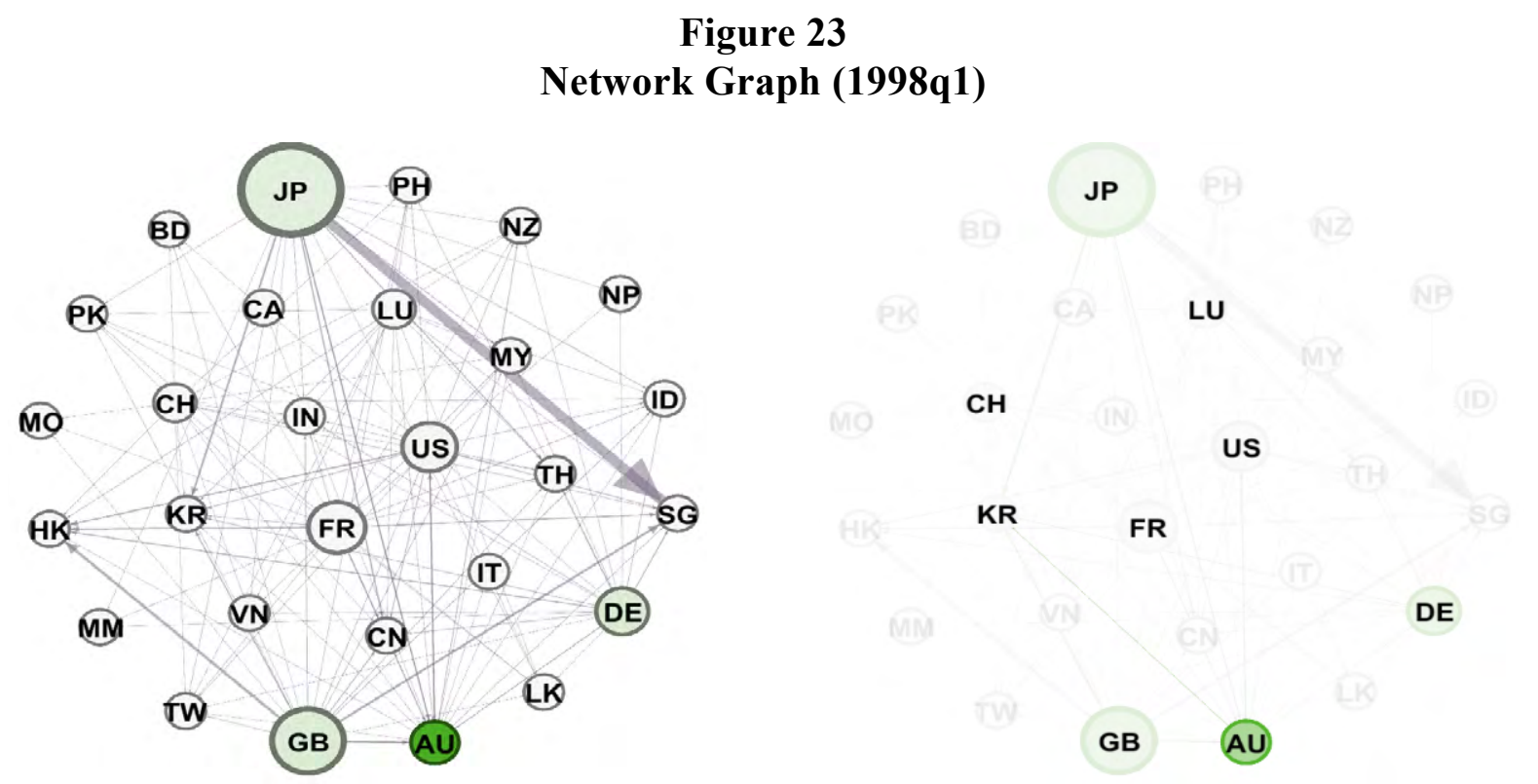

Notes: The node size indicates weighted out-degree, the colour of node betweenness connectivity, and the thickness of arrows the amount of bank flows. The right panel highlights the nodes that have bilateral link with Korea.

Sources: BIS Locational Banking Statistics.

13. Gephi is an open-source visualisation software for network graphs (https://gephi.org/). 


\section{Figure 24 \\ Network Graph (2000q1)}

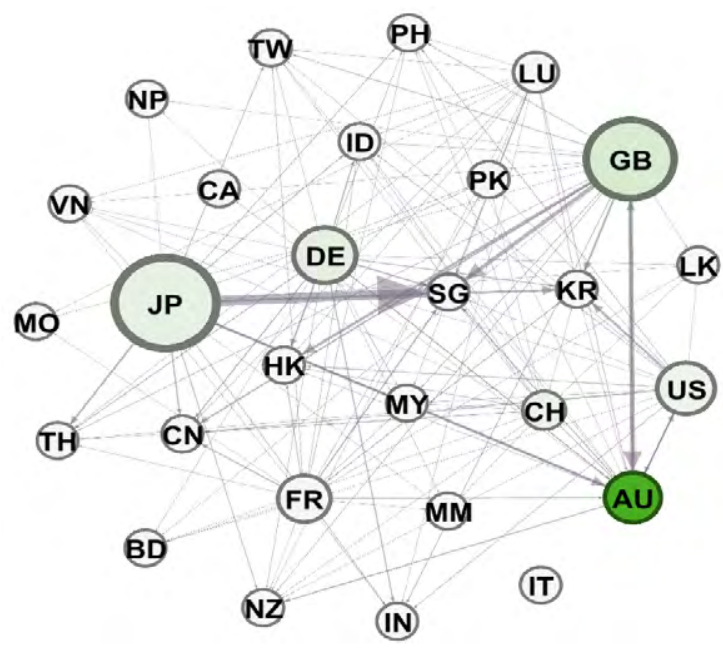

LU

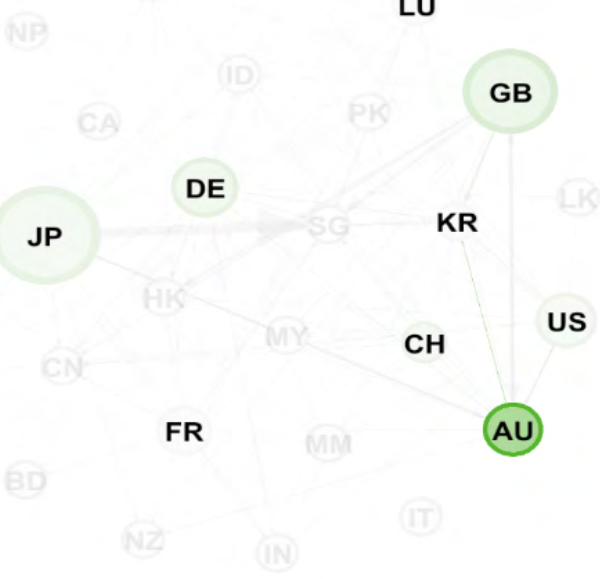

Notes: The node size indicates weighted out-degree, the colour of node betweenness connectivity, and the thickness of arrows the amount of bank flows. The right panel highlights the nodes that have bilateral link with Korea.

Sources: BIS Locational Banking Statistics.

From 2005q1, South Korea started to report bilateral cross-border bank flows data to the BIS and, therefore, Korea has out-links as well as in-links. In 2005q1, betweenness centrality of Korea was above the average and weighted out-degree increased. All countries except Hong Kong have either in- or out-links with Korea. ${ }^{14}$ Korean banks own assets of 26 countries, including those of the US (the amount of the US claims relative to total amount of international claims is $34 \%$ ), China $(14 \%)$, the UK (13\%), Singapore (8\%) and Japan (6\%).

Figure 25

Network Graph (2005q1)
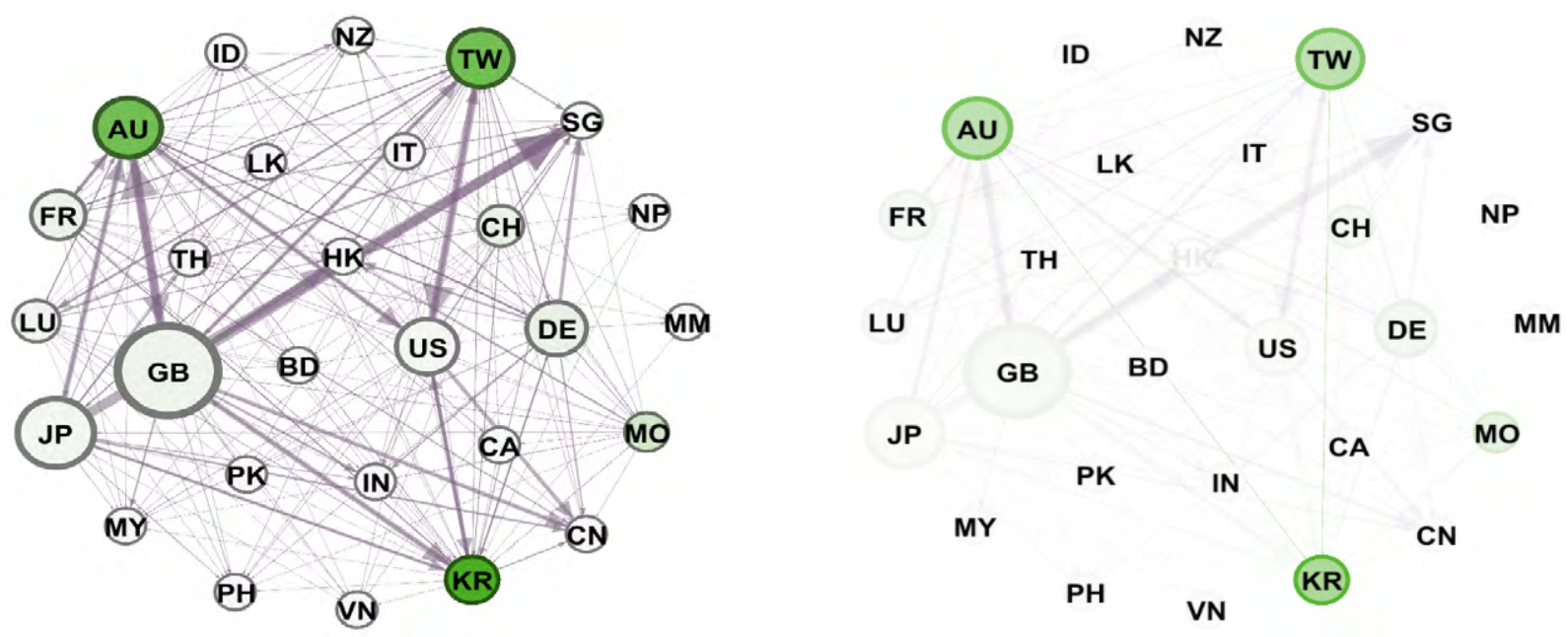

Notes: The node size indicates weighted out-degree, the colour of node betweenness connectivity, and the thickness of arrows the amount of bank flows. The right panel highlights the nodes that have bilateral link with Korea.

Sources: BIS Locational Banking Statistics.

14. There were no claims reported by Korean banks that belongs to Hong Kong. However, since Hong Kong started to report bilateral cross-border bank flows from 2014q1, we cannot rule out the possibility that an out-link from Hong Kong to South Korea exists. 
In 2007q1, before the GFC had occurred, the financial network in the region became more complicated with South Korea being an important funding source of the region. Korea focused on the emerging countries with high growth potential as there was no link between Korea and the under-developed countries, such as Myanmar, Nepal and Bangladesh. The top five largest borrowers are the same and their relative amounts remain similar as in $2007 \mathrm{q} 1$.

Figure 26

Network Graph (2007q1)
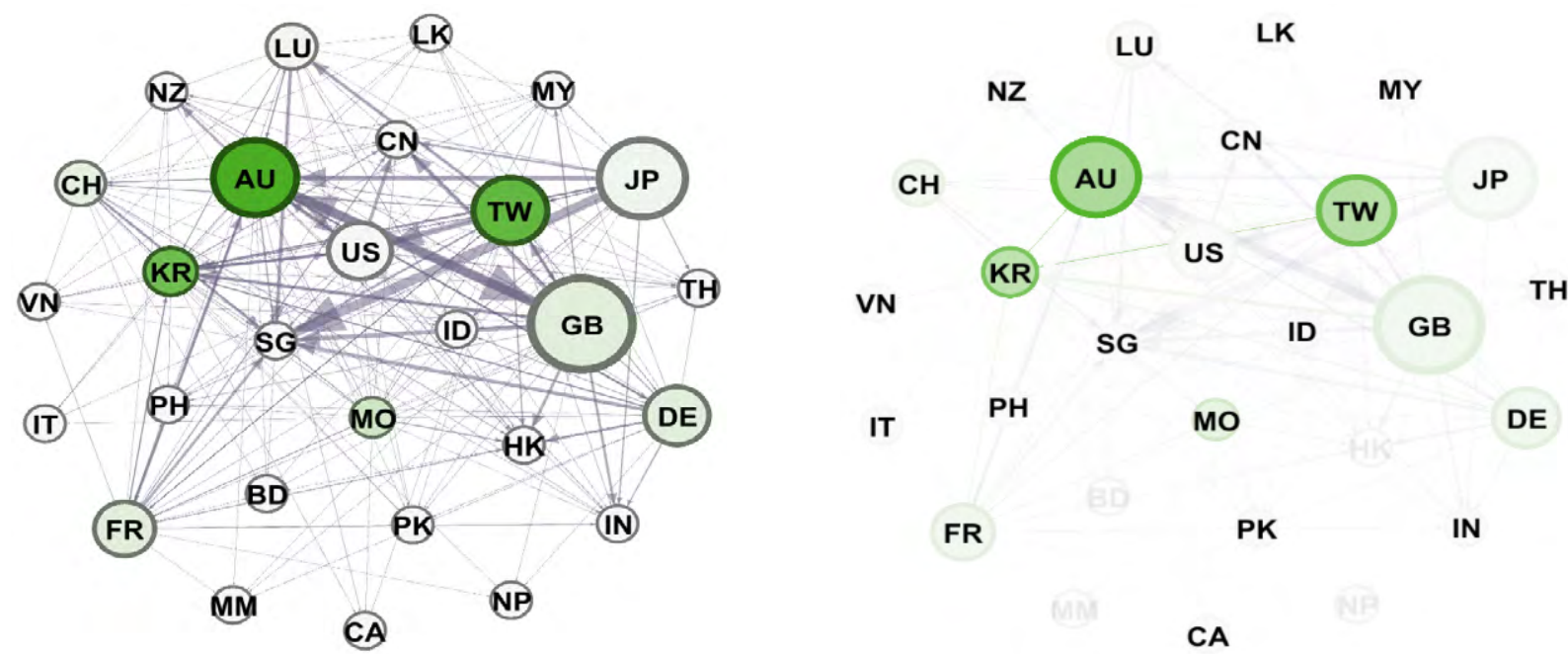

Notes: The node size indicates weighted out-degree, the colour of node betweenness connectivity, and the thickness of arrows the amount of bank flows. The right panel highlights the nodes that have bilateral link with Korea.

Sources: BIS Locational Banking Statistics.

In 2008q1, the aggregate amount of foreign claims that South Korean banks own increased dramatically from US\$47 billion in $2007 q 1$ to US\$74 billion. The proportion of the US claims declined slightly due to higher risks during the GFC while the European countries, such as the UK and France, attracted more funding from Korea. The in-links are mainly with advanced economies, such as the UK, the US, Japan, France and Germany. 


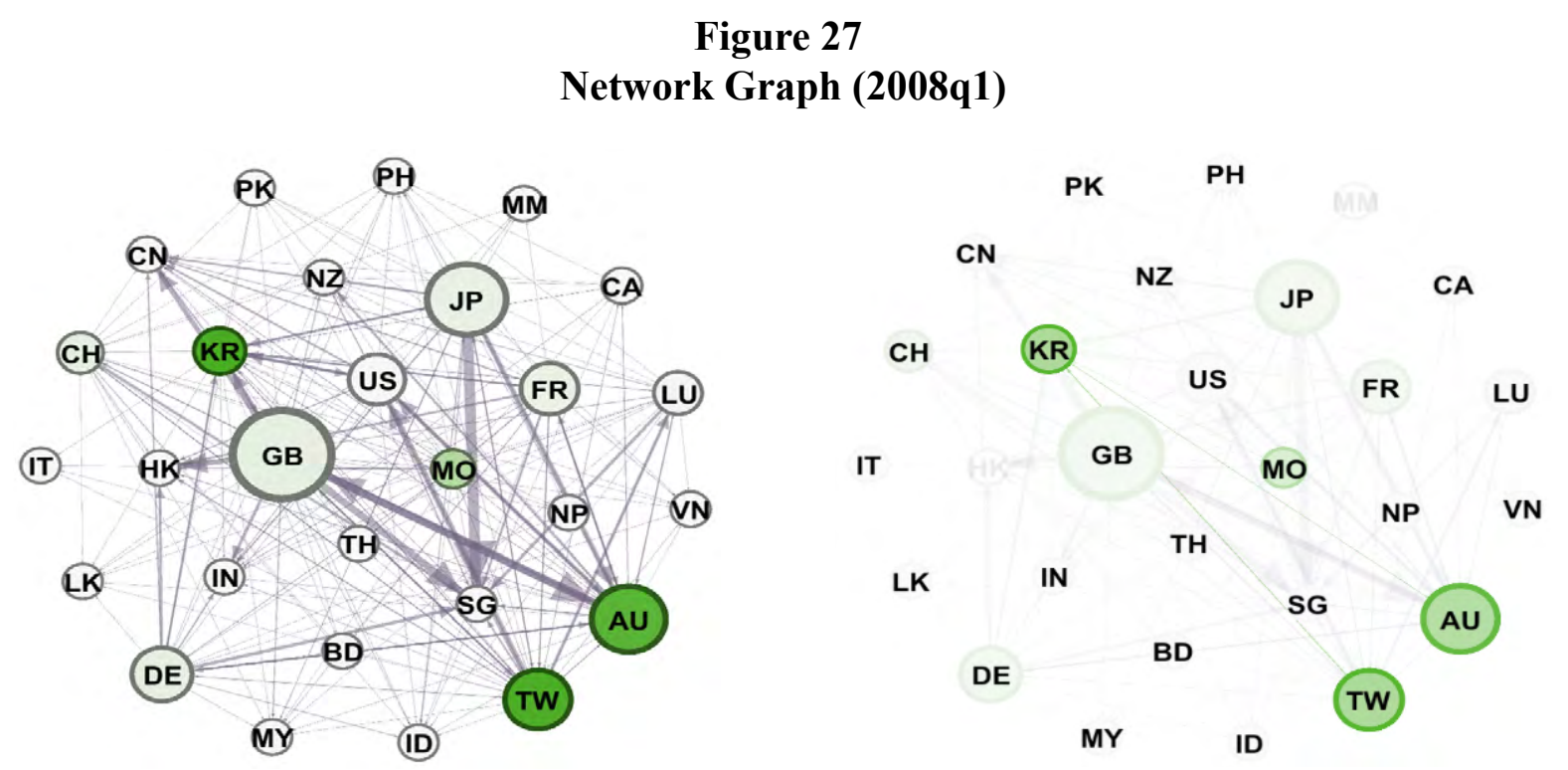

Notes: The node size indicates weighted out-degree, the colour of node betweenness connectivity, and the thickness of arrows the amount of bank flows. The right panel highlights the nodes that have bilateral link with Korea.

Sources: BIS Locational Banking Statistics.

In the aftermath of the crisis (2009q1), the size of foreign claims held by Korean banks dropped by $20 \%$. The US, the UK and China remained as major borrowers of Korean banks. However, Korean banks no longer held as much Japanese financial assets due to the prolonged recession in Japan. The proportion of Japanese assets out of total foreign assets owned by Korean banks dropped from $7 \%$ in 2008 to $2 \%$ in 2009. But they held more assets of Singapore, the financial hub for fast growing ASEAN countries. ${ }^{15}$ The Korean assets owned by other 11 countries plunged, a $55 \%$ decrease, especially by the US and European countries, such as the UK, Germany and France.

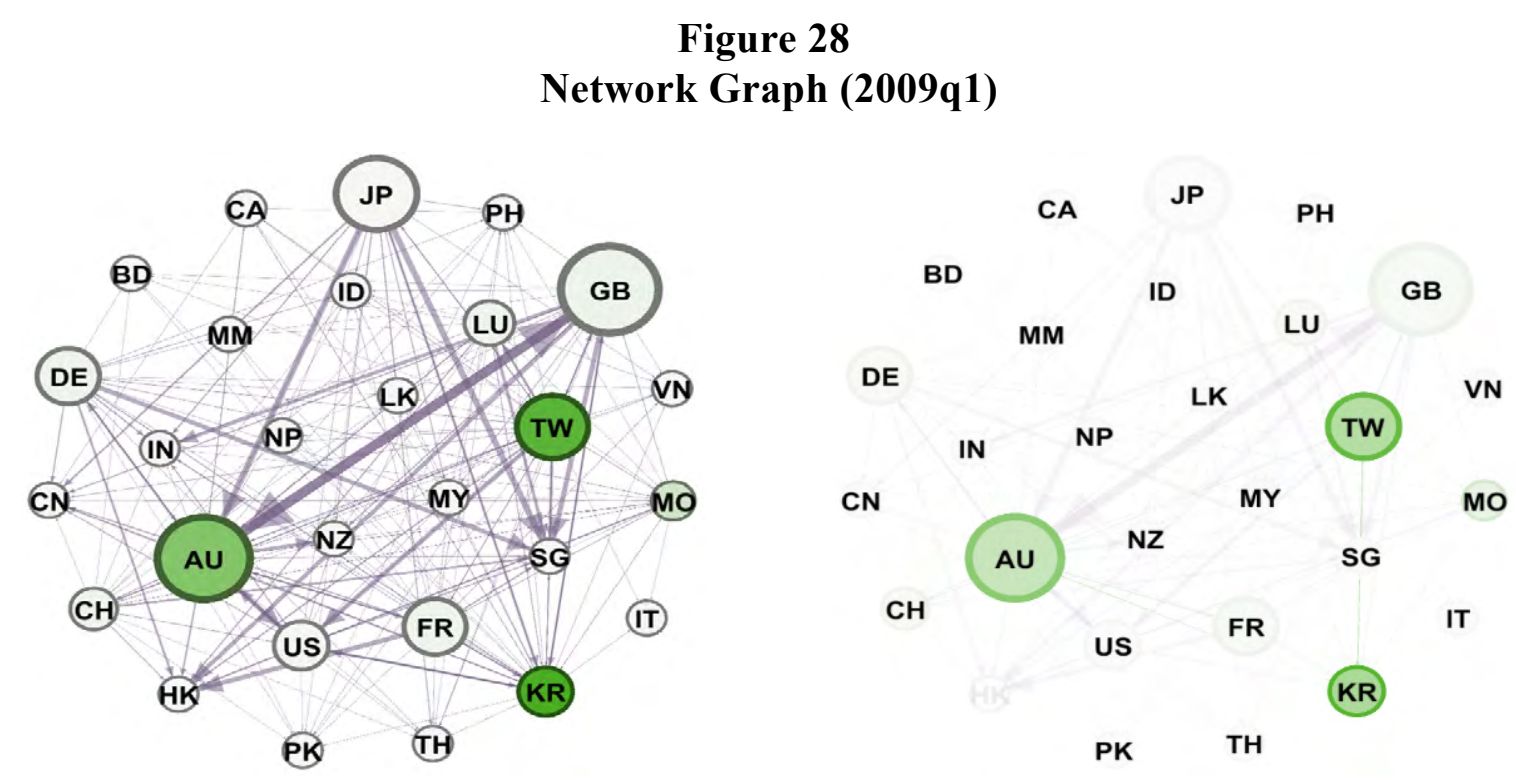

Notes: The node size indicates weighted out-degree, the colour of node betweenness connectivity, and the thickness of arrows the amount of bank flows. The right panel highlights the nodes that have bilateral link with Korea.

Sources: BIS Locational Banking Statistics.

15. The proportion of Singaporean assets to the total foreign assets increased from $5 \%$ to $7 \%$ in 2009 . 


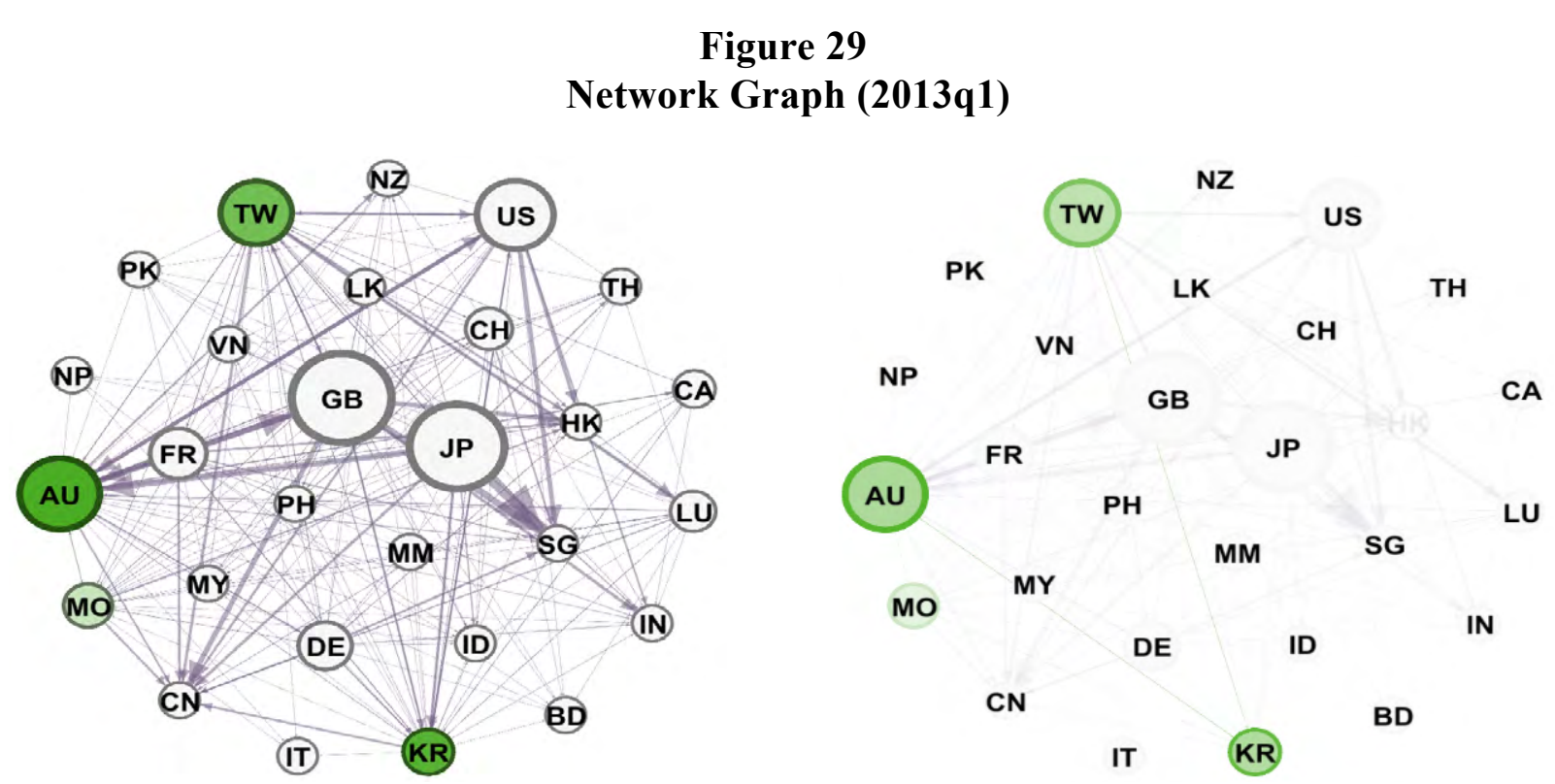

Notes: The node size indicates weighted out-degree, the colour of node betweenness connectivity, and the thickness of arrows the amount of bank flows. The right panel highlights the nodes that have bilateral link with Korea.

Sources: BIS Locational Banking Statistics.

There was a structural change in the banking network in 2013q1. While the foreign claims held by Korean banks showed a robust increase, Korean banks held more assets of China (the share of Chinese assets in total foreign assets of Korea is $41 \%$ ) and Indonesia (4\%). In contrast, the proportions of claims of the US (20\%) and the UK (5\%) declined. This implies that Korea became an important source of funding in the Asia-Pacific region. In terms of claims of Korea held by foreign banks, Japan, the UK, and the US are the main sources of Korean banks funding.

In 2015q1, we observe that Hong Kong appears as a major player of the network. This is because Hong Kong had started to report the LBS data since 2014q4. In addition, it may be affected by the launch of the Shanghai-Hong Kong Stock Connect in November 2014. The Stock Connect allows mainland Chinese investors to purchase equities that are listed in Hong Kong, and lets foreigners buy mainland Chinese stocks in a less restrictive manner. It opened the investment opportunities to China for wider investors.

Major borrowers of Korean banks include China (the proportion of its assets owned by Korean banks out of the total foreign assets amounts to $44 \%)$, the US (17\%), Indonesia (5\%), Singapore (5\%), and Vietnam (5\%). Countries with higher Korean asset holdings are Hong Kong, Japan, the US and the UK. 


\section{Figure 30 \\ Network Graph (2015q1)}
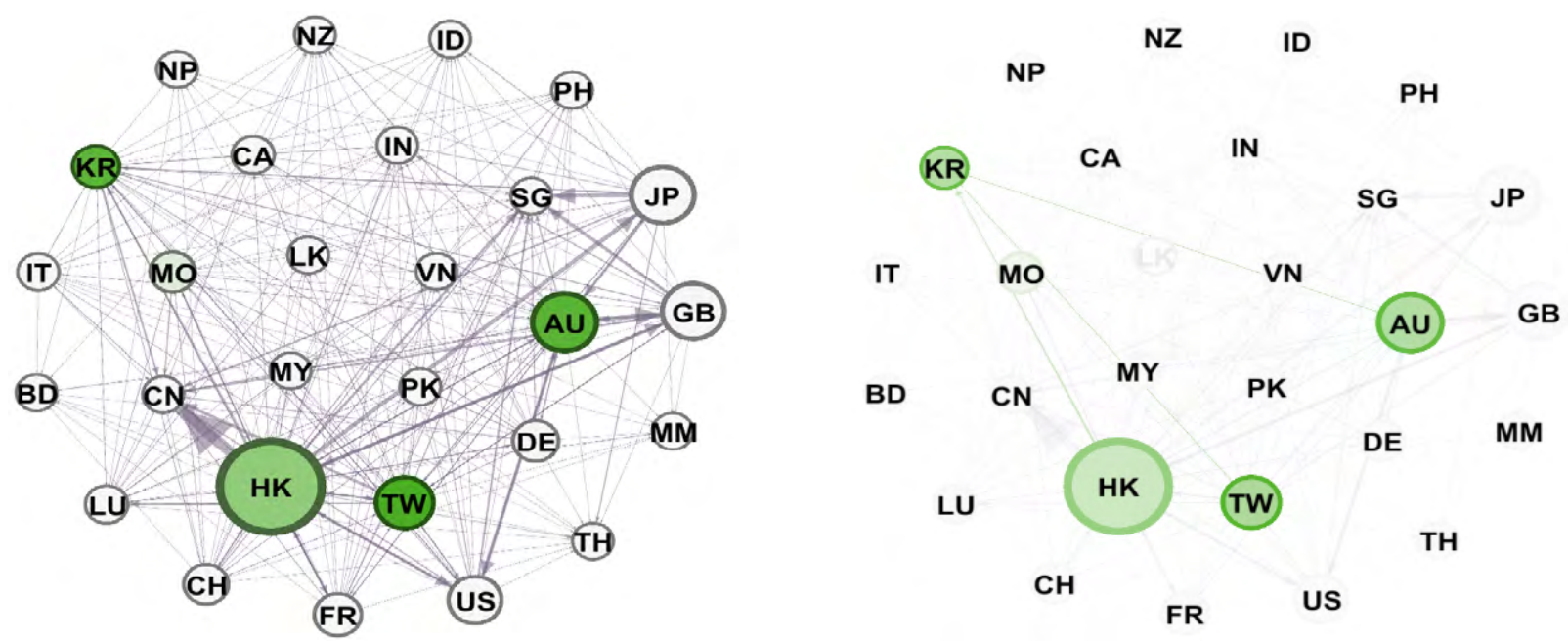

Notes: The node size indicates weighted out-degree, the colour of node betweenness connectivity, and the thickness of arrows the amount of bank flows. The right panel highlights the nodes that have bilateral link with Korea.

Sources: BIS Locational Banking Statistics.

The recent financial network graph (see Figure 31) shows somewhat similar structure as in the previous graph. Hong Kong remains as an important funding source of the region. The network has become denser and complex. As for Korea, borrowing to China has declined by $10 \%$, leading to a drop in the share of Chinese claims to total foreign claims from $44 \%$ to $32 \%$. This is due to the recent slowdown in the Chinese economy. Korean banks hold more US assets as the Fed has been normalising its policy rate.

Figure 31

\section{Network Graph (2018q1)}
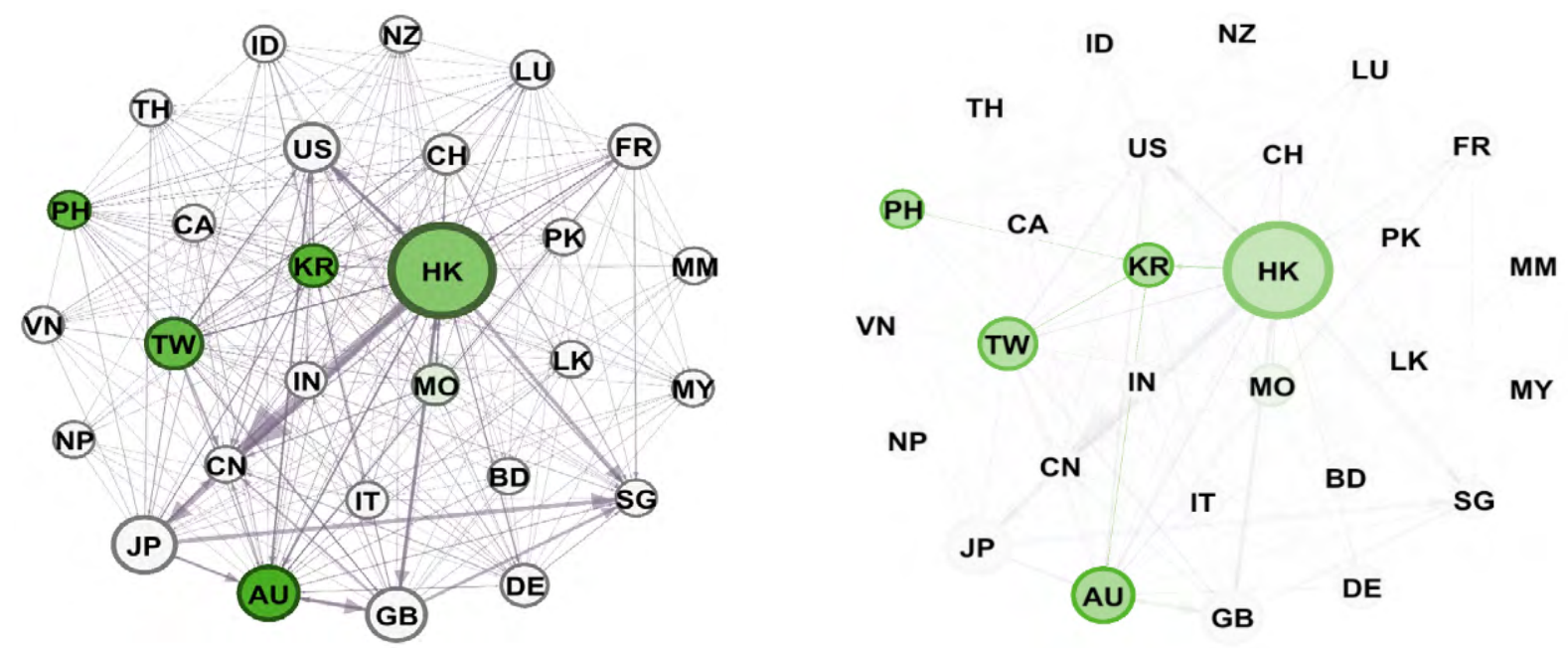

Notes: The node size indicates weighted out-degree, the colour of node betweenness connectivity, and the thickness of arrows the amount of bank flows. The right panel highlights the nodes that have bilateral link with Korea.

Sources: BIS Locational Banking Statistics. 
As for liabilities network structure, we summarise only some key features here (see the network graphs in the Appendix). From the network graphs from 1998 to 2004, we find that Korean residents had deposits in the banks of advanced economies, such as the US, the UK and Japan. In 2005q, South Korea started to report bilateral cross-border banking flows data to the BIS and both betweenness centrality and weighted out-degree increased. However, Korea had no links with some under-developed countries, like Sri Lanka and Nepal. Over time, the network has become more complex as in the claims network. Liabilities of Korean banks were distributed mainly in the US, the UK, China and Singapore as of the first quarter of 2018.

\section{Conclusions}

In this paper, we have shown that the financial network of cross-border banking activities in the Asia-Pacific region has become more complicated and interconnected. After the GFC, South Korea has been more active in serving as a financial intermediary for capital flows into and out of Asia and the Pacific: Korea is a net creditor to Asia-Pacific countries while being a net borrower from the advanced economies. This pattern of bank flows has been driven by several macroeconomic and financial factors. First, stronger growth in emerging Asia relative to the advanced economies attracted capital flows from the advanced countries and South Korea. While this trend continues, the recent economic slowdown in emerging Asia has slightly reduced the amount of capital flows to the region. Second, the advanced economies' monetary policies have significant implications on cross-border bank activities and their network. The search for yield in the low interest rate environment after the GFC was the main driver of international banking flows towards the region. Recently, the normalisation of the US monetary policy has changed the direction of capital flows to the US. Lastly, high demands for lending in emerging Asia have influenced the trend. However, this trend also can be reverted as lending in advanced economies recovers with robust economic growth.

Several key policy implications can be drawn from the analyses of financial network. Although the central banks and regulators of the region have implemented various regulatory measures to mitigate the systemic risks due to cross-border financial interconnectedness, there is still room for improvement. Authorities in the region need to be more cooperative to identify and monitor regionally active banks, common and concentrated creditors. Sharing information between home and host countries is crucial for establishing the ground for multilateral cooperation in banking regulation. Constructive dialogue with banks is another way to support financial stability. It is important for policymakers to consider the balance between the prudential objectives and efficiency in the banking sector. Effective communication with banks help regulators understand more about the functions and objectives of financial institutions as well as ensure commitment of banks to prudential measures. Finally, in order to ensure financial stability, in-depth research on financial network should be strongly supported by the central bankers and financial regulators in the region. In today's globally integrated world, it is essential to facilitate multilateral surveillance on economic and financial development. 


\section{References}

Battiston, S.; D. D. Gatti; M. Gallegati; B. Greenwald and J. E. Stiglitz, (2012) "Liaisons Dangereuses: Increasing Connectivity, Risk Sharing, and Systemic Risk," Journal of Economic Dynamics and Control, 36(8), pp. 1121-1141.

Bank of Korea, (2018), Financial Stability Report, June.

Bank for International Settlement, (2003), "Guide to the International Banking Statistics," BIS Paper, No 16, Available at: <https://www.bis.org/publ/bppdf/bispap16.htm>

Broner, F.; T. Didier; A. Erce and S. L. Schmukler, (2011), "Gross Capital Flows: Dynamics and Crises," The World Bank.

Caballero, J.; C. Candelaria and G. Hale, (2018), "Bank Linkages and International Trade,” Journal of International Economics, 115, pp. 30-47.

Committee on the Global Financial System, (2014), "Workshops on EME Banking Systems and Regional Finance Integration,” CGFS, Paper No. 51a, December.

Federal Reserve Bank of San Francisco, (2015) "Capital Flows Go into Reverse in Asia's Financial Hubs," October 8, Available at: <https://www.frbsf.org/banking/asia-program/pacificexchange-blog/capital-flows-reverse-in-asias-financial-hubs/>

Forbes, K. J. and F. E. Warnock, (2012), "Capital Flow Waves: Surges, Stops, Flight, and Retrenchment," Journal of International Economics, 88(2), pp. 235-251.

Jain-Chandra, S.; M. J. Kim; S. H. Park and J. Shin, (2013), "The Impact of Foreign Bank Deleveraging on Korea," No. 13-101, International Monetary Fund.

Milesi-Ferretti, G. M. and C. Tille, (2011), “The Great Retrenchment: International Capital Flows During the Global Financial Crisis,” Economic Policy, 26(66), pp. 289-346.

Minoiu, C. and J. A. Reyes, (2013), “A Network Analysis of Global Banking: 1978-2010,” Journal of Financial Stability, 9(2), pp. 168-184.

Remolona, E. M. and I. Shim, (2015), "The Rise of Regional Banking in Asia and the Pacific," BIS Quarterly Review, September. 


\section{Appendices}

\section{Appendix A: Network Graphs of Total Liabilities}

\section{Figure 32: Network Graph (1998q1)}

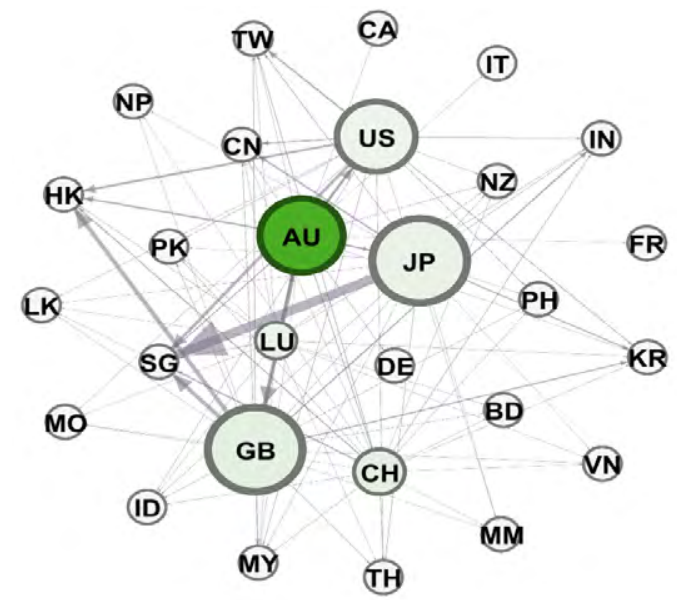

US

Figure 33: Network Graph (2000q1)
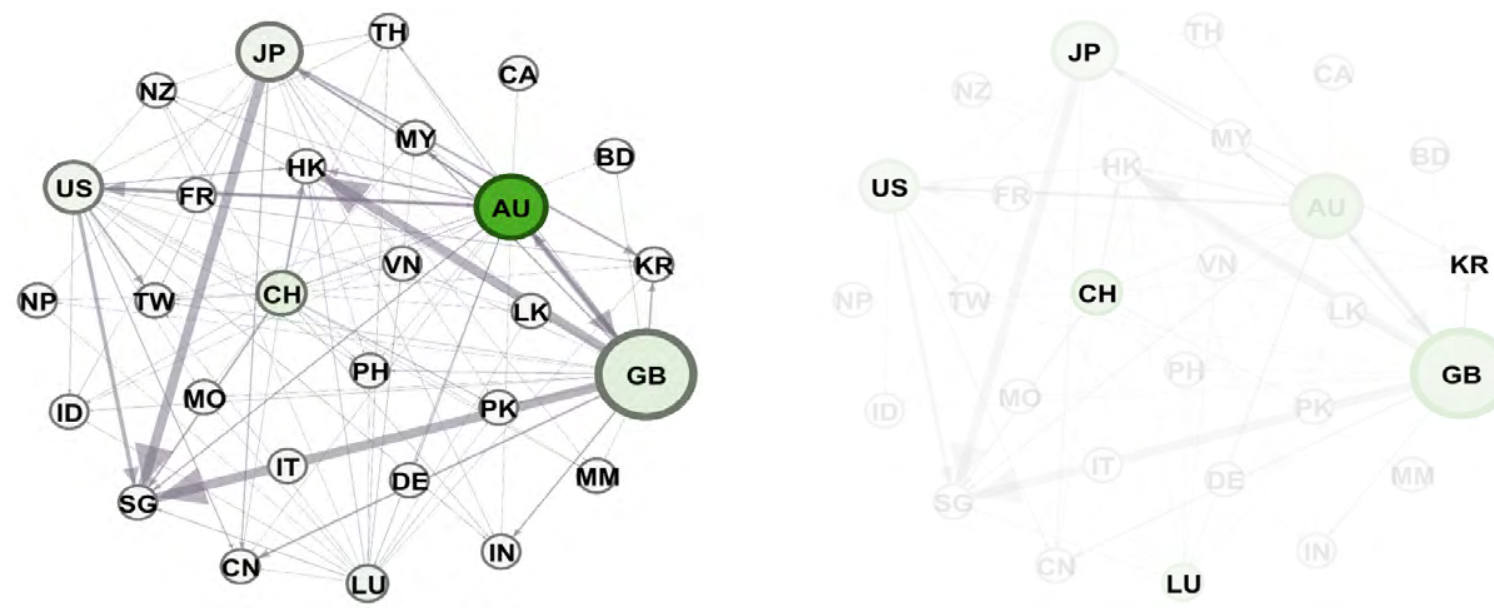

Figure 34: Network Graph (2005q1)
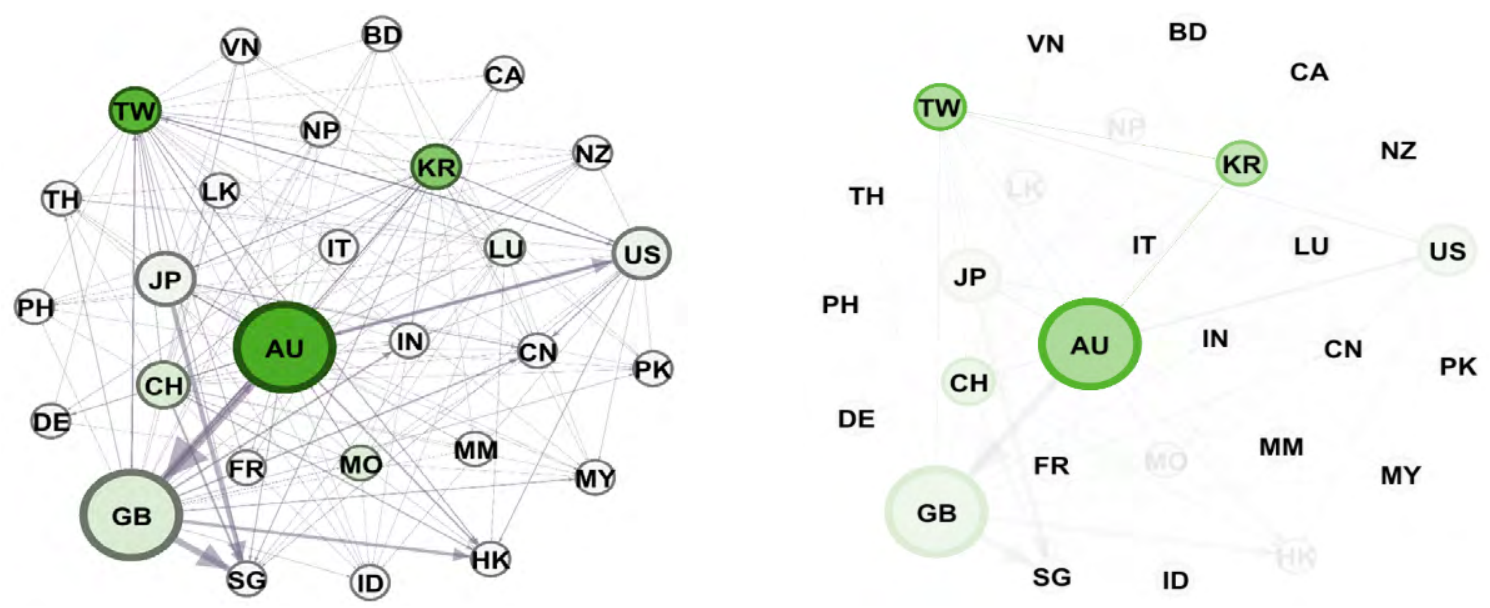

Notes: The node size indicates weighted out-degree, the colour of node betweenness connectivity, and the thickness of arrows the amount of bank flows. The right panel highlights the nodes that have bilateral link with Korea.

Sources: BIS Locational Banking Statistics 
Figure 35: Network Graph (2007q1)
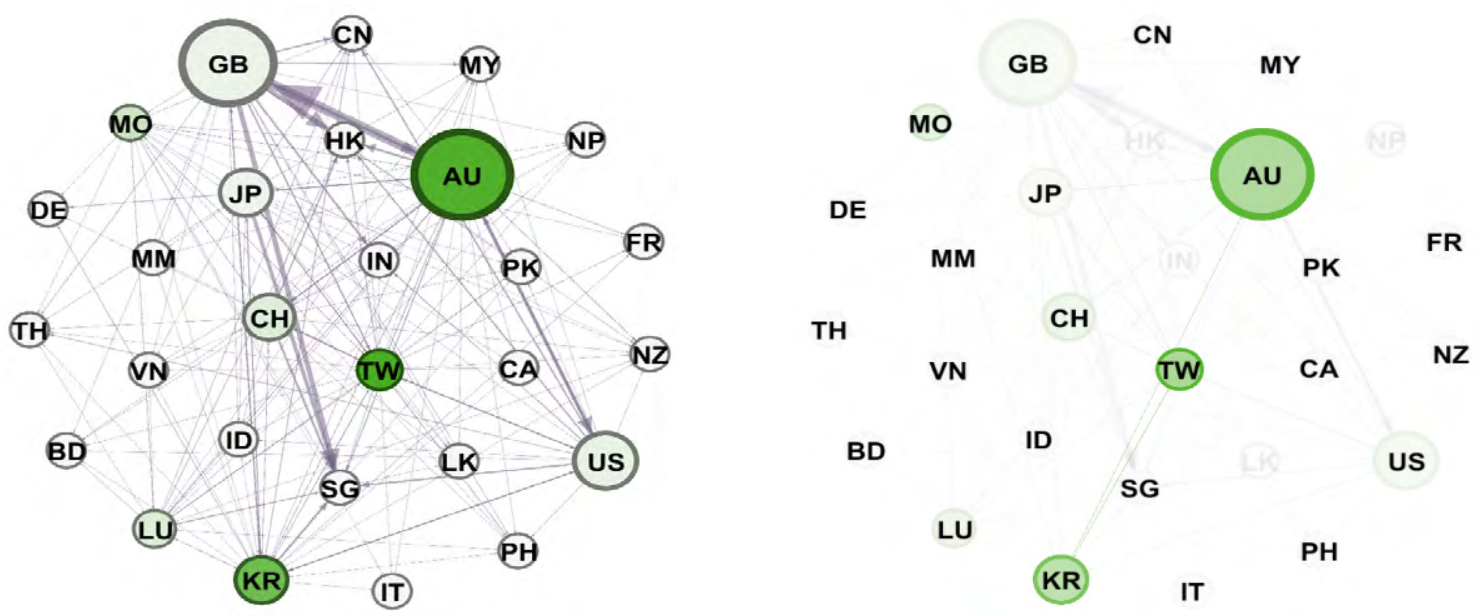

Figure 36: Network Graph (2008q1)
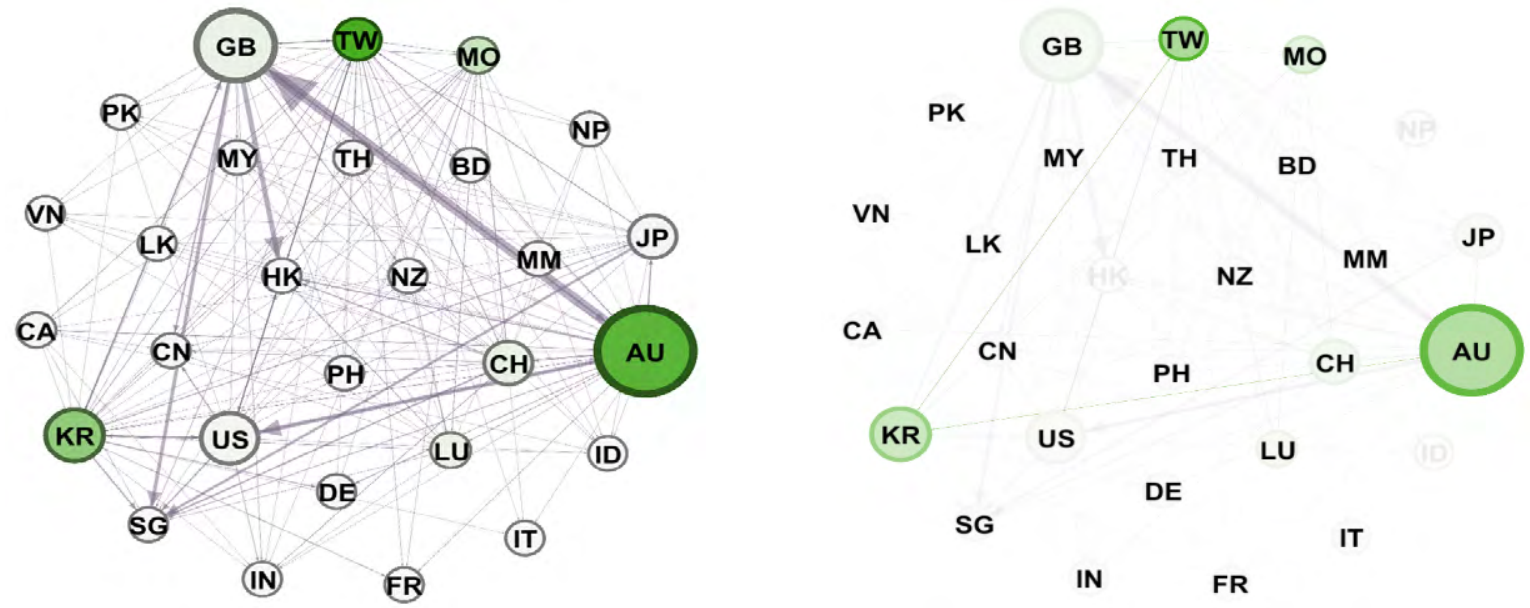

Figure 37: Network Graph (2009q1)
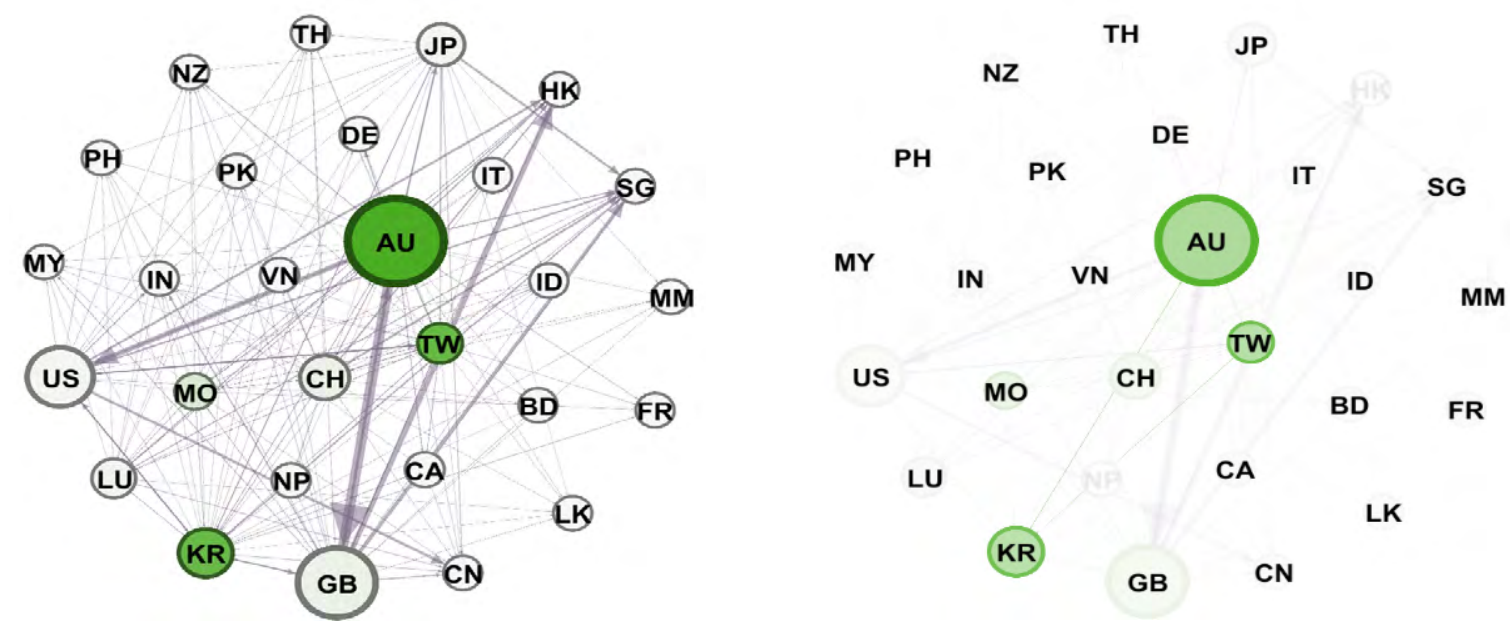

Notes: The node size indicates weighted out-degree, the colour of node betweenness connectivity, and the thickness of arrows the amount of bank flows. The right panel highlights the nodes that have bilateral link with Korea.

Sources: BIS Locational Banking Statistics. 
Figure 38: Network Graph (2013q1)
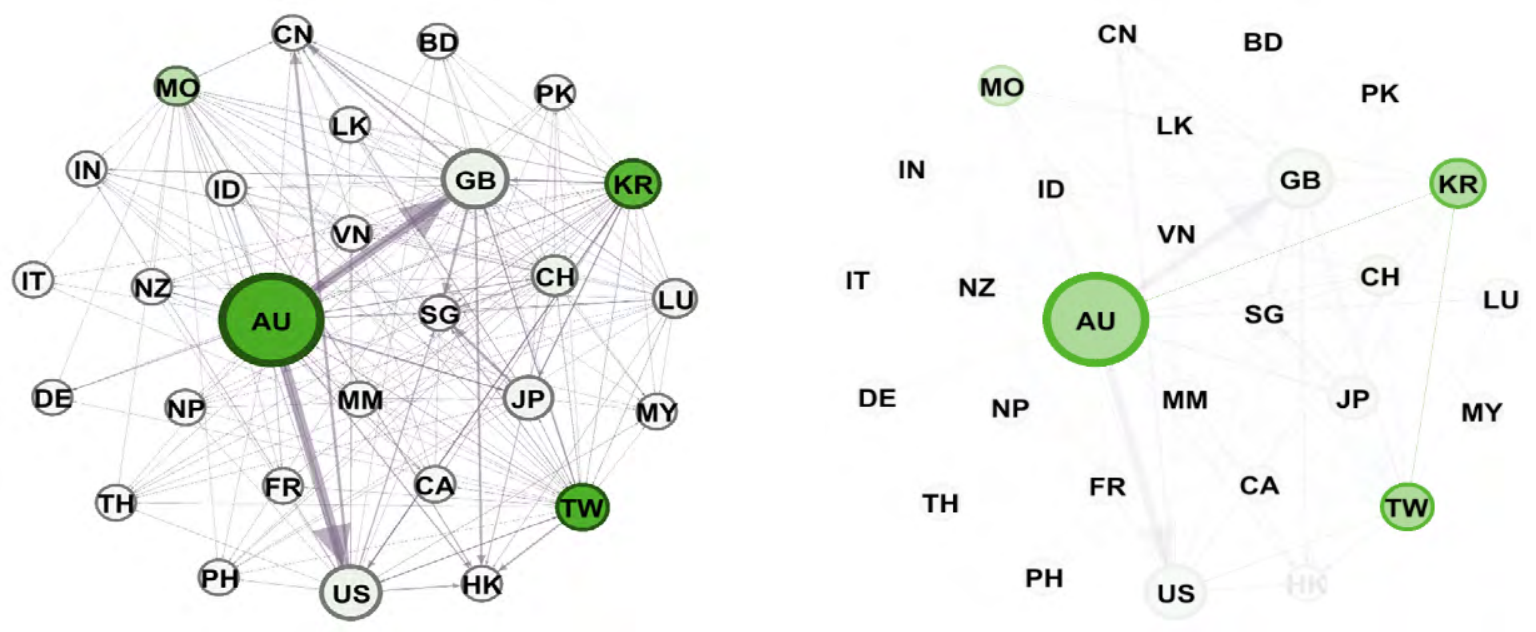

Figure 39: Network Graph (2015q1)
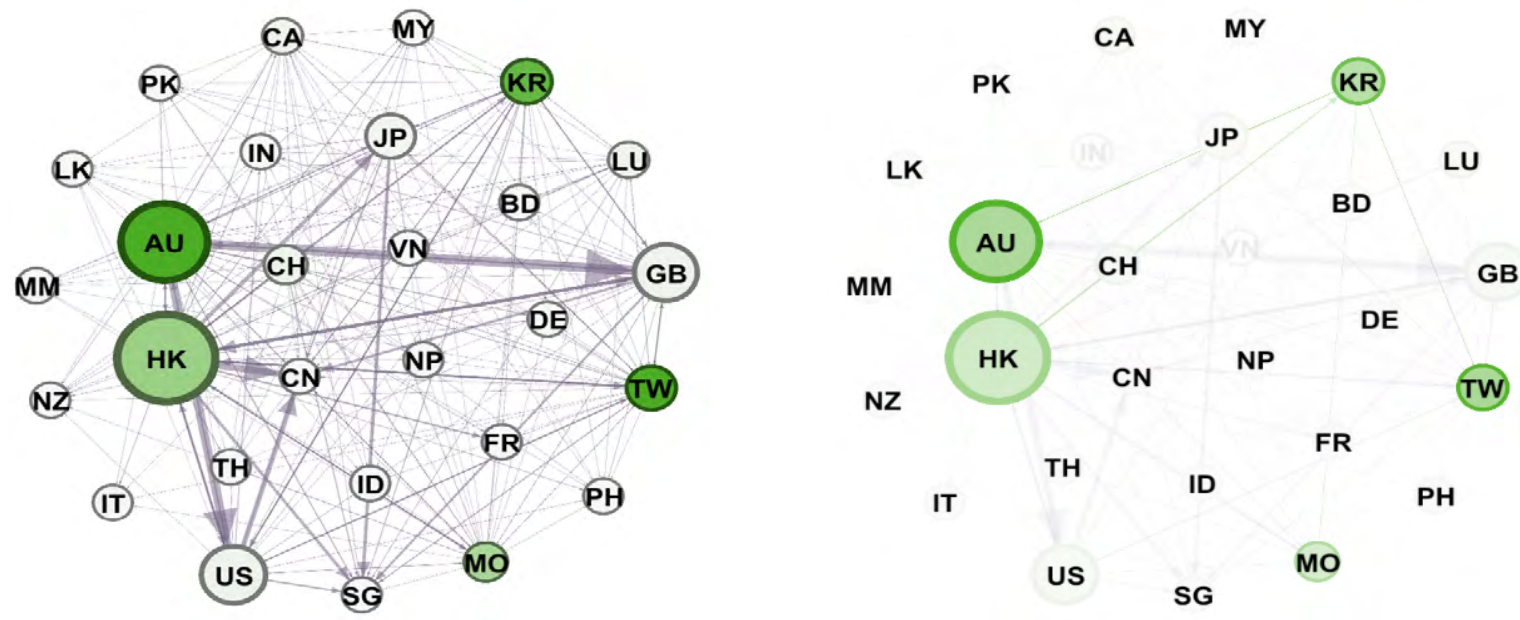

Figure 40: Network Graph (2018q1)
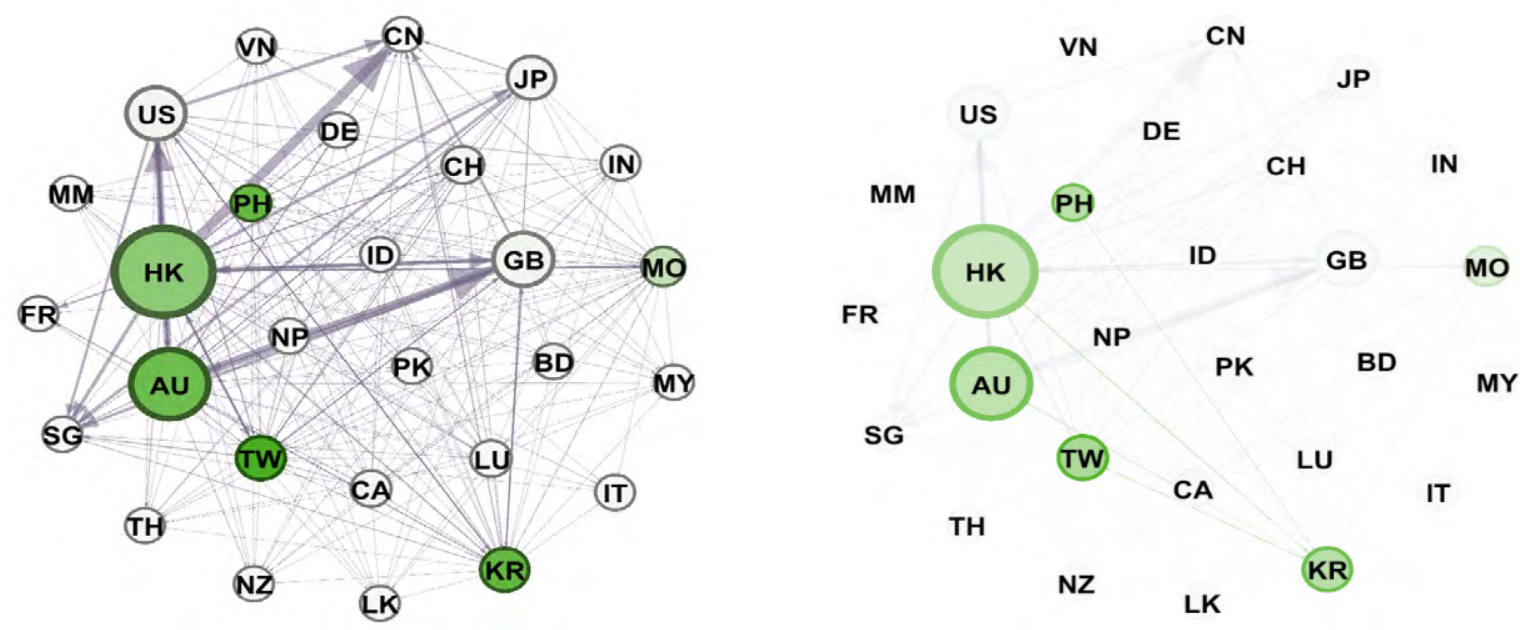

Notes: The node size indicates weighted out-degree, the colour of node betweenness connectivity, and the thickness of arrows the amount of bank flows. The right panel highlights the nodes that have bilateral link with Korea.

Sources: BIS Locational Banking Statistics. 


\title{
Chapter 6
}

\section{CROSS-BORDER INTERBANK CONTAGION RISK TO THE MALAYSIAN BANKING SYSTEM}

\author{
By \\ Harikumara Sababathy and Lim Sheng Ling ${ }^{1}$
}

\section{Introduction}

In recent times, more so after the Global Financial Crisis (GFC), regulatory authorities worldwide have taken a keen interest in being better able to assess risks of contagion events from occurring. This is because effects of financial contagion were one of the key features of the GFC as localised distress in specific segments of financial markets rapidly morphed into a crisis of global proportions. The OECD (2012) estimates that contagion shocks induced via bank balance-sheet interconnectedness, which had been an important driver of financial crises, reached unprecedented heights during the GFC. True enough, the extent and nature of international banking integration which contributed to an unprecedented transmission of financial instability, was one factor that made the recent financial crisis so deep and widespread.

While most global banks held back cross-border banking activity in the aftermath of GFC, banks in Asia Pacific stepped up, intensifying their cross-border activities particularly within the region, with financial centres such as Hong Kong SAR and Singapore playing important roles (Remolona and Shim, 2015). Notwithstanding the benefits, Remolona and Shim (2015) go on to highlight three potential sources of risks to financial stability caused by greater banking integration in Asia: (i) growing systemic importance ${ }^{2}$ of foreign banks in host jurisdictions, both as common and concentrated lenders within the region; (ii) high reliance on wholesale and derivative markets for foreign currency funding; and, (iii) shortening maturity of foreign currency borrowing.

There are several factors which makes the Malaysian banking system susceptible to potential financial instability induced by greater cross-border interconnectedness. First, the Malaysian banking system has one of the highest foreign bank participation among most Asian

1. The authors are Associate Analysts in the Financial Surveillance Department, Bank Negara Malaysia. The authors would like to thank Qaiser Iskandar Anwarudin, Hafiz Abu Samah, Syairah Hanin Shaharudin, Nik Ahmad Rusydan bin Nik Hafizi and the participants of the SEACEN Seminar on the Research Project on Cross-Border Interbank Contagion Risk Analysis for their invaluable feedback. The authors can be contacted via the following email addresses: harikumara@bnm.gov.my and sheng@bnm.gov.my

Disclaimer: This paper represents the views of the authors and may not necessarily be those of Bank Negara Malaysia (BNM) or BNM policy. The views expressed herein should therefore be attributed to the authors and not to BNM.

2. Refers to banks whose distress or failure may result in severe negative spillover impact to the financial system and real economy. At the global stage, the Financial Stability Board and Basel Committee of Banking Supervision assess and identify banks that are deemed to be systemically important on an annual basis, referred to as global systemically important banks (G-SIB). Similarly, national authorities identify banks that are systemically important in their respective jurisdiction, commonly referred to as domestic systemically important banks (D-SIB). 
peer jurisdictions, with foreign banks accounting for $19.8 \%$ of total domestic banking system assets as at end-2017. Second, Malaysian banks' cross-border exposures, particularly in the form of short-term borrowings, has increased rapidly in recent times in tandem with growth of domestic banking groups in the regional markets and strong domestic presence of foreign banks. Since 2008, Malaysian banks' external debt almost tripled to RM316.8 billion or $23.4 \%$ of GDP as at end-2017. Third, Malaysian banking system is both concentrated and large compared to the domestic economy; with top five largest banking groups by asset size, which also has significant cross-border presence, accounting for $70 \%$ of total banking system assets and $231 \%$ of Malaysian GDP as at end-2017.

Against this backdrop, a comprehensive and reasonably accurate assessment of cross-border contagion risks is crucial to ensure financial stability. Our contributions in this paper are twofold, we utilise network analysis and counterfactual simulation to show that (i) interconnectivity within the interbank market and (ii) solvency contagion risks of Malaysian banks have declined between 2013 and 2017. In this paper, we build on the assessment conducted by Bank Negara Malaysia (2013) on cross-border contagion risk by (i) conducting an in-depth study of the dynamics of Malaysian banks cross-border and domestic interbank exposures and (ii) incorporating two indirect channels of contagion in the counterfactual simulation, namely valuation losses due to common asset exposures and mark-to-market losses resulting from credit quality deterioration or a loss of confidence. To the best of our knowledge, this is the first paper to illustrate the evolution of the domestic and cross-border interbank network in Malaysia over a time period.

The rest of the paper is organised as follows: in Section 2 we will discuss the related literature on network theory and counterfactual simulations to assess contagion risk; in Section 3 we will provide an overview of the Malaysian banking system and banks' external exposures; in Section 4 we describe the data and introduce the methodology used in Section 5; in section 6 we present our results; while in Section 7 we draw some conclusions and outline possible policy implications of our work.

\section{Literature Review}

There are two main strands of literature related to our work. The first discusses the use of network analysis to assess contagion risk while the second deals with the use of counterfactual simulation to quantify the impact of contagion risk.

\subsection{Network Analysis}

Network analysis has been increasingly recognised as a powerful surveillance tool for modelling the interconnectedness of the banking system network, although not widely employed due to data limitations. Hattori and Suda (2007) explored the 'core-periphery' network of crossborder bank exposures for 215 countries using the Bank for International Settlement (BIS) locational banking statistics data for the period 1985-2006. They found that the network has become more tightly connected with higher average degree, higher clustering coefficient and shorter average path length over time. In addition, network features remain largely undisrupted by any disturbances or crises in the international financial markets. Although systemic risk build-up is inevitable, financial markets are allocating capital and risk more efficiently. 
Using similar dataset, Minoiu and Reyes (2011) analysed interconnectivity of the global banking network for 184 countries over 1984-2009. They enhanced existing literatures on network study through the use of cross-border flows data to reflect liquidity conditions and applied the weighted degree approach to capture the heterogeneity in cross-border exposures. The authors posited that network density tends to expand and contract in line with the cycle of capital flows. Furthermore, country centrality decreases during and after banking and sovereign debt crises, with the GFC standing out as an unusually large disruption to the global banking network, contradictory to findings from Hattori and Suda (2007).

Utilising data on bilateral cross-border exposures between 1980 to 2005 for 18 advanced and emerging economies, Kubelec and Sa (2010) found increasing financial interconnectivity over time. The global financial network is clustered among few key nodes with large financial links and lower average path length over time, focusing around the United States and United Kingdom as its central hubs. Due to its robust yet fragile network structure, disturbances to the key hubs would transmit shocks rapidly and widely throughout the network. Comparison with the trade network shows similar increase in interconnectivity over time. Nonetheless, the trade network exhibits strong intracontinental links, concentrating around three clusters, the European cluster (centred on Germany), American cluster (centred on United States) and Asian cluster (centred on China).

\subsection{Counterfactual Simulations}

Whilenetworkanalysishas aided ourunderstanding onrisksposedbygreaterinterconnectedness, actual occurrences of default cascade events (referring to instances of a bank's default impacting or inducing default of other banks via direct balance sheet linkages or indirect linkages such as precipitation of bank run following loss of confidence) remained rare even during the height of GFC, largely due to widespread regulatory intervention. This has led to the lack of reliable empirical evidence, which allows for reasonably accurate estimation of such risks and impact to the financial system and economy upon materialisation of such events. Against this backdrop, counterfactual simulations have emerged as an important approach to assess the likelihood of contagion occurring (Upper, 2011; Elsinger, Lehar and Summer, 2012). Such simulations are increasingly being used by regulators either on a stand-alone basis to assess resilience of a particular financial system or as part of broader macroeconomic stress testing approaches, for example the Bank of England's RAMSI (Burrows et al., 2012).

Upper (2011), which provides an excellent summary of counterfactual simulation studies of the bank-driven contagion, specifically via the interbank market channel, found two major shortcomings in the reviewed literature: (i) an exaggerated focus involving the idiosyncratic failure of an individual bank in constructing shock scenarios and (ii) the general neglect of mechanisms that extends beyond direct balance-sheet linkages. Such mechanisms like the amplification of losses by behaviour and asset pricing, which can be significant during crisis periods ${ }^{3}$, can lead to misleading conclusion that contagion risk is small. Therefore, it was not surprising that the early literature on counterfactual simulations using interbank exposures established the following two premises: (i) contagion of insolvency due to interbank exposures are rare and (ii) it is difficult to create realistic scenarios that will induce significant amount of contagion (Summer, 2013). Much recent literature, however, has emphasised the importance of

3. BCBS (2018) estimates that mark-to-market losses from credit quality deterioration exceeded losses incurred from outright defaults during the GFC. 
considering other contagion channels in constructing counterfactual simulations. Glasserman and Young (2015) highlights the importance of mechanisms which goes beyond simple spillover effects (referring to default cascade approaches) to magnify shocks such as (i) bankruptcy costs and (ii) valuation losses resulting from deterioration of counterparty creditworthiness or a loss of confidence. In particular, they found that loss of confidence can lead to widespread losses of value - with their analysis suggesting this channel of contagion is likely to be more important than simple spillover effects.

Put differently, a possible explanation for the general neglect of other forms of contagion mechanisms could have been the reliance on default cascades to propagate distress within networks i.e. distress within the network is only induced upon the failure of a bank in response to either a common shock or idiosyncratic events, a rather common feature across early counterfactual simulation (refer to Upper, 2011; Elsinger, Lehar and Summer, 2012; Glasserman and Young, 2015). Beyond being an unrealistic assumption considering how recent financial crises events have proven $^{4}$, default cascade approach turned out to be problematic as it was difficult to induce contagion having bank defaults as a precondition, limiting the usefulness of such simulation studies. For example, given banks are typically subjected to single counterparty exposure limits which typically falls well below banks' total capital, a simulation study with shock scenario involving a single defaulting bank would neither be sufficient to induce other banks' default nor induce widespread contagion. To induce meaningful contagion in such studies, one has to create a shock scenario with simultaneous instances of bank defaults within the financial system, which are both rare and again, unrealistic in actuality.

In this regard, development of DebtRank methodology motivated by work on distance to default, which enabled propagation of distress within network without assuming defaults (Battiston et al., 2012) gained prominence as a method to estimate the impact of shocks within financial networks (Aoyama et. al., 2013; Tabak et al. 2013; Bardoscia et al., 2015; Fink et al., 2016; Bardoscia et al., 2017). Of significance, DebtRank methodology using relative loss of bank equity within a network as a measure of distress, enabled the propagation of distress induced by valuation losses within networks following deterioration of counterparty creditworthiness or a loss of confidence to be incorporated in simulation studies. Consistent with this, the impact of shocks measured using DebtRank is typically larger than the traditional default cascade approach given the ability to induce further losses within the network. Battiston et al. (2015), which incorporated DebtRank to carry out a stress-test exercise on interbank exposures of 183 listed European banks over the years 20082013 found that the second-round and third-round effects of distress dominate first-round effects, further underscoring the importance of taking into account other contagion channels/mechanism in counterfactual simulation. The original DebtRank assumed that (distress and thus) losses are propagated linearly between connected bank. This assumption was subsequently relaxed in later studies (Bardoscia et al., 2016; Bardoscia et al., 2017) to introduce other non-linear propagation functions.

4. For instance, the onset of Global Financial Crisis and ensued contagion were largely driven by sudden and pervasive averseness following a general loss in confidence as opposed to widespread defaults. 


\section{Malaysian Banking System}

The Malaysian banking sector is well-developed and diversified, with a wide range of domestic and foreign financial institutions. At the end-2017, the banking system comprises 27 commercial banks ( 8 domestic and 19 foreign), 16 Islamic banks (10 domestic and 6 foreign) and 11 investment banks, with total assets worth approximately RM2.5 trillion, or close to $200 \%$ of GDP (Chart 1). Commercial banks are the largest providers of funds, performing retail banking services, including acceptance of deposits, supplying loans and providing payment and remittance services. Islamic banks conduct a similar range of banking activities based on Shariah principles. Meanwhile, investment banks are responsible as financial intermediary for capital market activities such as dealing in securities, raising capital and security underwriting besides providing corporate advisory services. In terms of financing, the banking system has about RM1.6 trillion in outstanding loans, equivalent to over $117 \%$ of GDP as at end- 2017 .

\section{Chart 1}

\section{Composition of Assets, Financing and Deposits Accepted for the Banking System}

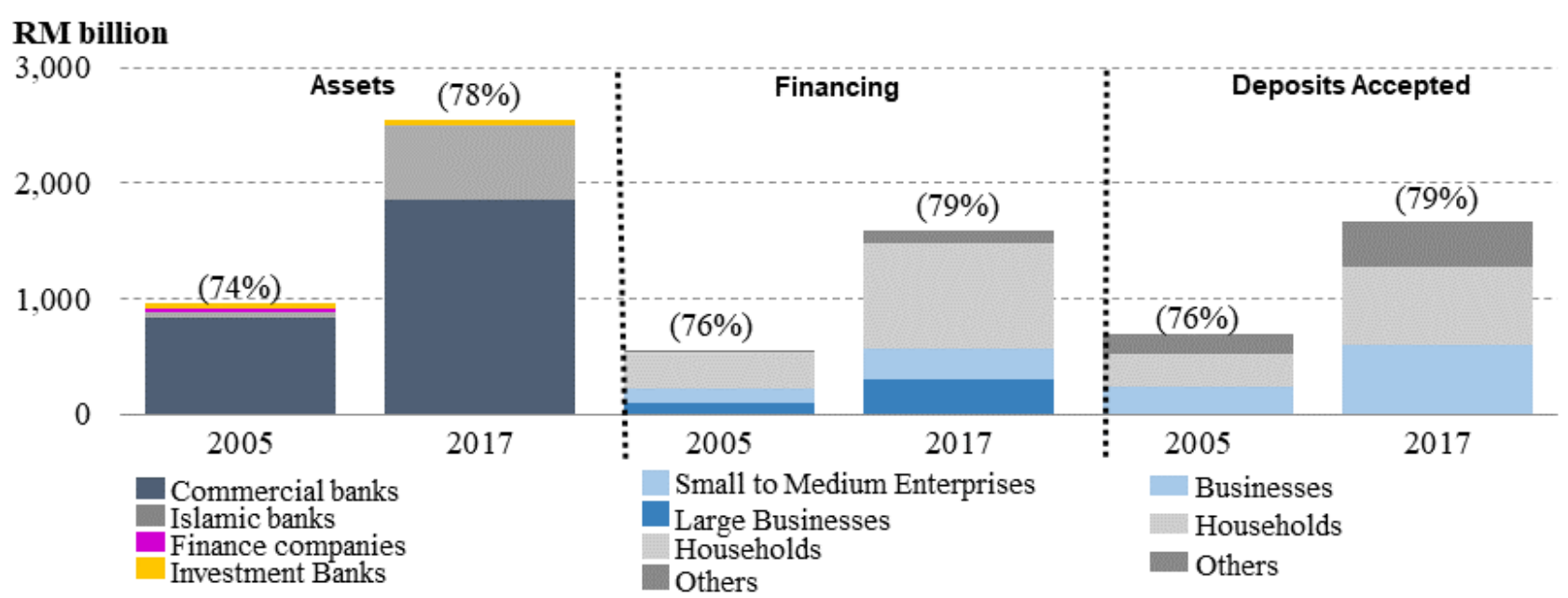

Note: Figures in parentheses refer to market share of domestic banks relative to banking system.

Source: Bank Negara Malaysia

Considerable efforts have been undertaken to strengthen the resilience of the banking system over the last decade, particularly in the aftermath of the Asian Financial Crisis. Realising the needs for stronger and larger domestic financial institutions, an industry-wide restructuring and consolidation programme was introduced by BNM in 1999. This has successfully reduced fragmentation and transformed the banking industry to better equip them with enhanced capacity to serve the domestic economy. The 77 domestic banking institutions that existed in the 1980s have merged to form 8 main domestic banking groups (Chart 2) under the consolidation programme. As highlighted in the introduction, the top five largest domestic commercial banks in Malaysia now account for $70 \%$ of total of total banking system assets. 5 out of 8 domestic banking groups have also expanded regionally and emerged as key players within the ASEAN region. 


\section{Chart 2}

Consolidation of the Financial Sector

1980s

2017

77 domestic banking institutions

29 domestic banking institutions

1986

\section{$22 \quad 16$ Commercial banks} $42 \quad 5$ Finance companies

0 Islamic banks

120 Investment banks

0 20

\section{7}

819 Commercial banks

00 Finance companies

106 Islamic banks

110 Investment banks

11 (1)

$80 \quad 0$
$20 \quad 40$
60

80

Source: Bank Negara Malaysia.

Although banks in advanced economies faltered during the GFC - with some ending in bankruptcy - the Malaysian banking system remained resilient with sound profitability levels and ample capital buffers to absorb shocks in the event of future stressed events. As at end-2017, the capital ratios of all banks were well above the regulatory minima. More than $75 \%$ of capital are in the form of highest quality loss-absorbing instruments, which includes equity, retained earnings and reserves, allowing banks to withstand macroeconomic and financial shocks without adversely affecting financial intermediation. A series of macroprudential measures implemented since 2010 and strengthened risk management practices of banks also further mitigated potential risks by reducing banks' exposures to over-leveraged households (Bank Negara Malaysia, 2017), thus improving the asset quality of banks to a low of $1.1 \%$. Liquidity Coverage Ratio (LCR) requirements have been phased in since June 2015 for the banking institution as part of the Basel III reform package, which required all banks to maintain sufficient high-quality liquid assets at a minimum of $100 \%{ }^{5}$ of total projected net cash outflows for the next 30 days. Banks have all transitioned smoothly to this requirement.

Table 1

\section{Key Financial Indicators of Banks}

\begin{tabular}{l|c|c}
\hline \multicolumn{1}{|c|}{ Banking System } & $\mathbf{2 0 0 0}$ & $\mathbf{2 0 1 7}$ \\
\hline $\begin{array}{l}\text { Capitalisation } \\
\text { Risk-Weighted Capital Ratio/Total } \\
\text { Capital Ratio (\%) }\end{array}$ & 12.4 & 17.8 \\
\hline $\begin{array}{l}\text { Asset Quality } \\
\text { Net NPL Ratio (\%) }\end{array}$ & 9.9 & 1.1 \\
\hline $\begin{array}{l}\text { Profitability } \\
\text { ROA (\%) }\end{array}$ & 1.5 & 1.5 \\
ROE (\%) & 19.5 & 13.1 \\
\hline $\begin{array}{l}\text { Liquidity } \\
\text { Liquidity Coverage Ratio (\%) }\end{array}$ & - & 134.9 \\
\hline
\end{tabular}

Source: Bank Negara Malaysia.

5. The LCR requirement was phased-in from June 2015, with an initial transitional requirement of $60 \%$. Full compliance of $100 \%$ requirement is in effect starting 1 January 2019. 
The nature and extent of financial linkages of Malaysian banking system has evolved and increased steadily since the GFC. While total external exposures ${ }^{6}$ of Malaysian banks remain low, on aggregate accounting for only $10.2 \%$ and $17.2 \%$ of the total assets and funding of the banking system in 2017 respectively, banks' claims on, and liabilities obligations to, non-resident counterparties grew at a compounded annual growth rate (CAGR) of $11.9 \%$ and $12.2 \%$ since 2008 (Chart 3). The rapid expansion Malaysian banks' external exposures is driven by the following: (i) the sizeable presence of foreign banks in Malaysia (Chart 4), including operations in Labuan International Banking and Financial Centre (LIBFC) ${ }^{7}$ and (ii) regionalisation of domestic banks, particularly in ASEAN region (Chart 5). In line with this, bulk of the external exposures are in the form of (i) intra-group transactions between banks and related offices ${ }^{8}$ abroad in the form of interbank placements and borrowings and capital funds, (ii) deposits accepted from non-residents, and (iii) loans extended to non-resident counterparties.

\section{Chart 3 \\ Banking System External Exposures}

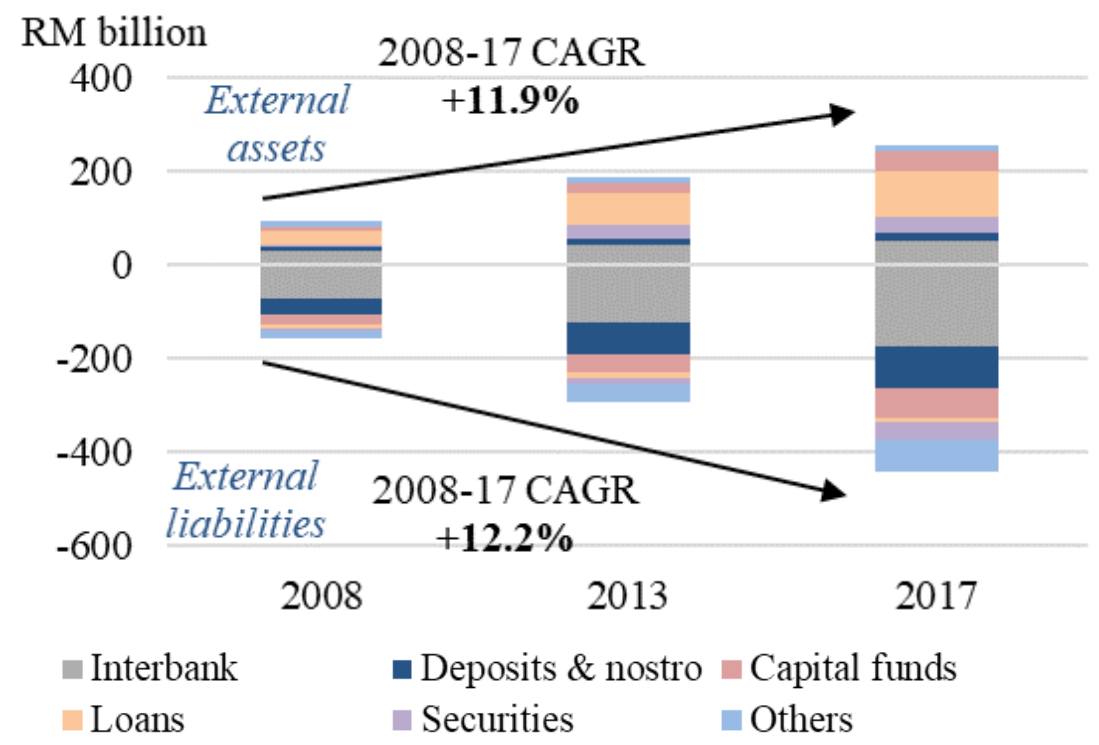

Source: Bank Negara Malaysia.

6. We shall be using the term 'external exposures' and 'cross-border exposures' interchangeably in this paper. Both refer to banks' exposures vis-à-vis non-resident counterparties.

7. LIBFC, established in 1990 is an offshore financial centre, which offers tax incentives for financial and capital market activities. In lieu of this, LIBFC banks' role as a booking centre is prominent, as onshore banks, primarily domestic banking groups, conduct their FCY intermediation activities via their Labuan offices. We shall be using the terminology LIBFC and Labuan interchangeably in this paper.

8. For foreign banks, related offices refer to overseas parent and regional offices. For domestic banks, related offices refer to overseas subsidiaries and branch operations. 


\section{Chart 4}

External Debt of Banks/GDP vs Foreign

Banks Market Share in Banking System

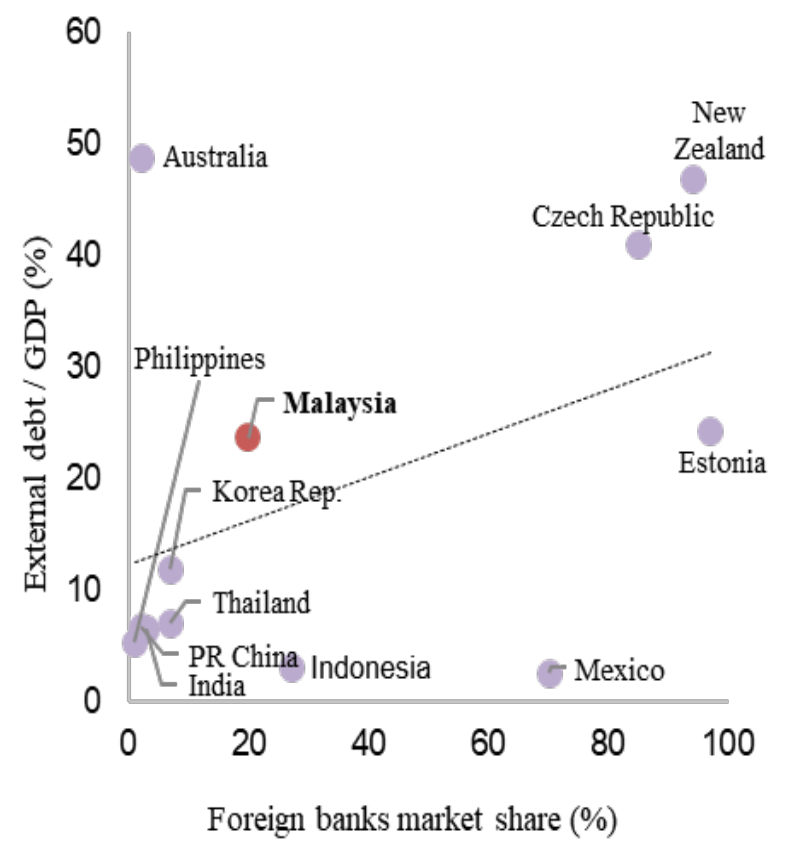

Note: Foreign bank market share data refers to proportion of total banking sector assets held by foreign banks.

Source: Global Financial Development Database, Bank Negara Malaysia, Haver Analytics, Bloomberg, IMF World Economic Outlook.

\section{Chart 5}

Total Foreign Claims of Domestic Banks

(\% of GDP)

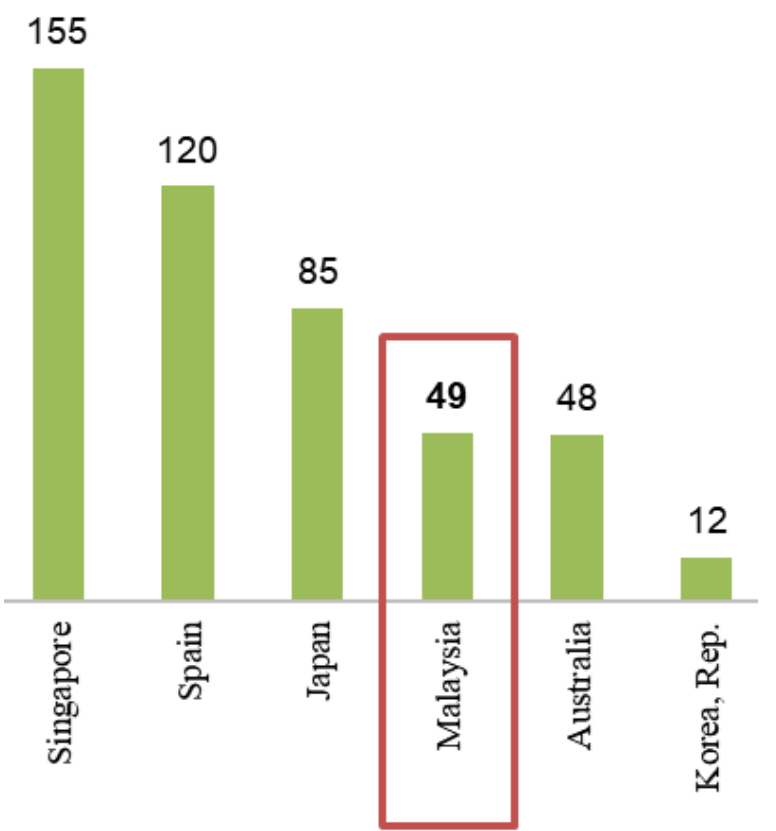

Note: Refers to total foreign claims of domestic banks in all currencies. Data as at end-3Q 2018.

Source: BIS International Banking Statistics, Bank Negara Malaysia, Haver Analytics, Bloomberg, IMF World Economic Outlook.

Of Malaysian banks' external exposures in 2017 (Chart 6):

i) $48 \%$ and $31 \%$ of external assets and liabilities were attributed to domestic banking groups (DBGs), with significant regional presence. Bulk of the exposures relates to centralised liquidity management practices ${ }^{9}$ of DBGs. For DBGs, liquidity is typically managed at the head office to manage maturity and currency mismatches across the group operations. Excess liquidity from related offices along with FCY funding raised in international capital markets as part of the broader funding diversification strategy are redistributed back to related offices.

ii) $35 \%$ and $30 \%$ of external assets and liabilities were attributed to LIBFC banks. External exposures of LIBFC banks predominantly reflect placements by related entities to fund foreign currency (FCY) intermediation activities. Such reliance on funding from related offices is expected for offshore banks, which typically operates as a branch and has limited alternative funding sources.

iii) $17 \%$ and $39 \%$ of external assets and liabilities were attributed to locally-incorporated foreign banks (LIFBs). LIFBs typically leverage on the stronger credit rating of internationally-active parent banks to source cheaper FCY funding. These are primarily channelled towards FCY lending in the domestic interbank market, short-term investments and to manage maturity mismatches in their FCY loan portfolio.

9. For further information on centralised liquidity management practices of Malaysian banks, refer to Chapter 1 of Financial Stability and Payment Systems Report 2017. 


\section{Chart 6}

Breakdown of Banking System External Exposures in 2017 by Banks

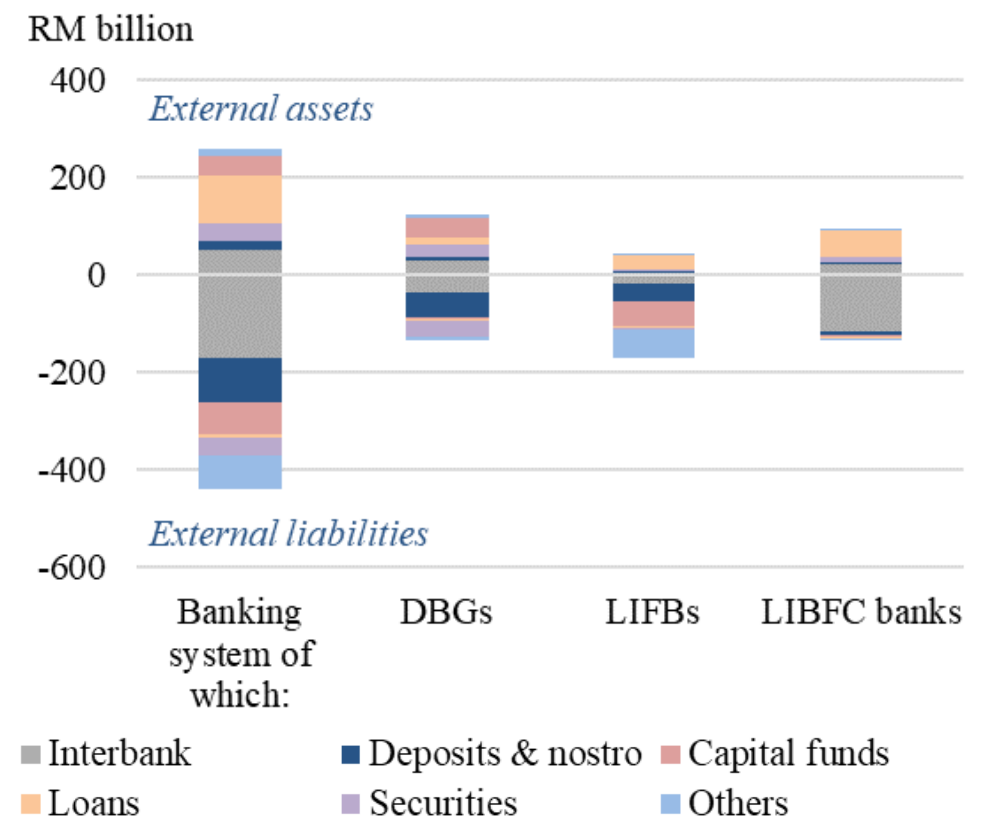

Source: Bank Negara Malaysia.

Consequently, from a geographical standpoint, Malaysian banks' external exposures are with counterparties situated in (i) regional financial centres, (ii) countries where Malaysian banks have overseas operations, and (iii) countries with internationally active banks, particularly those with locally-incorporated subsidiaries in Malaysia, with significant concentration observed to Asian region (62\% and $73 \%$ of cross-border assets and liabilities in 2017) (Charts 7 and 8).

\section{Chart 7}

External Assets by Location

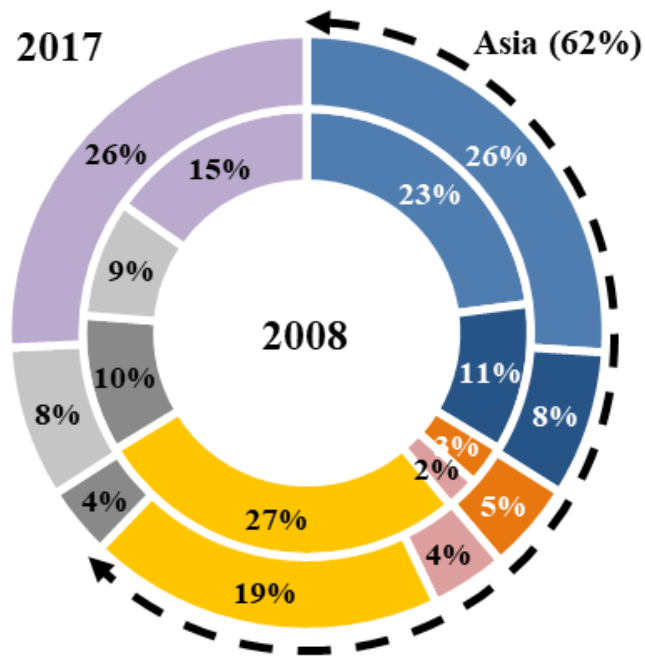

घingapore $\quad$ Hong Kong $\square$ Indonesia $\quad$ Thailand

Source: Bank Negara Malaysia.
Chart 8

\section{External Liabilities by Location}

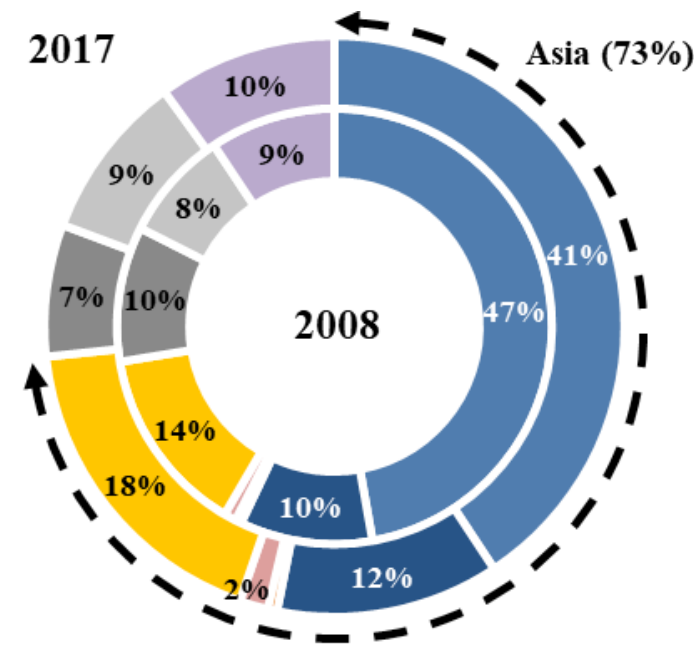

Other Asia $\square$ UK $\square$ US $\square$ Others

Source: Bank Negara Malaysia. 
Notwithstanding the low risk profile of banks' external exposures (refer to Bank Negara Malaysia's Financial Stability Review, 2018), Malaysian banks are more exposed to adverse market and geopolitical developments across different economies, particularly within Asia. This being as a natural consequence of the rapid growth and profile of banks' cross-border exposures. Moderate spillover effects were felt in the domestic market during periods of tightened US dollar conditions in 2008, as evident from the increased spreads of onshore USD/RM cross-currency swap rates and the widening of short-term US dollar liquidity mismatch positions of banks in Malaysia (Bank Negara Malaysia, 2013). In addition, with sizeable participation of foreign investors, domestic financial markets are also increasingly susceptible to volatile two-way portfolio flows induced by such regional and global developments. This has added to further concerns on banks' external debt ${ }^{10}$, which are predominantly in the form of short-term instruments such as deposits and interbank transactions and have evoked concerns of banks also being susceptible to sudden withdrawal shocks.

\section{Data}

This paper employs domestic and cross-border interbank exposures data sourced from two separate quarterly reporting submissions (i) Interbank Exposure for information on banks' bilateral exposures in the domestic interbank market and (ii) External Assets and Liabilities (EAL) for external cross-border exposures. As part of the Interbank Exposure submission, banks are required to submit information on their interbank claims and placements by currencies and counterparties (domestic and external), including placements and borrowings with BNM. Information on bilateral exposures (e.g. counterparty name) to cross-border financial institutions are not readily available for periods before 2017. As such, when looking at cross-border interbank exposures, we use aggregate country level exposures of each bank.

In this paper, we have identified 20 out of 54 banks, comprising domestic and foreign banks, as systemically important to facilitate our analyses. Such banks shall be referred to as systemically important banks (SIBs) hereafter. SIBs are selected based on a combination of balance sheet indicators namely total assets, total deposits and total loans outstanding.

\subsection{Network Analysis}

There is a total of 54 onshore banks and 24 non-resident countries (including Labuan ${ }^{11}$ ) in the dataset, forming a network with 78 nodes. The network is modelled using interbank lending data and the flow of exposures from a lender to a borrower is considered as a link. If credit exposures from one node to another is recorded as 'non-zero', a link is formed between the two nodes. Data was collected on quarterly basis from 2013 to 2017 . To ensure consistency in the dataset, the same 54 banks are retained throughout the sample period ${ }^{12}$. Similarly, 21 external

10. External debt is a subset of banks' external liabilities, referring to all external liabilities that require payment of principal and/or interest. This is in line with definition of International Monetary Fund (IMF), et al. (2013). In addition to external debt, banks' external liabilities comprise (i) custodial securities held on behalf of nonresident (NR) clients, (ii) capital funds maintained by NR in resident banks, primarily for LIFBs, and (iii) financial derivative balances.

11. For the purpose of the network analysis, Labuan banks are deemed as non-resident counterparties.

12. New (old) banks' entrants (exit) into the domestic banking system are removed from the dataset. Thus, this study does not consider the possibility of new links, except between the nodes fixed in the dataset. 
counterparty countries have been pre-identified based on their exposures, while the remaining countries clustered accordingly to 3 different regions ${ }^{13}$. These nodes form a directed network with a core-periphery structure, with core representing banks which are net lenders while periphery comprising the non-resident countries which are net borrowers only. Nevertheless, the core-core network structure (comprising both lenders and borrowers in the domestic interbank market) is also analysed.

Following the footsteps of Minoiu and Reyes (2011), we applied the same treatment on the bilateral interbank exposures data by retaining only positive flows in this study (corresponding to net placements or net assets), while negative flows (net liabilities) are replaced with zeros. The total claims and liabilities are not differentiated according to currency (domestic currency (i.e. Ringgit Malaysia) vs foreign currency) but aggregated as a whole. The resulting matrix is combined with the external cross-border exposures data for each period.

\subsection{Counterfactual Simulation Model}

For purposes of the counterfactual simulation model, we use annual data of 54 banks between 2013 and 2017. By using actual interbank exposures data, we partly overcome limitations typically associated with use of estimation techniques ${ }^{14}$ to construct bilateral interbank exposures. Other balance sheet information such as regulatory capital, placements with BNM and holdings of liquid securities were sourced from monthly reporting submissions by banks. In contrast to Bardoscia et al. (2015), we use banks' stock of CET $1^{15}$ capital in lieu of total equity.

\section{Methodology}

This section describes the statistical measures used to explain the network topological characteristics and the counterfactual simulation model used to assess contagion risk.

\section{$5.1 \quad$ Network indicators}

\subsubsection{Connectivity}

Network connectivity is the most commonly used topological measure and is defined as the likelihood of connection between nodes. A non-zero exposure between one node and another node, is known as a link. The total number of nodes and links in a network are identified as $n$ and $m$, respectively. Since the network is a directed network ${ }^{16}$, the probability, $p$ that two nodes share a link is defined as:

$$
p=\frac{2 m}{n(n-1)}
$$

13. Refer to Table A1 in Appendix 1 for full list of countries nodes.

14. Referring to techniques utilised to estimate bilateral interbank exposures in absence of actual data. Such techniques tend to distribute aggregate exposures as evenly as possible across institutions given set constraints. A general consensus in the literature is that use of such estimation typically leads to underestimation of contagion effects (Summer, 2013).

15. CET1 capital is a type of regulatory capital maintained by banks, referring to the highest quality and most lossabsorbing capital instrument under the Basel III capital framework.

16. For simplification, only directed links (where the edges point in a single direction) are analysed in this paper. Bidirectional links can be considered in future research work. 
As the number of nodes in the dataset are fixed, interconnectedness of banks and their respective counterparties is solely influenced by the number of links - the more the number of links, the higher the connectivity.

\subsubsection{Clustering Coefficient}

Clustering coefficient of a node $i$ is calculated as the ratio of the actual number of directed links between the neighbours of node $i\left(m_{n n, i}\right)$ over the number of potential links between them. When the total number of neighbours of node $i$ is $m_{i}$ and the number of potential links are $\left(m_{i}\left(m_{i}-1\right)\right)$, the likelihood of connection between two neighbours that are directly linked to a node in a directed network is:

$$
C_{i}=\frac{2 m_{n n, i}}{m_{i}\left(m_{i}-1\right)}
$$

The neighbours of node $i$ are defined as nodes that are directly linked to node $i$. For example, in a directed network of net exposures for the core-periphery structure in Figure A1 (refer to Appendix), if both neighbours, nodes $k$ and $j$ have a link with node $i$, the likelihood that nodes $k$ and $j$ are interlinked is known as the clustering coefficient. The clustering coefficient of a network, $C$ can be calculated as the average of the clustering coefficient of each node in the network. Thus, the likelihood of the network to cluster is $C=\frac{1}{n} \sum C_{i}$. The higher the coefficient, the more tightlyknit the nodes are together, indicating a 'small-world effect'.

\subsubsection{Betweenness Centrality}

Betweenness centrality of a node can be defined as the ratio of the total number of shortest paths through node $i\left(\sigma_{k j}(i)\right)$ to total number of shortest paths from node $k$ to $j\left(\sigma_{k j}\right)$. The measure used in this paper has been normalised for comparison purposes between different periods.

$$
B_{i}=\sum_{i \neq k \neq j} \frac{\sigma_{k j}(i)}{\sigma_{k j}}
$$

Nodes with high betweenness centrality are often important financial intermediaries as they act as a 'bridge' between nodes in a network. In the network example (Figure A2), bank $G$ is recorded to have the highest betweenness centrality between all other banks as it has the most number of times a transaction goes through the node. Being the key financial intermediator, a funding shock to bank $G$ would thus be transmitted towards all other nodes connected to it and restricts liquidity for bank $H$ and $J$.

\subsubsection{Average Degree (Outdegree and Indegree)}

The degree of a node computes the number of links for each node. Since the dataset is composed of a directed network, the number of outgoing links from a node, that is the number of counterparties a bank lends to (its debtors), is known as the outdegree (Figure A3). On the other hand, the number of counterparties a bank borrows from (its creditors), also known as the number of incoming links, is referred to as the indegree. The average degree of the network is therefore the ratio of the total number of links, $m$ and the total number of nodes, $n$. 
Moreover, node strength refers to the value of net interbank exposures originating or terminating at a given node. An increase in the amount of interbank lending by a creditor to its counterparties shows greater node outstrength. Although the number of outward links signals the importance of the bank as a credit provider in the system, the amount of lending should also be emphasised when determining the riskiness of the entity as a credit provider. To put it simply, a bank $(A)$ that lends to a single entity with an amount of RM100 million is more risky than a bank $(B)$ that lends to 5 different counterparties with an amount of RM10 million each. This paper adopted the weighted network approach proposed by Opsahl et al. (2010) by taking into account the total number of counterparties a bank lends to (outdegree) and their weighted size of exposures (outstrength) using a tuning parameter, $\alpha$. By assigning $\alpha=0.5$, both the number of outdegree and weight of the links are given equal relative importance. This centrality measure enables us to more accurately assess the contagion risk of banks with high outdegree relative to their size of interbank placements with their respective counterparties.

\subsection{Counterfactual Simulation Model}

Bank-driven contagion can take many channels (see Upper, 2011) but this paper focuses on the interbank market, specifically asset-side shocks due to lending and borrowing exposures to financial institutions in the cross-border interbank market (direct effects) and the spillover impacts onto the domestic interbank market via the confidence channel (indirect effects). To assess the resilience of Malaysian banks to susceptibility to shocks induced via the cross-border and domestic interbank markets, a counterfactual simulation adapting the DebtRank methodology developed by Battiston et al. (2012) shall be utilised. In particular, the DebtRank methodology shall be used to extend the simulation analysis presented in the 2013 Financial Stability and Payment Systems Report (Bank Negara Malaysia, 2013) by attempting to estimate, quantify and track the spillover impact of shocks incurred on banks' cross-border interbank exposures onto the Malaysian interbank system.

\subsubsection{Model Description}

In this section, we introduce and describe the key features of our counterfactual simulation model which had been calibrated by taking into account some of the key insights and shortcomings identified in similar studies highlighted earlier. Detailed information about the process and the main variables of interest can be found in Appendix 2.

Our model envisages a financial system of $n$ banks as a network. Each bank either lends to other banks within the network i.e. domestic interbank lending $\left(\mathrm{A}_{\mathrm{dib}}\right)$, or engage in any of the following (i) cross-border interbank lending to non-resident financial institutions $\left(A_{e a}\right)$, (ii) placements with central bank $\left(\mathrm{A}_{\mathrm{cb}}\right)$, (iii) holding of liquid securities $\left(\mathrm{A}_{\text {liqs }}\right)$, and/or (iv) holding of other assets $\left(\mathrm{A}_{\text {oth }}\right)$. Bank assets are assumed to be marked-to-market whereas liabilities are carried at their face value. The rationale being the value of banks' obligations do not change simply because they might not be able to meet the obligations. At any given time, total equity value, $\mathrm{E}_{\mathrm{t}}$ of a bank refers to its total assets, $\mathrm{A}_{\mathrm{t}}$ less its total liabilities, $\mathrm{L}$.

$$
A_{t}^{d i b}+A_{t}^{e a}+A_{t}^{c b}+A_{t}^{l i q s}+A_{t}^{o t h}=L+E_{t}
$$

The model is centred on measuring relative equity loss of each bank or the system as a whole at any given time. Given total liabilities are assumed to be carried at face value, changes in value of total assets would result in corresponding change in the value of banks' total equity. The relative 
or percentage loss in total equity, denoted by $h_{i}$ is taken as a proxy for distress for any given bank, also referred to as vulnerability of the bank. When $h_{i}=0$, a bank is deemed to be un-distressed. All values between 0 to 1 suggests a bank is under distress.

$$
\text { Relative loss in equity, } h_{i, t}=\min \left\{1, \frac{E_{i, t=0}-E_{i, t}}{E_{i, t=0}}\right\}, \mathrm{t}=0,1,2 \ldots
$$

At the system level, aggregate vulnerability, $H_{t}$ refers to the weighted average of each bank's vulnerability, with the weights given by its relative initial equity.

$$
\begin{aligned}
\text { System equity loss, } H_{t} & =\sum_{i} w_{i} h_{i t} \\
\text { weights, } w_{i} & =\frac{E_{i, t=0}}{\sum_{j} E_{j, t=0}}
\end{aligned}
$$

\subsubsection{Shock Scenarios}

Two types of shock scenarios were used for the simulation. The first scenario assumes banks experiencing a common shock on their cross-border interbank exposures i.e. interbank lending and borrowing exposures to non-resident financial institutions. Specifically, all banks would experience simultaneous credit and funding shocks at time, $t=1$ (also called the first round for brevity): (i) an effective ${ }^{17}$ negative credit shock, $r$ on cross-border interbank lending exposures and (ii) a reversal shock, $f$ on cross-border interbank borrowing exposures. Unable to replace the lost funding in the short-run, banks are forced to deleverage, first withdrawing their excess liquidity placements with the central bank, $\mathrm{A}_{\mathrm{cb}}$ and then liquidating a portion, $z$ of their holdings of liquid securities, $\mathrm{A}_{\text {liqs }}$ if there are insufficient placements with the central bank. Malaysian banks have high degree of common asset exposures with Malaysian sovereign debt securities forming $40.7 \%$ of the banking system's Basel III Liquidity Coverage Ratio High-quality Liquid Assets in 2017. As such, a haircut, $x$ is imposed on all remaining $(1-z)$ stock of liquid securities to replicate the potential price impact of simultaneous asset liquidation to replace lost interbank funding and adverse market movements that may be observed during periods of heavy portfolio outflows that could accompany the interbank funding reversal. This is in part cognisant of the concentration risk posed by emerging markets' limited access to other forms of high-quality liquid assets beyond sovereign debt, particularly following the implementation of Basel liquidity frameworks (Basel Committee on Banking Supervision, 2014). Notwithstanding any asset-specific qualities and market dynamics which may offset potential valuation losses during times of rapid deleveraging, we deliberately chose to adopt a conservative approach and impose a haircut on all of banks' liquid assets. The magnitude of the haircut is calibrated based on the historical worst possible adverse yield movement observed on Malaysian government debt.

17. The effective credit shock on banks' cross-border exposures refers to product of probability of default (PD) and loss-given-default (LGD). For simplicity, the current study only varies the effective credit shock in conducting sensitivity analysis. 
In the first round, banks will immediately incur the losses following the shocks and there is a corresponding reduction in equity level. The losses in equity at this point is referred to as first order impact. Following this, the likelihood of a distressed bank (referring to a bank suffering from relative loss in equity) repaying its obligations on the domestic interbank market becomes lower as its creditworthiness deteriorates. Here the DebtRank algorithm is adapted to trigger contagion effects in the domestic interbank market whereby banks that lent to distressed banks will incorporate information about the reduced creditworthiness into the valuation of their interbank lending exposure thereby incurring losses. We refer to the cumulative loss of equity at this point as second order impact. The value of the interbank asset will lie between its face value (repaid in full) and zero (assuming no recovery in the event of default). In our study, the losses incurred in the second round by creditor banks is proportional ${ }^{18}$ to relative loss of equity incurred by debtor banks in the first round. Should a bank have multiple interbank lending exposures to distressed banks in the domestic interbank market, overall losses incurred during the second round refer to total losses incurred on all its domestic interbank lending exposures.

The first scenario is repeated with various values of credit, funding and market shocks to assess sensitivity of impact to set parameters. The second scenario, meanwhile, subjects each bank to similar shocks (as in the first scenario) but individually. This step is then repeated for each bank within the sample. This is intended to decompose systemic risk properties of a bank into (i) its impact on the system and other banks in the event of the bank's distress or default and (ii) its vulnerability with respect to external shocks. Impact of bank $i$ refers to the relative equity loss of the system when bank $i$ is shocked. Both scenarios are then repeated for data ending 2013 and 2017 , respectively.

\section{Results}

The results in this section are divided into two parts: (i) the topological characteristics of the domestic and cross-border interbank network and (ii) the results of the counterfactual simulation. In highlighting our findings, where applicable, we shall focus on comparing (i) SIBs versus nonSIBs and (ii) domestic versus locally-incorporated foreign banks for greater clarity.

\subsection{Network Analysis}

Connectivity within the Malaysian banks' interbank exposures has declined over time (Chart 9). Interconnectivity of banks experienced a relatively steep decline in 2015 before reaching $18.2 \%$ in 2017 , compared to $20.7 \%$ in 2013 . As the number of nodes in the dataset are fixed, the decline in connectivity is a factor of the total number of links in the network, which dropped to an average of 559 for the year 2017 from 627 in 2013. Further breakdown shows this is largely attributed by lower connections from SIBs, mainly made up by domestic players. The average number of transactions made by these domestic SIBs fell to an average of 281 in 2017 (2013: 349).

18. Here we would like to highlight that that subsequent works on DebtRank have advanced refined valuation functions for various asset exposures which can more accurately calibrate the distress propagation mechanism (Bardoscia et al., 2017). In our view, although the extent of the over- and underestimations of using a linear propagation mechanism cannot be rigorously quantified, a reasonable assumption is that they roughly cancel each other out. 
Chart 9

Connectivity (\%)

22.0

21.0

20.0

19.0

18.0

17.0

16.0

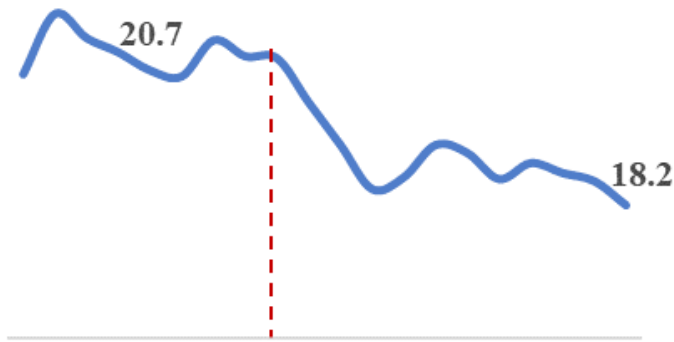

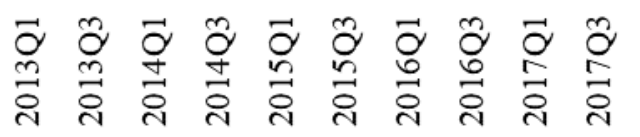

Source: Authors' estimation.
Chart 10

Clustering Coefficient

20.0

15.0

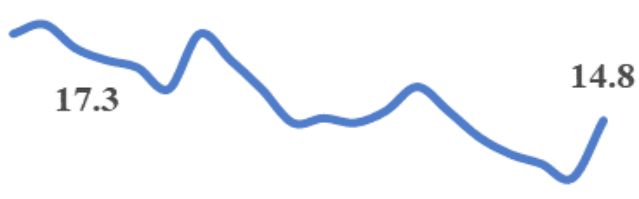

10.0

5.0

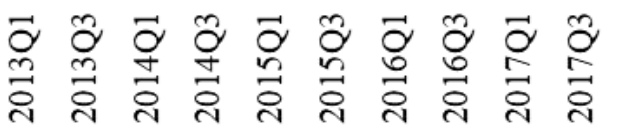

Source: Authors' estimation.

Similarly, the likelihood that two neighbouring counterparties are connected are also on a declining trend, with the clustering coefficient estimated at $14.8 \%$ in 2017 (Chart 10). There are generally two bouts of decline observed during the period, mainly in 3Q 2014 and mid-2016. This is largely due to outflows, particularly to Labuan. The results above signals that although lesser links are generated within the interbank market over time, the network is prone to movement of flows, observed by the increase in intensity of cross-border flows.

The change in betweenness centrality from 2013 to 2017 confirms that the role of some key SIBs remained important, recording a betweenness centrality of 0.05 to 0.08 as at 4Q 2017 ${ }^{19}$. The four largest parent SIBs remain as key financial intermediaries in the domestic market despite the declining role of their subsidiaries (Figures 1 and 2). Amongst the list of banks with the top ten highest betweenness centrality statistic, two of the banks are LIFBs consistent with the significance of foreign players as a provider of foreign currency liquidity.

19. Refer to Table A2 (Appendix 3). 
Figure 1

$1 Q 2013$ Network: Betweenness Centrality

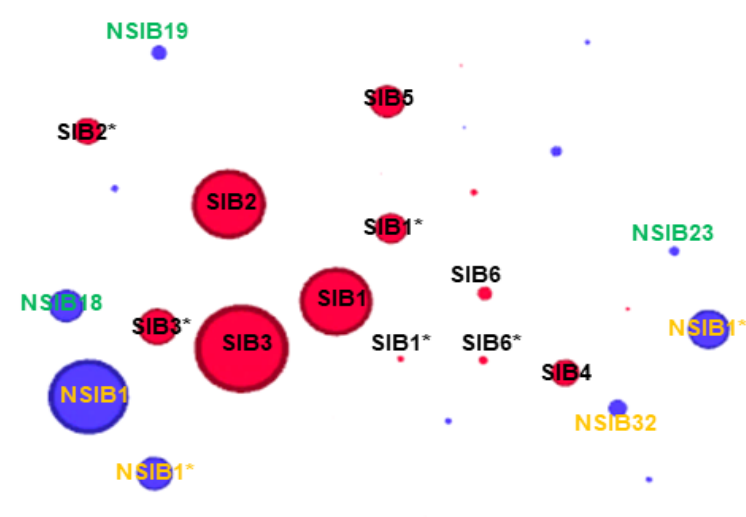

Figure 2

4Q 2017 Network: Betweenness Centrality

Note:

1. Size of the node represents measure of betweenness centrality i.e. the larger the node, the higher the betweenness centrality.

2. Red nodes represent SIBs, blue nodes represent non-SIBs.

3. Nodes with green labels represent non-SIB LIFBs, nodes with yellow labels represent non-SIB domestic banks.

4. *Subsidiaries of SIBs.

Source: Authors' estimation.

The average number of outgoing links has also been on a steadily declining trend, reflecting the decrease in interconnectivity of banks (Chart 11). Specifically, the fall in the average degree is observed since 3Q 2014. Narrowing on the domestic interbank market only (the core-core network), given that there are 54 banks, the maximum number of potential outgoing links in this study would be $1,431^{20}$. However, given that there are only 169 directed-out links in 2017 , only $12 \%$ of the potential links are utilised, deeming the domestic interbank system as an incomplete network. This is not much different from 2013, where there were 216 outgoing links, thus exploiting $15 \%$ of the potential core-core network. A look at the core-periphery structure, however, shows a slightly more complete network, with $54 \%$ of the potential outgoing links between banks and their respective external counterparty countries being utilised as at end-2017. This is reasonable because the greater regionalisation of domestic banks, deep and liquid financial market coupled with strong economic performance attracted a larger presence of foreign banks.

The decline in average outdegree is more apparent for SIBs, albeit remaining higher than non-SIBs (Chart 12). This is largely attributed to the increase in cross-border flows, where more than half of exposures are to non-residents (Chart 13).

20. The maximum number of potential outgoing links is as follows $=\frac{54 \times 53}{2}$ 
Chart 11

Average Degree and Average Outdegree

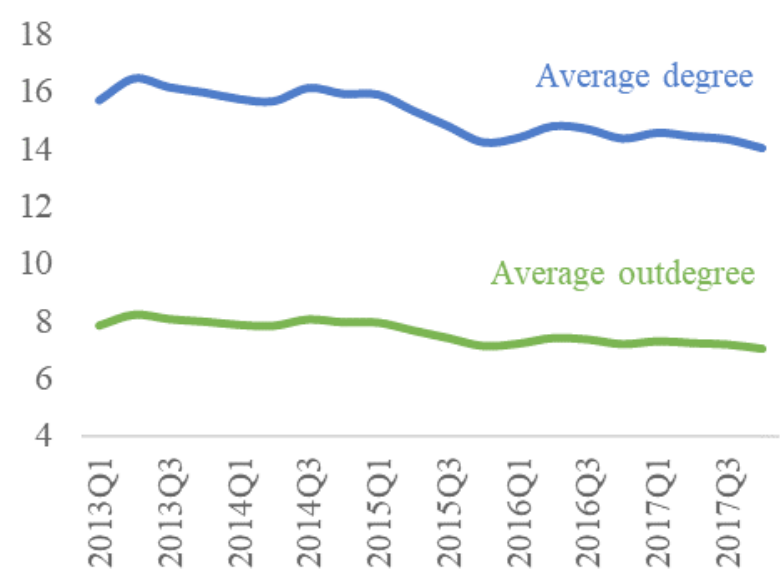

Source: Authors' estimation.
Chart 12

SIBs and Non-SIBs: Average Outdegree

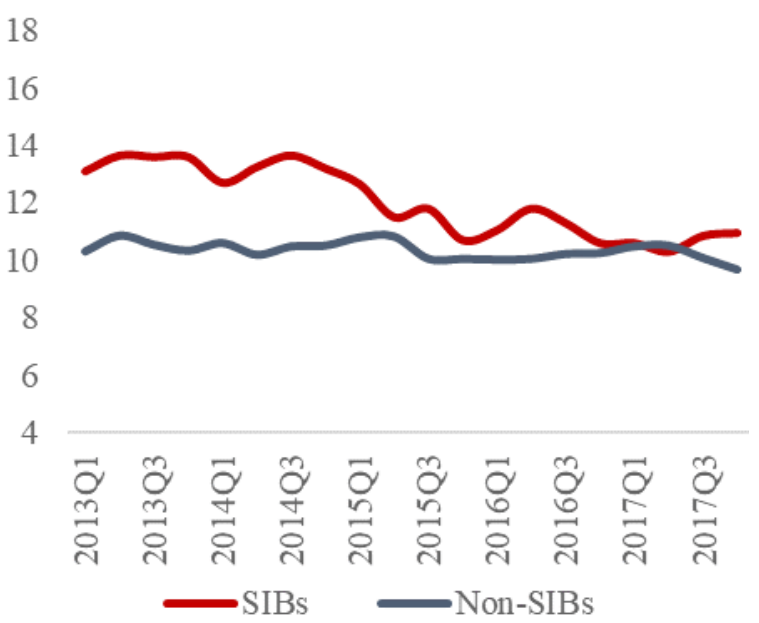

Source: Authors' estimation.

Further breakdown of net interbank exposures of SIBs to non-residents show that the largest exposure of our onshore banks was to the Asian region, specifically Labuan (Chart 14). Intragroup funding to Labuan expanded in mid-2014 following the increase in foreign currency lending to corporations to support business activities during the period. The general decrease in cross-border exposures observed in 3Q 2016, however, is partly explained by some DBGs' strategy to reduce reliance of overseas operations on parent funding, limiting external exposures.

\section{Chart 13 \\ SIBs: Net Interbank Exposures}

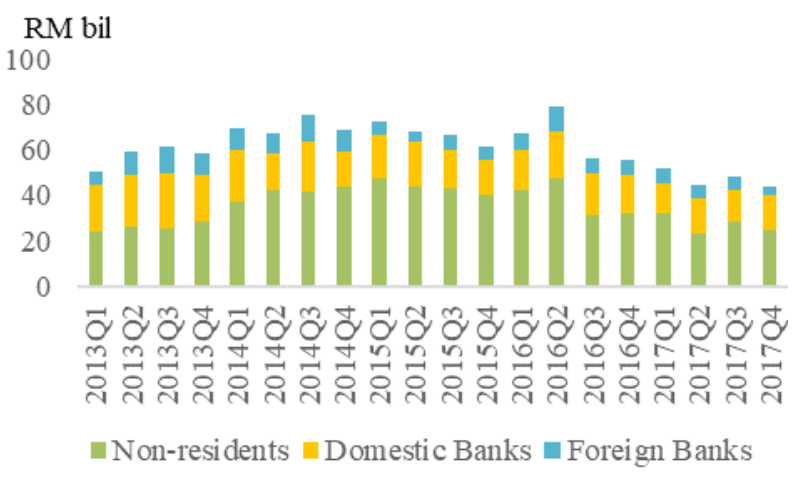

Source: Bank Negara Malaysia.

\section{Chart 14}
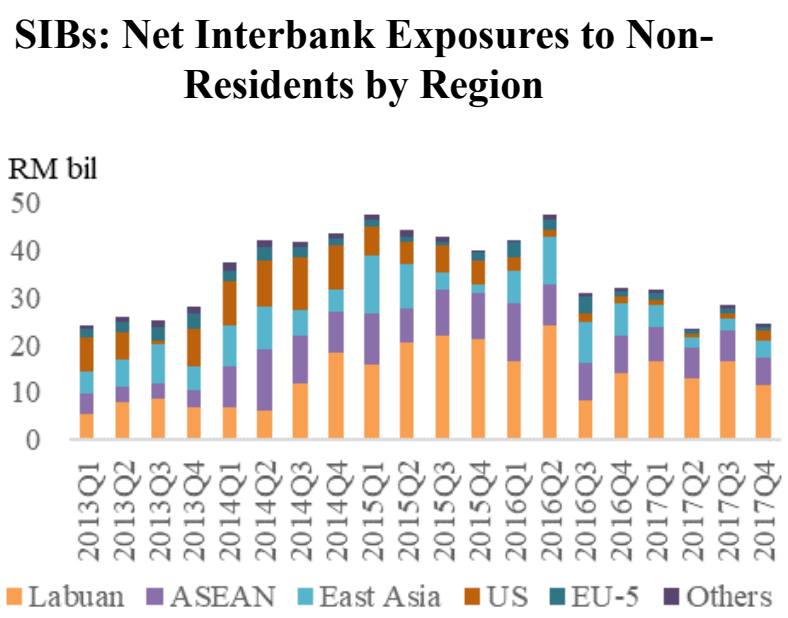

Source: Bank Negara Malaysia.

Table 2 shows the top 10 net exposures of D-SIBs to non-residents by countries. Net interbank placements in Labuan as at 1Q 2013 was recorded at RM5.4 billion. However, this figure ballooned to RM11.7 billion as at end-2017, showing the increasing role of Labuan as a booking centre. Cross-border interbank claims continue to be concentrated within the Asian region, particularly in countries dominated by our domestic banks' regional presence. 
Table 2

SIBs: Top 10 Net Exposures by Countries (1Q 2013 vs 4Q 2017)

\begin{tabular}{c|c|c|c|c}
\hline \multirow{2}{*}{ No } & \multicolumn{2}{|c|}{$1 \mathbf{2 0 1 3}$} & \multicolumn{2}{c}{ 4Q 2017 } \\
\cline { 2 - 5 } & Country & $\begin{array}{c}\text { Exposure } \\
\text { (RM bil) }\end{array}$ & Country & $\begin{array}{c}\text { Exposure } \\
\text { (RM bil) }\end{array}$ \\
\hline 1 & US & 7.1 & Labuan & 11.7 \\
2 & Labuan & 5.4 & Singapore & 3.1 \\
\hline 3 & Hong Kong & 2.5 & US & 2.2 \\
4 & Singapore & 2.2 & China & 1.6 \\
\hline 5 & China & 1.2 & Philippines & 1.1 \\
\hline 6 & Indonesia & 0.9 & Hong Kong & 0.8 \\
\hline 7 & France & 0.8 & Indonesia & 0.6 \\
\hline 8 & UK & 0.8 & Japan & 0.6 \\
\hline 9 & Vietnam & 0.5 & UK & 0.5 \\
\hline 10 & Philippines & 0.5 & Korea & 0.5 \\
\hline
\end{tabular}

Source: Bank Negara Malaysia.

The time evolution of the interbank network is illustrated in Figures 3 and 4. The network is shown at the beginning and end of the sample period (1Q 2013 vs 4Q 2017). There is a clear decline in network connectivity in the domestic and cross-border interbank market over time, suggesting a decline in the network susceptibility to contagion events. The decline in interbank connectivity can be explained by the following: (i) greater cross-border flows to specific non-residents by SIBs and (ii) concentration of interbank activities with related counterparties (i.e. intragroup exposures), a less risky source of exposure.

The LCR requirement, which was first announced in November 2014 could have contributed to the diminishing connectivity within the interbank network. To meet the requirements, banks are required to equip themselves with HQLA which includes placements with central banks and holding of liquid debt securities. In this regard, banks would have been incentivised under the requirement to increase placements with BNM (i.e. lending to BNM in the domestic interbank market) as opposed to lend to another financial institution within the domestic interbank market as the former counts as a HQLA, thus lowering interconnectivity. Following the implementation of LCR requirement in June 2015, we did observe a general decline in interbank lending by banks while placements with $\mathrm{BNM}^{21}$ rose and remained at elevated levels thereafter (Chart 15 ). In addition, the $100 \%$ runoff rate attached to interbank borrowings, which effectively means banks have to increase their stock of HQLA by an equivalent amount of their borrowings, could have dis-incentivised banks to borrow from the interbank market, thereby also lowering interconnectivity.

21. Central bank placements could be argued to be a safer option for banks compared to liquid securities holdings especially during times of volatility in the domestic financial markets with increased two-way portfolio flows, as was the case during 2015. 
Figure 3

1Q 2013: Network Outdegree

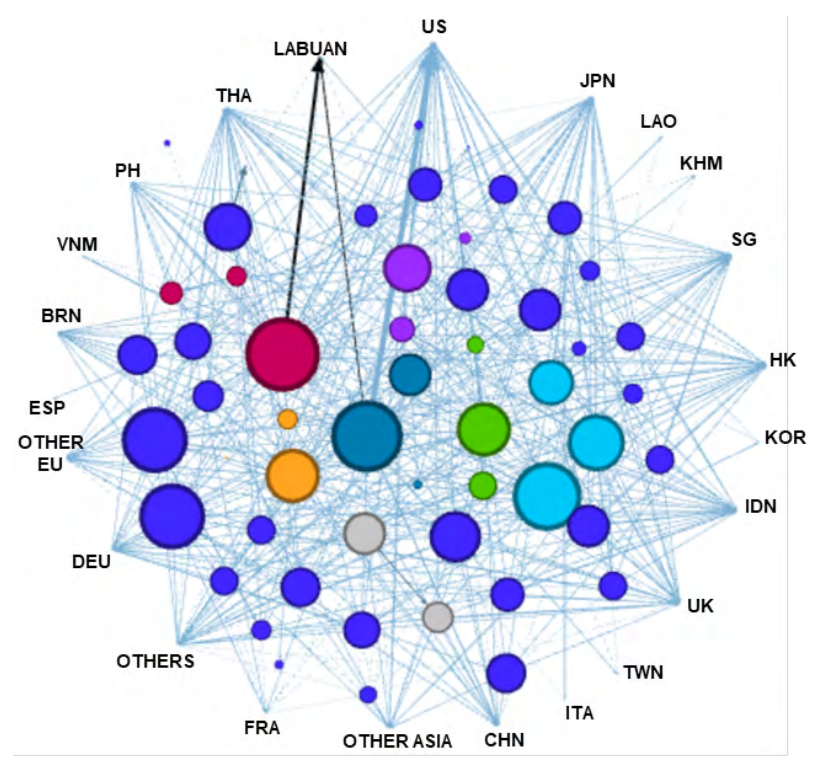

Figure 4

4Q 2017: Network Outdegree

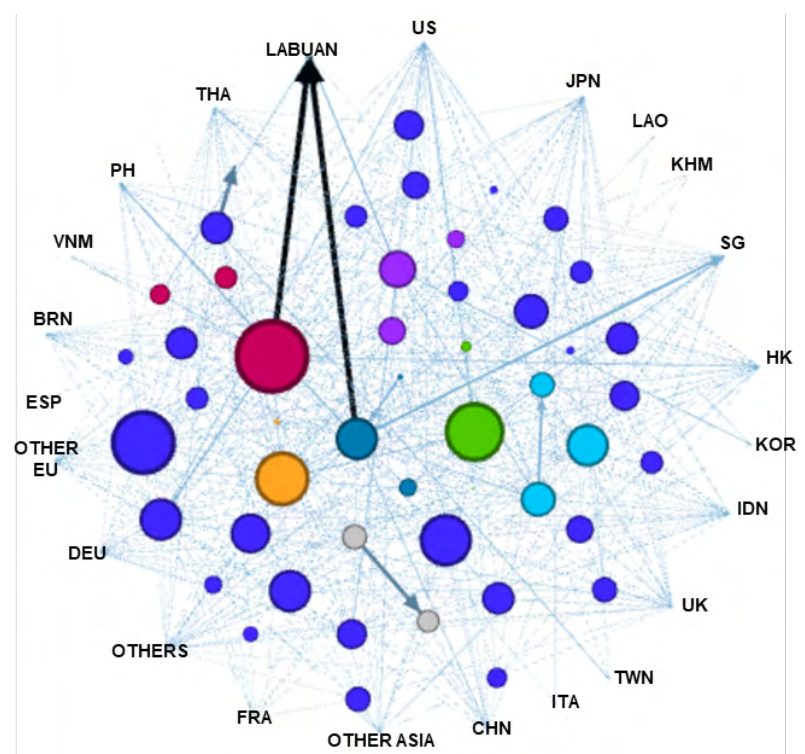

Nodes legend:

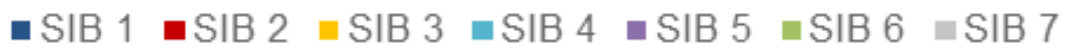

Note:

1. Royal blue nodes represent non-SIBs .

2. Size of the nodes represent the number of counterparties.

3. Direction and thickness of the arrows represent net placement and relative size of exposures.

Source: Authors'estimation.

\section{Chart 15}

\section{Banking System: Holdings of High-quality Liquid Assets}

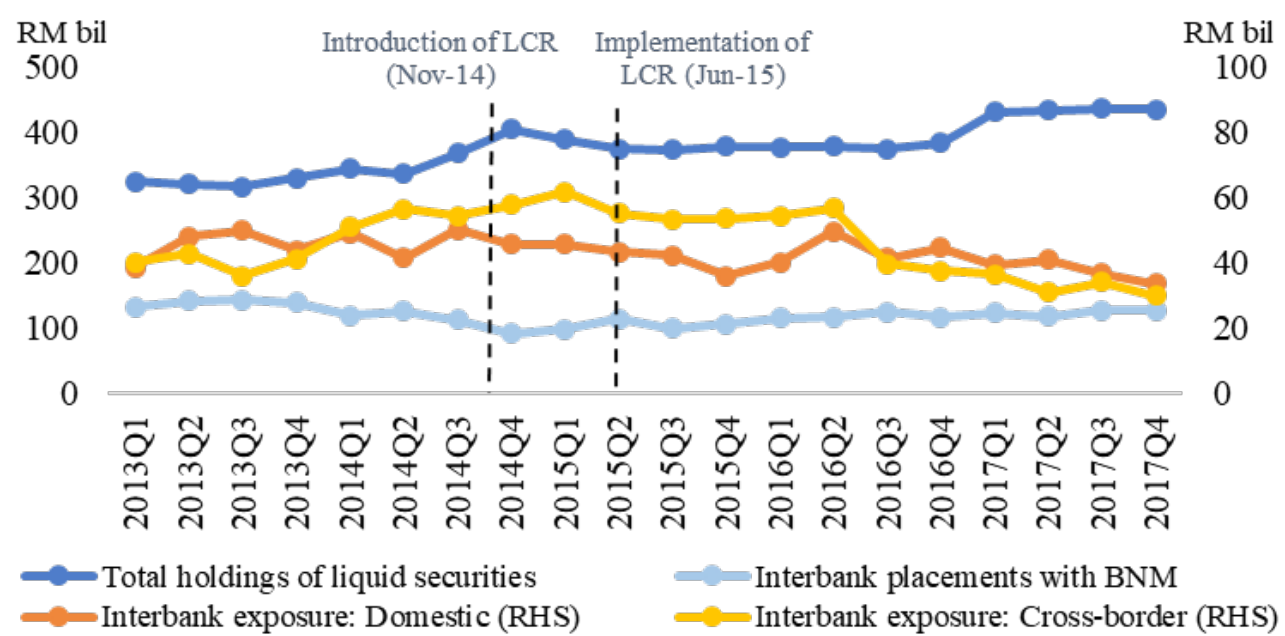

Source: Bank Negara Malaysia. 
Using a weighted network approach, we find that the risks for some SIBs have decreased slightly over time in line with diminishing connectivity (Figures 5 and 6). It is interesting to note also that contagion risk used to be widely distributed amongst SIBs, but now the risk is more concentrated within the larger SIBs. Nonetheless, SIBs remain relatively more susceptible to induce contagion compared to non-SIBs due to their large size and important role as a credit intermediator.

\section{Figure 5}

1Q 2013: Weighted Network Outdegree

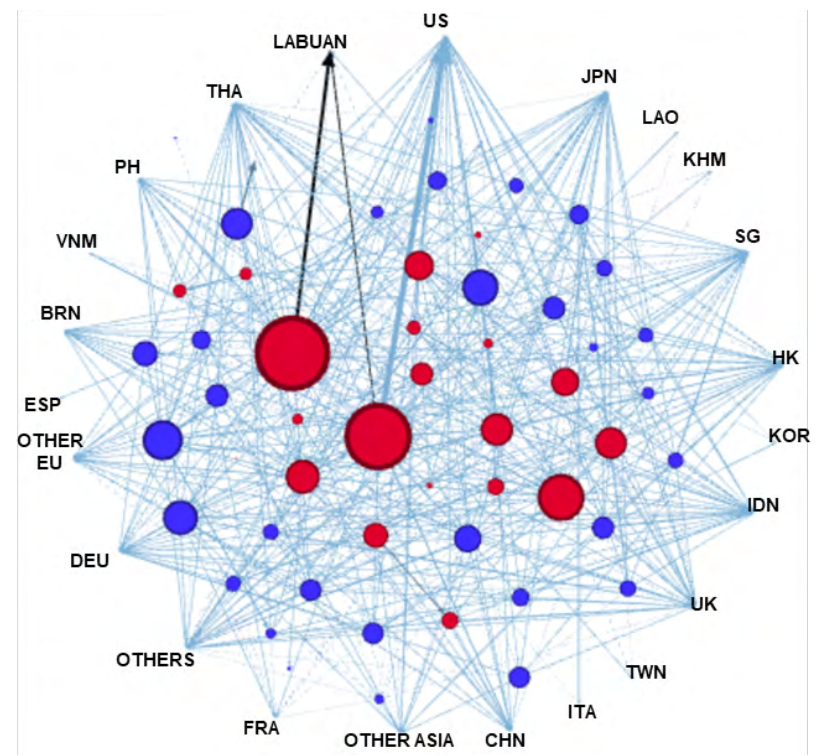

Figure 6 4Q 2017: Weighted Network Outdegree

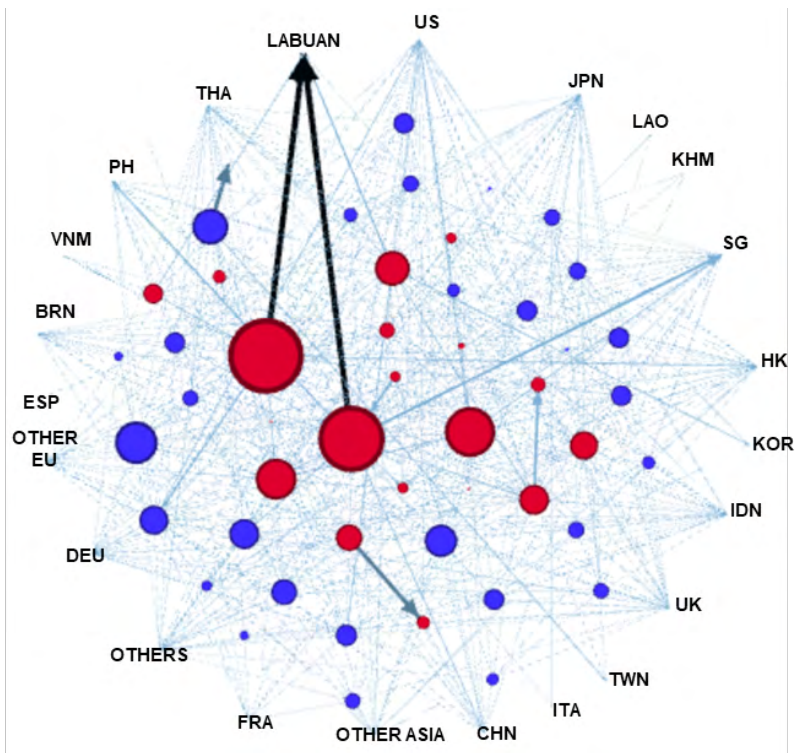

Note:

1. Red nodes represent SIBs, blue nodes represent non-SIBs.

2. Size of the nodes represent the degree of interconnectedness, taking into account the number of counterparties and weighted size of exposure.

3. Direction and thickness of the arrows represent net placement and relative size of exposures.

Source: Authors' estimation.

\subsection{Counterfactual Simulation Analysis}

In assessing the results of counterfactual simulation model, we start by exploring the losses incurred at the aggregate system level over the five-year period. Recall that this period also coincides with several key structural changes that took place in the Malaysia banking system: (i) implementation of Basel III capital and liquidity standards and (ii) a significant decline in the aggregate interbank exposures in the domestic interbank market. Chart 16, which offers a deconstruction of the losses according to shock types and rounds the losses were incurred in, shows that aggregate losses due to contagion has decreased significantly from 2013 to 2017. Consistent with findings of lower connectivity in the domestic interbank market, the decline in aggregate losses are driven by lower loss contribution from second round effects. That said, relative losses in equity due to the second round continue to be sizeable, suggesting that disregarding spillover or indirect impact can underestimate the true extent of potential losses. In addition, valuation losses incurred on liquid securities holdings arising from rapid deleveraging to replace lost interbank funding have steadily increased over the years, making up $42 \%$ of total aggregate losses at the system level in 2017 as compared to $25 \%$ in 2013 . While the banking system cross-border interbank funding has grown rather significantly in value terms during the same period, we have maintained the same 
haircut for liquid securities holdings for simplicity. Given this, the increase in valuation losses is primarily attributable to higher holdings of liquid assets holdings among Malaysian banks (Chart 15) following the implementation of Basel III LCR requirement. On aggregate, Malaysian banks' liquid securities holdings stood at RM433 bil or $17.0 \%$ of total assets in 2017 , a $32 \%$ increase since 2013.

\section{Chart 16 \\ Banking System: Vulnerability by Type of Shocks and Round}

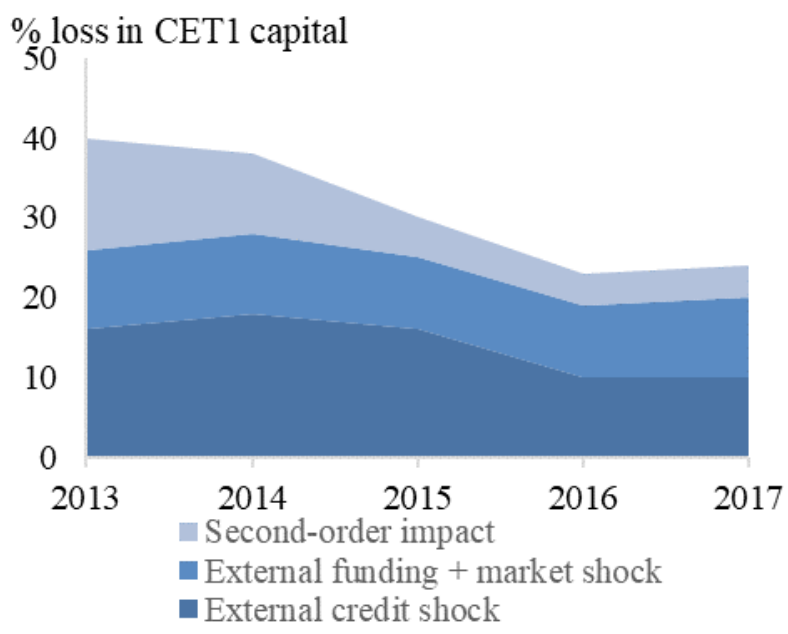

Source: Authors' estimations.

\section{Chart 17 \\ Breakdown of Losses (as \% of CET1 Capital)}

Number of banks

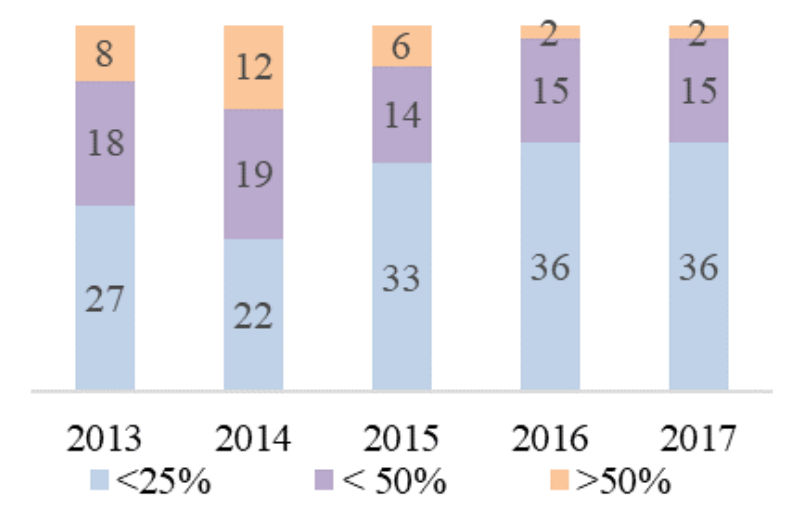

Source: Authors' estimations.

To affirm that improved resilience at the aggregate system level is not down to few large banks alone, we also compared the breakdown of overall losses incurred by each bank over the same period (Chart 17). Consistent with the system level trends, fewer banks suffered from large losses, with only 2 banks suffering from losses exceeding $50 \%$ of CET 1 capital. Again, during this period, bank capitalisation increased significantly (refer to Table 1) which could in part explain the improved resilience despite higher interconnectedness to cross-border financial institutions.

We then proceed to decompose aggregate losses across the five-year to losses attributable to SIBs and non-SIBs (Chart 18). Similarly, resilience of SIBs has improved over the years. Yet, unsurprisingly, system-wide losses induced by SIBs remain significant. However, the average vulnerability of SIBs, which reflects the average losses (as proportion of CET1 capital) incurred by SIBs across all iterations in Scenario 2, remains low (Chart 19). 


\section{Chart 18 \\ Banking System: Vulnerability by \\ Type of Banks}

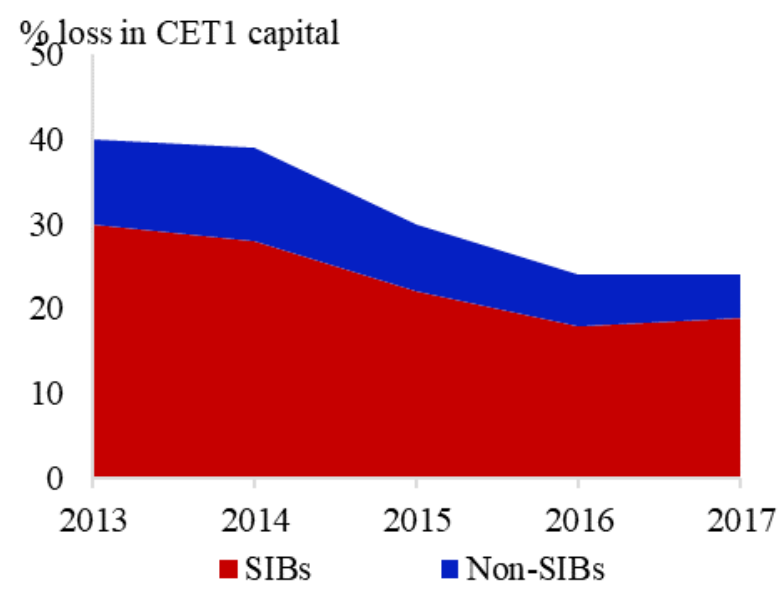

Source: Authors' estimations.

\section{Chart 19}

Median Average Vulnerability of SIBs to External Shocks

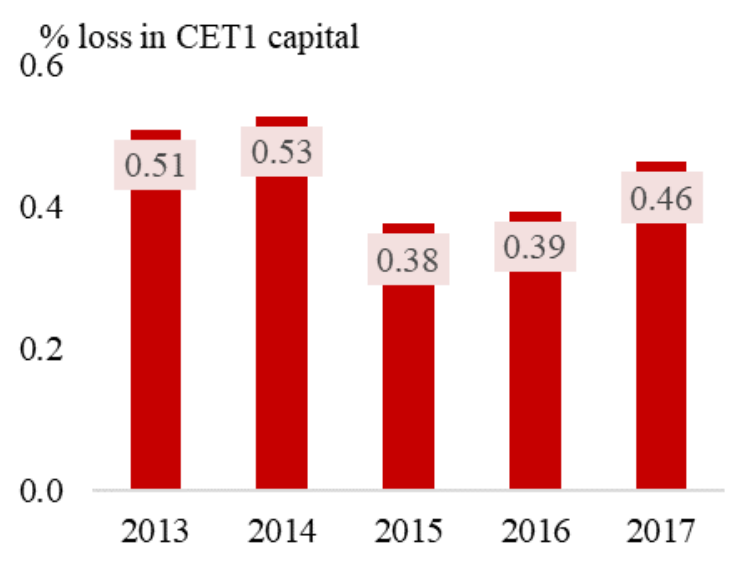

Source: Authors' estimations.

Next, we compare the first-round effects and the second-round effects (Chart 20). Here we observe banks with higher external and domestic interbank leverage suffer greater losses. These tend to be smaller foreign banks which typically operate as foreign currency liquidity provider in the domestic interbank market. As expected, overall impact is lower if related counterparties' exposures are excluded (Chart 21). Comparing with 2013 (Chart 22), we observe a significant reduction in the effects in 2017 , with banks being clustered to the bottom left hand corner. 


\section{Chart 20 \\ 2017: First Order Impact vs \\ Second Order Impact (as Proportion of CET1 Capital)}

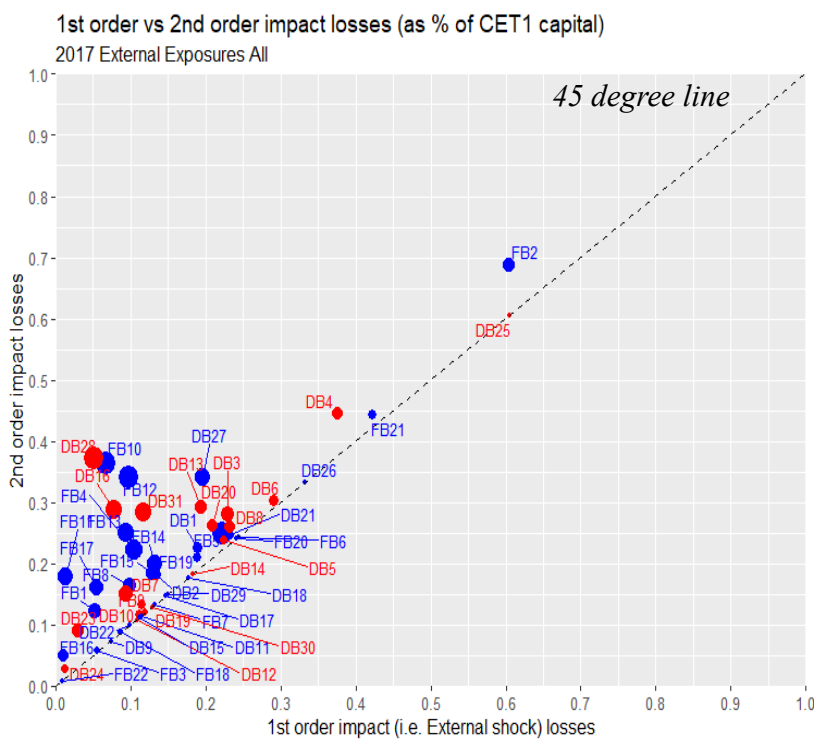

\section{Chart 21}

2017: First Order Impact vs Second Order Impact excluding Related Counterparties' Exposures (as Proportion of CET1 Capital)

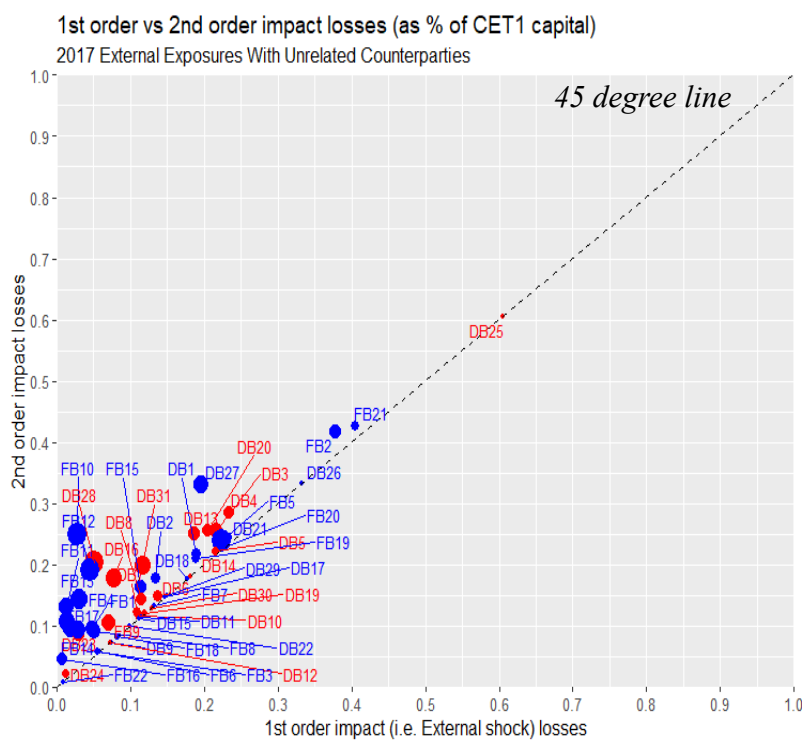

\section{Chart 22}

2013: First Order Impact vs Second Order Impact (as Proportion of CET1 Capital)

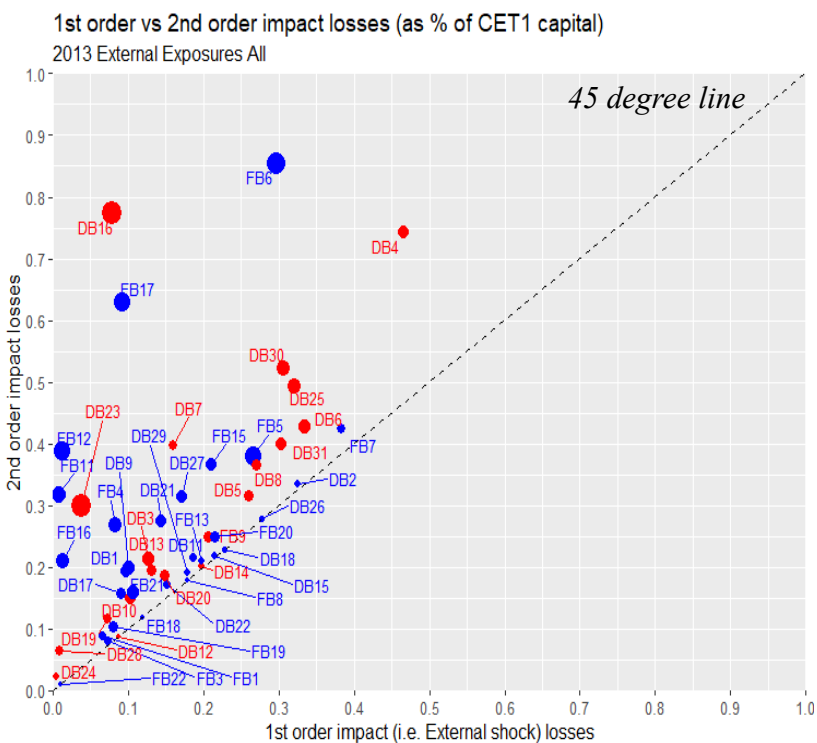

Note:

1. Marker size represents domestic interbank loans leverage (the bigger the marker, the greater the domestic interbank leverage).

2. Marker colour indicates type of bank: Red for SIBs, blue of non-SIBs.

Source: Authors' estimations. 
Next, we focus on the two following quantities: (i) losses (as proportion of CET1 capital) incurred by a bank when faced with shocks in the first round and (ii) total loss induced by each bank onto the system when faced with shocks in the first round. The former, a measure of vulnerability to external shocks and the latter, a measure of impact a bank has onto the interbank market sheds light into two separate systemic risk aspects (Charts 23 and 24). Comparing these quantities for 2013 and 2017, we observe that banks exhibiting relatively high external vulnerability are mostly small banks that also pose limited impact onto the domestic interbank market. Nevertheless, our results show that SIBs continue to exhibit high vulnerability (vulnerability exceeding median vulnerability) and can potentially pose significant impact due to their prominent role in the domestic interbank network. Unsurprisingly, size which is regarded as a key measure of systemic importance appear to be associated with high values of vulnerability and impact.

\section{Chart 23}

\section{3: Vulnerability to External Shocks vs Impact in Domestic Interbank Market}

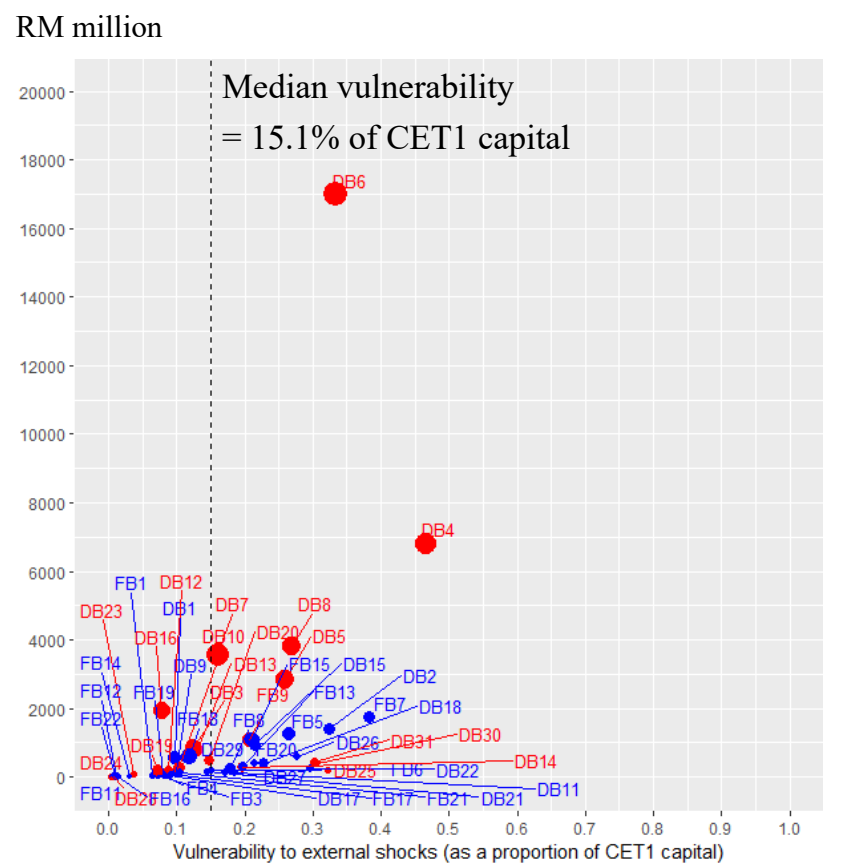

\section{Chart 24}

2017: Vulnerability to External Shocks vs Impact in Domestic Interbank Market

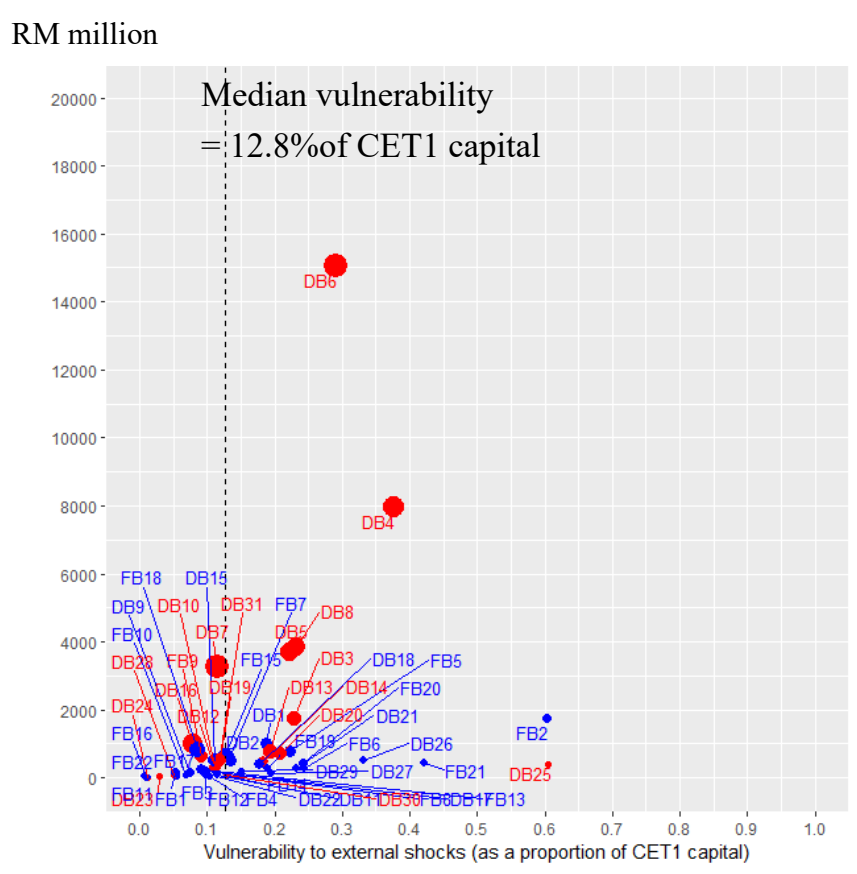

Note:

1. Marker size represents relative measure of bank assets (the bigger the marker, the larger the bank in terms of asset size).

2. Marker colour indicates types of bank: Red for SIBs, blue of non-SIBs.

Source: Authors' estimations. 


\section{Conclusion and Policy Implications}

We have demonstrated that interconnectivity and solvency contagion risk in the Malaysian banking system to external shocks have declined significantly since 2013, despite the rapid growth in cross-border exposures in value terms. Nonetheless, due to their large size and interconnectedness, i.e. importance as a financial intermediator, SIBs are found to be more susceptible to induce contagion within the network. In assessing potential losses arising from contagion induced by external shocks, we incorporated two other channels of contagion that are often disregarded in similar counterfactual simulation studies: (i) valuation losses due to common asset exposures and (ii) mark-to-market losses resulting from credit quality deterioration or a loss of confidence (also known as 'credit quality channel', refer to Fink et al. (2016)).

We believe that network analysis and counterfactual simulation, particularly those which extends beyond simple spillover mechanisms, are good complements to other macroprudential surveillance tools that are being used to monitor financial system vulnerabilities. Such analysis helps to provide useful insights on financial system vulnerability to shock scenarios and the propensity of financial institutions to amplify contagion due to significance within a particular network and/ or degree of interconnectedness to other financial institutions, i.e. 'too connected to fail' which cannot be gauged by simply looking at the size of balance sheet. In this regard, our study has demonstrated that SIBs continue to exhibit relatively higher vulnerability to external shocks due to their cross-border exposures and can potentially cause significant impact onto Malaysian banking system during times of distress. This serves as a reminder on the need to be cognisant of the risks posed by systemically important banks and have necessary policy measures in place to both manage the risks and reduce the impact of SIBs failure. Furthermore, considering how financial interconnectedness is an increasingly regional and global phenomenon, there is a role for collective efforts by policymakers to improve the monitoring of systemic linkages. This should include having in place effective arrangements for multilateral information sharing and surveillance, and wider coverage of reporting on cross-border financial obligations.

Moving forward, this study could be extended in three key directions. First, with access to more complete information on banks cross-border exposures, particularly identity of counterparties, a more comprehensive and an accurate assessment of contagion risks posed by systemically important banks in other jurisdictions to the domestic financial system and economy can be conducted. Second, calibration of distress propagation mechanism for counterfactual simulation deserves further discussion. In this regard, a more refined and economically accurate mechanism that take into account counterparties' probability of default and the recovery rate of the assets could be explored (refer to Fink et al., 2016; Bardoscia et al., 2017). Third, our analysis can be expanded to assess contagion risk to take into account other form of interlinkages through which banks are interconnected with other financial institutions such as a wider set of asset classes, e.g. cross holdings of securities or markets, e.g. OTC derivative markets. This would allow a more comprehensive assessment of contagion risk within the financial system arising from higher level of interconnectedness. 


\section{References}

Aoyama, H.; S. Battiston and Y. Fujiwara, (2013), "DebtRank Analysis of the Japanese Credit Network," RIETI Discussion Paper Series, 13-E-087, Available at: https://www.rieti.go.jp/jp/ publications/dp/13e087.pdf

Bank Negara Malaysia, (2013), Financial Stability and Payment Systems Report, [online], Bank Negara Malaysia, pp. 46-51, Available at: http://www.bnm.gov.my/index.php?ch=en_ publication\&pg $=$ en_fspr\&ac $=8 \&$ lang $=$ en

Bank Negara Malaysia, (2017), "Indebted to Debt: An Assessment of Debt Levels and Financial Buffers of Households," Financial Stability and Payment Systems Report, Bank Negara Malaysia, pp.39-48, Available at: http://www.bnm.gov.my/files/publication/fsps/en/2017/ cp01_001_box.pdf

Bank Negara Malaysia, (2018), Financial Stability Review - First Half 2018, Bank Negara Malaysia, pp.20-24, Available at: http://www.bnm.gov.my/index.php?ch=en_publication\&pg=en_ fsr\&ac $=25 \&$ en

Bardoscia, M.; S. Battiston; F. Caccioli and G. Caldarelli, (2015), "DebtRank: A Microscopic Foundation for Shock Propagation," PLOS ONE, 10(6), p. e0130406.

Bardoscia, M.; F. Caccioli; J. Perotti; G. Vivaldo and G. Caldarelli, (2016), "Distress Propagation in Complex Networks: The Case of Non-Linear DebtRank," PLOS ONE, 11(10), p. e0163825.

Bardoscia, M.; P. Barucca; A. Codd and J. Hill, (2017), "The Decline of Solvency Contagion Risk," Staff Working Paper, No. 662, Available at: https://www.bankofengland.co.uk/-/media/ boe/files/working-paper/2017/the-decline-of-solvency-contagion-risk [Accessed 7 Jan. 2019].

Basel Committee on Banking Supervision, (2014), "Impact and Implementation Challenges of the Basel Framework for Emerging Market, Developing and Small Economies," Working Paper, No. 27, Available at: https://www.bis.org/bcbs/publ/wp27.pdf [Accessed 7 Jan. 2019].

Basel Committee of Banking Supervision, (2018), "Capital Treatment for Bilateral Counterparty Credit Risk Finalised by the Basel Committee," [Available at: https://www.bis.org/press/ p110601.htm [Accessed 17 Dec. 2018].

Battiston, S.; D. Delli Gatti; M. Gallegati; B. Greenwald and J. Stiglitz, J., (2012), "Liaisons Dangereuses: Increasing Connectivity, Risk Sharing, and Systemic Risk," Journal of Economic Dynamics and Control, 36(8), pp. 1121-1141.

Battiston, S.; M. Puliga; R. Kaushik; P. Tasca and G. Caldarelli, (2012), "DebtRank: Too Central to Fail? Financial Networks, the FED and Systemic Risk," Scientific Reports, 2(1). 
Battiston, S.; G. Caldarelli; M. D’Errico and S. Gurciullo, (2015), "Leveraging the Network: A Stress-Test Framework Based on DebtRank," SSRN Electronic Journal.

Burrows, O.; D. Learmonth, J. McKeown and R. Williams, (2012), "RAMSI: A Top-down Stresstesting Model Developed at the Bank of England," Quarterly Bulletin, 2012 Q3, Bank of England, pp.204-210, Available at: 7. https:/www.bankofengland.co.uk/-/media/boe/files/ quarterly-bulletin/2012/ramsi-a-top-down-stress-testing-model-developed-at-the-boe.pdf [Accessed 28 Dec. 2018].

Elsinger, H.; A. Lehar and M. Summer, (2012), "Network Models and Systemic Risk Assessment," Available at: https://www.researchgate.net/publication/309187281_Network_models_and_ systemic_risk_assessment [Accessed 7 Jan. 2019].

Fink, K.; U. Krüger; B. Meller and L. Wong, (2016), The Credit Quality Channel: Modeling Contagion in the Interbank Market," Journal of Financial Stability, 25, pp. 83-97.

Glasserman, P. and H. Young, (2015), “How Likely is Contagion in Financial Networks?” Journal of Banking \& Finance, 50, pp. 383-399.

Hattori, M. and Y. Suda, Y., (2007), Developments in a Cross-Border Bank Exposure Network, Bank of Japan Working Paper, No. 07-E-21.

International Monetary Fund (IMF), Bank for International Settlements (BIS), the Commonwealth Secretariat (Comsec), Eurostat, the Organization for Economic Co-operation and Development (OECD), the Paris Club Secretariat, the United Nations Conference on Trade and Development (UNCTAD) and the World Bank, (2013), External Debt Statistics: Guide for Compilers and Users, Available at: https://unstats.un.org/unsd/nationalaccount/docs/External_debt_statistics_ guide.pdf [Accessed 28 Dec. 2018].

Kubelec, C. and F. Sa, (2010), "The Geographical Composition of National External Balance Sheets: 1980-2005," SSRN Electronic Journal.

OECD, (2012), "Financial Contagion in the Era of Globalised Banking?" OECD Economics Department Policy Notes, No. 14, June.

Opsahl, T.; F. Agneessens and J. Skvoretz, (2010), Node Centrality in Weighted Networks: Generalizing Degree and Shortest Paths," Social Networks, 32(3), pp. 245-251.

Remolona, E. and I. Shim, I., (2015), "The Rise of Regional Banking in Asia and the Pacific," BIS Quarterly Review, pp. 119-134, September, Available at: https://www.bis.org/publ/qtrpdf/r_ qt1509j.pdf [Accessed 28 Dec. 2018].

Reyes, J. and C. Minoiu, (2011), “A Network Analysis of Global Banking:1978-2009,” IMF Working Papers, 11(74), p. 1. 
Summer, M., (2013), "Financial Contagion and Network Analysis," Annual Review of Financial Economics, 5(1), pp. 277-297.

Tabak, B.; S. Souza and S. Guerra, (2013), "Assessing Systemic Risk in the Brazilian Interbank Market," Banco Central do Brasil Working Papers, Working Paper n. 318, Available at: https:// www.bcb.gov.br/pec/wps/ingl/wps318.pdf [Accessed 17 Dec. 2018].

Upper, C., (2011), "Simulation Methods to Assess the Danger of Contagion in Interbank Markets," Journal of Financial Stability, 7(3), pp. 111-125. 


\section{Appendix 1: Network Data and Methodology}

a. Table A1: List of Countries Nodes

\begin{tabular}{|c|l|l|}
\hline No. & Country Node & \multicolumn{1}{|c|}{ Label } \\
\hline 1 & Labuan & LABUAN \\
\hline 2 & Singapore & SG \\
\hline 3 & Cambodia & KHM \\
\hline 4 & Indonesia & IDN \\
\hline 5 & Thailand & THA \\
\hline 6 & Vietnam & VNM \\
\hline 7 & Laos & LAOS \\
\hline 8 & Brunei & BRN \\
\hline 9 & Philippines & PHL \\
\hline 10 & Myanmar & MMR \\
\hline 11 & Hong Kong SAR & HK \\
\hline 12 & China & CHN \\
\hline
\end{tabular}

\begin{tabular}{|c|l|l|}
\hline No. & \multicolumn{1}{|c|}{ Country Node } & \multicolumn{1}{|c|}{ Label } \\
\hline 13 & Japan & JPN \\
\hline 14 & Republic of Korea & KOR \\
\hline 15 & Chinese Taipei & TWN \\
\hline 16 & United States & US \\
\hline 17 & United Kingdom & UK \\
\hline 18 & Germany & DEU \\
\hline 19 & France & FRA \\
\hline 20 & Italy & ITA \\
\hline 21 & Spain & ESP \\
\hline 22 & Other Asia & OTHER ASIA \\
\hline 23 & Other Europe & OTHER EU \\
\hline 24 & Other Non-Residents & OTHER NR \\
\hline
\end{tabular}

b. Network Methodology

Figure A1

Clustering coefficient in a

Core-Periphery Structure

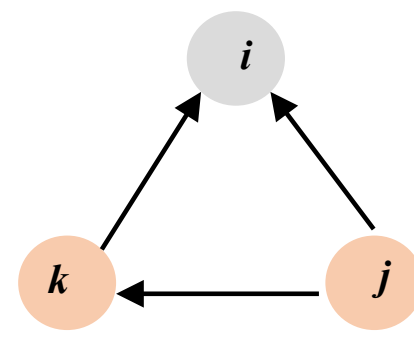

Figure A2

Betweenness Centrality in a

Network

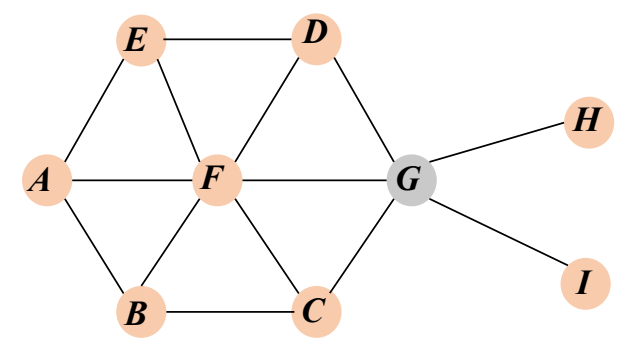

Figure A3

Average Outdegree and Indegree

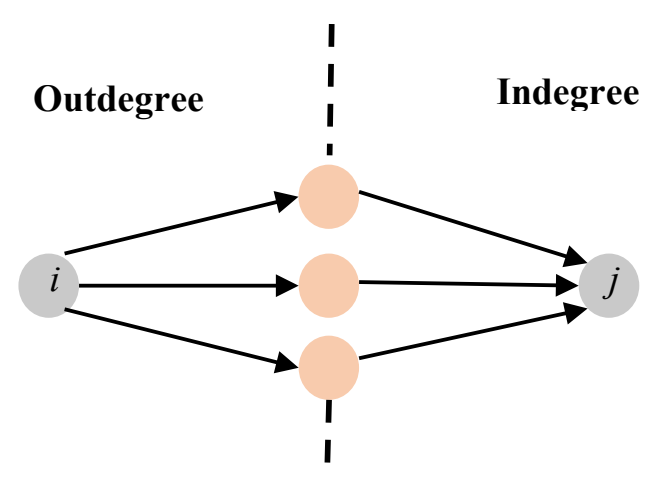




\section{Appendix 2: Counterfactual Simulation Model}

\section{a. Table 1: Description of the Main Variables}

\begin{tabular}{c|c|c}
\hline \multicolumn{1}{c|}{ Name } & Symbol & \multicolumn{1}{c}{ Description } \\
\hline Individual bank vulnerability & $h_{i}(t)$ & Relative loss in equity of bank $i$ at time $t$ \\
\hline System level vulnerability & $H(t)$ & Relative loss of equity for the whole system at time $t$ \\
\hline
\end{tabular}

\section{b. Table 2: Balance Sheet Dynamics}

Bank's assets are assumed marked-to-market whereas liabilities are carried at their face value

$$
\text { Assets, } A_{t} \quad=\quad \text { Liabilities, } L+\text { Equity, } E_{t}
$$

Each bank $i$ either lend to other banks within the network i.e. domestic interbank lending (Adib), or engage in any of the following (i) cross-border interbank lending $\left(A_{\text {ea }}\right)$, (ii) placements with central bank $\left(\mathrm{A}_{\mathrm{cb}}\right)$, (iii) holding of liquid securities $\left(\mathrm{A}_{\text {liqs }}\right)$ and (iv) holding of other assets $\left(\mathrm{A}_{\text {oth }}\right)$.

$$
A_{t}^{d i b}+A_{t}^{e a}+A_{t}^{c b}+A_{t}^{l i q s}+A_{t}^{o t h}=L+E_{t}
$$

Total leverage of each bank at time $t$ is the ratio of total assets and its equity, which can be disaggregated into its additive subcomponents as follows

$$
\begin{aligned}
\text { Total leverage, } l_{t}= & \frac{A_{t}}{E_{t}} \\
= & \frac{A_{t}^{d i b}}{E_{t}}+\frac{A_{t}^{e a}}{E_{t}}+\frac{A_{t}^{c b}}{E_{t}}+\frac{A_{t}^{\text {liqs }}}{E_{t}}+\frac{A_{t}^{o t h}}{E_{t}} \\
& l_{t}^{\text {dib }}+l_{t}^{\text {ea }}+l_{t}^{c b}+l_{t}^{\text {liqs }}+l_{t}^{\text {oth }}
\end{aligned}
$$

\section{c. Table 3: Contagion Stress-test Process}

At time, $t=1$ each bank experiences an effective negative credit shock, $r$ on cross-border interbank lending exposures to bank $k$

$$
\sum_{k} r_{k} A_{i, k}^{e a}=E_{t} \sum_{k} r_{k} l_{i, k}^{e a} \quad \text { where } \quad A_{i}^{e a}=\sum_{k} A_{i, k}^{e a}
$$

The loss incurred on cross-border interbank lending results in corresponding reduction in equity for each bank $i$ as follows:

$$
A_{i, k, t=0}^{e a}-A_{i, k, t=1}^{e a}=\sum r_{k} A_{i, k}^{e a}=E_{i, t=0}-E_{i, t=1}
$$


Simultaneously, each bank $i$ also experiences a reversal shock, $f$ on cross-border interbank borrowing exposures. Unable to replace the lost funding in the short-run, banks are forced to deleverage, first withdrawing their excess liquidity placements with central bank, $\mathrm{A}_{\mathrm{cb}}$ and then liquidating a portion, $z$ of their holdings of liquid securities, $A_{\text {liqs }}$ if there are insufficient placements with the central bank. A haircut, $x$ on banks' remaining holdings of securities replicates the potential price impact of simultaneous asset liquidation to replace lost interbank funding and adverse market movements. The reduction in value of liquid securities results in corresponding reduction in equity is given by:

$$
A_{i, t=0}^{l i q s}-A_{i, t=1}^{l i q s}=x(1-z) A_{i, t=0}^{l i q s}=E_{i, t=0}-E_{i, t=1}
$$

Cumulatively, individual relative equity loss at time $t=1$ is computed as follows:

$$
\text { Relative loss in equity, } h_{i, t=1}=\min \left\{1, \sum_{k} r_{k} A_{i, k}^{e a}+x(1-z) l_{i, t=0}^{l i q s}\right\}
$$

Following this, the likelihood of a distressed bank (referring to bank suffering from relative loss in equity) repaying its obligations on the domestic interbank market becomes lower as its creditworthiness deteriorates. At time $t=2$, banks that lent to distressed banks will incorporate information about the reduced creditworthiness into the valuation of their interbank lending exposure thereby incurring losses. The value of the interbank asset will lie between its face value (repaid in full) and zero (assuming no recovery in the event of default). In our study, the losses incurred in the second round by creditor bank is proportional to relative loss of equity incurred by debtor banks in the first round.

DebtRank excludes more than one reverberation, i.e. a bank can only transmit distress once to the network. We adopt similar premise in our study.

Individual relative equity loss at time $t=2$ is computed as follows:

$$
\text { Relative loss in equity, } h_{i, t=2}=\min
$$




\section{Appendix 3: Results}

Table A2

Betweenness Centrality (1Q 2013 vs 4Q 2017)

\begin{tabular}{l|c|c|c|c}
\hline \multirow{2}{*}{ SIB/ Non-SIB } & & \multicolumn{2}{|c}{ Betweenness Centrality } & Change \\
\cline { 2 - 5 } & & $\mathbf{1 Q} \mathbf{2 0 1 3}$ & 4Q 2017 & 4Q 2017 \\
\hline SIB 4 & 0.03 & 0.08 & $\uparrow$ \\
\hline SIB 2 & 0.09 & 0.08 & $\downarrow$ \\
\hline SIB 1 & 0.08 & 0.08 & $\leftrightarrow$ \\
\hline SIB 3 & 0.11 & 0.05 & $\downarrow$ \\
\hline NSIB 23 & 0.01 & 0.05 & $\uparrow$ \\
\hline SIB 4* & 0.01 & 0.03 & $\uparrow$ \\
\hline NSIB 12 & & 0.00 & 0.02 & $\uparrow$ \\
\hline NSIB 2 & 0.01 & 0.02 & $\uparrow$ \\
\hline SIB 5 & & 0.04 & 0.02 & $\downarrow$ \\
\hline NSIB 1 & & 0.09 & 0.01 & $\downarrow$ \\
\hline
\end{tabular}

${ }^{*}$ Subsidiaries of SIBs; fonts in green represent foreign banks, purple represents domestic banks.

Source: Authors' estimations. 



\title{
Chapter 7
}

\section{CROSS-BORDER INTERBANK CONTAGION RISK ANALYSIS FOR PAPUA NEW GUINEA}

\author{
By \\ Ludwig Aur Aba ${ }^{1}$
}

\section{Introduction}

The objective of this research is to highlight the contagion risks faced by banks with respect to their cross-border dealings and establish the networks through which potential contagion can spread from one country to another country. The research also attempted to identify the various sources of contagion risks, both domestic and external and estimate the size of their impacts on the domestic banks through the banking network. Another key aspect of the research is to increase the Central Bank's understanding of the sources of contagion and contagion transmission channels so it can be able to undertake proactive micro and macro prudential measures to intervene and mitigate potential losses associated with the banks' exposures from their cross-border trading.

This study is necessary given the important roles played by the banks in the PNG economy and the development of the banking and financial system into a more complicated network, with products and services more complex than before. A more complex financial system can conceal risks and will make it hard to detect potential contagion across borders.

I employed the network simulation analysis, combined with a stress testing and simple ordinary least squares (OLS) regressions to trace bank linkages and connectivity for systematic important countries (SIC), establish the stability of domestic banks and estimate the size of foreign shocks, especially from Australia. The analysis showed that connectivity of banks are straightforward, domestic banks are highly capitalized with limited impact of global commodity prices, interest rates and credits shocks from Australia. The network analysis showed an expansion in the network between countries, which reflected increases in both claims and liabilities of PNG against its trading partner countries.

The unprecedented changes in the global financial markets enabled the activities of banks and financial institutions to become closely linked and interconnected. The integration of financial markets nowadays provide opportunities for banks and financial institutions to expand and improve on sharing risks but the interconnectedness can pose threats as well. The growth in the banks' networks both domestic and across borders, combined with the growing complexity in the products they offer, can induce risks that can spread contagion across the entire financial system. This growing complexity in the financial system and products offered by financial intermediaries can make the detection of possible risks in the financial system very difficult. Central Banks, as regulators should be concerned about what is going on in the financial markets to ensure financial

1. Ludwig Aur Aba currently works as a Senior Research Analyst at the Research Department of the Bank of PNG. He can be reached via email: laba@bankpng.gov.pg.

Disclaimer: The views and opinions expressed in this paper are that of the author alone and does not necessarily reflect that of the Bank of PNG and/or The SEACEN Centre. 
system stability, an area that they directly regulate and supervise ${ }^{2}$. Therefore, it is important that the Central Banks understand the classes of exposures, the risks and the possible transmission channels of the contagion so they can introduce mitigating mechanisms to prevent contagions.

Shocks elsewhere can be transmitted via these channels of network and may cause financial distress and imbalance in the domestic financial system that can affect the health of the economy. The great financial crisis (GFC) in 2008 and the 1997 Asian Contagion presented valuable lessons about how contagion can spread through different transmission channels and how to manage risks in an era of increasingly complicated financial system network. With rapid globalization and evolution in information technologies, financial products and services offered by the banks and finance companies are becoming increasingly complex as well, which can provide opportunities for growth and profitability but also pose risks. In such a case, it is important to have an efficient and reliable banking and finance model and a regulator with robust regulatory policy platforms. This is to detect and mitigate risks arising from the more integrated financial market and the complex products and services offered by the banks, and also to ensure that the general condition of banking industry is healthy.

The number of literatures on cross-border contagions around the world is growing and is contributed mostly by Central Banks, International Monetary Fund (IMF), Bank for International Settlement (BIS) and others. However, there are limited studies for PNG and the Pacific Island countries so this paper is intended to fill that gap in the existing literature by using BIS locational banking statistics for PNG. Thus this analysis aims to contribute to this body of knowledge by providing both a qualitative and quantitative analysis on cross-border and domestic risks faced by banks in PNG. It is the aim of this research that policy makers are fully aware and equipped with appropriate policy models to deal with risks emanating from cross-border and domestic activities by banks.

In the paper outline, the second section is dedicated to reviewing existing literatures on the topic to see why this topic is important and what we already know about the topic; the third part looks at the overview of the financial system of PNG; the fourth section focus on data and methodology; the fifth section is on empirical analysis on capital adequacy ratio, credits, asset quality, liquidity and bank failure; section six is on cross-border activities, section seven is on cross-border shocks followed by the conclusion.

\section{Literature Review}

A number of studies have been done on this topic on Cross-border Interbank Contagion Risk Analysis. For example, the paper by Degryse et al. (2008) which discussed "Cross-border Interbank Exposures and Financial Contagion' noted that even though financial markets are integrated which enhanced global financial market intermediation, they also pose as threats for contagion. They cited the crises in Mexico in 1994, Asia in 1997-1998, Russia in 1998, Brazil in 1999 and the Long Term Capital Management (LTCM) in 1998 as examples of what can go wrong if the channels of financial contagion are not understood properly. Experiences in these countries showed that it is worthwhile to study the channels through which the contagion is transmitted. Therefore, they proposed that on the back of banks resorting to cross-border relationships and holding more international assets and liabilities, the banking sector require special attention because of the importance of their roles in the financial markets and the economy.

2. Bank of PNG regulates and supervises the Banks and Finance companies in PNG. 
Empirical studies by Halden and May (2011), Allen and Gale (2000), Yellen (2013) and Cerutti (2015) on the impact of the global financial crisis and the role of SIBs point to cross-border interbank exposures as the main factor affecting the systemic stability of the individual banking system through the transmission of shocks. According to Genberg (2017), the financial integration and network has become more complicated, especially in emerging market economies in Asia. Accelerated economic growth in the emerging markets is normally financed by banks, and the crossborder interbank linkages could have played a role in their growth. This type of interconnectedness can allocate funding efficiently on the back of innovation and competition, while posing higher contagion risk through systemic instability within the banks and financial institutions. The paper done by Glasserman and Young (2015) indicated that contagion risks can cause higher loses in a more strongly integrated and linked financial system. The complexity of the financial network is such that it can be hard to detect contagion risk related to interbank activities across borders. This is made even worse when banks are linked through off balance sheet financial activities. Therefore, with a complex financial cross-border interbank linkage, shocks are often concealed and potential for spill-over to other financial systems exist without being known.

According to the BIS statistical release (2018), there was a pickup in international banking activity between 2017 and first quarter of 2018. The fastest growth was in cross-border credit to nonbank financial borrowers, especially Governments in emerging and developing market economies. Cross-border lending also expanded across emerging economies in Asia, Africa, Latin America, Middle East and emerging Europe. The Asia-Pacific region saw rapid growth in financial flows since the GFC, which included the use of currencies of Asia-Pacific countries to trade that represented $40 \%$ of global trades (BIS, 2014). Cross-border financial integration captures capital flows as well as trade linkages, incipient flows, remittances, price arbitrage and risks. Financial integration offers enormous benefits but it can also present challenges. This is where macroprudential policy and liquidity management strategies becomes important and can play a role in reducing systemic risk in financial markets (BIS, 2014).

According to a number of literatures on the GFC, high capital inflows to emerging market and developing economies can be traced back to excessive global liquidity. The excess liquidity provided cheap dollars while at the same time forced global investors to seek higher yields and returns by shifting their portfolios towards emerging markets with higher interest rates and better economic prospects. This is the reason why there was strong capital flows into emerging market and developing economies. This means that a high and unstable capital flows can lead to macro and financial stability concerns, and managing capital flows to minimize such concerns can disturb macroeconomic management in emerging market and developing economies.

The paper by Remolona and Shim (2015) noted the intensification of the cross-border banking activity within the Asia-Pacific region after the GFC. Before the GFC, much of the crossborder activity in the region had been driven by dollar credit intermediated largely by banks, which have had origins in advanced economies. Banks within the Asia-Pacific region stepped in and dominated the cross-border banking activity after the crisis. The rise in the intra-regional trend was further boosted by the ASEAN member governments which adopted a regional banking integration framework, with the aim to balance the efficiency gains of regional integration against the risks of financial instability. The authors analysed the proliferation of regional bank branches and subsidiaries in the region, how these units fund themselves, and what the implications are for 
their lending behaviour. They raised some specific issues relating to financial stability: vis-a-vis the potential for concentration of lending to a few creditors and systemic risks involving foreign branches; liquidity risks in foreign currency funding; and the increasing share of short-term foreign currency loans in Asia-Pacific banks' intraregional lending.

The GFC shook the foundations of the international banking and financial system and put the banks under immense stress. Cross-border bank lending proved to be one of the major financial channels through which stresses in the international financial system were transmitted to individual emerging markets and developing economies (Takáts, 2018). During the GFC, cross-border lending by banks fell affecting economies and banks which relied heavily on cross-border lending. The catch was that although cross-border lending in dollars declined, lending by international banks in local currencies increased in the emerging market and developing countries (Takats, 2018). This indicated that foreign banks became major players in the domestic financial markets of most emerging market and developing economies because they operated almost as local banks with foreign ownership and expanded their credits in local currencies. Other regions, like the Euro continued to rely on cross-border lending that exposed their banking sector to risks such as currency mismatches (Takats, 2018).

Cihak and Ong (2007) examined the scope for cross-border spill overs among major EU banks and found that spill overs were more likely to happen within domestic banking systems, but cross-border links were expanding more than the domestic banks, which evidently supported the need for strong cross-border supervision. One important funding source was parent-bank lending during and after the crisis when other funding sources dried up. By 2007, domestic savings dried up and was insufficient to finance the growing credit creating funding gaps in many countries. Some economies lived with it for longer period, in other countries, credit stock was above deposits, while in others, deposit coverage was high. During the crisis, these financial gaps widened further due to the depreciation that increased the weight of forex loans in the stock of credit, lifting debt burdens of borrowers more (Cihak and Ong, 2007). Therefore, parent-bank lending accounted for a significant and increasing share of financing of these funding gaps in many countries. The growth in foreign currency lending was mainly to borrowers in the private sector who did not hedge, which resulted in a build-up in vulnerabilities during the run-up to the crisis. The main risks facing the financial stability were insufficient domestic funding base, deteriorating quality of bank's assets and increased exposures to the property market (Cihak and Ong, 2007).

Battiston et al. (2015) acknowledged that the global financial system has become increasingly large and interconnected, which is a key factor in precipitating the financial crisis as troubles in one financial institution spread quickly to others. In their work, and in the economic literature, network theory was used to study the financial sector as a complex system of interlinked agents, where they assessed the likelihood of systemic contagion, the different channels through which a contagion can spread, the linkages between the network and the resilience of the financial system.

Benelli et al. (2011) mapped out the cross-border financial linkages and identified key factors that drive them and the complexity that aided instability in the global financial system. This can underscore the value of safety net designed to prevent risks from spreading through the financial network and turn into a large-scale systemic crisis. In terms of mapping out the linkages, financial linkages increased and became more complex, with advanced economies still dominating the network of links across asset classes and regions, both as sources and recipients. From this, 
emerging markets' strongest links remain with advanced economies, although linkages among the emerging economies increased rapidly during the last decade. One of the key aspects of increased cross-border financial linkages is the diversification of risks for individual country, which tend to reduce exposure to local shocks. On the other hand, increased interconnectedness can facilitate the transmission of shocks throughout the financial network and make the global financial network more prone to systemic risk. The extent and complexity of cross-border financial linkages grew; with investor information on exposures becoming less certain that amplified systemic risks from panic respond to shocks. Benelli et al. (2011) pointed out that countries with shallow domestic financial markets and have their exposures concentrated in a few lenders are prone to drastic changes in the cross-border flows. Risk aversion can drive global financial markets and tend to intensify sharply during the crisis which amplified the transmission of shocks. These features highlighted that the costs of systemic shocks to others not affected by the crisis are high, which reinforced the case for policy-makers to design macroprudential policies to help ring-fence such countries from systemic shock contagion. Benelli et al. (2011) showed that geography and history played a key role in determining linkages between neighbouring economies and with those that are larger, developed, and financially advanced.

According to Upper (2007), creating a detailed mapping of links in the interbank trading across borders can simulate a credit default or liquidity contraction on the banks. Also, Nier et al. (2008) showed how the transmission of market and idiosyncratic shocks can be simulated, which become important in identifying the triggers of the contagion risk from market or idiosyncratic shocks. This is useful in assessing the impact of risk-sharing on cross-border interbank activities, which addresses solvency, liquidity contagion risks and ensuring effective prudential management policies by regulators.

\section{An Overview of the Financial System in Papua New Guinea}

The Central Bank (Bank of PNG) plays an oversight role in regulating and supervising the banking and financial system under the Banks and Financial Institution Act 2000 (BFIA), apart from its other functions. The financial system includes banks, savings and loans societies, superannuation funds, finance companies, micro-banks and life insurance companies. The overarching goal of such a supervisory and regulatory function is to maintain a sound market-based financial system and a risk-based supervision to achieve the stability objectives of the Bank of PNG. As part of the regulatory and supervisory roles, the Bank of PNG issues licenses to the banks and other financial institutions to conduct banking and other financial services in PNG. 
Figure 1

A Simple Overview of the Structure of the Banking and Financial System in PNG

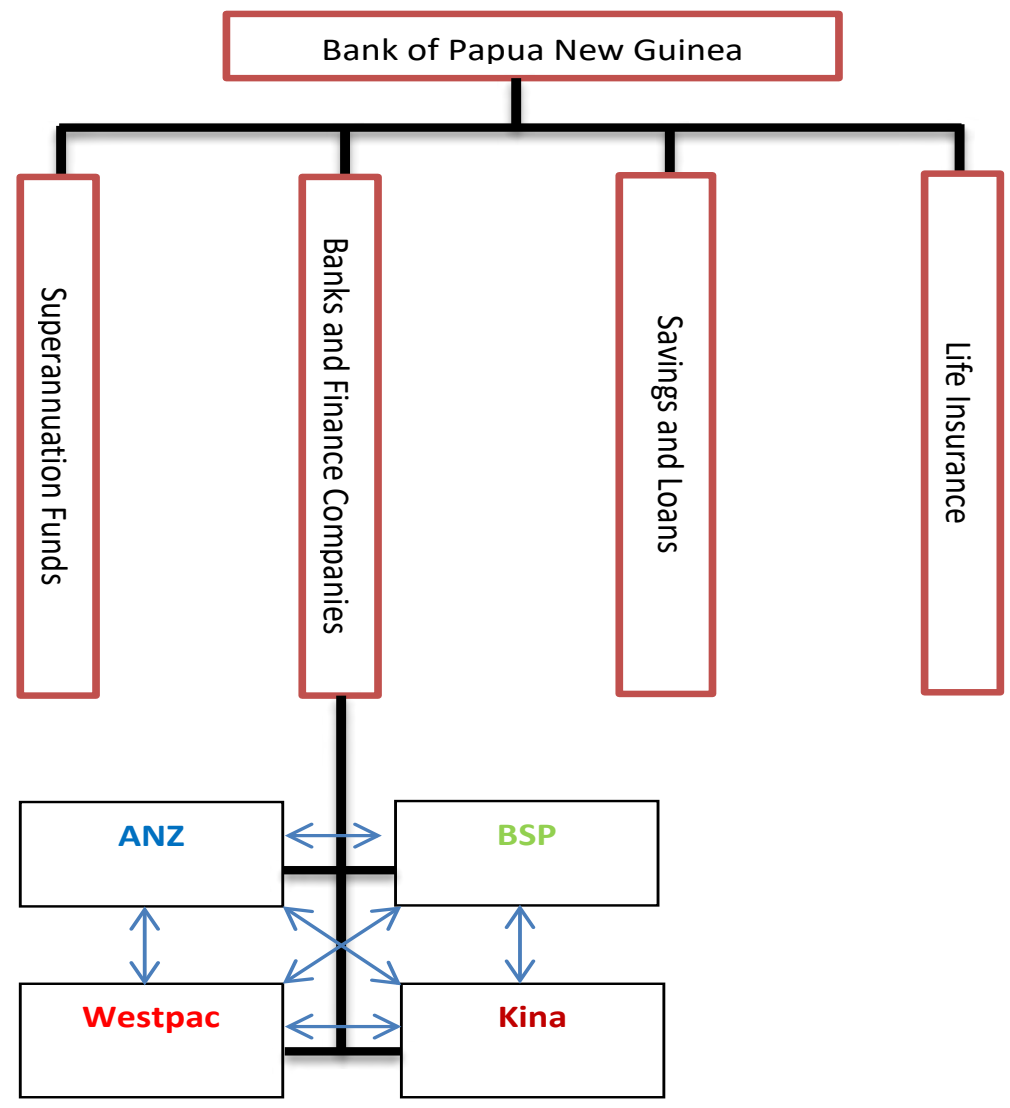

To operate a bank or finance company requires a license from the Bank of PNG. There are minimum regulatory requirements the licensee must meet. For example, meeting the minimum capital requirement; banks pay around US\$4.6 million, while for financial company is US\$0.46 million to obtain the license to operate. Apart from this, there are also other supplementary regulatory requirements. For example, the banks' top management have to meet the 'Fit and Proper" requirement. Figure 1 above shows the general regulatory structure of the whole financial system in PNG, having Bank of PNG as the regulator.

\subsection{Domestic Banking Activity}

One of the major objectives of the Bank of $\mathrm{PNG}$, as the regulator is to ensure that the financial system in PNG is stable. The PNG financial system is worth over 50\% of PNG's gross domestic product (GDP), thus it is important that stability is maintained to secure its integrity and the health of the PNG economy. The Bank of PNG drafts and implements appropriate legislations, regulatory and supervisory policies to achieve stability. The benefits of having these regulatory and supervisory policies are that the risks that would otherwise pose as threats to the financial system stability are detected early and mitigated or if they materialise, they are addressed appropriately to manageable levels. They also ensure that the financial and operational soundness of banks and financial companies are maintained, the interest of depositors, superannuation contributors and holders of life insurance policies are protected, as well as maintaining the general stability of the whole financial system to generate confidence about the financial system and economy. 
The banking industry consists of four commercial banks and a number of micro-banks. The four banks are; Bank South Pacific Ltd (BSP), Australia and New Zealand Bank (ANZ), Westpac and Kina bank. BSP, a locally owned bank is the largest, with branches and agents right across the country and the Pacific region; in Fiji, Samoa, Tonga, Solomon, Islands, Cook Islands, Vanuatu and a subsidiary in Cambodia. ANZ and Westpac are subsidiaries of Australian-based banks, while Kina is a new foreign bank, which bought off May bank in 2015. The micro-banks are very small players in the financial market.

The major challenges that are currently confronting the banking industry are the lack of foreign currency and trading in the interbank forex market. The banks are short in forex due to the growing demand for foreign currency spurred by increased import demand, combined with a drop in foreign currency inflows from lower prices of export commodities and foreign direct investments (FDI). There is access liquidity in local currency in the domestic banking system because banks have reached their exposure limits on lending to certain sectors of the economy, hence contributing to liquidity hangover in the system. The holding of liquidity is distributed unevenly across the banks with bulk of it is in the hands of only 1 or 2 banks, while others resort to borrowing in the domestic interbank and repo markets. Generally, the provision of banking services in the country present opportunities as well as challenges. The country's topography is rugged and remote and rolling out the banking and associated services such as telecommunications, roads etc. to other regions continue to remain major hindrances.

Despite the challenges, the banks have been performing strongly with huge profits. Arguably, the profits from their operations in PNG subsidize the costs of other branches in the Pacific. Their balance sheet is healthy, with positive net assets. Adequate capital is maintained and credit is also growing and is extended to all sectors of the economy. While lending to some sectors like the real estate dropped, home and personal loans increased, offsetting the fall in the real estate and commercial lending. However, credit as a fraction of GDP has fallen since April 2013. Declines in bank credit, GDP growth, commodity prices, and interest and exchange rates are seen as shocks in domestic banks' activity and can escalate to contagion in the banking network. For example, a liquidity shortage faced by a SIB both in the forex and domestic markets can lead to shortages in other banks that can spread and infect other healthy banks.

\subsection{Early Warning Indicators}

Contagion by definition is the spreading of disturbances from one market to other markets and comes in different forms and sources. Early warning indicators provide advance signals of an impending crisis. These can be in the form of excessive credit growth and asset prices, real economy, monetary aggregates, inflation, interest rates and others. It is important in PNG and elsewhere to establish protocols to identify early warning indicators of financial and macroeconomic risks and the necessary actions to mitigate them.

There must be advance warning signals about an impending underlying financial or real sector probable crisis so that policy makers are aware in advance and adopt pre-emptive measures to mitigate potential damages to the economy. This is because a crisis, when it occurs, is very expensive to restore the damages it caused. For example, building a counter cyclical capital buffer will go a long way in safeguarding the banks if there are signs that the banking sector is in distress. Some of the indicators identified by the International Monetary Fund (IMF) that may be used to generate early warning signals for crisis are listed in Table 1 below. 
Table 1

Early Warning Indicators

\begin{tabular}{|c|c|c|c|c|c|c|c|c|c|}
\hline $\begin{array}{l}\text { Credit } \\
\text { Developments }\end{array}$ & $\begin{array}{l}\text { Private } \\
\text { Sector } \\
\text { debt } \\
\text { burden }\end{array}$ & $\begin{array}{l}\text { Overvaluation } \\
\text { of Property } \\
\text { Prices }\end{array}$ & $\begin{array}{l}\text { External } \\
\text { Imbalances }\end{array}$ & $\begin{array}{l}\text { Mispricing } \\
\text { of Risks }\end{array}$ & $\begin{array}{l}\text { Health of Bank } \\
\text { Balance Sheet }\end{array}$ & Real Economy & $\begin{array}{l}\text { Monetary } \\
\text { Aggregate }\end{array}$ & Inflation & Others \\
\hline $\begin{array}{l}\text { Total Credit to } \\
\text { Private sector }\end{array}$ & $\begin{array}{l}\text { Real } \\
\text { Mortgage } \\
\text { Interest } \\
\text { rate }\end{array}$ & House prices & $\begin{array}{l}\text { Current } \\
\text { Account/GDP }\end{array}$ & $\begin{array}{l}\text { Short-term } \\
\text { interest rates }\end{array}$ & Leverage ratio & GDP & M1 & $\begin{array}{l}\text { Commodity } \\
\text { Prices }\end{array}$ & $\begin{array}{l}\text { Income } \\
\text { Inequality }\end{array}$ \\
\hline $\begin{array}{l}\text { Bank Credit to } \\
\text { Private sector }\end{array}$ & $\begin{array}{l}\text { Debt } \\
\text { service } \\
\text { ratio }\end{array}$ & $\begin{array}{l}\text { Ratio of House } \\
\text { Prices and } \\
\text { Income }\end{array}$ & Trade Balance & $\begin{array}{l}\text { Long term } \\
\text { interest rates }\end{array}$ & Bank profits & Global GDP & Global M1 & Inflation & $\begin{array}{l}\text { Deposit } \\
\text { Insurance } \\
\text { Schemes }\end{array}$ \\
\hline $\begin{array}{l}\text { Household } \\
\text { Credit }\end{array}$ & $\begin{array}{l}\text { Household } \\
\text { debt } \\
\text { service } \\
\text { ratio }\end{array}$ & $\begin{array}{l}\text { Ratio of House } \\
\text { prices and Rent }\end{array}$ & Trade/GDP & Yield curve & Bank deposits & $\begin{array}{l}\text { Real GDP per } \\
\text { Capital }\end{array}$ & M2 & $\begin{array}{l}\text { Global } \\
\text { Inflation }\end{array}$ & $\begin{array}{l}\text { Financial } \\
\text { Deregulation }\end{array}$ \\
\hline $\begin{array}{l}\text { Mortgage } \\
\text { Loans }\end{array}$ & $\begin{array}{l}\text { Corporate } \\
\text { debt } \\
\text { service } \\
\text { ratio }\end{array}$ & $\begin{array}{l}\text { Global House } \\
\text { prices }\end{array}$ & Exports & $\begin{array}{l}\text { Lending } \\
\text { rate/deposit } \\
\text { rate }\end{array}$ & Loan/Deposits & Output Gap & M2/Reserves & $\begin{array}{l}\text { Real } \\
\text { Interest Rae }\end{array}$ & $\begin{array}{l}\text { Capital } \\
\text { Requirement }\end{array}$ \\
\hline $\begin{array}{l}\text { Corporate } \\
\text { Credit }\end{array}$ & & $\begin{array}{l}\text { Ratio of global } \\
\text { house prices } \\
\text { and income }\end{array}$ & Imports & Stick returns & $\begin{array}{l}\text { Non-core } \\
\text { Liabilities }\end{array}$ & Unemployment & M3 & & Contagion \\
\hline Public credit & & \begin{tabular}{l}
\multicolumn{2}{l}{ Commercial } \\
Real estate \\
prices
\end{tabular} & $\begin{array}{l}\text { Capital } \\
\text { Flows/GDP }\end{array}$ & $\begin{array}{l}\text { Global stock } \\
\text { returns }\end{array}$ & $\begin{array}{lr}\text { Banks Net } \\
\text { Foreign Assets }\end{array}$ & $\begin{array}{l}\text { Industrial } \\
\text { Production }\end{array}$ & & & $\begin{array}{l}\text { Fixed } \\
\text { Exchange } \\
\text { Rate }\end{array}$ \\
\hline Global credit & & & Foreign Assets & $\begin{array}{l}\text { Aggregate } \\
\text { asset prices }\end{array}$ & $\begin{array}{l}\text { Bank } \\
\text { Reserves/Assets }\end{array}$ & $\begin{array}{l}\text { Industry } \\
\text { of GDP }\end{array}$ & & & Tax burden \\
\hline $\begin{array}{l}\text { Credit-to-GDP } \\
\text { ratio }\end{array}$ & & & Foreign Liabilities & $\begin{array}{l}\text { LIBOR OIS } \\
\text { spread }\end{array}$ & Bank Liquidity & Consumption & & & \\
\hline $\begin{array}{l}\text { Bank credit-to- } \\
\text { GDP ratio }\end{array}$ & & & $\begin{array}{l}\text { Foreign } \\
\text { Liabilities/Foreign } \\
\text { Assets }\end{array}$ & $\begin{array}{l}\text { Corporate } \\
\text { bond spread }\end{array}$ & $\begin{array}{l}\text { Banking Sector } \\
\text { CDS Spread }\end{array}$ & Investment & & & \\
\hline $\begin{array}{l}\text { Household } \\
\text { credit-to-GDP } \\
\text { ratio }\end{array}$ & & & $\begin{array}{ll}\text { Foreign } & \text { Direct } \\
\text { Investment } & \\
\text { (Decline) } & \end{array}$ & & $\begin{array}{l}\text { Financial Sector } \\
\text { Size }\end{array}$ & Capital/Output & & & \\
\hline $\begin{array}{l}\text { Mortgage } \\
\text { loans-to-GDP } \\
\text { ratio }\end{array}$ & & & $\begin{array}{l}\text { Foreign Portfolio } \\
\text { Investments } \\
\text { (decline) }\end{array}$ & & & $\begin{array}{l}\text { Government } \\
\text { Consumption }\end{array}$ & & & \\
\hline
\end{tabular}

Source: SEACEN workshop on Financial Cycles and Crisis (2018).

\section{Data and Methodology}

I used three approaches to estimate the impact of a macroeconomic shock on banking activities. Firstly, I used a simple stress testing model developed by Cihak (2007) to estimate the impact on banking activity by shocking some key macroeconomic variables. A shock from a credit default, non-performing loans (NPLs), credit and funding difficulties of a bank that causes a liquidity squeeze on other banks are also captured. Secondly, I used Gephi, a network simulation analysis software to trace the links between banks' claims and liabilities using the BIS locational banking statistics. In the third approach, I used a simple ordinary least squares (OLS) regressions using Eviews to estimate the extent to which a shock in commodity prices, GDP, interest rates and credit in Australia impacted domestic banking activity, especially credit, capital adequacy and liquidity in PNG. GDP, credit and interest rates in Australia are chosen because; (i) Australia is a major trading partner, (ii) two big banks operating in PNG have headquarters in Australia, and have operations in the Pacific and across Asia, and (iii) geographical proximity. The analysis is on the source of possible contagion spill-over and triggers in the domestic banking system and between banks in PNG and Australia. 


\subsection{Data}

The quality of data is important in order to do a good empirical analysis. In this study, I used the commercial banks' 2017 financial statements, including monthly data for the active commercial banks obtained from the Bank of PNG for the period January 2011- June 2018. The following data were also sourced from the Bank for International Settlement (BIS) website; (i) 2018 March quarter data on cross-border positions by instrument, sector and currency, (ii) 2018 March quarter crossborder positions by location of banking office, and (iii) Consolidated positions on counterparties resident in Papua New Guinea for amount outstanding at the end of March 2018.

The monthly data for commodity prices were from the World Bank for the period January 2000 to June 2018. Crude oil prices are in US dollar per barrel and are the average of Brent, Dubai and West Texas Intermediate (WTI). The price for the Liquefied Natural Gas (LNG) is in US dollar per one million British Thermal Units ( $\$ / \mathrm{mmbtu})$, the prices of coffee, cocoa, tea and oil palm are also in US dollar per kilogram $(\$ / \mathrm{kg})$, while the prices of gold is in US dollar per troy ounce $((\$ /$ troy oz) and the price of copper is in US dollar per metric tonne $(\$ / \mathrm{mt})$.

The GDP data for PNG is available by year (not monthly). For this study, I used Eviews Quadratic match sum ${ }^{3}$ to convert the annual data into monthly data. This is useful to calculate the monthly credit-to-GDP ratio from 2011 to 2018. The actual GDP for 2011-2014 is from the National Statistical Office, while the estimates for 2015-2018 are sourced from the 2018 PNG National Government Budget.

The GDP, credit and interest rates data for Australia for the period January 2011 to June 2018 were sourced from Reserve Bank of Australia. These data are important because ANZ and Westpac, which operate in PNG have their headquarters in Australia and operations in New Zealand, Fiji and across the Asia - Pacific region. This is to ensure there is consistency in the story about the contagion being passed on to other countries through such networks.

For the network analysis, I used the December Quarter 2005 and June Quarter 2018 BIS Banking Location Statistics to do comparison between this 2 periods and the movement in their linkages.

All the data were converted into US\$ using the end of period exchange rates, PGK/US\$ and AU\$/US\$.

\subsection{Methodology}

For the banks' stress testing, I used the same approach as in Cihak (2007) Stress Testing Framework. ${ }^{4}$ In this approach I shocked domestic credit, exchange rate, NPL and interest rate to see the impact on capital adequacy ratio, credit and liquidity.

3. It has the benefit of relatively few data points being interpolated and the source data is fairly smooth.

4. In this framework, there is a macroeconomic model where external shocks are linked to GDP, Interest rates and exchange rate that affect a satellite model that links the macroeconomic variable to the asset quality of banks. Both model mapped the shocks to the banks' balance sheets, its impact and the correction needed. This article can be found here: https://www.imf.org/external/pubs/ft/wp/2006/wp06163.pdf. 
The OLS equation to estimate the extent of the impact on PNG domestic credit from external shocks, especially interest rates and credit in Australia, which is given by:

$$
\Delta C_{t p}=\Delta R_{a}+\Delta C_{b a}+\Delta C_{i h a}+\Delta C_{o o h a}+\Delta C_{t a}+\Delta I_{u}
$$

(Equation 1)

where: $\Delta \mathrm{C}_{\mathrm{tp}}=$ Total Credit Extended by banks in PNG, $\Delta \mathrm{R}_{\mathrm{a}}=$ Overnight Call Rate in Australia, $\Delta \mathrm{C}_{\mathrm{ba}}=$ Business Credit in Australia, $\Delta \mathrm{C}_{\mathrm{iha}}=$ Credit for investor housing in Australia, $\Delta \mathrm{C}_{\text {ooha }}=$ Credit for Owner Occupied Housing in Australia, $\Delta \mathrm{C}_{\mathrm{ta}}=$ Total Credit for Australia, and $\Delta \mathrm{I}_{\mathrm{u}}=$ Unsecured lending rate in Australia.

The OLS equation to estimate the extent of the impact on PNG domestic credit from commodity price shocks is given by:

$$
\Delta C_{t p}=\Delta M_{p i}+\Delta C L N G_{p i}+\Delta A_{p i}
$$

(Equation 2)

where: $\Delta \mathrm{C}_{\mathrm{tp}}=$ Total Credit Extended by banks in PNG, $\Delta \mathrm{M}_{\mathrm{pi}}=$ Mineral price index ${ }^{5}, \Delta \mathrm{CLNGpi}=$ Crude oil and liquefied natural gas price index, and $\Delta \mathrm{A}_{\mathrm{pi}}=$ Agriculture commodity price index ${ }^{6}$

For the network simulation, the concepts explained are specific for this paper. The crossborder exposures are represented as a visual network, in which the network consists of nodes and the connection between them is represented by links. The number of nodes (n) defines the size of the network. The links can be directed or undirected and it is said to be directed when the link from one node to the other node is known and meaningful, and a node represent a country. From a sequence of nodes, where a node is linked to the next node is called walk, and a walk is referred to as a path if all links are directed. The length of a path between two nodes is measured by the number of links between the two nodes (Hattori and Suda, 2007).

The BIS Banking Location Statistics was used to cover individual countries and the amounts outstanding of cross-border bank exposures in terms of asset and liability between PNG and other countries. Given the definitions above and in the literature on network analysis, a node represents a country in the database, while a link represent the exposure from one reporting country to another country. A link in these statistics is treated as a directed link; a path and length of a path still retain their definitions as above. The size of the nodes represents the size of the exposure; that is, the bigger the nodes, the bigger the exposures, while the size of the links represents the importance and closeness of the nodes to each other. The cross-border bank exposure network is visualised in Figures 11 and 12. We see that the network is growing despite the low number of nodes and links.

In this paper, Gephi was used for the network simulation and visualization including using its properties of basic centrality measures such as indegree, outdegree and degree. According to Macpherson et al. (2001), and Wasserman and Faust (1994), a directed network is the sum of the indegree and outdegree and the average degree can be represented as: average degree $=\frac{\text { Total number of links }}{\text { Total number of nodes }}$. Betweenness centrality measures the number of times a

5. Index is calculated using the prices of Gold and Copper.

6. Index is calculated using the prices of palm oil, coffee and cocoa. 
node lies on the shortest path between other nodes and is represented by: betweenness centrality $=\frac{\text { Total number of shortest path through a node }}{\text { Total number of shortest paths between each node }} . \quad$ Closeness centrality measures the average length of the shortest path (d) between the node ( $i$ and $j$ ) and all other nodes and is represented by: Closeness centrality $(\mathrm{c})=\sum \frac{\mathrm{d}}{\mathrm{d}(\mathrm{i}, \mathrm{j})}$. Network simulation can be represented as in Espinosa-Vega and Sole (2010):

$$
\sum_{\mathrm{n}} \mathrm{Xnm}+\mathrm{an}=\mathrm{kn}+\mathrm{bn}+\mathrm{dn}+\sum_{\mathrm{m}} \mathrm{Xmn}
$$

where: $X n m$ stands for bank $n$ lending to bank $m$, an stands for bank $n$ 's other assets, $k n$ stands for bank $n$ 's capital, $b n$ are long term and short-term borrowing, $d n$ stands for deposits, and Xmn stands for bank $n$ borrowing from bank $m$. Network connectivity is calculated as; $\mathrm{p}=\frac{\mathrm{m}}{\mathrm{n}(\mathrm{n}-1)}$, where: $p=$ probability of connectivity between two nodes, $m=$ the number of links, $n=$ nodes.

\section{Empirical Analysis}

The empirical part is divided into three sections. In the first part, I used a stress testing model to shock the banks' sectoral credit, NPLs, exchange rate and interest rates to see their impact on capital adequacy ratios, credit, liquidity and the probability of default. The purpose of a bank stress test is to ensure that banks have enough capital on their balance sheets to counteract a severe economic downturn and that they maintain strong capital levels. This will make sure that the banks retain their ability to lend to households and businesses during a downturn. The following shocks were applied concurrently to see the impact on the banks' capital adequacy ratio (CAR), probability of default, liquidity, asset quality and sensitivity to market risks; (i) a $30 \%$ increase in nonperforming loans (NPL), (ii) a 5\% depreciation in the kina exchange rate, (iii) a $10 \%$ shock in the agriculture/forestry/fishery, (iv) a 15\% shock in real estate, and (v) a 5\% shock in commerce trade, and a $4 \%$ shock in the other sectors. In the second part, I used the network simulation analysis to study the linkages between PNG and other countries through their claims and liabilities using the BIS banking locational statistics. In the third part, I used a simple OLS regression to estimate the correlation between a shock in global commodity prices, GDP, credit and interest rates in Australia and credit in PNG and by how much the bank activities in PNG are impacted.

\subsection{Capital Adequacy}

The balance sheet contains information about the asset and liability of the banks that reveals the underlying health of the bank. Part of this is the capital base of the banks, which is critical to the banks, financial system and economy because they act as cushion to absorb any unforeseen shocks. It reveals the source of the banks' credits and debts, non-performing loans and bad debts, which are important in identifying the sector/industry that the bank borrows or lend money to. For banks in PNG, the total asset/liability gap is positive and showed a positive trend, indicating a more robust capital base. This can act as a buffer against unforeseen shocks. However, a banking crisis in Australia or elsewhere will spread quickly because of the integrated financial network between Australia and PNG. As shown by the correlation between credit and interest rates in Australia and PNG, prudential measures remain important to ensure domestic banks maintain their capital buffers. 
Table 2

Regulatory Minimum Capital Requirements

\begin{tabular}{l|l|l|l}
\hline Capital Threshold & $\begin{array}{l}\text { Minimum } \\
\text { Leverage Ratio }\end{array}$ & $\begin{array}{l}\text { Tier 1 Risk-based } \\
\text { Capital }\end{array}$ & $\begin{array}{l}\text { Total Risk-based } \\
\text { Capital }\end{array}$ \\
\hline Well Capitalized & $\geq 8 \%$ & $\geq 10 \%$ & $\geq 14 \%$ \\
\hline Adequately Capitalized & $6 \%<8 \%$ & $8 \%<10 \%$ & $12 \%<14 \%$ \\
\hline Undercapitalized & $4 \%<6 \%$ & $4 \%<8 \%$ & $8 \%<12 \%$ \\
\hline Significantly Undercapitalized & $2 \%<4 \%$ & $<4 \%$ & $<8 \%$ \\
\hline Critically Undercapitalized & $<2 \%$ & \multicolumn{2}{|l}{ Not relevant anymore } \\
\hline
\end{tabular}

Source: Bank of PNG.

Table 2 above shows the regulatory threshold minimum capital requirements for banks operating in PNG. Figure 2 below shows the actual capital held by banks against the minimum threshold required by the Bank of PNG, as the regulator.

The capital adequacy ratio measured as the ratio of 'pre-shock capital and risk-weighted asset" is used to reflect how much high-quality, highly liquid capital a bank has relative to a riskweighted measure of assets. It is one of the critical elements of the prudential standards to maintain the capital buffers to absorb any potential losses. It prescribes the range of capital ratios to measure whether a bank is under, adequately or over capitalized.

\section{Figure 2}

\section{Minimum Capital Threshold Against Actual}

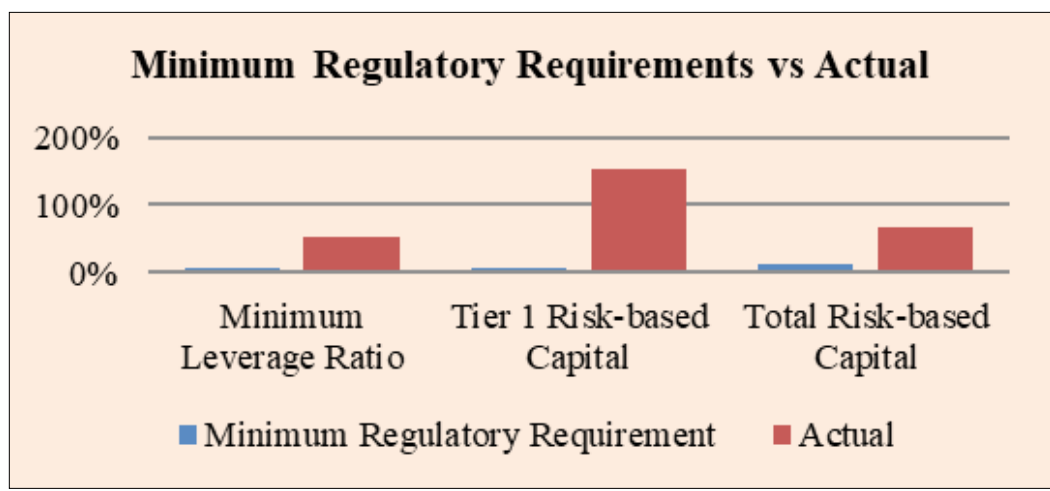

Source: Bank of PNG.

Most of the banks in PNG are in the category of highly capitalized banks. Their position is way above the minimum regulatory requirement of $8 \%$ for Tier 1 , total risk-based ratio of $12 \%$ and leverage ratio of $6 \%$ set by Bank of PNG. This means that a shock in non-performing loans, interest and exchange rates will have minimal shock to the banking system. However, this is not to say, the impact is the same on each bank. For example, the impact on foreign banks is larger than domestic banks. This may be explained by foreign banks being exposed to external risks. This is shown in Figure 3 below, where aftershocks and contagion are higher in foreign banks than domestic banks. In PNG, the Central Bank sets the prudential standards on their assets and liabilities, including placing $10 \%$ of deposits at the Central Bank. 
Figure 3

\section{Capital Adequacy Ratio (Total and by Banks)}
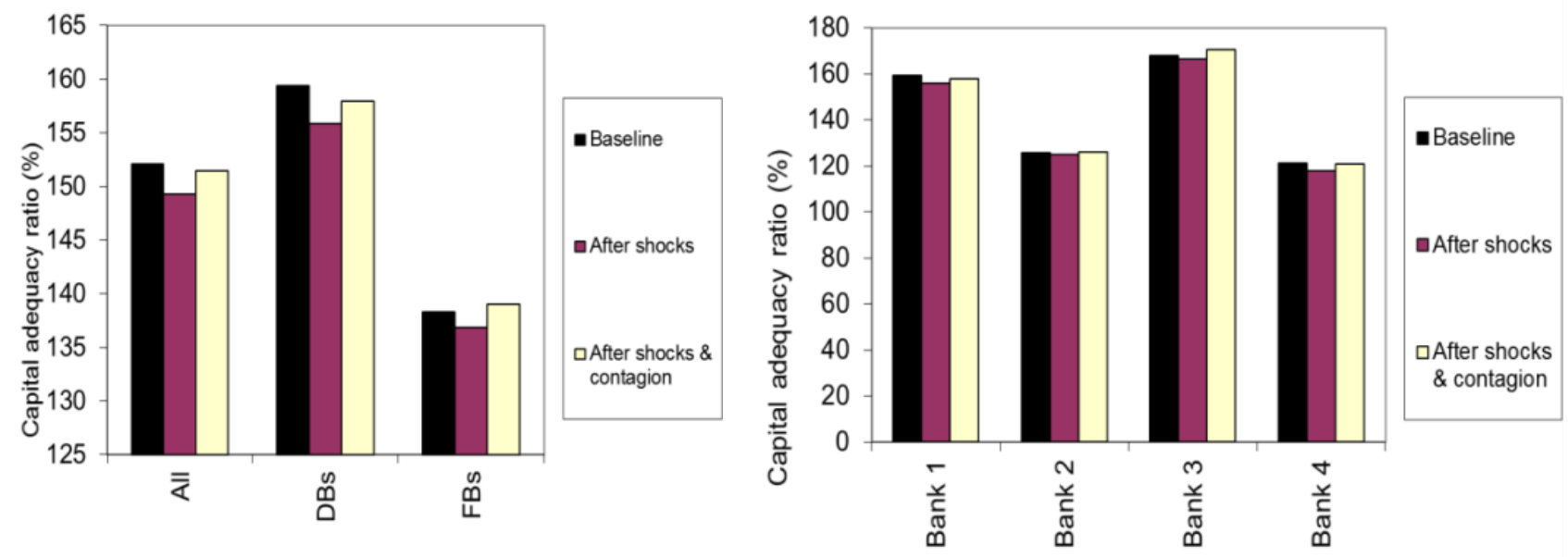

Source: Bank of PNG.

\subsection{Credits and Asset Quality}

The 2008 GFC was a red flag for financial institutions, more so banks in their approach to their credit lines and lending and the quality of asset they hold. Credit performance (loan portfolio) is one of the key indicators of a bank performance. Bad loans can lead to defaults and cause a bank into distress and eventually causing losses and affecting their balance sheets. If this is a SIB, others which are connected to it can be affected as well. Bank lending depends on the total amount of loanable funds available to the bank to lend and its success depends on the borrower's ability to repay the loan. Generally, bank lending has shown mixed trends in PNG.

Figure 4 below show the trends in loan portfolios; personnel, housing and commercial as well as defaults. Commercial lending started to increase after 2010 and remained relatively flat until 2015, which started to decline. Housing and personal loans remained flat until after 2015 that started to increase. Defaulting loans remained relatively flat until mid-2015 when it soared dramatically, reflecting default on loans, mainly personal. This presents a fundamental underlying risk and if not addressed quickly, can lead to more defaults and potential stress in the banking system. NPLs extended by banks remained low against the total loans and regulatory capital. 
Figure 4

Bank Lending and Defaults

\section{Banks Credit: Commercial, Housing \&}

Personal Loans

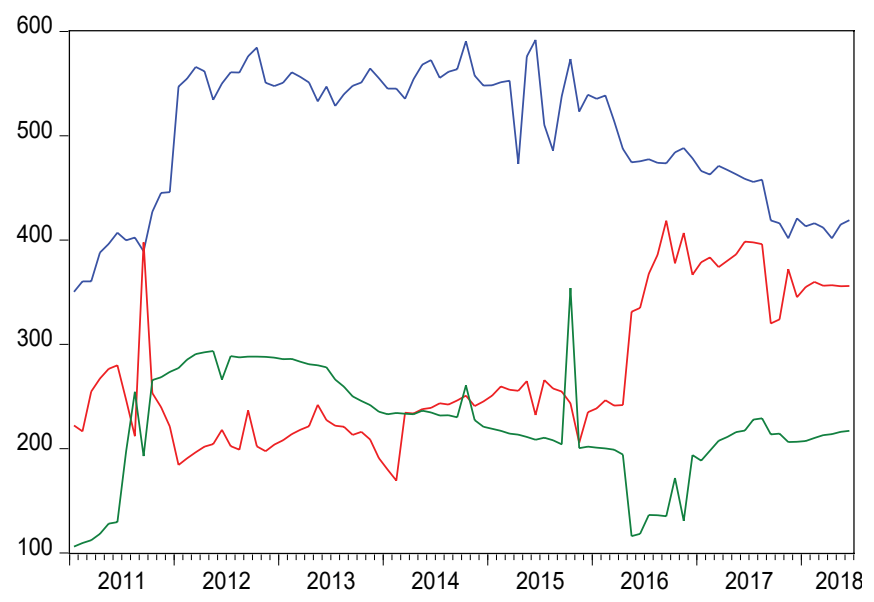

Default (Bank Loss)

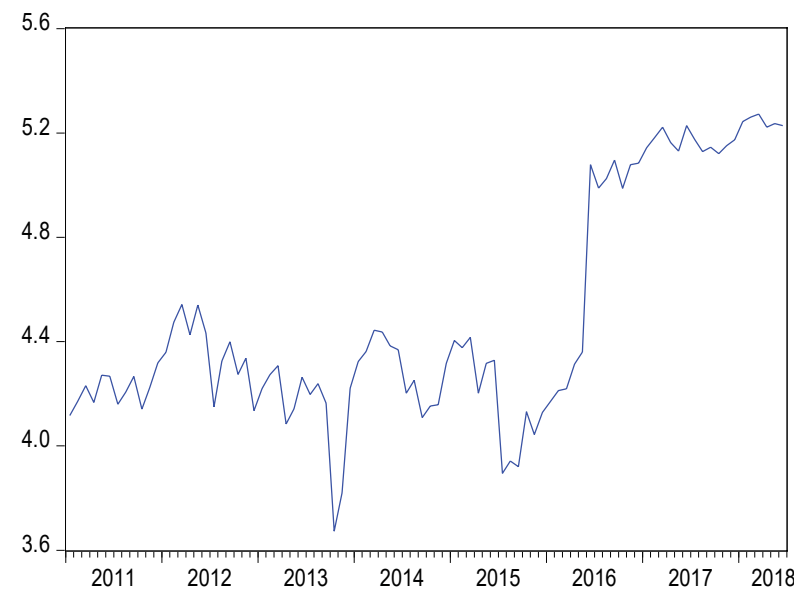

Source: Bank of PNG.

Figure 5 below shows that NPLs is low, which is only $1.4 \%$ of total loans, while NPLs provisions as a fraction of regulatory capital is negative, which reflect the low level of NPLs against a higher provision. This indicated sufficient buffer that any loss can be covered with higher provisions.

Figure 5

Non-performing Loans

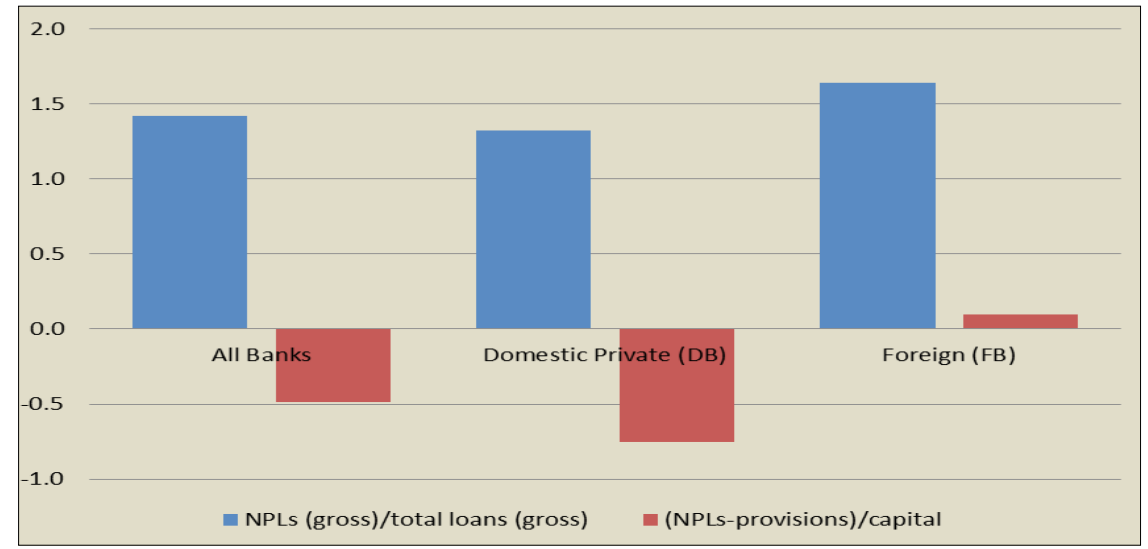

Source: Bank of PNG.

The banks' traditional focus is on extending credit and loans to customers therefore, credit risk remains the most important for banks. Banks mainly take deposits and provide banking and extend credit to households and firms. However, the risk is that if an increase in lending is concentrated in only one sector of the economy, firm or household and the borrower is unable to repay and default, the bank is going to be in serious trouble. 
Figure 6 below shows the distribution of loans across different sectors of the economy, mainly in wholesale and retail, households, others and real estate sectors. Domestic banks extended 51\% of their lending to the wholesale and retail, $21 \%$ to the household, $12 \%$ to the real estate and the remaining $16 \%$ to other sectors. On the other hand, foreign banks concentrated their lending in other sectors by $36 \%$, wholesale and retail and real estate with $17 \%$ apiece, household by $12 \%$, manufacturing by $11 \%$, and the other remaining sectors by $7 \%$. Generally, bulk of the total lending is extended to wholesale and retail, and household sectors, while equal and sizeable amount is extended to the real estate and other sectors.

Figure 6

\section{Banks' Lending to Different Sectors of the Economy}

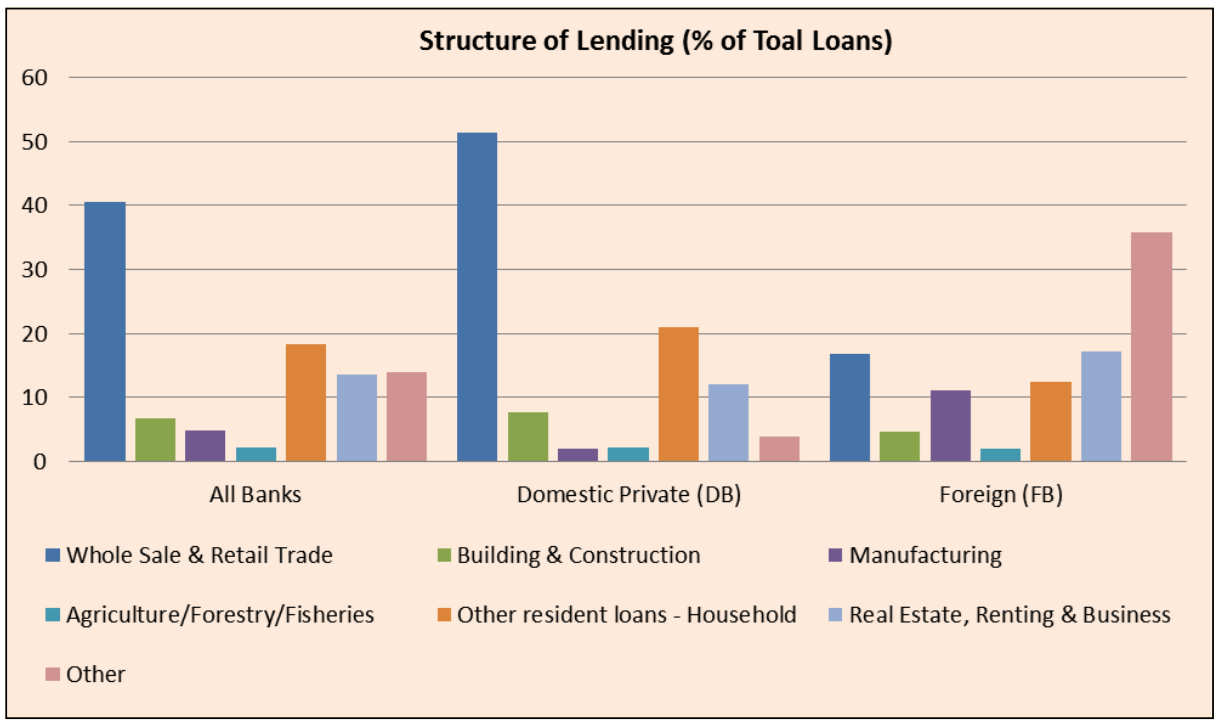

Source: Bank of PNG.

Each sector presents its own unique risks and as part of the banks' management of risks, they have to distribute their lending fairly across the various industries. The decision to lend should be based on the borrower's ability and willingness to repay the loan. Banks should not only rely on the value of collateral or some other guarantee offered by the borrowers to approve a credit. Although collateral is important, the primary factor should be the ability to repay the loan. Collateral and guarantees may not be enough to prevent financial losses when the customers fail to repay their loans. Therefore, knowing your customers and assessing their creditworthiness is critical to the banks because their ability to repay is important to ensure banks extend credit to the right customers and remain profitable. Banks in PNG do have mechanisms to monitor credit exposures in line with the Bank of PNG prudential standards that require loans are classified into various grades of default risk to which, the banks have to comply.

\subsection{Liquidity and Bank Failures}

Banks, by virtue of their operations are exposed to liquidity risks where they are unable to meet their financial obligations as they fall due. The key to eliminate these risks is to have sufficient funds available to meet all financial obligations. Therefore, it is important that banks match and control mismatch their maturities and interest rates on assets and liabilities. Although, unmatched position can enhance profitability, it can also increase the risk of losses. 
In PNG, the banks are required by the Central Bank to hold a fraction of customers' deposits as Cash Reserve Requirement (CRR) with the Central Bank on a daily basis. It is $10 \%$ of total deposits. With respect to the stress test, their ratio of liquid assets and liabilities dropped but remain positive. Individually, all but only one bank dropped by $1.9 \%$. This can be seen in Figure 7 below where liquid asset as a faction of total liability remain positive, over US\$10 million.

Figure 7

Liquidity and Liability

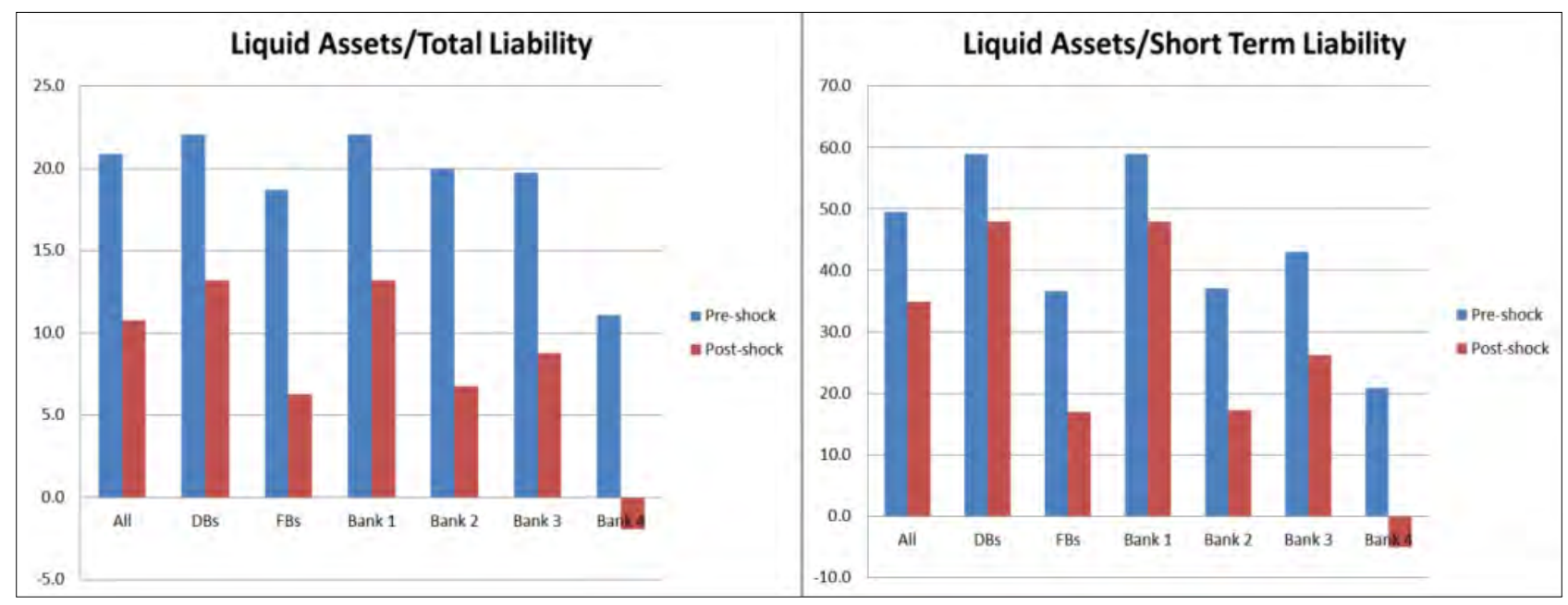

Source: Bank of PNG.

According to Cihak (2007), the z-score shows the probability of default by the banking industry, calculated as the weighted average of the z-scores of an individual bank in a country by comparing a bank's buffers on capitalization and returns with the volatility of those returns. It provides a measure of bank soundness, i.e. the probability that the value of its assets becomes lower than the value of its debt. It also measures how much return has to fall in order to trigger depletion in equity. A higher z-score corresponds to a lower probability of insolvency risk. With the stress testing for banks in PNG, it shows that probability of default is more prominent in smaller banks than bigger adequately-capitalized banks.

Figure 8

Probability of Default

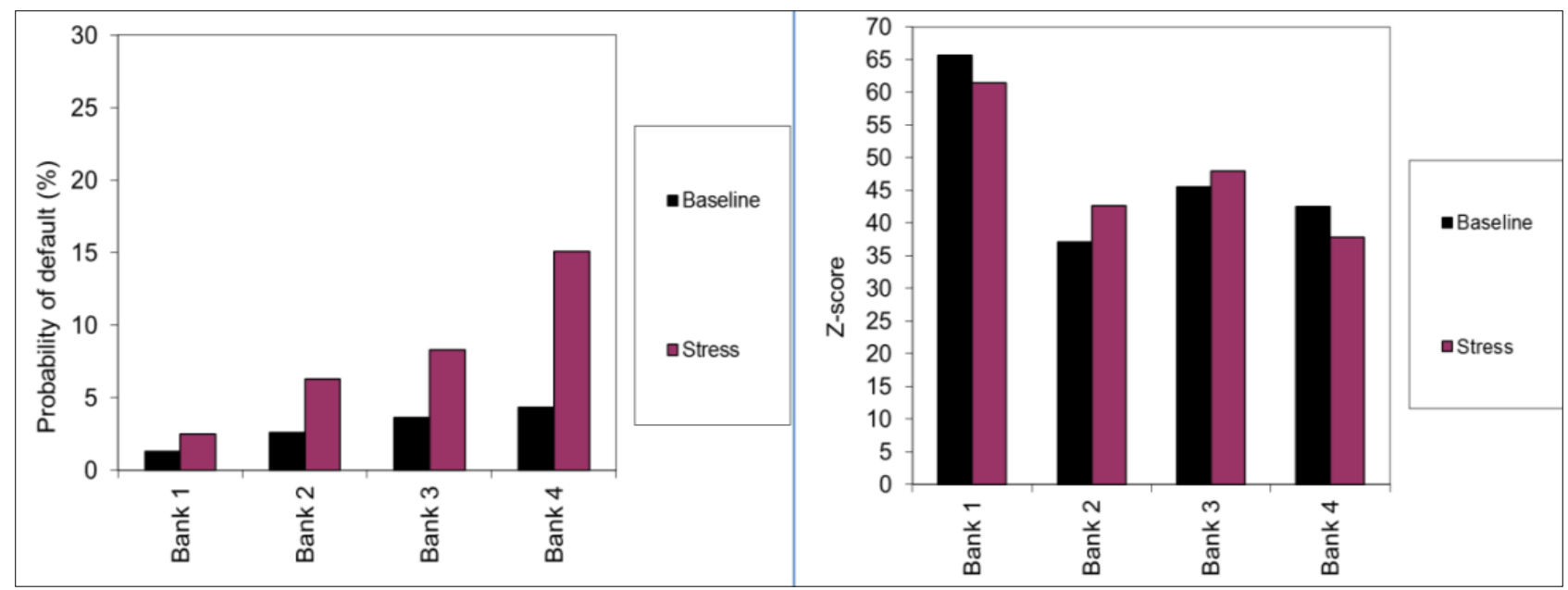

Source: Bank of PNG. 
In any banking crisis, the banking system can experience financial disturbance in the form of a large number of people withdrawing their money from the banks (bank runs) and that banks are making loses and/or are liquidated. These may result in the banks receiving help from either the Central Bank or the Government to bail them out. According to the International Monetary Fund (IMF), the situation becomes serious if at least three of the following take place: (i) liquidity support from the Central Bank is more than $5 \%$ of deposits and foreign liabilities, (ii) cost of restructuring the banks, including recapitalizing are at least 3\% of GDP, (iii) large scale nationalisations of SIBs, (iv) significant guarantees by the Government on bank liabilities, (v) the Central bank purchases assets from financial institutions of at least 5\% of GDP, and vi) the bank is placing a freeze on deposits. None of the above has happened or faced PNG banks yet.

Figure 9

\section{Liquidity Test and Capital Flight}

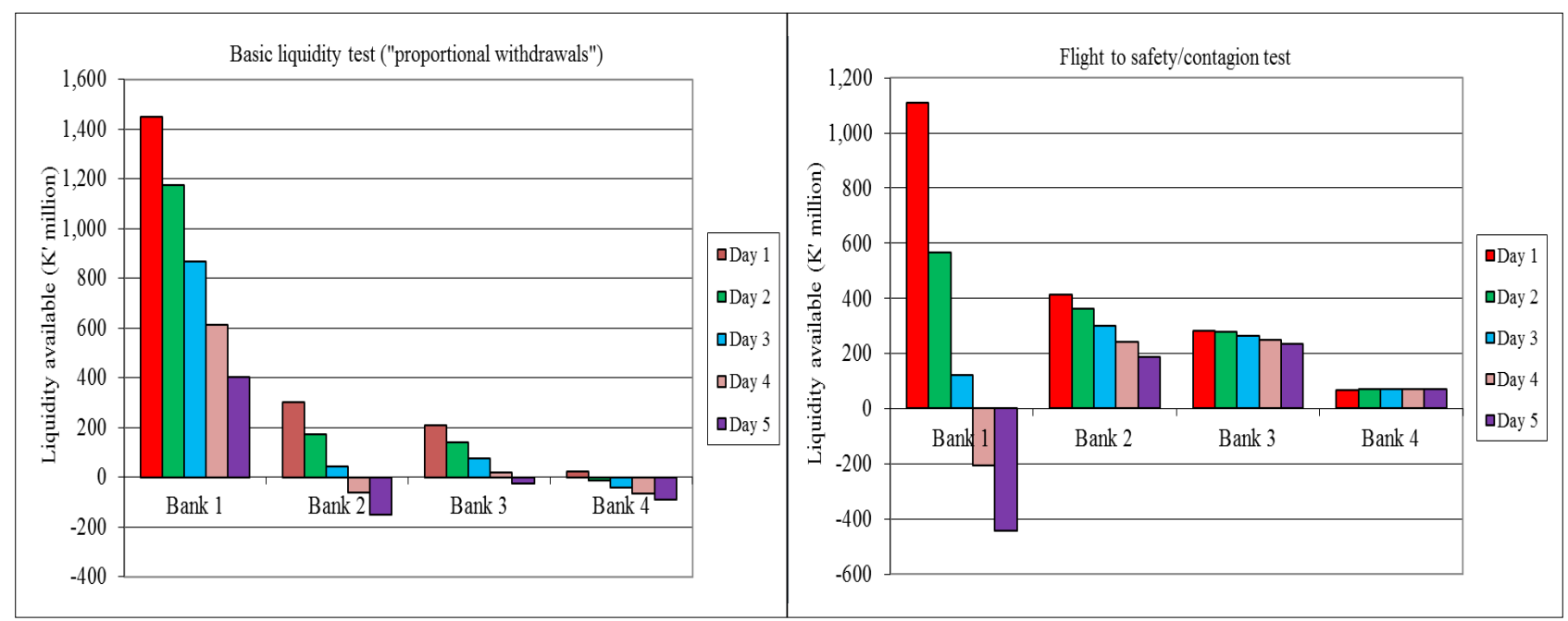

Source: Bank of PNG.

For PNG domestic banks, liquidity was still adequate 5 days after the shocks were introduced. However, flight to safety was enforced after the third day. For foreign banks, liquidity was reduced after 3 days, while there was limited capital flight.

\section{Cross-border Activities}

\subsection{Foreign Exchange Interbank Market in PNG}

The forex interbank market is where banks trade different currencies to facilitate trading of goods and services. An ideal interbank market ensures that there is competition for banks to buy and sell forex at a price that is fair to all dealers. The dealers can undertake forex deals for their clients or for themselves and are willing to offer prices to other participants as well as ask for prices. The forex interbank market in PNG has been dysfunctional, mainly from a lack of foreign exchange inflows since 2013 (Sampson, 2018) that resulted in an imbalance in the forex market. There was evidently imbalance in the demand and supply of foreign exchange in the interbank market, where the demand for US dollar was more than the supply of US dollar, leading to an oversupply of the local currency spurred by increased Government spending that led to an increase in import orders. The key reasons for the shortage in the forex were fall in prices of PNG's export commodities since 2011 and the end of the construction phase of the PNG Liquefied Natural Gas (LNG) in mid-2014, 
combined with rigidity in the exchange rate not adjusting fast enough to accommodate the fall in foreign exchange inflows into the economy. With the rigidity in the exchange rate, the role of the forex interbank market to set the price failed resulting in the local currency (kina) not adjusting to find its equilibrium level. With the lack of forex interbank trade and no alternative markets to access the forex, dealers that have a short position have no incentive to bid the kina exchange rate down. One of the main reasons why there is a bottleneck in the forex inflows is because only a small fraction of the export receipts is being repatriated back to PNG, because project development agreements allowed export proceeds to be held in offshore accounts.

Forex interbank trading is very critical in any economy as it facilitate international trade and ensures that external balance is achieved. At the forex interbank market, the demand for and supply of forex should interact to determine the price (kina exchange rate) and meet the needs of both importers and exporters. Since 2012, the forex interbank market in PNG has not been functioning as a normal market would otherwise do. According to Sampson (2018), there were four factors that caused the forex interbank market not to work. Firstly, there were absences of forex interbank transactions since mid-2012 to determine the value of the kina, which is an indication of the failure of the price-setting role of the forex interbank market. This caused the imbalance in the supply and demand for forex. Secondly, the forex dealers were unable to meet the demand for forex and resorted to selling kina in the interbank market, while controlling the forex they provided to their clients. Thirdly, the control of forex by dealers delayed resident firms from obtaining the foreign currency they need to pay for their imports and took a little longer for a few firms from sending any dividend payments abroad. Finally, there were some suggestions that real effective exchange rate is overvalued from its equilibrium level, hence the need for flexibility and adjustment. A dysfunctional forex interbank market can limit the movement of capital between countries, especially making repatriation of profits and dividends difficult.

Maintaining external balance leads to minimizing risks associated with the exchange rate and settlement for banks. Most banks have netting agreements that require the offset of transactions in the same currency pair that settle on the same date with the same counterpart. This reduces the amount of money that changes hands and the settlement risk involved. The Central Banks collect data from interbank market participants to assess whether there are any economic implications arising from the forex interbank transactions. The importance of the forex interbank market cannot be underplayed because it is very critical to the economy as it facilitates international trade and ensures that external balance is achieved. Because it is a channel through which potential contagion can be transmitted, achieving external balance is key to mitigating these potential risks. Therefore, regulators need to ensure that the trading of currencies in the forex interbank market is supervised and monitored so that negative external shocks are mitigated and not transmitted easily.

\subsection{Domestic Banks' Foreign Exchange Holding}

After 2011, the interbank forex market was a one-sided market where the local currency was flooding the domestic forex market on the back of a shortage in foreign currencies, especially US dollar. To support their forex needs, domestic banks resorted to borrowing from their counter parties abroad or accessed the forex supplied by the Central Bank through its intervention to support the market. On an average basis, the holdings of foreign assets constitute around $7.9 \%$ of total assets, while liabilities constitute $7.0 \%$ of total liability. Both forex assets and liabilities declined over the period from 2010 to 2017 . After 2013, forex liability has matched foreign assets and continued to 
remain above the forex assets, reflecting the shortage of US dollars in the domestic forex interbank market. This indicated that the domestic banks have been borrowing forex from their counterparties abroad to meet their forex needs. The increase in forex liability can pose a threat to the domestic banks if the shortage in forex is not addressed by the Government.

Figure 10

\section{Forex Holding of Banks}

Ratio of Forex holdings in Ass et/Liability

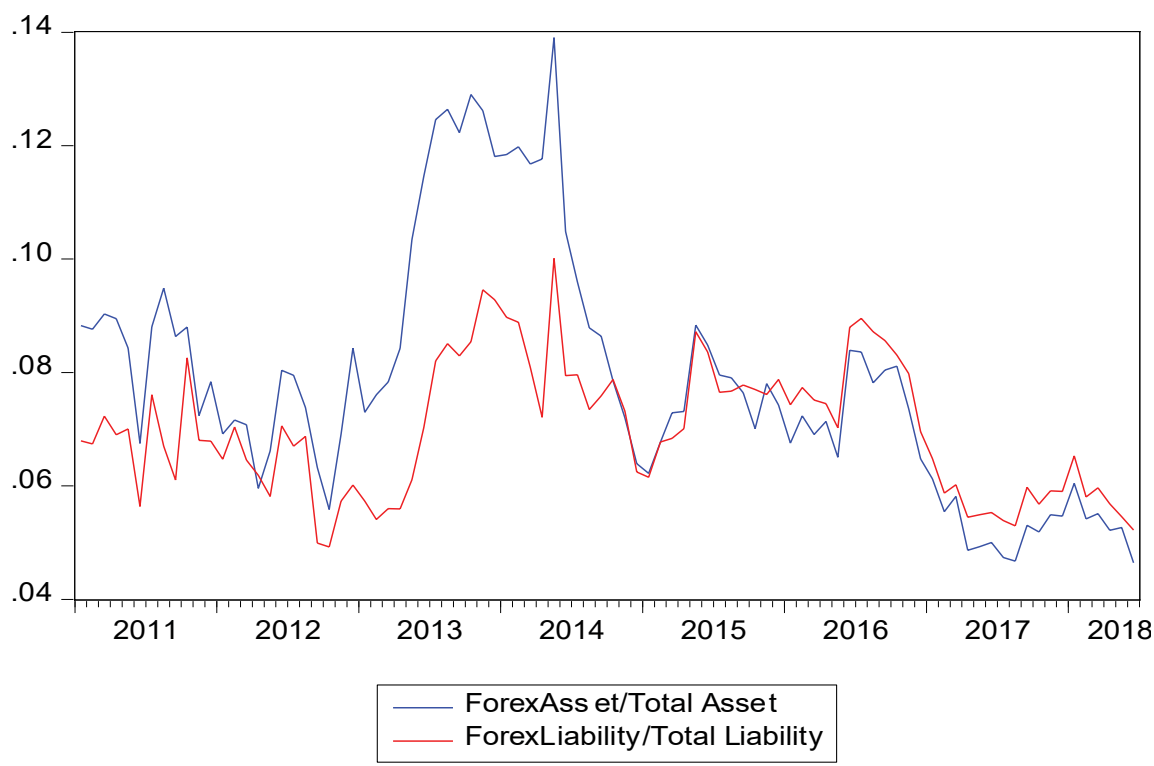

Source: Bank of PNG.

\subsection{Cross-border Network Visualization}

I used the Gephi software to visualize the network of claims and liabilities of banks by using the BIS banking locational statistics. Between December quarter of 2005 and June quarter of 2018, the network expanded with the inclusion of five new countries in terms of foreign liabilities, while it increased by 3 countries in foreign claims. Interbank trading by banks in PNG is only limited to banks within PNG and to some extent Australia. The other claims and liabilities relates to nonbanking activities, especially in derivative contracts, extended guarantees and credit commitments. The expansion in the foreign claims network related to increase in PNG registered companies' investments in France, Switzerland, Chinese Taipei, Hong Kong, apart from their traditional investment destinations of Australia, Japan, Germany and Korea. This has somewhat increased the foreign exposure of PNG, and the likelihood of a contagion spreading quickly to PNG through such a well-connected network.

\subsection{Foreign Liabilities}

PNG claims (foreign liabilities to PNG) increased from US\$296.0 million in December quarter of 2005 to US\$307.541 million in the June quarter of 2018. The traditional countries which were linked to PNG are Australia, Japan, United Kingdom and Korea. The increase in PNG claims reflected the liberalization of the foreign exchange controls, which gave PNG-registered foreign companies, especially mineral and petroleum companies to use the project development agreements to invest their earnings in financial markets abroad. Combined with the higher price 
of commodities, the firms diversified their investments that led to an expansion in the network to include other countries such as France, China, United States, Chinese Taipei, Hong Kong and Switzerland. Figure 11 below show the visual network of PNG claims and its expansion in the network over time from December 2005 to June quarter 2018. Australian-based banks have the largest share of $41.2 \%$ in liabilities.

\section{Figure 11}

\section{Foreign Liabilities (PNG Claims) - December Quarter 2005 Vs June Quarter 2018}
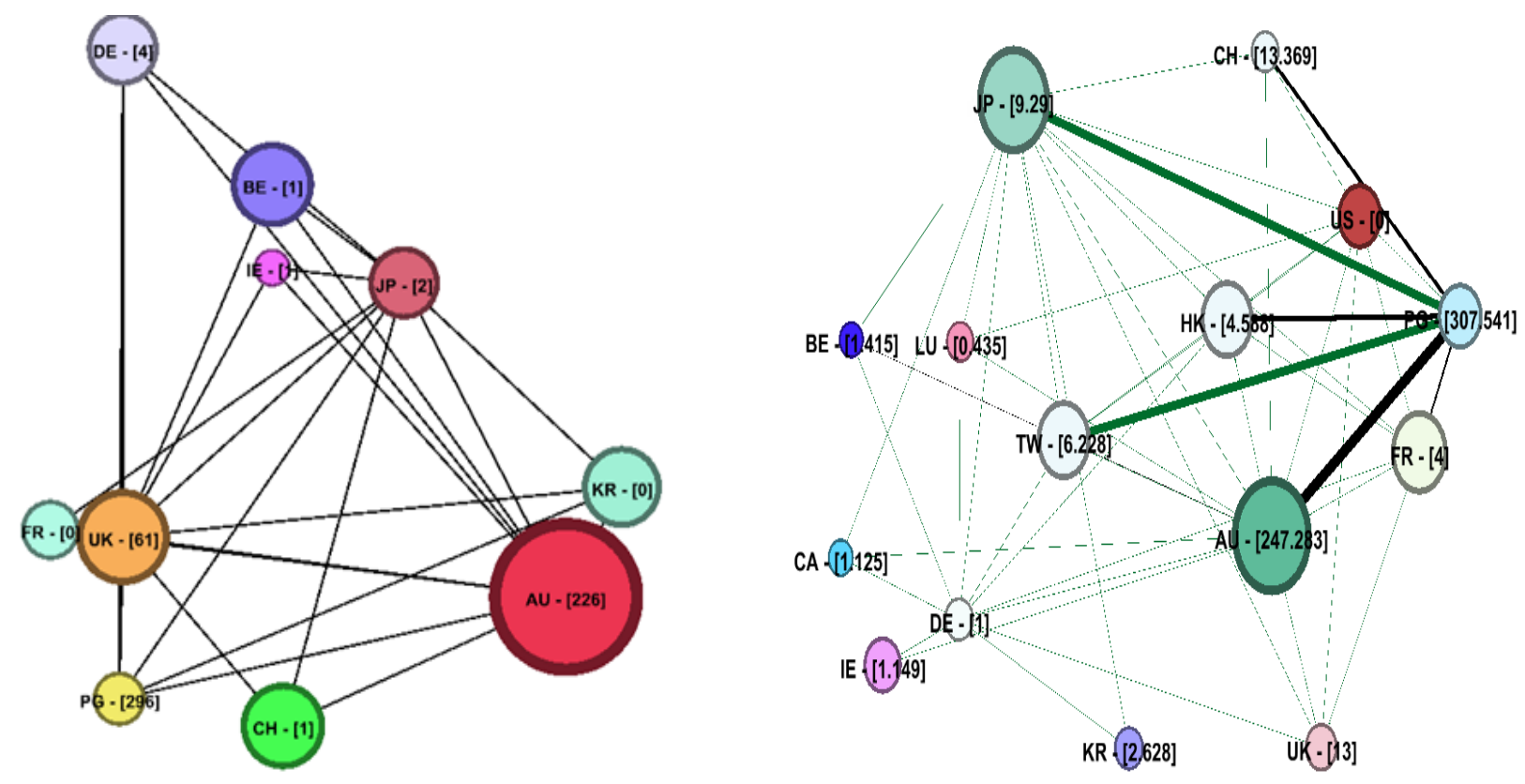

\subsection{Foreign Claims}

The network of foreign claims on PNG expanded to US\$913.0 from US\$540.00. This reflected the expansion in the size of the networks as PNG attracted foreign direct investments (FDIs) from other countries, apart from its traditional lender countries, Australia and Japan. PNG has become one of the new frontiers for investments in mining and petroleum projects from the USA, France, Chinese Taipei, Korea, Hong Kong and Japan. Most of the expansion in financial network happened in 2008 and thereafter, which directly relates to financing of the Exon Mobile led PNG Liquefied Natural Gas (LNG), which commenced construction in 2008, the construction of the Ramu Nickel/ Cobalt mine in 2012, and other mineral and petroleum investments in the country. The other factor included the liberalization of the PNG foreign exchange controls in 2005/2006, which paved the way for the flow of funds. Figure 12 below shows the network of PNG liabilities over time from December quarter of 2005 to June quarter of 2018.

Japan and Australia both have assets worth over 10\%, while China has 4.4\%, Hong Kong has $6.4 \%$, France has $1.3 \%$ and Korea $2.3 \%$. 
Figure 12

Foreign Claims (PNG Liabilities) - December Quarter 2005 Vs June Quarter 2018
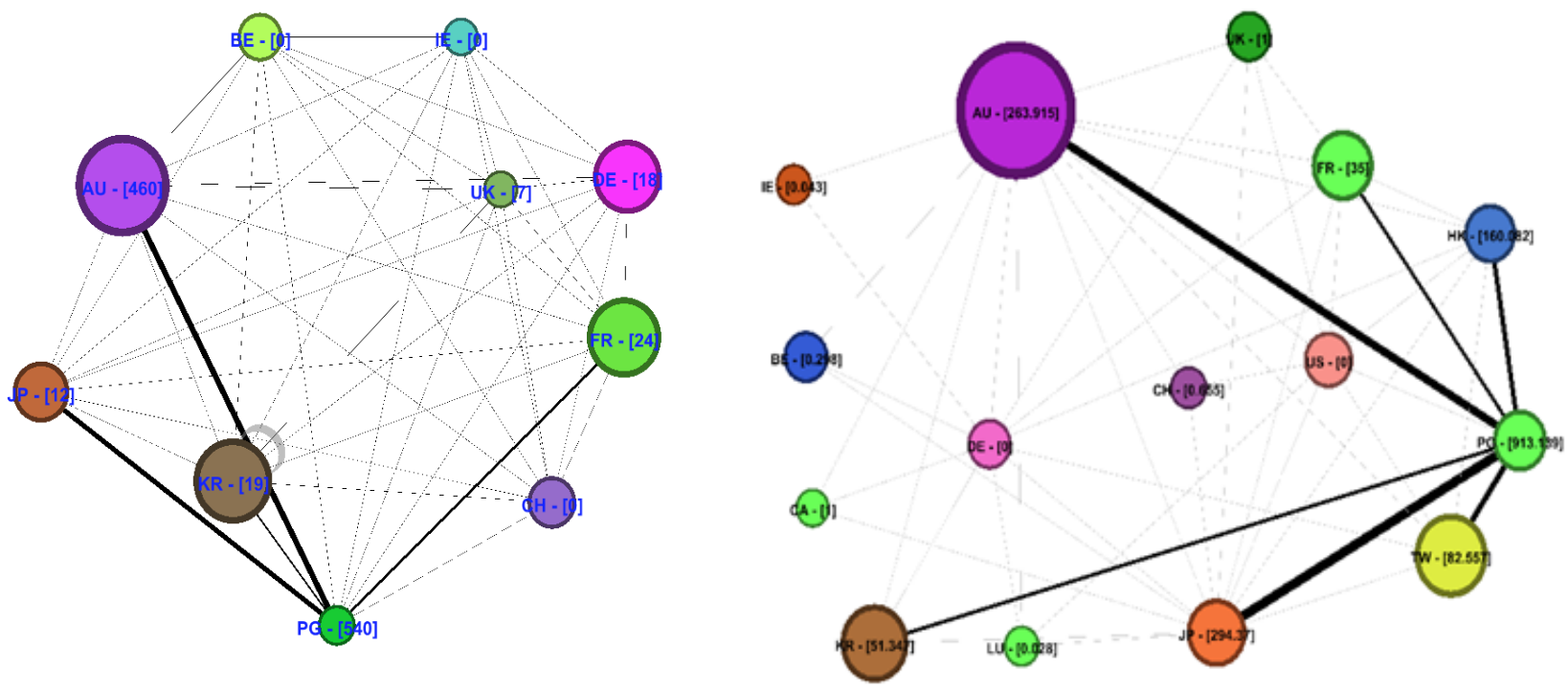

Figure 13 shows the claims and liabilities with respect to the banking location from June quarter 2005 to June quarter 2018. From the chart we can deduce that PNG's largest exposure was between June quarter 2008 and June quarter 2014. This is the period when the financing and construction of the PNG LNG project started and ended and FDIs flowed into the country.

Figure 13

Claims and Liabilities on Banking Location June Quarter 2005 - June Quarter 2018

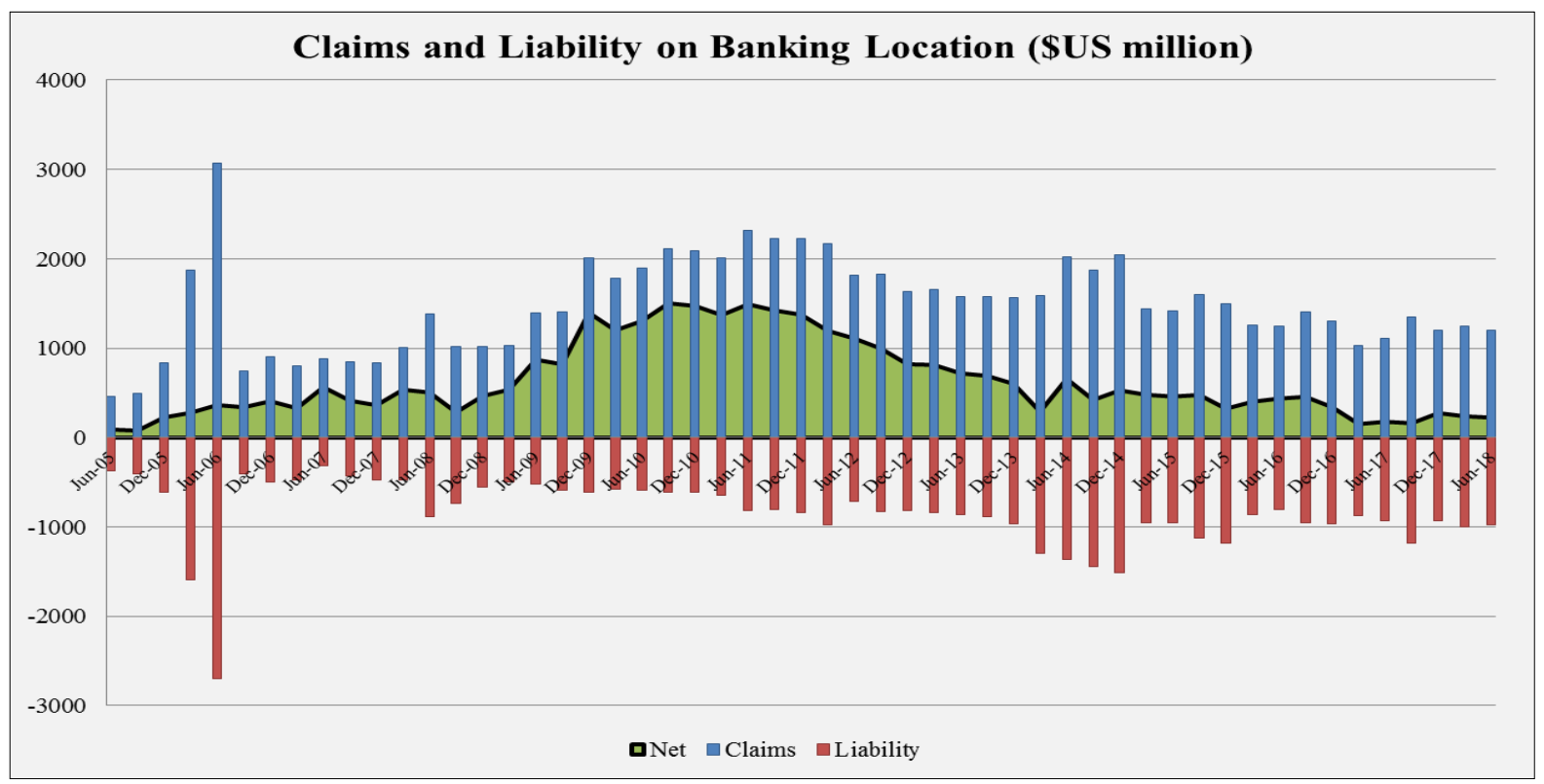

Source: BIS. 
According to the cross-border position by banking location, Japan and Australia have the highest deposits in the PNG non-banking sector, while only Australia has the highest liability, both in the banking and non-banking sector. This indicates Australia's increased interest and dominance in the banking and non-banking sectors in PNG. There are also growing interests from Hong Kong and Chinese Taipei.

Figure 14

Cross-border Position by Location of Banking Office

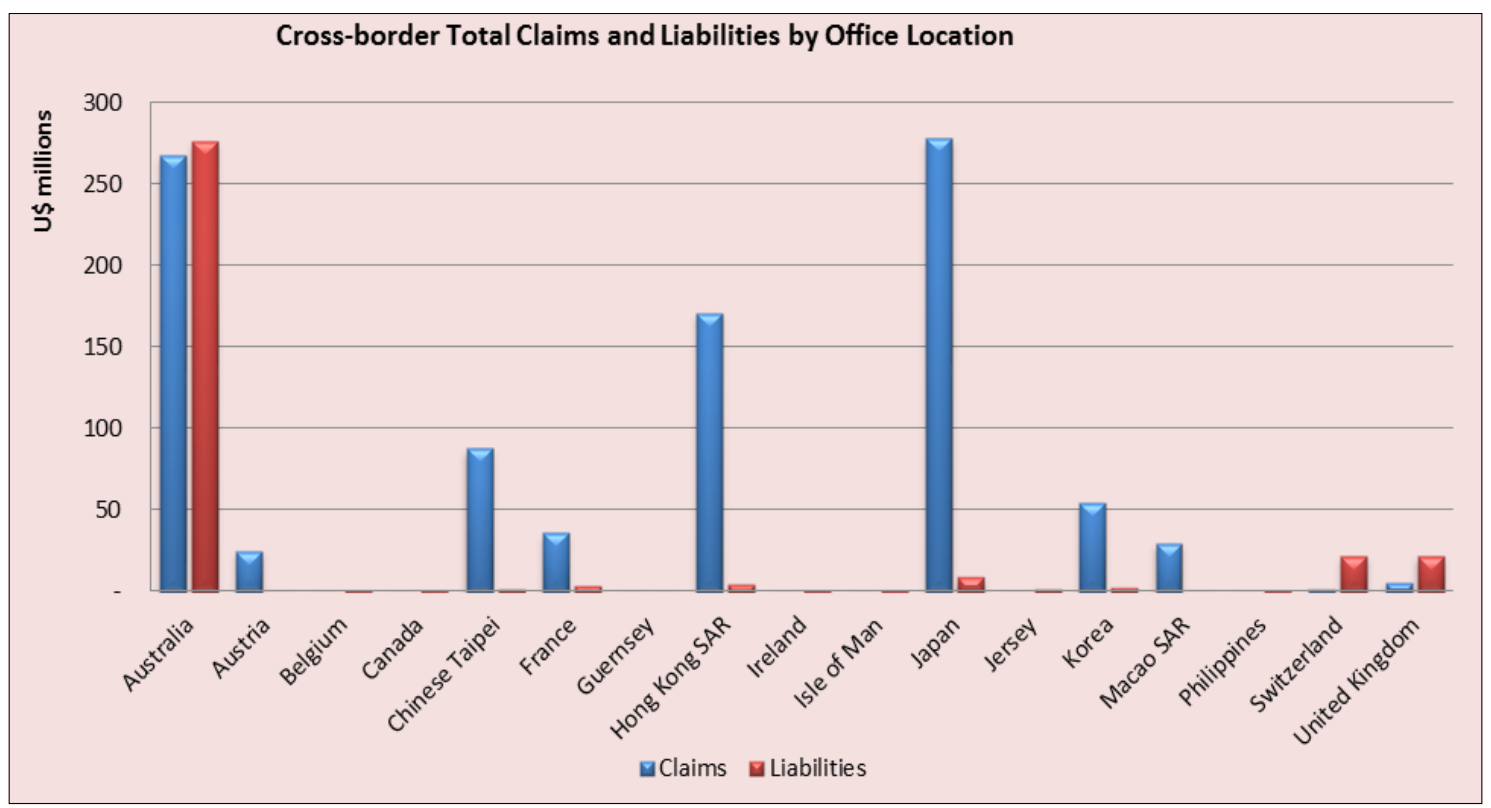

Source: Bank for International Settlement.

\subsection{Cross-border Position Instrument, Sector and Currency (US\$ million)}

The bulk of the cross-border positions is in loans and deposits denominated in US dollar, held mostly by non-banks. Deposits are greater than their liability, which means that if there is a domestic shock, for example, a bank run or interest rate dip, the chances of repatriation are high and this could cause trouble for the domestic banks, especially those banks which are not adequately capitalized as it present currency, exchange rate, sectoral and other associated risks. Therefore, mitigation measures by the Central Bank are critical.

Figure 15 below show the net risk transfers, claims on an ultimate risk basis and other potential exposures not included in claims on an ultimate risk basis, especially derivative contracts, extended guarantees and credit commitments. Transfer of risks between banks and non-banks in one country to another country remains the focal point of creditor banks and countries managing risks across counterparty countries. The transfer of risks reallocates a bank's exposure from the immediate counter party country to the country where the obligor is located. There are outward risk transfers that reduce risk exposure to a given counterparty country, as well as inward risk transfers that increase risk exposures. The difference between the inward risks and outward risk is called the net risk transfer. A negative risk transfer indicate that inward risk exposure is higher than outward risk exposure, while a positive risk transfer indicate a higher outward risk transfer. Hence, for PNG, there are more inward risk transfers from France, United Kingdom, Chinese Taipei and Austria. While, outward risk transfers are to Australia, Japan and Switzerland. On average, there is net inward risk transfer reflecting investments in petroleum and LNG in PNG. 
Figure 15

Net Risk Transfers and Other Potential Exposures

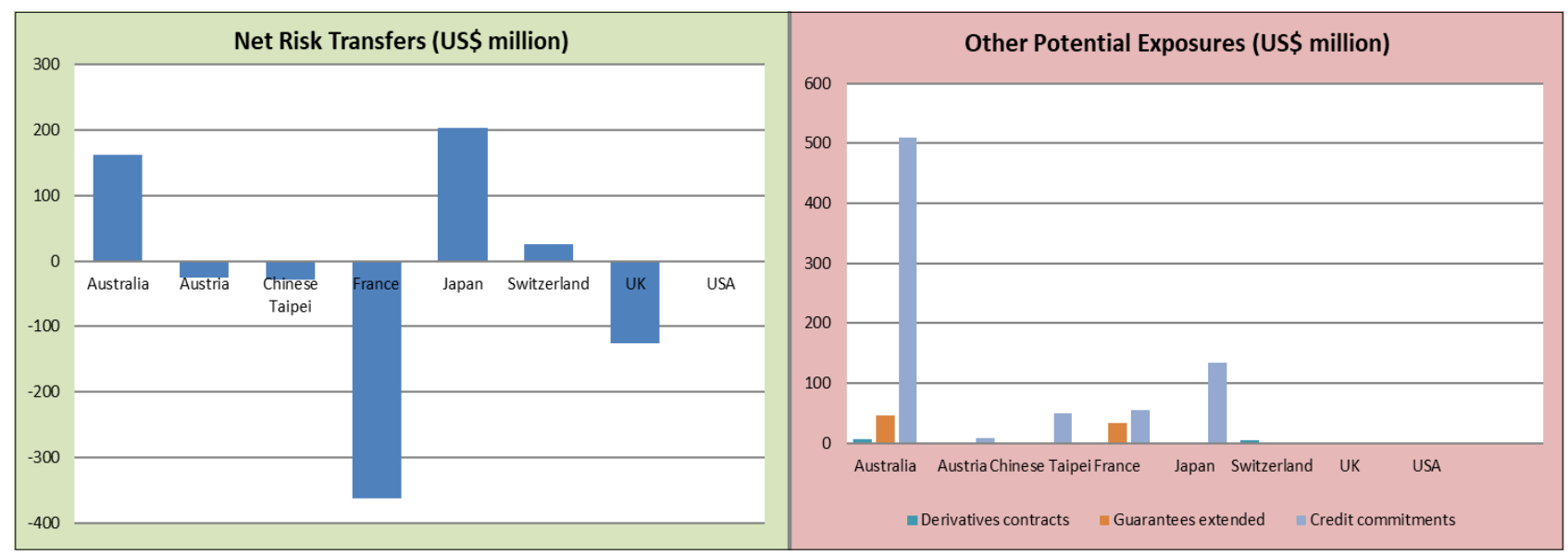

Source: Bank for International Settlement.

\section{Cross-border shocks through Interest Rates and Credit from Australia and Commodity Prices}

PNG banks, apart from domestic activity conduct their activities with other banks across borders. The few banks in PNG have forex deals with other banks in Australia and across the Asia Pacific region. Most of the cross-border transactions by PNG banks are between banks in PNG and Australia as two of the large banks in PNG, have headquarters in Australia and have operations across the Pacific, Asia and globally. Therefore, any financial crisis in Australia, Japan or elsewhere will be transmitted quickly to PNG because of the financial and banking linkages between the banks in these countries. In assessing the banking network and trading, I will concentrate on analysing how shocks in credit and interest rates in Australia and global commodity prices impact bank credit and real sector activity in PNG.

\subsection{Cross-border shocks through Interest Rates and Credit from Australia}

Eye balling the variables and the regressions show that total credit extended by banks in Australia is somewhat unrelated to the credit extended by banks in PNG as they trend in the opposite direction. This could mean that the banks in PNG are operating independently from their Australian counterparts. However, individual credits for business, housing investment and owner-occupied housing tend to have positive correlation with credit extended by banks in PNG, which implied positive correlation as shown by their positive coefficients. The results although inconclusive, indicate that in the event of a credit and interest rate shock in Australia, it will have positive but minimal impact on credit extended by banks in PNG in the short run.

The regression result showed that a $1 \%$ shock to credits for business, investor housing, and owner-occupied housing in Australia affect credits in PNG by $2.1 \%, 1.4 \%$ and $2.9 \%$, respectively. A 1\% change in the OCR in Australia will lead to a 3.6\% change in the credit extended by banks in PNG. It also showed that unsecured lending rate is also significant and may also have some influence in lending in PNG. Lending to household and private sector are also significant at 5\% significance level. This indicates the links between banks operating in Australia and their subsidiaries operating in PNG as shown by the positive correlation. This is a possible transmission channel a contagion 
can occur. Australia's GDP was not significant while interest rates ${ }^{7}$ were significant and negative, indicating a negative correlation. The regression results contained in Table 3 below, as expected confirmed a negative correlation between interest rates in Australia and credit in PNG.

Figure 16

Eyeballing the Credit in PNG and Interest Rates and Credits in Australia
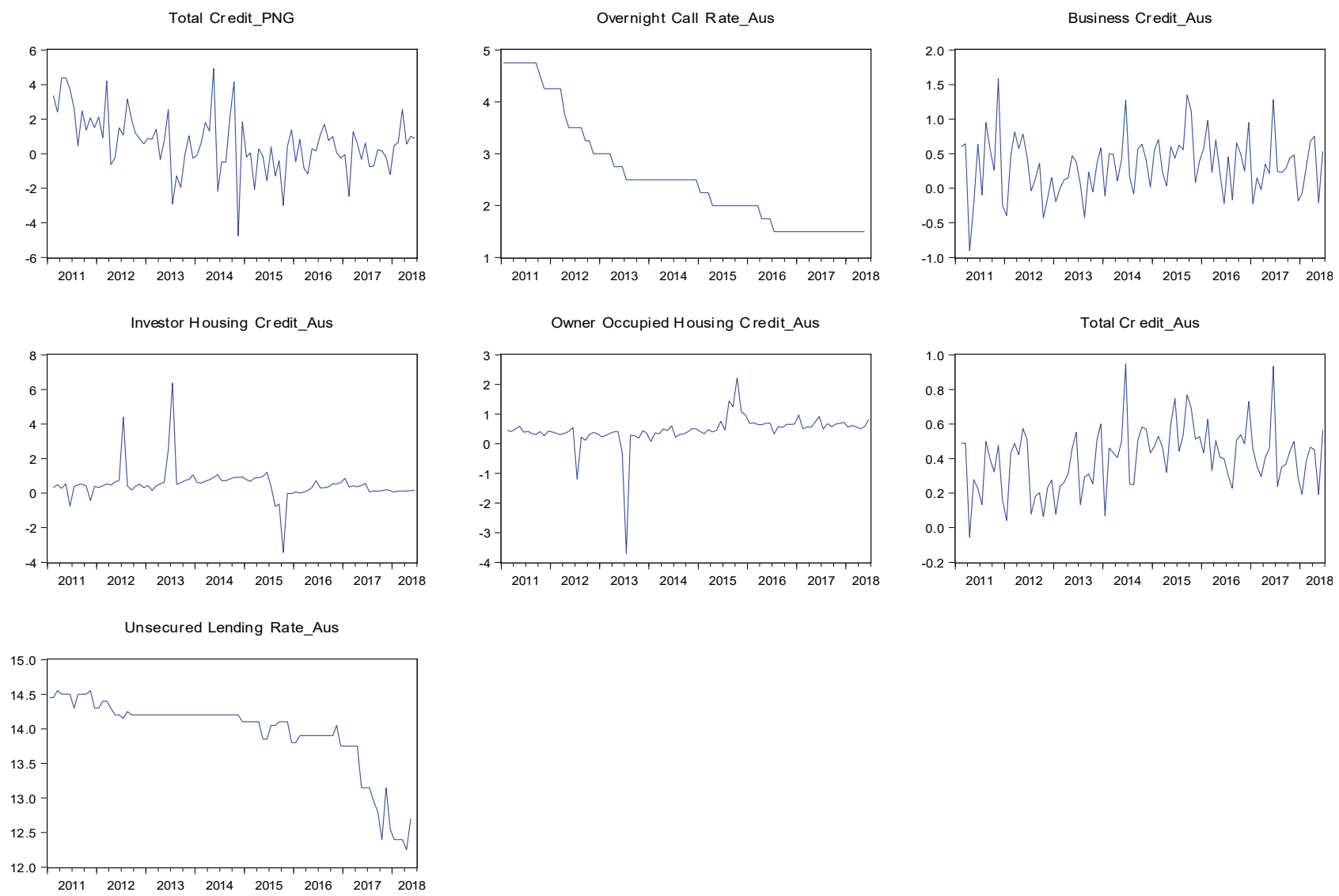

Source: Reserve Bank of Australia.

Table 3

OLS Regression Results, Dependent Variable: Total_Credit

\begin{tabular}{l|c|c|c|c}
\hline Variable & Coefficient & Standard Error & t-Statistics & Probability \\
\hline OCR_AU & -3.573 & 1.874 & -1.907 & 0.060 \\
Credit_Business_AU & 2.051 & 0.955 & 2.147 & 0.035 \\
Credit_Investor_Housing_AU & 1.353 & 0.572 & 2.364 & 0.021 \\
Credit_Owner_Occupier_Housing_AU & 2.852 & 1.051 & 2.714 & 0.008 \\
Total_Credit_AU & -6.708 & 2.616 & -2.564 & 0.012 \\
Unsecured_Rate_AU & -0.132 & 0.060 & 0.060 & 0.031 \\
Treasury_Note_Rate_AU & 4.660 & 1.967 & 1.967 & 0.020 \\
\hline R2 $=0.3572$, Adjusted R2 $=0.3096$, & $\sigma=1.4326$, & DW $=2.2978$ & AIC $=3.633$ & SIC $=3.8301$ \\
\hline
\end{tabular}

Source: Author's calculation using Eviews.

7. It refers to the Overnight Call Rate (OCR) and unsecured lending rate. 


\subsection{Commodity Prices}

As a small open economy and an exporter of commodities, PNG is exposed to shocks in the international prices of commodities. The impact can be positive or negative depending on the type of shock. A sharp decline in the price of commodities can induce a negative shock to the economy via a fall in Government revenue, foreign reserves and exchange rate depreciation. Its impact on the domestic banking sector can be direct through a decline in their forex holdings. This could lead to an imbalance in the forex interbank market and domestic banks may resort to forex borrowing leading to an increase in the exposures of domestic banks. In the same manner, a sharp increase in prices of commodities will have positive shock on the economy, via an increase in Government revenue, foreign reserves and exchange rate appreciation. High commodity prices can also lead to high inflation.

Figure 17

\section{Commodity Prices}
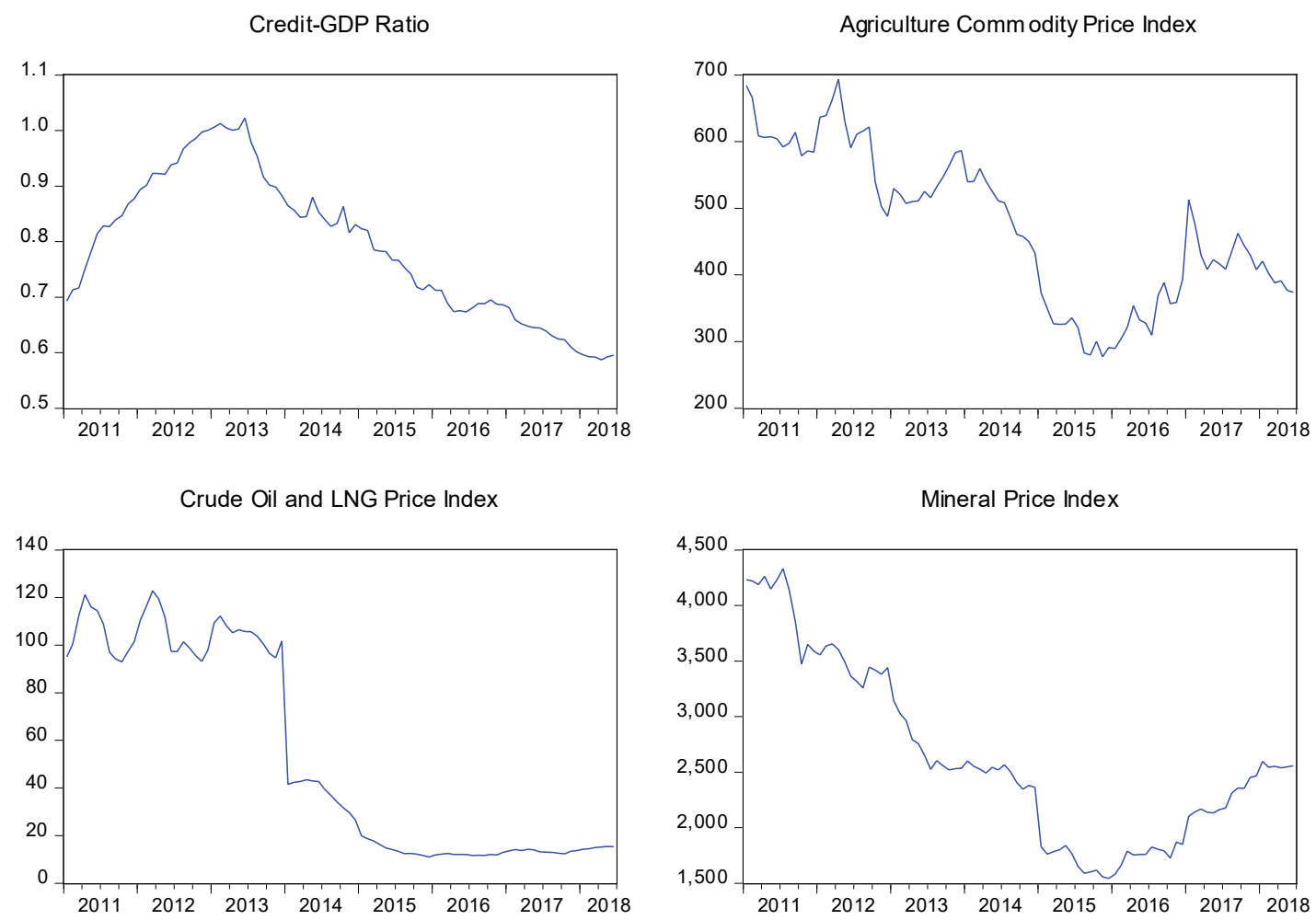

Source: World Bank.

Table 4

OLS Regression Results (Credit/GDP against Commodity Prices): Dependent Variable_Credit_GDP_Ratio

\begin{tabular}{l|c|l|l|c}
\hline Variable & Coefficient & Standard Error & t-Statistics & Probability \\
\hline Mineral_Index & -0.037 & 0.049 & -0.751 & 0.455 \\
Crude_LNG_Index & 0.045 & 0.024 & 1.819 & 0.072 \\
Agri_Price_Index & -0.011 & 0.034 & -0.312 & 0.756 \\
\hline R2 $=0.041$, Adjusted R2 $=0.007$, & $\sigma=1.829$, & DW $=1.551$ & AIC $=4.089$ & SIC $=4.201$ \\
\hline
\end{tabular}

Source: Author's calculation using Eviews. 
Figure 17 above show the trend in the prices of PNG's major export commodities. Although commodity price shocks can be transmitted to domestic bank credits, results of the regression were insignificant, except crude oil and LNG price index. Only crude and LNG price shock is significant at $10 \%$ confidence level. However, the impact is very limited at only $0.04 \%$. Commodity prices display their swings frequently while not impacting the PNG domestic credit directly; the impact of commodity price shocks could be transmitted via other channels.

\section{Conclusion}

The banks in PNG are highly capitalized, over and above the minimum regulatory threshold, therefore shocks emanating from NPLs, credit, interest rates, liquidity and exchange rate will have minimal impact on the banking industry and the financial institutions. Banks are also flushed with liquidity but unfairly distributed among the banks, while accessing forex continue to remain a challenge.

On cross-border positions and risk transfers, most of the claims against PNG are held by non-bank firms from Australia, Japan, France, Hong Kong and Chinese Taipei. This is where most of the risks are coming from. There are more inward risk transfers than outward. The networks in liabilities and claims have increased since 2005 and continue to remain high. The network visualizations gave clear idea about which country is connected and on what purpose.

Credit and interest rates in Australia have some correlation on credit and banking activity in PNG because of the links of domestic banks to Australian banks. However, the magnitude of the impact was not very big to cause an upset in the event of a shock in Australia. Even if there is a shock, PNG banks have adequate capital buffers to withstand the shock. However, the potential for domestic and external shocks are real and present a number of risks for the domestic banks. Therefore, it is the job of the Central Bank as the regulator and supervisor of the banking industry to ensure that banks operate with adequate capital and take risk that they understand and can measure, while at the same time intermediate banking and financial service to earn enough income to compensate for the risks they take.

In so far as regulation and supervision is concerned, the Bank of PNG, the authority responsible for regulating and supervising the banks and finance companies in PNG, including issuing of prudential standards ${ }^{8}$ on the deposit taking institutions, ensures that banks are adequately capitalized and remain profitable. This is to protect the health of the banking system, protect depositors' funds and the economy. Prudential standards become very critical because of the complexity of the networks of banks and the products and services they offer. This requires the use of financial regulations to take control of the banks and financial institutions exposed to risks and hold adequate capital as buffers, specified in the capital requirements to mitigate shocks.

8. The Central Bank issued the following prudential standards: Single Borrower and Large Exposure Limits; Fit and Proper Requirements; Transactions with Related Parties; External Audits; Capital Adequacy; Asset Classification, Provision and Suspension of Interest; Limits on Loans to Related Parties; Limits on Inter-Bank Placements; Foreign Currency Exposure Limits; Mobile Banking and Mobile Payments; Compliance Function Requirements; Corporate Governance; Customer Due Diligence Standard; Business Continuity Management and Outsourcing of business activities, functions and processes. 
The Central Bank has in place robust prudential policies in regards to regulating and supervising the banking industry in PNG. Apart from the various prudential standards and ensuring compliance by the banks, the Central Bank conducts onsite inspections and audits. The advancement in technology and introduction of a lot of new online banking products and e-money, apart from enhancing banking experience, also reinforces the need to strengthen regulation and supervision in these areas of banking. They could be the next biggest threats, if not harnessed properly. 


\section{References}

Allen, F. and D. Gale, (2000), "Financial Contagion," Journal of Political Economy, Vol. 108, No. 1, pp. 1-33.

Anqi, L.; M. Paddrik; S. Yang and X. Zhang, (2016), "Interbank Contagion: An Agent-based Model Approach to Endogenously Formed Networks," Office of Financial Research (OFR) Working Paper, United States Department of Treasury.

Bank of Papua New Guinea, (2003), Prudential Standard 1/2003: Capital Adequacy. Bank of PNG.

Battiston S.; J. B. Glattfelder; D. Garlaschelli; F. Lillo F. and G. Caldarelli, (2010), "The Structure of Financial Networks," in E. Estrada, M. Fox, D. Higham and G. L. Oppo (Eds), Network Science, Springer, London.

Battiston, S.; G. Iasio; L. di Infante and F. Peirobon, (2015), "Capital and Contagion in Financial Networks," IFC Bulletin, No 39.

Bi, R..; M. Chivakul; M. Goretti; K. Guo; S. Lanau; R. Llaudes; Y. Miao; Noah Ndela Ntsama; J. Porter; N. F. Presciuttini; F. Salman; C. Serra and R. Benelli, (2011), Mapping Cross-Border Financial Linkages: A Supporting Case for Global Financial Safety Nets, IMF.

BIS, (2018), Statistical Release: BIS International Banking Statistics, End-March.

Camelia, M. and A. R. Javier, (2011), “A Network Analysis of Global Banking: 1978-2009,” IMF Working Paper, IMF Institute.

Cerutti, E., (2015), "Drivers of Cross-border Banking Exposures During the Crisis," Journal of Banking and Finance, 55, pp. 340-375.

Cerutti, E.; S. Claessens and P. McGuire, (2012), "Systemic Risks in Global Banking: What Available Data Can Tell Us and What More Data are Needed?" NBER Working Paper, No. 18531.

Cihak, M., (2007), “Introduction to Applied Stress Testing,” IMF Working Paper, WP/07/59.

Čihák, M. and L. L. Ong, (2007), "Estimating Spillover Risk Among Large EU Banks," IMF Working Paper, European Department and Monetary and Capital Markets Department.

Craig, H. F., (1999), "Interbank Exposures: Quantifying the Risk of Contagion," BIS Working Papers, No. 70, Monetary and Economic Department, Bank for International Settlements, Basel, Switzerland.

Degryse, H.; M. A. Elahi and M. F. Penas, (2008), "Cross-border Interbank Exposures and Financial Contagion," Tilburg University, Netherlands. 
Degrysea, H. and G. Nguyenb, (2006), "Interbank Exposures: An Empirical Examination of Contagion Risk in the Belgian Banking System," aCentER-Tilburg University, TILEC and K.U. Leuvenb, National Bank of Belgium.

Espinosa-Vega, M., and J. Solé, (2010), "Cross-Border Financial Surveillance: A Network Perspective," IMF Working Paper, 10/105.

Genberg, H., (2017), "Global Shocks and Risk to Financial Stability in Asia," Working Paper, 25/2017, The South East Asian Central Banks (SEACEN) Research and Training Centre, Kuala Lumpur, Malaysia.

Glasserman, P. and H. P. Young, (2014)., "How Likely is Contagion in Financial Networks?" Journal of Banking and Finance, 50, pp. 383-399.

Hałaj G. and C. Kok, (2013), “Assessing Interbank Contagion Using Simulated Networks,” Working Paper Series, No. 1506, European Central Bank.

Haldane, A. G. and R. M. May, (2011), "Systemic Risk in Banking Ecosystems," Nature, 469, pp. $351-355$.

Iñaki, A. and E. Torstenm, (2017), Risk Transfers in International Banking," Bank for International Settlement Quarterly Review.

Marco, A. E. and S. Juan, (2007), "Cross-border Financial Surveillance: A Network Perspective," IMF Working Paper, WP/10/105.

Masazumi, H. and S. Yuko, (2007), "Developments in a Cross-border Bank Exposure 'Network'," CGFS - The Use of BIS International Financial Statistics.

Matousek, M., (2018), "Cross-border Interbank Contagion Risk Analysis," The South East Asian Central Banks (SEACEN), Kuala Lumpur, Malaysia.

Nier, E.; J. Yang; T. Yorulmazer and A. Alentorn, (2008), "Network Models and Financial Stability," Bank of England Working Paper, No.346.

Kartik A.; B. Craig and G. Peter, (2014), "Filling in the Blanks: Network Structure and Interbank Contagion," BIS Working Papers, No. 455, Monetary and Economic Department, Basel, Switzerland.

Remolona, E. and I. Shim, (2015), The Rise of Regional Banking in Asia and the Pacific," BIS Quarterly Review, September.

Takáts, E., (2018), “Cross-border Bank Lending To Emerging Market Economies,” BIS Papers, No 54.

Upper, C., (2007), "Using Counterfactual Simulations to Assess the Danger of Contagion in Interbank Markets," BIS Working Paper, No. 234. 
Wheeler, G., (2014), BIS Conference on Cross-border Financial Linkages: Challenges for Monetary Policy and Financial Stability, Wellington, New Zealand.

World Bank, (2018), Bank Z-Score for United States retrieved from FRED, Federal Reserve Bank of St. Louis; Available at: https://fred.stlouisfed.org/series/DDSI01USA645NWDB, 14 October.

Xiping, L.; D. Tripe and C. Malone, (2017), Measuring Bank Risk: An Exploration of Z-Score, Massey University, Palmerston North, New Zealand.

Yellen, J., (2013), Interconnectedness and Systemic Risk: Lessons from the Financial Crisis and Policy Implications, Board of Governors of the Federal Reserve System, Washington, D.C. 


\section{Appendix 1}

Countries' Initials Used in the Network Visualization

\begin{tabular}{|c|c|}
\hline Subject & Initial \\
\hline Austria & AT \\
\hline Australia & $\mathrm{AU}$ \\
\hline Belgium & $\mathrm{BE}$ \\
\hline Canada & $\mathrm{CA}$ \\
\hline Switzerland & $\mathrm{CH}$ \\
\hline Germany & $\mathrm{DE}$ \\
\hline Denmark & DK \\
\hline Spain & ES \\
\hline France & FR \\
\hline United Kingdom & UK \\
\hline Hong Kong SAR & HK \\
\hline Ireland & IE \\
\hline Isle of Man & IM \\
\hline Japan & JP \\
\hline Korea & $\mathrm{KR}$ \\
\hline Luxembourg & LU \\
\hline Philippines & $\mathrm{PH}$ \\
\hline Chinese Taipei & TW \\
\hline United States & US \\
\hline Total Liabilities & $\mathrm{L}$ \\
\hline Total Assets & A \\
\hline
\end{tabular}





\title{
Chapter 8
}

\section{PHILIPPINES: CONTAGION RISK ANALYSIS OF CROSS-BORDER EXPOSURES OF BANKS ${ }^{1}$}

\author{
By \\ Jenny T. Dizon ${ }^{2}$, Jessica P. Hutalla ${ }^{3}$ and Jaime M. Rariza, Jr. ${ }^{4}$
}

\section{Introduction}

Empirical data reveal increasing interlinkages in the global financial system. A sizable portion of which have been channeled through cross-border bank flows and have been found to have contributed to the amplification of the Global Financial Crisis (GFC) in 2007 to $2008 .^{5}$ The proliferation of cross-border lending activities can transmit foreign shocks to recipient markets, especially to emerging markets (Bruno and Shin, 2015; Schnabl, 2012). Transmission of these shocks can be spread by contagion, a much broader concept of systemic risks and a major financial stability concern due to its potential threat to the stability of the local banking system. Thus, our understanding of the extent of the countries' cross-border exposure is a policy imperative.

In the Association of Southeast Asian Nations (ASEAN) region, the increase in cross-border banking flows was due mainly to the following: (1) adoption of the ASEAN Banking Integration Framework $(\mathrm{ABIF})^{6}$; and (2) evolution of financial technologies that facilitate complex and extensive linkages across global markets.

This paper intends to map cross-border exposures ${ }^{7}$ of the U/KBs in the Philippines with their key cross-border counterparties ${ }^{8}$ from neighbouring countries in the ASEAN region and the United States - the country's major foreign counterparty ${ }^{9}$ - both in terms of cross-border claims and cross-

1. The views and opinions expressed in this paper are those of the authors and not necessarily reflect those of the Bangko Sentral ng Pilipinas (BSP) or the SEACEN Centre.

2. Bank Officer II, Department of Economic Research, BSP.

3. Bank Officer IV, Supervisory Policy and Research Department, BSP.

4. Bank Officer II, Department of Economic Research, BSP.

5. For instance, Brunnermeier et al. (2012) confirmed that the large bulk of cross-border debt during the GFC was intermediated through the domestic banking system based on the Bank for International Settlements (BIS) data.

6. ABIF aims to achieve free flow of financial services within the ASEAN regional banking market (BSP, 2018).

7. In the Philippines, the Manual of Regulations for Banks (MORB) X301.6(e) requires banks to "take into account the nature of their business and the complexity of their products. In any case, a bank's exposures to a counterparty should include its on and off-balance sheet exposures and indirect exposures."

8. Foreign counterparties pertain to non-resident banks, non-bank financial institutions and non-financial institutions which (i) are located in a country or economy other than the Philippines and (ii) participate as another party in a financial transaction with a domestic financial institution (i.e., domestic banks in the current case).

9. Cross-border exposures of domestic banks are determined using BSP's internal statistics on Philippine crossborder report. As of end-March 2018, United States counterparties represent $27.6 \%$ and $62.3 \%$ of the total crossborder claims and cross-border liabilities, respectively. 
border liabilities. ${ }^{10}$ In addition, the paper aims to assess the impact of credit and liquidity shocks to domestic banks and foreign banks' capital.

Following the definition in the BIS international banking statistics guidelines (BIS, 2013), cross-border claims consist of loans and deposit to banks and non-banks, holding of securities and other claims. Meanwhile, loans and deposits from banks and non-banks, own issues of debt-securities and other liabilities comprise cross-border liabilities. ${ }^{11}$ In terms of international operations, cross-border transactions may take two forms: 1) transactions with foreign residents, in foreign currency, or with counterparties outside the country; and 2) institutional presence in other countries such as a branch or a subsidiary.

Relatively little analysis has been published on country-specific cases for Asian emerging market economies such as the Philippines (Claessens and Forbes, 2001). In particular, the region still has much to learn about contagion, risk transfers and exposures to and from the global financial system. Thus, the results of this study could serve as valuable inputs in monitoring and analyzing contagion risk in the Philippines in greater detail.

This study could inform or serve as a useful input to the Bangko Sentral ng Pilipinas' (BSP) conduct of macrofinancial surveillance amid increasing complexities in the financial system and the evolving nature of systemic risks. As far as policy is concerned, the findings in this paper are consistent with the BSP's prudential measures targeted at curbing the degree of systemic risks. One way of improving the terms of tradeoffs would be to reduce the spillover risks, without sacrificing the risk-sharing gain. Policy efforts along both lines will complement each other towards a common goal in mitigating the financial stability impact of financial interconnectedness.

The study utilizes the BSP's internal statistics (partly aggregated) from the cross-border reports of banks. ${ }^{12}$ Such data and related information are analysed via simulation exercises on the plausible impact of exogenous shocks to the financial position of foreign and domestic banks operating in the country.

The paper proceeds as follows: Section 2 provides a brief overview of the literature on the impact of interconnectedness of financial institutions on the financial system. Section 3 discusses the overview of the Philippine banking system while Section 4 presents the data and methodology. The simulation results are presented in Section 5, which focuses on the potential impact, both direct (credit shock) and indirect (funding shock), of cross-border spillovers on the domestic financial system. Section 6 concludes with a summary of results and some policy implications.

10. Following the definition in the BIS international banking statistics guidelines (BIS, 2013), cross-border claims consist of loans and deposit to banks and non-banks, holding of securities and other claims. Meanwhile, loans and deposits from banks and non-banks, own issues of debt-securities and other liabilities comprise cross-border liabilities.

11. Guidelines on the Completion of the Report on Cross-Border Financial Position, Annex A of the BSP Circular No. 850 dated 8 September 2014.

12. Circular No. 850 dated 8 September 2014 - Phase 1 implementation required universal and commercial banks, as well as thrift banks that are subsidiaries of $\mathrm{U} / \mathrm{KBs}$ to report their cross-border financial claims and liabilities to the BSP without the need to identify specific counterparty. The succeeding submission after September 2014 was March 2015. 


\section{Review of Related Literature}

The majority of global finance is intermediated by a number of large and complex financial institutions (LCFIs), which commonly operate in a number of developed economies serving as global lenders and borrowers. The resulting transactions with LCFIs as counterparties comprise the core of cross-border financial flows and connect countries with one another (IMF, 2010).

The transmission of external shocks through the interest rate, exchange rate and other economic and financial channels could threaten the stability of the financial system. The external shocks transmitted through these channels work their way into the domestic financial system via cross-border financing intermediated mostly by banks. It is in this regard that Smaga (2014) underscored the inherent vulnerability of banks to contagion risks or negative externalities caused by cross-border activities and interconnectedness. ${ }^{13}$ In an ECB Financial Stability Review (2004), contagion risk is an important element in banking crises and a subset of a much broader concept of systemic risks, thus a major financial stability concern. However, for a systemic contagion to occur, the institution from which the distress starts must be systemically important ${ }^{14}$ to affect other institutions and the financial system as a whole. Once (systemically important) sources of distress are identified, it is important to consider the potential transmission of shock and exposures to vulnerabilities that the banking sector could face.

The study of Ahrend and Goujard (2012) underscores the role that strict financial regulations play in lessening contagion risks. One of the main findings of the study is that countries with lessleveraged banking sector and lower credit-over-deposits ratio face lower risk of bank-balance-sheetdriven contagion that could possibly lead to a banking crisis. These analyses corroborate earlier OECD findings (Ahrend et al., 2011a) that indicators of regulatory and supervisory strength are correlated with how well countries managed the damage to their banking sector during the global financial crisis. Ahrend and Schwellnus (2012) and Ahrend and Goujard (2011) further suggest that countries with stronger banking supervision are less affected by investor-sentiment driven capital flow reversals and thus have a lower risk of suffering from financial crises. Considerably, lower risks and lesser vulnerability to international bank-balance sheet shocks could be achieved if there are longer debt maturity; better capitalised banking system; and adequate central bank reactions during financial turmoil (Ahrend and Goujard, 2012). Nonetheless, while stricter financial oversight reduces overall financial fragility, there are some indications that stricter domestic banking supervision may increase short-term foreign bank borrowings due to regulatory arbitrage or increased attractiveness on the part of financial investors which could further expose the banking sector to balance-sheet shocks (Ahrend and Schwellnus, 2012).

Meanwhile, to the best knowledge of the researchers, literature on the analysis of contagion risk in the Philippine banking system appears to be limited. Hence, this paper could serve as a good starting point for researchers in analysing contagion risk in the Philippines in greater detail.

13. Smaga, P. (2014). The Concept of Systemic Risk, SRC Special Paper No. 5, August 2014.

14. In the case of the Philippines, the systemic importance of a bank is assessed using an indicator-based measurement approach (BSP Circular No. 856, Series of 2014). 


\section{Overview of the Philippine Banking System (PBS) ${ }^{15}$}

The PBS, which represents the core of the financial system in the Philippines, is classified into the following categories: ${ }^{16} \mathrm{U} / \mathrm{KBs}$, thrift banks (TBs) ${ }^{17}$ and rural and cooperative banks (RCBs). ${ }^{18}$ $\mathrm{U} / \mathrm{KBs}^{19}$ represent the largest group of financial institutions in the PBS in terms of total assets and also offer the widest variety of banking services. TBs are composed of savings and mortgage banks, private development banks, stock savings and loan associations and microfinance thrift banks. ${ }^{20} \mathrm{U} /$ KBs and its TBs subsidiaries comprise $9.2 \%$ of the 585 operating banks' head offices. As of endMarch 2018, U/KBs still dominated the Philippine banking sector, holding P15,333.4 billion in total assets or $90.8 \%$ of the banking system's total assets. Likewise, loan portfolio of U/KBs took up $88.9 \%$ of the total banking system's portfolio, and represent $49.5 \%$ of gross domestic product (GDP). ${ }^{21}$

For the purposes of having a broader view of the PBS, universal banks are classified further into three types: (i) private domestic banks (PDBs), (ii) government banks, (iii) and foreign bank branches (FBBs). Likewise, commercial banks are classified further into three types: (i) PDBs; (ii) foreign bank subsidiaries (FBS); and (iii) FBBs. Most of the $\mathrm{FBBs}^{22}$ and subsidiaries, categorized either both universal and commercial, originate from the Asia-Pacific region. In particular, around $57.9 \%$ of FBBs and subsidiaries originate in countries within Asia-Pacific region.

Meanwhile, the Basel Committee on Banking Supervision (BCBS) has developed a methodology for assessing systemic importance of banks using an indicator-based approach of different categories. According to the BCBS, a bank's size ${ }^{23}$ is a key measure of systemic importance (BIS, 2011). Aside from the bank's size, other indicators include interconnectedness, ${ }^{24}$ substitutability and complexity. However, countries may adopt new methodologies, introduce new indicators, and/or vary the weights of factors in identifying the D-SIBs based on its assessment.

15. As of end-March 2018.

16. As of end-2018, the PBS accounts for 78\% of the Philippine financial system's total resources (BSP, 2018).

17. Some TBs are subsidiary of U/KBs.

18. Rural banks and cooperative banks are differentiated from each other by ownership. Rural banks are privately owned and managed, while cooperative banks are organised/owned by cooperatives or federation of cooperatives.

19. U/KBs in the Philippines represent the largest single group, resource-wise, of financial institutions. They offer the widest variety of banking services among financial institutions. In addition to the function of an ordinary commercial bank, universal banks are also authorised to engage in underwriting and other functions of investment houses, and to invest in equities of non-allied undertakings (BSP).

20. www.bsp.gov.ph/banking/bspsup.asp

21. Year-to-date nominal GDP as of end- March 2018.

22. The FBBs' target markets include companies registered and domiciled in the originating countries that are probable investors in the Philippines. The FBBs also target small and medium enterprises, overseas Filipino (OF) workers and other entities involved in government project financing. See the BSP's Report of the Philippine Financial System as of $2^{\text {nd }}$ Semester 2015 for detailed reference.

23. Size is measured using the definition in Basel 3 items $§ 157-164$, which includes total assets and other off-balance sheet items such as loan commitments and financial guarantees.

24. Interconnectedness measures a bank's systemic impact on other financial institutions. Individual indicator of interconnectedness is composed of intra-financial system assets (IFS assets), intra-financial system liabilities (IFS liabilities) and wholesale funding ratio (BIS, 2011). 
Table 1 assesses the systemic importance of banks in this study using banks' size and interconnectedness as indicators. A bank's size is measured using the definition of total exposure under Basel 3 (i.e. the sum of on-balance and off-balance sheet items). ${ }^{25}$ The size of the universalPDBs comprises $71.5 \%$ of the total $\mathrm{U} / \mathrm{KB}$ exposure, followed by universal- government banks and commercial- FBBs at $15.5 \%$ and $4.8 \%$, respectively.

Another selected indicator developed by the BCBS is interconnectedness with other financial institutions. Individual indicators of interconnectedness, by BCBS' definition, is composed of intra-financial system assets (IFS assets), intra-financial system liabilities (IFS liabilities) and the wholesale funding ratio. IFS assets of U/KBs such as debt securities issued by financial institutions (held by the bank) and loans (from the bank) to financial institutions are largely attributed to universal-PDBs, which has $81.8 \%$ share in the total for U/KBs. On the other hand, IFS liabilities refer to funds and deposits (at the bank) from financial institutions, while the wholesale funding ratio considers how banks source their funds from other financial institutions in the funding market (Table 1).

Table 1

Size and Interconnectedness of U/KBs

(in Percent)

\begin{tabular}{|c|c|c|c|c|c|}
\hline & & \multirow[b]{2}{*}{$\begin{array}{l}\text { Bank Size }^{1 /} \\
\text { (share to total } \\
\text { for all U/KBs) }\end{array}$} & \multicolumn{3}{|c|}{ Interconnectedness } \\
\hline & & & $\begin{array}{l}\text { IFS Assets }{ }^{2 /} \\
\text { (share to total } \\
\text { for all U/KBs) }\end{array}$ & $\begin{array}{l}\text { IFS Liabilities } \\
\text { (share to total } \\
\text { for all U/KBs) }\end{array}$ & $\begin{array}{c}\text { Wholesale } \\
\text { Funding Ratio }^{4 /}\end{array}$ \\
\hline \multicolumn{6}{|c|}{ by bank category } \\
\hline Universal - & Foreign Bank Branches (FBBs) & 4.15 & 3.32 & 1.44 & 0.46 \\
\hline Universal - & Government Banks & 15.50 & 7.82 & 21.53 & 1.33 \\
\hline Universal - & Private Domestic Banks (PDBs) & 71.54 & 81.83 & 59.03 & 0.86 \\
\hline Commercial - & Foreign Bank Branches (FBBs) & 4.82 & 3.34 & 3.52 & 0.93 \\
\hline Commercial - & Foreign Bank Subsidiaries (FBSs) & 1.08 & 1.01 & 0.95 & 0.94 \\
\hline Commercial - & Private Domestic Banks (PDBs) & 2.91 & 2.68 & 13.54 & 4.57 \\
\hline \multicolumn{6}{|c|}{ by nature of operations } \\
\hline Commercial & & 8.81 & 7.02 & 18.01 & 6.44 \\
\hline Universal & & 91.19 & 92.98 & 81.99 & 2.65 \\
\hline \multicolumn{6}{|l|}{ by ownership } \\
\hline Domestic & & 89.95 & 92.33 & 94.09 & 6.76 \\
\hline Foreign & & 10.05 & 7.67 & 5.91 & 2.34 \\
\hline
\end{tabular}

1/ Measured using the definition of total exposure under Basel 3 (i.e. the sum of on-balance and off-balance sheet items).

2/ Assets issued by financial institutions and loans to financial institutions.

3/ Deposits from financial institutions.

4/ Share of deposit liabilities from other banks to total liabilities.

Source: BSP Authors' Computation.

25. Basel 3 items $§ 157-164$ include total assets and other off-balance sheet items such as loan commitments and financial guarantees. 
The combined significant share of domestic banks at $90 \%$ (U/KBs- PDBs, as well as U/ KBs- government banks) in terms of size suggests that domestic banks could transmit contagion to other resident banks through its investment in debt securities, extension of loans and acceptance of deposits.

The aforementioned indicators provide an overview of the U/KBs' systemic importance in the financial system. However, in order to further assess the contagion and effects of possible spillovers following a failure from banks' counterparties, a more detailed study on the nature of cross-border exposures of these banks is necessary. These are discussed in the succeeding sections.

\subsection{Assessment of the Philippine Banking System's Cross-Border Exposures ${ }^{26}$}

The increasing trend in cross-border lending and borrowing exposes banks to distress, uncertainties and even burden sharing during crisis. When banks respond to a deterioration in their balance sheets through large reductions in cross-border loans, a financial contagion in the international banking system could be triggered. For instance, during the GFC, several Central and Eastern European banks that were particularly exposed to Western European banks suffered deterioration in their financial conditions as the latter tried to cut their exposure to the former in reaction to losses incurred in their asset portfolio.

\section{Figure 1}

\section{Total Cross-border Financial Position of U/KBs and its Subsidiary TBs ${ }^{1 /}$}

(Consolidated Basis, in US Billion Dollar) ${ }^{27}$

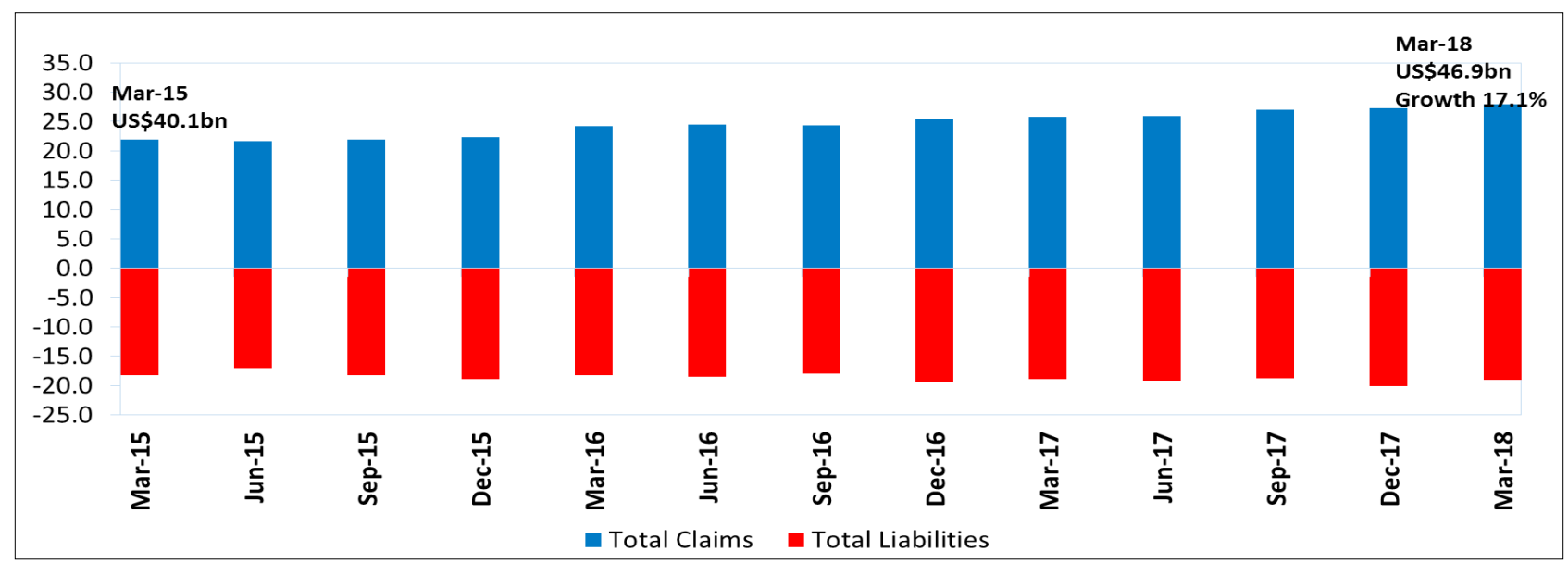

1/ Total Cross-Border Financial Position is the sum of Cross-Border Financial Claims and Cross-Border Financial Liabilities.

Source: BSP- Supervisory Data Center (SDC).

26. Under Basel 3, total exposure is the sum of on-balance and off-balance sheet items. In the Philippines, crossborder exposures of domestic banks are determined using BSP's internal statistics as reported in the Philippine cross-border report.

27. The best way for management to obtain a picture of an international bank's overall exposure to foreign borrowers outside a bank's own organisation is by measuring country exposure on a consolidated basis. 
Using the gross cross-border financial position of $\mathrm{U} / \mathrm{KBs}$ and its subsidiary thrift banks, it has been observed that there is an increasing trend of cross-border exposures (in terms of asset holdings) in the PBS albeit at a gradual pace. The gross cross-border financial position or the sum of cross-border financial claims and cross-border financial liabilities, has grown by $17.0 \%$ from US\$40.1 billion as of end-Mar $2015^{28}$ to US\$46.9 billion as of end-Mar $2018^{29}$ (Figure 1).

Table 2

Cross-Border Exposures of U/KBs and its Subsidiary TBs (in US Billion Dollar)

\begin{tabular}{|c|c|c|c|c|c|c|c|c|c|c|c|}
\hline \multicolumn{2}{|c|}{$\begin{array}{c}\text { Total Cross-Border } \\
\text { Claims }\end{array}$} & \multicolumn{3}{c|}{$\begin{array}{c}\text { Total Cross-Border } \\
\text { Liabilities }\end{array}$} & \multicolumn{2}{c|}{$\begin{array}{c}\text { Gross Cross-Border } \\
\text { Financial Position }\end{array}$} & \multicolumn{3}{c|}{$\begin{array}{c}\text { Net Cross-Border } \\
\text { Financial Position }\end{array}$} \\
\hline $\begin{array}{c}\text { Mar- } \\
\mathbf{1 5}^{3 /}\end{array}$ & $\begin{array}{c}\text { Mar- } \\
\mathbf{1 8}\end{array}$ & $\begin{array}{c}\% \\
\text { change }\end{array}$ & $\begin{array}{c}\text { Mar- } \\
\mathbf{1 5}^{3 /}\end{array}$ & $\begin{array}{c}\text { Mar- } \\
\mathbf{1 8}\end{array}$ & $\begin{array}{c}\% \\
\text { change }\end{array}$ & $\begin{array}{c}\text { Mar- } \\
\mathbf{1 5}^{\mathbf{3} /}\end{array}$ & $\begin{array}{c}\text { Mar- } \\
\mathbf{1 8}\end{array}$ & $\begin{array}{c}\% \\
\text { change }\end{array}$ & $\begin{array}{c}\text { Mar- } \\
\mathbf{1 5}^{3 /}\end{array}$ & $\begin{array}{c}\text { Mar- } \\
\mathbf{1 8}\end{array}$ & $\begin{array}{c}\% \\
\text { change }\end{array}$ \\
\hline 21.9 & 27.9 & $27.7 \%$ & 18.2 & 19.0 & $4.3 \%$ & $\mathbf{4 0 . 1}$ & $\mathbf{4 6 . 9}$ & $\mathbf{1 7 . 0 \%}$ & 3.6 & 8.9 & $144.8 \%$ \\
\hline
\end{tabular}

1/ Sum of cross-border financial claims and cross-border financial liabilities.

2/ Cross-border financial claims less cross-border financial liabilities.

3/ Data available as of end-March 2015.

Source: BSP-SDC, Authors' computation.

Table 2 shows that the Philippine U/KBs altogether remain a net cross-border lender with a net cross-border financial asset position of US\$8.9 billion as of end-March 2018. Meanwhile, year-on-year (y-o-y) growth of cross-border exposures has averaged at $6.7 \%$ from 2016 to 2018 . In terms of level, U/KBs cross-border exposures relative to the total banking system asset is at $16.9 \%$ as of end-March 2018 (from 16.3\% as of end-March 2015) ${ }^{30}$.

These balances are gathered from the quarterly Cross-Border Financial Position Reports submitted by U/KBs and its subsidiary thrift banks. ${ }^{31}$ In this paper, cross-border exposures refer to claims and liabilities of all banks in the Philippines regardless of their nationality and bank type.

28. BSP Circular No. 850 dated 8 September 2014 mandates a 2-phase submission of the Report on Cross-Border Financial Position. Phase 1 covered initial submission of a one-time report on total cross-border financial position according to geographic region/country and currency. Meanwhile, Phase 2 included the quarterly submission of the report on total cross-border financial position starting $31 \mathrm{March} 2015$. The report shall be categorized according to the sector of their non-resident counterparty within a country.

29. As of the recent quarter, total number of reporting U/KBs and subsidiary TBs reached 43 and 11(6 have exposures of cross-border), respectively.

30. Total assets of the banking system grew by $47.2 \%$ in end-March 2018 relative to end-September 2014 partly due to entry of new foreign banks. Hence, the share of cross-border to total banking asset remained around $16.0 \%$ despite a 27.4\% growth from end-September 2014 to end-March 2018.

31. BSP Circular No. 850 dated 8 September 2014. 


\subsection{Cross-Border Position of U/KBs by Region}

By region, majority of U/KBs' cross-border claims are from Asia Pacific economies, followed by claims in North American and European economies. In particular, Asia Pacific economies own a significant share in universal PDBs and government banks, and in commercial PDBs and FBBs. Likewise, United States and Canada, which comprise the North American region, have sizeable shares in universal banks and in commercial PDBs. Figure 2 below summarizes the cross-border claims of $\mathrm{U} / \mathrm{KBs}$ categories by region.

Figure 2

Cross-Border Claims of Universal (lhs) and

Commercial Banks (rhs) by Region*

(As of End-March 2018, Percent Share to Total**)
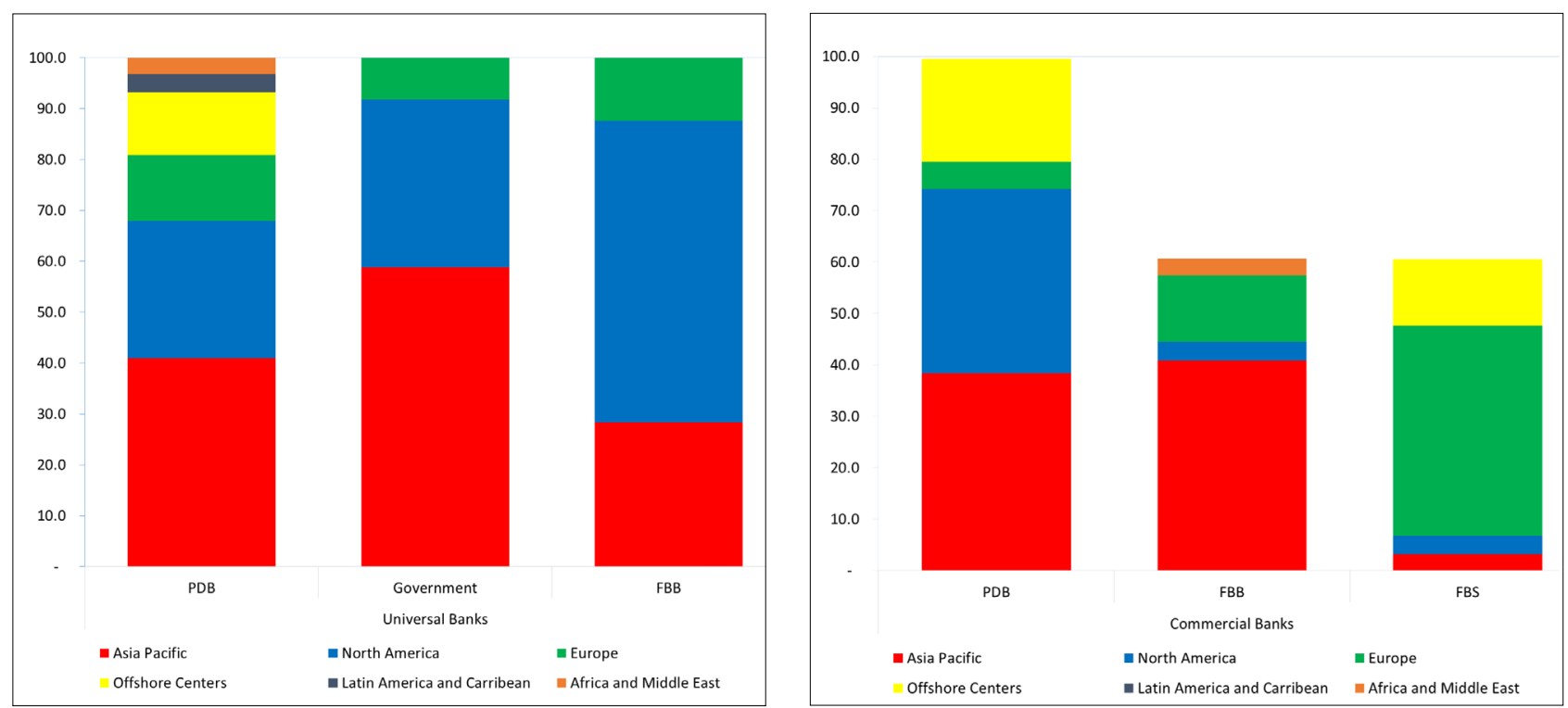

* By regional location of the counterparty.

** Regional share of cross-border claims to total claims by category (i.e., Universal Banks: PDB- Private Domestic Banks; Government; FBB- Foreign Bank Branches and Commercial Banks: PDB- Private Domestic Banks; FBBForeign Bank Branches; FBS- Foreign Bank Subsidiaries).

Source: BSP-SDC, Authors' Computation.

\subsection{Cross-Border Position of U/KBs by Country}

Figure 3 shows the cross-border positions of $\mathrm{U} / \mathrm{KBs}$ by counterparty, in particular, on selected Asia-Pacific countries plus the United States. The size of the "nodes" represents the level of cross-border exposure of a particular bank category. The larger the nodes, the bigger is the said cross-border exposure (cross-border financial claims and liabilities) of a particular bank category. Meanwhile, the thickness of the "edges" represents the magnitude of Philippine banks' exposure to a specific country. The thicker the edge, the more exposed a particular bank category is to a specific country. In terms of cross-border claims, majority are claims to the United States, while major sources of cross-border funding as of end-March 2018 are both from the United States and Singapore. 
Figure 3

Cross-border Claims (lhs) and Cross-border Liabilities (rhs)*

(As of End-March 2018)
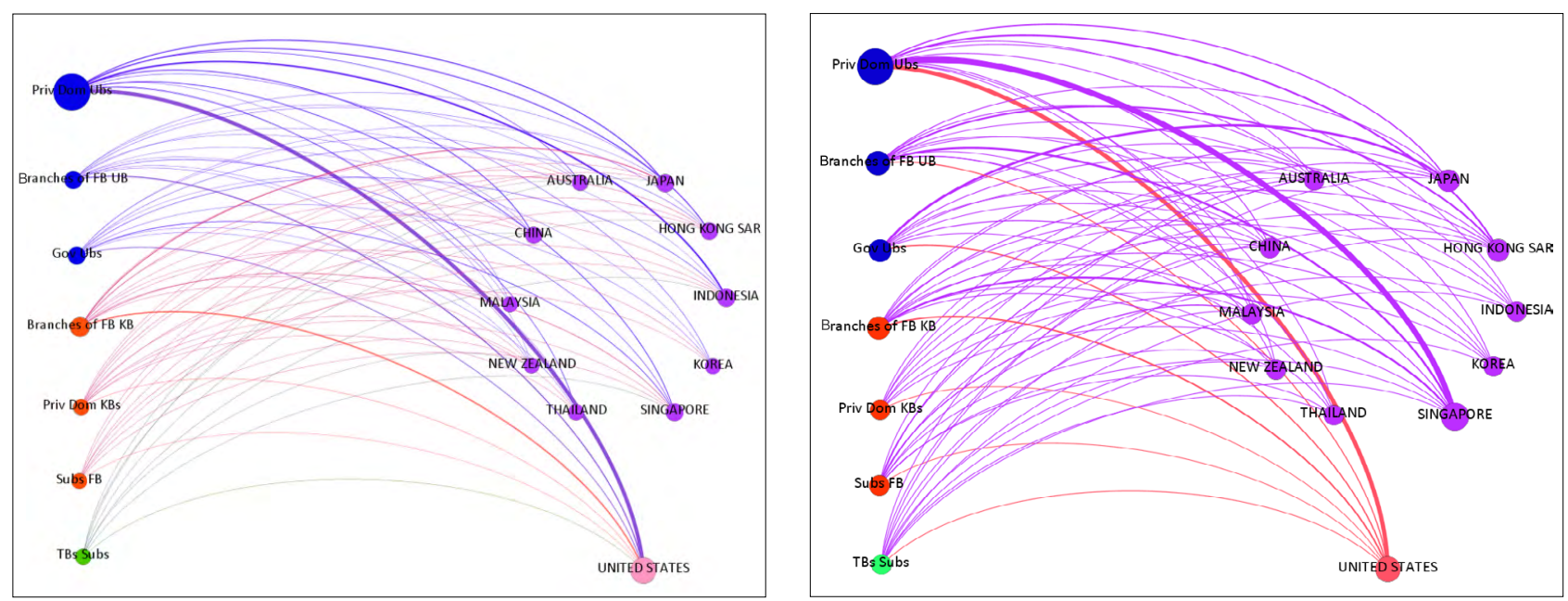

* United States and selected Asia-Pacific Counterparties.

Source: Authors' Computation.

\section{Data and Methodology}

This study focuses on the cross-border exposures of $\mathrm{U} / \mathrm{KBs}$ in the Philippines in terms of claims from and liabilities to counterparty economies. Foreign counterparties pertain to nonresident banks, non-bank financial institutions and non-financial institutions which (i) are located in the a country or economy other than the Philippines; and, (ii) participate as another party in a financial transaction with a domestic financial institution (i.e., domestic banks in the current case).

Consistent with the BIS' international banking statistics and the BSP's adoption of the same definition, the cross-border claims in this study consist of loans and deposit to other banks and non-banks, holding of securities and other claims. Meanwhile, cross-border liabilities consist of loans and deposits from other banks and non-banks, own issues of debt securities, and other liabilities. The data are obtained from banks' quarterly submissions of Report on Cross-Border Financial Position beginning 31 March 2015 and ending in 31 March 2018. Under BSP Circular No.850 in 2014, the regular submission of cross-border positions should cover transactions from 31 March 2015 onwards. These positions are reported in US dollar at the prevailing exchange rate as of reporting period. Cross-border exposures are denominated in US dollars and are converted to Philippine peso using end-March 2015 and end-March 2018 exchange rates at P44.80 and P52.20, respectively. ${ }^{32}$

To assess the potential systemic implications of cross-border linkages of Philippine banks with its counterparty countries such as the United States and selected Asia-Pacific economies, ${ }^{33}$ a simple interbank exposure model employed by Espino-Vega and Sole (2010) was replicated in this

32. Using the Philippine Dealing System (PDS) Peso/US Dollar closing rate and the New York US Dollar/Third Currencies closing rate (BSP Circular No.850, series 2014, Annex A).

33. i.e., China, Hong Kong, Indonesia, Japan and Singapore. 
paper. This network model allows identification of systemic and vulnerable institutions in terms of capital absorption within a network of banks. It also enables monitoring of contagion chains stemming from different financial shocks.

The researchers acknowledge the limitations in replicating the model. Data limitations on inter-institutional exposures and assumptions on different parameters are limited to post-crisis as the initial quarterly cross-border reporting in the Philippines only covers March 2015 as the reference quarter. ${ }^{34}$ Given this, the comparison of Philippine banks' exposures were limited to end-March 2015 data and end-March 2018 data. Moreover, foreign counterparty banks are not specifically identified in the analyzes due to data limitations. Likewise, analysis and results are also limited to the application of the empirical strategy between domestic and foreign banks.

There are two scenarios wherein Philippine banks' balance sheets are subjected to different shocks. The first scenario includes assessing vulnerability due to credit shock, while the second scenario considers the impact of funding shock to the domestic banking system. The paper defines credit shock as the reduction in the capital of U/KBs triggered by the default of foreign counterparties. ${ }^{35}$ Meanwhile, funding shock is the reduction in the capital of U/KBs as a result of foreign counterparties' withdrawal of interbank funds from local banks, thereby affecting the liquidity condition of the borrowing counterparty.

Similar to the balance sheet model designed by Espino-Vega and Sole (2010), Equation (1) represents the Philippine bank $i$ balance sheet covering the banks' total assets, total liabilities and equity, of which the portion of cross-border claims to specific countries are identified:

$$
\sum_{j} X_{j i}+a_{i}=k_{i}+b_{i}+d_{i}+\sum_{j} X_{i j}
$$

Equation (1)

Where $x_{i}$ stands for Philippine bank $i$ 's (by bank category) cross-border claims on country $j$ (i.e., United States, selected Asia-Pacific counterparties and other counterparties) ${ }^{36}, a_{i}$ stands for Philippine bank $i$ 's other assets (total banking asset less claims to other jurisdictions), $k_{i}$ stands for Philippine bank $i$ 's capital, $b_{i}$ represents Philippine bank $i$ 's borrowings less liabilities from other jurisdictions, $d_{i}$ stands for deposits, and $X_{i}$ stands for Philippine bank $i$ 's liabilities to country $j$.

Equation (2) provides the basis for the first set of simulations on the impact of cross-border counterparties' default on their obligations to domestic PBS. This credit shock to the asset side of the balance sheet of Philippine banks affects its capital when an account in default is written-off. This paper simulates Equation (2) and uses the same initial loss-given-default (LGD) parameter

34. BSP Circular No. 850 dated 8 September 2014 mandates a 2-phase submission of the Report on Cross-Border Financial Position. Phase 1 covered initial submission of a one-time report on total cross-border financial position according to geographic region/country and currency. Meanwhile, Phase 2 included the quarterly submission of the report on total cross-border financial position starting 31 March 2015.

35. Foreign counterparties pertain to non-resident banks, non-bank financial institutions and non-financial institutions which (i) are located in a country or economy other than the Philippines and (ii) participate as another party in a financial transaction with a domestic financial institution (i.e., domestic banks in the current case).

36. Cross-border exposures in USD were converted to PHP using end of March 2015 and end of March 2018 exchange rates at 44.80 and 52.207 PHP/USD, respectively. Reference rate is the Philippine Peso per US Dollar - Daily Rate found in the Bangko Sentral ng Pilipinas website. 
(equivalent to 100 percent on impact) in the paper of Espino-Vega and Sole (2010) and tests the other LGD scenarios (i.e., $20.0 \%, 50.0 \%$ and $75.0 \%$ ). At an LGD rate of $100 \%$, when the credit shock first materializes, bank $i$ is unable to recover any of their loans from country $j$ as it takes time for secondary and debt-distressed markets to price recently defaulted instruments.. The different credit shock scenarios should help determine the level of percentage default upon which a bank's capital starts to deteriorate.

Counterparty shock is exogenous to the economic and financial developments within the Philippines and may emanate from countries suffering from either economic or political turmoil. For purposes of stress testing, identified trigger countries are the following: United States, and the top 5 Asia-Pacific counterparties of Philippine banks in terms of cross-border claims, namely, Indonesia, Singapore, Japan, Hong Kong and China.

A default of each of these trigger countries, represented by the assumed LGD (denoted by the parameter $\lambda$ ), reduces the capital of banks because the assumption is that banking system's $i$ capital absorbs the losses on impact. This negative impact on capital is reflected as a percentage capital reduction in the simulation. The baseline balance sheet identity of bank $i$ becomes:

$$
a_{i}+\sum_{j \neq h} X_{j i}+(1-\lambda) X_{h i}=\left(k_{i}-\lambda X_{h i}\right)+b_{i}+d_{i}+\sum_{j} X_{i j}
$$

Equation (2)

Insufficiency of capital to cover its losses due to default happens when $\left(k_{i}-\lambda X_{h i}\right)<0$. Equation 2 is a modification of Equation 1 with two additional parameters on both sides of the equation, interpreted as follows:

$X_{h i}$ : bank i's loans to counterparty $h$

$(\lambda)$ : default (LGD) rate of counterparty $h$

$(\lambda) X_{h i}$ : amount of hypothetical default of counterparty $h$

In addition to the assumption that the loss due to credit shock is absorbed by the banks' capital, this paper also assumes that any capital reduction due to writing-off of bad accounts cannot be replaced easily by raising new capital due to high cost of external funding.

Equation 3 simulates funding shock when a cross-border counterparty pulls out interbank funds from local banks, thereby affecting the liquidity condition of the borrowing counterparty. When the affected bank is unable to roll over its (part of) funding in the interbank cross-border market, it will have to sell assets at a discount in order to re-establish its balance sheet position. The Espino-Vega and Sole (2010) model for this funding shortfall is shown as:

$$
a_{i}+\sum_{j} X_{j i}-(1+\delta) \rho X_{i h}=\left(k_{i}-\delta \rho X_{i h}\right)+b_{i}+d_{i}+\sum_{j} X_{i j}-\rho X_{i h}
$$

Where $\rho$ represents the lost funding rate from country/counterparty $h$ and Philippine banks will be able to replace only a fraction $(1-\rho)$. To be able to provide the liquidity in the absence of alternative sources of funding, a bank may be forced to sell (fire sale) part of its assets worth $(1+\delta) \rho X_{i h}$ in order to restore its balance sheet position. Capital reduction $\left(k_{i}-\delta \rho X_{i h}\right)$ is equivalent to the portion deducted from the capital pertaining to the haircut $\delta$ during fire sale, multiplied by lost funding $\rho X_{i h}$. 
Assumptions for the first scenarios are $50.0 \%$ haircut in the fire sale of assets and a $65.0 \%$ roll-over ratio (partial ratio) of interbank debt ${ }^{37}$ similar to the assumptions used in the paper of Espino-Vega and Sole (2010). The 50.0\% haircut is a conservative assumption given that typical central banks' haircut framework suggests a close to zero haircut for most liquid assets and high haircuts (e.g. $0.5 \%$ to $65 \%$ haircut rates for different asset categories) ${ }^{38}$ for the least liquid assets. ${ }^{39}$

\section{Simulations and Results}

\subsection{Vulnerability Due to Credit Shock}

Table 3 shows the reduction in capital of domestic and foreign banks due to hypothetical default of counterparties. The results of the simulation show that the four hypothetical default scenarios could potentially reduce foreign banks' capital. Capital reduction appears to be moderate under the $20 \%$ default scenario. Considering the case under the lowest default rate, the simulation shows that a $20 \%$ hypothetical default of claims from United States could lead to a decrease in foreign banks' capital by $37.5 \%$.

Notably, the results are more moderate for domestic banks. A double-digit percentage reduction in domestic bank capital will result under the 50.0, 75.0 and 100.0\% (the last one being considered as the worst case scenario) hypothetical default on claims from United States.

Table 3

Capital Reduction Due to Credit Shock in Selected Countries* (As of End-Mar 2015)

\begin{tabular}{|c|c|c|c|c|c|c|c|}
\hline Default Scenario & Bank Category & CH & HK & ID & JP & SG & US \\
\hline \multirow{2}{*}{$20 \%$ Default } & Domestic Banks & $-0.6 \%$ & $-1.0 \%$ & $-1.7 \%$ & $-0.6 \%$ & $-0.6 \%$ & $-4.5 \%$ \\
\cline { 2 - 7 } & Foreign Banks & $-3.0 \%$ & $-3.0 \%$ & $-0.3 \%$ & $-1.2 \%$ & $-6.6 \%$ & $-37.5 \%$ \\
\hline \multirow{2}{*}{$50 \%$ Default } & Domestic Banks & $-1.5 \%$ & $-2.6 \%$ & $-4.2 \%$ & $-1.4 \%$ & $-1.5 \%$ & $-11.2 \%$ \\
\cline { 2 - 7 } & Foreign Banks & $-7.6 \%$ & $-7.6 \%$ & $-0.8 \%$ & $-3.0 \%$ & $-16.5 \%$ & $-93.8 \%$ \\
\hline \multirow{2}{*}{$75 \%$ Default } & Domestic Banks & $-2.3 \%$ & $-3.8 \%$ & $-6.3 \%$ & $-2.2 \%$ & $-2.3 \%$ & $-16.7 \%$ \\
\cline { 2 - 7 } & Foreign Banks & $-11.4 \%$ & $-11.3 \%$ & $-1.1 \%$ & $-4.5 \%$ & $-24.8 \%$ & $-140.7 \%$ \\
\hline \multirow{2}{*}{$100 \%$ Default } & Domestic Banks & $-3.0 \%$ & $-5.1 \%$ & $-8.4 \%$ & $-2.9 \%$ & $-3.1 \%$ & $-22.3 \%$ \\
\cline { 2 - 7 } & Foreign Banks & $-15.2 \%$ & $-15.1 \%$ & $-1.5 \%$ & $-6.0 \%$ & $-33.1 \%$ & $-187.5 \%$ \\
\hline
\end{tabular}

* CH-China, HK-Hong Kong, ID-Indonesia, JP-Japan, SG-Singapore, US-United States.

Source: Authors' computation.

37. Parameter values of $\delta=1$ and of $\rho=0.35$. In the same paper of Espino-Vega and Sole (2010), an alternative way of interpreting the values is presented as follows: "Let $\rho x$ be the amount of funding that cannot be replaced. Let $\rho$ be the current market price for assets and let $y$ be the quantity of assets sold. That is, $\rho^{\wedge} 1 y=\rho x$. Hence, $\delta=\left(p^{\wedge} 0-p^{\wedge} 1\right) / p^{\wedge} 1 \ldots ”$ (where higher $\delta$ reflects higher distress in markets).

38. Referring to European Central Banks' haircut rates for different securities classified in liquidity categories according to issuer types, for three buckets of residual maturity and for two rating classes. (ECB, 2013)

39. Bindseil, Ulrich, 2013. Central Bank Collateral, Asset Fire Sales, Regulation and Liquidity, Working Paper Series No. 1610, European Central Bank, November 2013. 
The estimated capital reduction of domestic banks appear to be manageable for all assumed default rates from counterparties in China, Hong Kong, Indonesia, Japan and Singapore. However, simulated impacts on capital of foreign banks are larger in magnitude across all scenarios from counterparties in China, Hong Kong, Singapore and United States. This could be attributed to sufficient build-up of capital buffers by domestic banks in the Philippines in an environment of increasing cross-border transactions.

Philippine domestic and foreign banks appear to be more exposed to defaults/write-offs by counterparties in the United States as the country is considered a net supplier of US dollar funding in the international market (BIS, 2018). The resulting larger reduction in capital could be attributed to the foreign banks' substantial US dollar investment abroad. ${ }^{40}$ Notably, Philippine foreign banks could experience double-digit percentage capital reduction even with the lowest 20.0 percent assumed default by United States counterparties.

Meanwhile, based on the latest available data as of end-March 2018, the assumed default in counterparties' claims showed a generally lower reduction (when compared to that as of end-March 2015) in foreign banks' capital (Table 4). Reduction in foreign banks' capital with claims from Japan turned double-digit under the 50.0, 75.0 and $100.0 \%$ default rate scenarios.

Table 4

Capital Reduction Due to Credit Shock in Selected Countries*

(As of End-Mar 2018)

\begin{tabular}{|c|c|c|c|c|c|c|c|}
\hline Default Scenario & Bank Category & CH & HK & ID & JP & SG & US \\
\hline \multirow{2}{*}{$20 \%$ Default } & Domestic Banks & $-0.7 \%$ & $-0.9 \%$ & $-1.9 \%$ & $-0.8 \%$ & $-1.0 \%$ & $-4.7 \%$ \\
\cline { 2 - 7 } & Foreign Banks & $-0.6 \%$ & $-2.6 \%$ & $-0.2 \%$ & $-8.1 \%$ & $-6.4 \%$ & $-26.7 \%$ \\
\hline \multirow{3}{*}{$50 \%$ Default } & Domestic Banks & $-1.8 \%$ & $-2.3 \%$ & $-4.7 \%$ & $-2.1 \%$ & $-2.5 \%$ & $-11.7 \%$ \\
\cline { 2 - 7 } & Foreign Banks & $-1.6 \%$ & $-6.4 \%$ & $-0.4 \%$ & $-20.1 \%$ & $-16.0 \%$ & $-66.7 \%$ \\
\hline \multirow{2}{*}{$75 \%$ Default } & Domestic Banks & $-2.7 \%$ & $-3.4 \%$ & $-7.0 \%$ & $-3.2 \%$ & $-3.8 \%$ & $-17.5 \%$ \\
\cline { 2 - 7 } & Foreign Banks & $-2.4 \%$ & $-9.7 \%$ & $-0.6 \%$ & $-30.2 \%$ & $-24.0 \%$ & $-100.0 \%$ \\
\hline \multirow{3}{*}{$100 \%$ Default } & Domestic Banks & $-3.6 \%$ & $-4.6 \%$ & $-9.3 \%$ & $-4.2 \%$ & $-5.1 \%$ & $-23.4 \%$ \\
\cline { 2 - 7 } & Foreign Banks & $-3.2 \%$ & $-12.9 \%$ & $-0.8 \%$ & $-40.3 \%$ & $-32.0 \%$ & $-133.4 \%$ \\
\hline
\end{tabular}

* CH-China, HK-Hong Kong, ID-Indonesia, JP-Japan, SG-Singapore, US-United States.

Source: Authors' computation.

The results for foreign banks were consistent with the BIS (2018) report suggesting that the largest cross-border claims of banks in the Philippines were on the United States and neighbouring Asian economies (BIS, 2018). Relative to the end-March 2015 data, estimates using end-March 2018 data indicate larger capital reduction owing to increased share of foreign banks in crossborder claims from Singapore, Japan, China and Indonesia, particularly under the assumption of a $100 \%$ LGD.

40. "Statistical Release: BIS International Banking Statistics at end-September 2017," Bank for International Settlements, 18 January 2018. 


\subsection{Vulnerability Due to Funding Shock}

The impact of funding shock on both domestic and foreign banks' capital follows from the assumption that banks may resort to fire sale of assets in order to replace all the funding previously granted by the defaulting counterparties (Bisias et al., 2012). The resulting lower capital reduction in both domestic and foreign banks capital from a funding shock indicates sufficient amount of highly liquid asset holdings by Philippine banks. In fact, banks in the country have maintained satisfactory asset quality, adequate provisioning, capital buffers and ample liquidity which serve at its defense against external shocks (BSP, 2017).

Table 5

\section{Capital Reduction Due to Funding Shock in Selected Countries*}

(As of End-Mar 2015)

\begin{tabular}{|l|c|c|c|c|c|c|c|}
\hline Default Scenario & Bank Category & CH & HK & ID & JP & SG & US \\
\hline $\begin{array}{l}\text { 50\% haircut; } \\
65 \% \text { roll-over rate }\end{array}$ & Domestic Banks & $-0.5 \%$ & $-0.9 \%$ & $-1.5 \%$ & $-0.5 \%$ & $-0.5 \%$ & $-3.9 \%$ \\
\cline { 2 - 7 } & Foreign Banks & $-2.7 \%$ & $-2.6 \%$ & $-0.3 \%$ & $-1.1 \%$ & $-5.8 \%$ & $-32.8 \%$ \\
\hline & & & & & & & \\
\hline \multirow{2}{*}{$\begin{array}{l}75 \% \text { haircut; } \\
50 \% \text { roll-over rate }\end{array}$} & Domestic Banks & $-1.1 \%$ & $-1.9 \%$ & $-3.2 \%$ & $-1.1 \%$ & $-1.2 \%$ & $-8.4 \%$ \\
\cline { 2 - 8 } & Foreign Banks & $-5.7 \%$ & $-5.7 \%$ & $-0.6 \%$ & $-2.3 \%$ & $-12.4 \%$ & $-70.3 \%$ \\
\hline
\end{tabular}

* CH-China, HK-Hong Kong, ID-Indonesia, JP-Japan, SG-Singapore, US-United States.

Source: Authors' computation.

Tables 5 and 6 present the results of the stress-test using $65.0 \%$ roll-over rate and $50.0 \%$ haircut for the first scenario; while $50.0 \%$ roll-over rate and a $75.0 \%$ haircut were used in the second scenario. ${ }^{41}$

Table 6

\section{Capital Reduction Due to Funding Shock in Selected Countries*}

(As of End-Mar 2018)

\begin{tabular}{|c|c|c|c|c|c|c|c|}
\hline Default Scenario & Bank Category & CH & HK & ID & JP & SG & US \\
\hline $\begin{array}{c}50 \% \text { haircut; 65\% } \\
\text { roll-over rate }\end{array}$ & Domestic Banks & $-0.6 \%$ & $-0.8 \%$ & $-1.6 \%$ & $-0.7 \%$ & $-0.9 \%$ & $-4.1 \%$ \\
\cline { 2 - 7 } & Foreign Banks & $-0.6 \%$ & $-2.3 \%$ & $-0.1 \%$ & $-7.0 \%$ & $-5.6 \%$ & $-23.3 \%$ \\
\hline \multirow{2}{75\%}{$\begin{array}{c}75 \text { haircut; 50\% } \\
\text { roll-over rate }\end{array}$} & Domestic Banks & $-1.3 \%$ & $-1.7 \%$ & $-3.5 \%$ & $-1.6 \%$ & $-1.9 \%$ & $-8.8 \%$ \\
\cline { 2 - 7 } & Foreign Banks & $-1.2 \%$ & $-4.8 \%$ & $-0.3 \%$ & $-15.1 \%$ & $-12.0 \%$ & $-50.0 \%$ \\
\hline
\end{tabular}

* CH-China, HK-Hong Kong, ID-Indonesia, JP-Japan, SG-Singapore, US-United States.

Source: Authors' computation.

41. In the Philippines, a haircut is applied by a collateral taker as a risk control measure as a protection against losses arising from a decline in market value. Specific haircuts (ranging from 15\% to 50\%) are applied depending on the level and type of an asset class (BSP Circular No. 905, series of 2016). 
Table 7 summarizes the results of the stress tests on a combination of credit and funding shocks. It shows the amount of banks' capital reductions can come largely from United States and Japanese counterparties. This could still be attributed to the increasing claims of Philippine banks on neighbouring Asian economies, which includes Japan (BIS, 2018). The result is consistent with the impact of credit shock on claims covering end-March 2018 (see discussion in Table 4).

Table 7

Capital Reduction Due to Credit-plus-Funding Shocks in Selected Countries*

(As of End-Mar 2018)

\begin{tabular}{|c|c|c|c|c|c|c|c|}
\hline Default Scenario & Bank Category & CH & HK & ID & $\mathbf{J P}$ & SG & US \\
\hline \multicolumn{8}{|c|}{$50 \%$ haircut; $65 \%$ roll-over rate } \\
\hline \multirow{2}{*}{$20 \%$ Default } & Domestic Banks & $-1.4 \%$ & $-1.7 \%$ & $-3.6 \%$ & $-1.6 \%$ & $-1.9 \%$ & $-8.9 \%$ \\
\hline & Foreign Banks & $-1.2 \%$ & $-4.9 \%$ & $-0.3 \%$ & $-15.3 \%$ & $-12.2 \%$ & $-50.7 \%$ \\
\hline \multirow{2}{*}{$50 \%$ Default } & Domestic Banks & $-2.4 \%$ & $-3.1 \%$ & $-6.4 \%$ & $-2.9 \%$ & $-3.4 \%$ & $-15.9 \%$ \\
\hline & Foreign Banks & $-2.2 \%$ & $-8.8 \%$ & $-0.5 \%$ & $-27.4 \%$ & $-21.8 \%$ & $-90.8 \%$ \\
\hline \multirow{2}{*}{$75 \%$ Default } & Domestic Banks & $-3.3 \%$ & $-4.3 \%$ & $-8.7 \%$ & $-3.9 \%$ & $-4.7 \%$ & $-21.8 \%$ \\
\hline & Foreign Banks & $-3.0 \%$ & $-12.0 \%$ & $-0.7 \%$ & $-37.5 \%$ & $-29.8 \%$ & $-124.1 \%$ \\
\hline \multirow{2}{*}{$100 \%$ Default } & Domestic Banks & $-4.2 \%$ & $-5.4 \%$ & $-11.0 \%$ & $-5.0 \%$ & $-6.0 \%$ & $-27.6 \%$ \\
\hline & Foreign Banks & $-3.8 \%$ & $-15.2 \%$ & $-0.9 \%$ & $-47.5 \%$ & $-37.8 \%$ & $-157.5 \%$ \\
\hline \multicolumn{8}{|c|}{$75 \%$ haircut; $50 \%$ roll-over rate } \\
\hline \multirow{2}{*}{$20 \%$ Default } & Domestic Banks & $-2.1 \%$ & $-2.7 \%$ & $-5.5 \%$ & $-2.5 \%$ & $-3.0 \%$ & $-13.7 \%$ \\
\hline & Foreign Banks & $-1.9 \%$ & $-7.6 \%$ & $-0.4 \%$ & $-23.6 \%$ & $-18.8 \%$ & $-78.2 \%$ \\
\hline \multirow{2}{*}{$50 \%$ Default } & Domestic Banks & $-3.2 \%$ & $-4.1 \%$ & $-8.3 \%$ & $-3.7 \%$ & $-4.5 \%$ & $-20.7 \%$ \\
\hline & Foreign Banks & $-2.9 \%$ & $-11.4 \%$ & $-0.7 \%$ & $-35.7 \%$ & $-28.4 \%$ & $-118.3 \%$ \\
\hline \multirow{2}{*}{$75 \%$ Default } & Domestic Banks & $-4.1 \%$ & $-5.2 \%$ & $-10.6 \%$ & $-4.8 \%$ & $-5.7 \%$ & $-26.6 \%$ \\
\hline & Foreign Banks & $-3.7 \%$ & $-14.6 \%$ & $-0.9 \%$ & $-45.8 \%$ & $-36.4 \%$ & $-151.6 \%$ \\
\hline \multirow{2}{*}{$100 \%$ Default } & Domestic Banks & $-5.0 \%$ & $-6.4 \%$ & $-12.9 \%$ & $-5.8 \%$ & $-7.0 \%$ & $-32.4 \%$ \\
\hline & Foreign Banks & $-4.5 \%$ & $-17.9 \%$ & $-1.1 \%$ & $-55.8 \%$ & $-44.4 \%$ & $-185.0 \%$ \\
\hline
\end{tabular}

* CH-China, HK-Hong Kong, ID-Indonesia, JP-Japan, SG-Singapore, US-United States.

Source: Authors' computation. 


\subsection{Vulnerability Due to Funding Shock with Changes in Exchange Rate}

The third stress-test scenario employed in this paper focuses on the effect of depreciation on the liability side of the balance sheet. The results of the stress tests should explore the possibility of dollar-denominated bank liabilities exceeding dollar-denominated bank assets to financial systems in the event of a large and sudden exchange rate depreciation. The imbalance could trigger large losses and may cause banking vulnerability. Such asset-liability mismatch was behind some of the most severe financial crises in emerging market economies during the mid-1990s and early 2000s - including Turkey in 1994, Argentina in 1995, Russia in 1998, and Argentina again in 2001 (Catao and Terrones, 2016).

Currency/exchange rate risk is the risk that foreign exchange rates or the implied volatility will change, thereby affecting the value of banks' assets held in foreign currency. With greater integration in the global financial system, the financial channel of exchange rates has become more important. A stronger dollar is associated with slower dollar-denominated cross-border bank flows and lower real investment in emerging market economies. Moreover, there is an association between the depreciation of an international funding currency and higher borrowing in that same currency by non-residents.

The stress-test activity in this empirical strategy determines the percentage reduction of capital due to domestic currency depreciation against the US dollar. In the Philippines, the peso has notably depreciated against the US dollar at an average of 200-basis points (bps) between end-March 2015 and end-March 2018. An assumption of a slightly more conservative 300-bps depreciation of the peso is applied in the third stress-testing scenario. Since data are reported in US-dollar denominated positions, data are converted using the BSP reference exchange rate for the respective periods covered. Table 8 shows that a 300-bps depreciation of the peso against the US dollar could cause a large reduction of capital of foreign banks, in particular, due to the sudden negative shock in the collection of liability funding from these counterparty countries: United States, Singapore and Japan. For other countries in the table, minimal reductions are observed in the results.

Table 8

\section{Capital Reduction Due to Funding Shocks in Selected Countries*} with 300-bps Peso Depreciation ${ }^{42}$

(As of End-Mar 2018)

\begin{tabular}{|l|c|c|c|c|c|c|c|}
\hline Default Scenario & Bank Category & CH & HK & ID & JP & SG & US \\
\hline \multirow{2}{*}{$\begin{array}{l}50 \% \text { haircut; } \\
65 \% \text { roll-over rate }\end{array}$} & Domestic Banks & $-0.6 \%$ & $-0.8 \%$ & $-1.7 \%$ & $-0.8 \%$ & $-0.9 \%$ & $-4.2 \%$ \\
\cline { 2 - 7 } & Foreign Banks & $-0.6 \%$ & $-2.3 \%$ & $-0.1 \%$ & $-7.3 \%$ & $-5.8 \%$ & $-24.1 \%$ \\
\hline & & & & & & & \\
\hline $\begin{array}{l}75 \% \text { haircut; } \\
50 \% \text { roll-over rate }\end{array}$ & Domestic Banks & $-1.4 \%$ & $-1.8 \%$ & $-3.6 \%$ & $-1.6 \%$ & $-2.0 \%$ & $-9.0 \%$ \\
\cline { 2 - 8 } & Foreign Banks & $-1.3 \%$ & $-5.0 \%$ & $-0.3 \%$ & $-15.6 \%$ & $-12.4 \%$ & $-51.6 \%$ \\
\hline
\end{tabular}

* CH-China, HK-Hong Kong, ID-Indonesia, JP-Japan, SG-Singapore, US-United States.

Source: Authors' computation.

42. Cross-border exposures, which were reported in US dollar, were subsequently converted to PHP using end of March 2018 exchange rates at PHP/USD-52.207/1. The 300 bps depreciation rate or PHP/USD-53.821 was applied across the reported balance of cross-border exposures. 
The results of the simulations reflect the structure of the banking system, which is characterized by varying degrees of domestic banks' exposure to cross-border risks depending on the source and level of the haircuts or shocks. A rare event of large haircuts could possibly lead to greater crossborder risks for foreign banks with higher exposure to United States and Japan. Domestic banks are less vulnerable to such cross-border risks, even in the case of a 300-bps depreciation of the local currency. Balance sheet structure shows that banks' assets are the channels through which crossborder risks are transmitted, rather than through their liabilities. ${ }^{43}$ The conclusion supports the fact that the Philippine banking system remains a net cross-border lender with a net cross-border financial asset position of US\$8.9 billion as of end-March 2018 (see Table 2).

\section{Summary and Policy Implications}

\subsection{Summary of Results}

Results of the first simulation, involving a credit shock scenario, show that foreign banks are mostly affected by the failure of counterparty banks in the United States. Assuming different and increasing LGD rate scenarios, hypothetical default in counterparty banks, particularly those of Japan and Singapore results in a relative impairment (less than 20\%) of foreign banks' capital (given realistic haircuts). The notable impact of hypothetical default in Japanese and Singapore counterparty banks could be attributed to the relatively large cross-border claims of Philippines banks to the neighbouring Asian economies, in addition to the United States.

Meanwhile, results of the simulations involving funding shock show lower impact relative to the results of the first scenario due to the availability of sufficient and highly-liquid bank assets during a fire sale. In general, foreign banks' capital is more likely to be affected than domestic banks' capital. The increasing trend in cross-border activities of both domestic and foreign banks provides a case for continued surveillance of cross-border exposures of Philippine banks to Asian counterpart countries such as China. In particular, in the paper of Koch and Remolona (2018), it has been pointed out that Chinese banks have become an increasingly important provider of international bank credit to borrowers both within and outside Asia. This area of risk to funding is termed as "common lender channel."

Results show that the risk of contagion through the reduction in domestic banks' capital may be lower in comparison with foreign banks' upon the application of both credit and funding shocks. Nevertheless, the paper suggests continued surveillance on cross-border exposures of domestic banks in the Philippines despite the results of the spillover effects of the scenario simulations.

43. Banks in the Philippines are net suppliers of US dollar (on balance sheet) funding in the international banking market (BIS, 2018). 


\subsection{Policy Implications}

Financial interconnectedness offers many benefits such as facilitating financial flows for efficient capital allocation, risk-sharing and diversification. However, these activities of financial institutions warrant constant surveillance as exposures are sensitive to macroeconomic conditions, including sharp movements in interest rates, exchange rates and other variables. If banks are highly exposed to such sharp movements, changes in cross-border assets and liabilities could threaten the stability of the domestic financial system.

Stress tests conducted in this paper show that there could be possible thresholds in which double-digit percentage rate reduction in capital and funding conditions can change substantially. This could be attributed to the changing bank balance sheet structure as a result of greater crossborder exposures and financial globalization. ${ }^{44}$

The corresponding results from the simulation exercises suggest that there are unexplored data which can be of use to policymakers. This information could enhance existing policy toolkits for dealing with the challenges of macrofinancial linkages particularly, in the financial system. Results of empirical studies and analysis can change depending on the period covered. Data with greater detail and longer time series maybe be more reflective of the status of the financial sector and from which policies could be calibrated in response to changing economic conditions (Canuto and Ghosh, 2013).

Results show differences in funding, assets and liabilities structure between foreign and domestic banks which could affect the relevance and efficacy of policy measures. Policymakers and concerned multilateral agencies may need to revisit capital flow policies and regulatory mix between domestic and foreign banks to effectively address the challenges of a globally-integrated financial markets.

Moreover, continued coordination on issues concerning cross-border presence and macroprudential policies at the international level maybe warranted to ensure regulation and stability both in the domestic and global financial system (BIS, 2012).

The study may be useful to the BSP in monitoring periods of elevated contagion risks due to increasing complexities in the financial system and the evolving nature of systemic risks. While the findings of the study may be valuable inputs in analyzing contagion risk in the Philippines, the determinants of contagion risks are not examined in this paper. Thus, exploration of contagion and its determinants could be a possible area for future research.

44. Banks are now allowed to tap cross-border funds as well to diversify away from traditional funding sources and towards international interbank markets (Fender and McGuire, 2010). 


\section{References}

Ahrend, R.; J. Arnold and F. Murtin, (2011a), "Have More Strictly Regulated Banking Systems Fared Better During the Recent Financial Crisis?" Applied Economics Letters, Vol. 18(5), pp. 399-403.

Ahrend, R. and A. Goujard, (2011), "Drivers of Systemic Banking Crises: The Role of BankBalance-Sheet Contagion and Financial Account Structure," OECD Economics Department Working Papers, No. 902, OECD Publishing.

Ahrend, R. and A. Goujard, (2012), "International Capital Mobility and Financial Fragility - Part 3. How Do Structural Policies Affect Financial Crisis Risk?: Evidence from Past Crises Across OECD and Emerging Economies," OECD Economics Department Working Papers, No. 966, OECD Publishing, Paris, Available at: http://dx.doi.org/10.1787/5k97fmtj5vtk-en

Ahrend, R. and C. Schwellnus, (2012), "Which Structural Policies Stabilise Capital Flows When Investors Suddenly Change Their Mind? Evidence from Bilateral Bank Data," OECD Economics Department Working Papers, No. 967, OECD Publishing.

Bangko Sentral ng Pilipinas (BSP) Regular Publication, "A Status Report on the Philippine Financial System for Second Semester 2015, Available at: http:/www.bsp.gov.ph/downloads/ Publications/2015/StatRep_2Sem2015a.pdf.

Bisias D. et al., (2012), "A Survey of Systemic Risks Analytics," U.S. Department of Treasury Office of the Financial Research Working Paper, No.0001, 5 January.

BSP, (2018), BSP Regular Publication, 2018 Annual Report: Navigating the Future.

BSP Supervised Banks/ Statistics, Available at: www.bsp.gov.ph/banking/bspsup.asp

BSP, (2014), BSP Circular No. 850, "Report on Cross-Border Financial Positions on Banks," Series of 2014.

BSP, (2014), BSP Circular No. 856, "Implementing Guidelines on the Framework for Dealing with Domestic Systemically Important Banks under Basel III,” Series of 2014.

BSP, (2016), BSP Circular No. 905, "Implementation of Basel III Framework on Liquidity Standards-Liquidity Coverage Ratio and Disclosure Standards," Series of 2016.

BSP (2017), BSP Media Releases, "Philippine Financial System Continues Build-up of Buffers Amid Sustained Credit Growth," 27 October.

Bindseil, U., (2013), “Central Bank Collateral, Asset Fire Sales, Regulation and Liquidity,” Working Paper Serie,s No. 1610, European Central Bank, November.

BIS, (2011), "Global Systemically Important Banks: Assessment Methodology and the Additional Loss Absorbency Requirement- Rule Text," BIS Basel Committee on Banking Supervision, November, Available at: https://www.bis.org/publ/bcbs207.pdf with revised version published in July 2013, http://www.bis.org/publ/bcbs255.htm 
BIS, (2012), "Financial Sector Regulation for Growth, Equity and Stability," BIS Paper, No. 62, January.

BIS, (2013), "Guidelines for Reporting the BIS International Banking Statistics," Monetary and Economics Department, March.

BIS, (2018), "Statistical Release: BIS International Banking Statistics at End-September 2017," Bank for International Settlements, 18 January.

Brunnermeier, M. et al., (2012), "Banks and Cross-border Capital Flows: Policy Challenges and Regulatory Responses," Committee on International Economic Policy Reform, September.

Bruno, V. and H. S. Shin, (2015), "Cross-Border Banking and Global Liquidity," Review of Economic Studies, 82, pp. 535-564.

Canuto, O. and S. Ghosh, (2013),'Dealing with the Challenges of Macro Financial Linkages in Emerging Markets," The World Bank Economic Premise, No. 129, November.

Catao, L. and M. Terrones, (2016),'Financial De-Dollarization; A Global Perspective and the Peruvian Experience," IMF Working Papers, 16/97.

Claessens, S. and K. Forbes, (2001), "International Financial Contagion: An Overview of the Issues and the Book," 10.1007/978-1-4757-3314-3_1.January 2001.

ECB, (2004), "Cross-Border Bank Contagion Risks in Europe," IV Special Features, Financial Stability Review, December.

Espinosa-Vega, M.A. and J. Sole, (2010), "Cross-Border Financial Surveillance: A Network Perspective," IMF Working Paper, No. WP/10/105.

Fender, I. and P. McGuire, (2010), “European Banks’ US Dollar Funding Pressures,” BIS Quarterly Review, pp. 57-64, June.

IMF, (2010), "Understanding Financial Interconnectedness," Prepared by the IMF's Strategy, Policy and Review Department and the Capital Markets Department, in Collaboration with the Statistics Department and in Consultation with other Departments, 4 October, Available at: https://www. imf.org/ /media/Websites/IMF/imported-full-text-pdf/external/np/pp/eng/2010/_100410.ashx

Koch, C. and Remolona, E., (2018), "Common Lenders in Emerging Asia: Their Changing Roles in Three Crises," BIS Quarterly Review, 11 March.

Lane, P. R. and G. M. Milesi-Ferretti, (2007), "External Wealth of Nations Mark II: Revised and Extended Estimates of Foreign Assets and Liabilities 1970-2004," Journal of International Economics, 73, pp. 223-250 (updated in 2009).

Schnabl, P., (2012), "The International Transmission of Bank Liquidity Shocks; Evidence from an Emerging Market," J. Finance, 67 (3) (2012), pp. 897-932, 21 May.

Smaga, P., (2014), “The Concept of Systemic Risk,” SRC Special Paper, No. 5, August. 


\title{
Chapter 9
}

\section{CROSS BORDER INTERBANK CONTAGION RISK FROM VIETNAM'S BANKING SYSTEM}

\author{
By \\ Nguyen Ha Phuong, Phan Manh Cuong and Ngo Thi Huyen Linh ${ }^{1}$
}

\section{Introduction}

Opening one country's financial market brings both opportunities and challenges to its development. While some papers focus on the benefits of financial integration in an open economy, our research studies cross-border interbank contagion exposure for Vietnam's case, using the data from 2011-2017. Our research uncovers little evidence for contagion risk through the linkages of banks in the Asian region.

Vietnam is a developing country for which the banking system has been growing rapidly in terms of the asset volumes and the diversity of its services. At this point in time, Vietnam's banking system has become increasingly connected to the world's financial system, with the proliferation of overseas transactions between Vietnam's banks and foreign banks, the opening of foreign bank branches or investments in local banks and vice versa. Thus, the linkage between Vietnam's banks and foreign banks has been clear over time. While the Asian financial crisis of 1997 did not have too much effect on the financial sector in Vietnam, the global financial crisis in 2008 had a stronger impact on the Vietnamese banking system. However, up to now, there has been no research on the cross-border interbank contagion risk between the banking systems in Vietnam, the region or more broadly, the world. Meanwhile, while financial contagion is a rare phenomenon, nonetheless its repercussions are great but when it happens. As such, this research gap is important to be investigated.

Contagion means the spillover process of one issue onto others through some connections and interactions (European Central Bank, 2016). Interbank contagion refers to a situation in which the problem of one bank is transferred to other banks through some common channels. In interbank markets, contagion could occur when the liquidity assets of a bank are insufficient to absorb unexpected deposit outflows. As a result, market expectations can cause a spillover effect like a domino effect which can lead to a single bank's collapse which subsequently impacts other banks in the system. Freixas et al. (2000) study the correlation between depositors' behavior and/ or a bank's characteristics. An illustration of this is a liquidity crisis happening when a depositor knows other depositors are withdrawing their money from a bank in a particular region. He/she may start withdrawing his/her money without any plausible reason from his/her own non-problem bank, which may or may not be in the same area. The similarities in banks' credit concentration, investment portfolios, macroeconomic policies, capital base, may be other sources of correlation. Theory indicates that the extent to which a crisis spill-overs to the system depends a lot on the structure of the interbank linkages. Allen and Gale (2000) find that 3 structures, namely, (i) the "complete structure" that banks are linked to other banks symmetrically, (ii) the "incomplete market

1. Authors are from the Banking Strategy Institute, Banking Supervisory Agency and Monetary-Financial Stability Department of the State Bank of Vietnam, respectively. 
structure" that banks are only linked to neighboring banks, and (iii) the "disconnected incomplete market structure" that two disconnected markets coexist. The researchers prove that the "complete structure" is less prone to contagion as compared to the "incomplete market structure", because with the former structure, the effect of a financial crisis on one bank is absorbed by a number of banks.

To estimate interbank contagion risk, Muller (2003) combines a network and a simulation approach in order to assess contagion risk in the Swiss interbank market, taking credit and liquidity effects into account. Elsinger et al. (2006) simulates the joint effect of exchange rate shocks, interest rate shocks and stock market movements on interbank payment flows in Austrian banks. The researchers distinguish between insolvency caused by correlated exposures and by domino effects. Their simulation result shows that though the possibility of contagious default is lower than the total default possibility, there are situations where up to $75 \%$ of the defaults are caused by contagion.

In terms of this research, we find the following issues are important for investigation: Vietnam's SIBs clarification, assessment of their sensitiveness to potential domestic economic shocks, then extending the scope to external shocks. To elaborate further, we identify SIBs of Vietnam via simple financial ratios and their market share in terms of deposits, loans and/or other indicators. Subsequently, we determine the SIBs' main activities which can cover consumer loans, business loans, mortgages, derivatives, off balance sheet activities as well as the sources of funds for such business activities. Then we evaluate their sensitivity to potential internal economic shocks, including market risk and macroeconomic variables. The study then is extended to the external shocks.

This paper aims to contribute to the literature by investigating empirically the cross-border interbank contagion risk using BIS data on international interbank exposure. Our research combines qualitative and quantitative analysis by modelling the simulation of cross-border interbank contagion risk in Vietnam. Our main goal is to inform policy makers of the alternative scenarios of potential risk triggers of cross-border interbank contagion. Also, we highlight some recommendations to the regulators to mitigate contagion risk, firstly in Vietnam and secondly, in the South-East Asian region.

Our research includes four parts as follows: the first section focuses on and maps the interconnectedness of domestic SIBs with the key cross-border SIBs. Section 2 comprises an overview of the financial market - banking system in Vietnam. Section 3 discusses data and methodology. Section 4 elaborates the empirical research work already done on this topic, while Section 5 concludes. 


\section{An Overview of the Financial Market - Banking System in Vietnam}

\subsection{Overview on the Structure of the Banking System}

Vietnam's financial system includes credit institutions, securities companies and insurance companies. The banking system dominates with total assets accounting for more than $95 \%$ of the total assets of the whole financial system. In 2017, Vietnam's credit institutions (excluding people's credit funds) comprise of 7 State owned banks (SOBs) 2 , 28 Joint stock (private) commercial banks (JCBs), 7 foreign banks, 2 joint venture banks, 47 branches of foreign banks, 1 cooperative bank, 1 social policy bank, 18 non-bank credit institutions (including financial companies and finance leasing companies) and 3 microfinance institutions, established and operating under the Law on Credit Institutions 2010.

The total assets of credit institutions have increased, with total assets at the end of December 2017 reaching $10,001.8$ trillion VND, up by $17.6 \%$ from the end of 2016 , thanks to the development of Vietnam's economy, with the strongest increase recorded in the State Owned Banks $(+18.4 \%)$ and Joint stock (private) commercial banks $(+17.7 \%)$. Total assets of State owned banks and Joint stock banks in 2017 were 4,570 trillion dong and 5,431 trillion dong, respectively. By 2017, total assets reached over 10 trillion dong, up by $17.6 \%$ from 2016, equivalent to $200 \%$ of GDP in 2017.

In terms of total asset structure, $7 \mathrm{SOBs}$ accounted for $45.7 \%$ of the total assets of the credit system, while the remaining $54.3 \%$ belonged to JCBs and other credit institutions. It can be seen that while the proportion of assets of JCBs is on the rise, the SOBs still play the leading role in the banking sector.

Total equity of the system at the end of December 2017 reached 660.1 trillion dong, increasing by 65.2 trillion dong $(+11 \%)$ compared to the end of 2016. This is the highest rise since 2013 .

\subsection{Main Challenges}

\subsubsection{Capital Adequacy}

The banks are under pressure to raise capital to meet Basel II's minimum capital adequacy ratio. In 2017, the chartered capital and equity capital have improved, thanks to positive business outcomes of the system. Most credit institutions were able to meet the minimum capital adequacy ratio. However, if fully calculating the amount of specific provisions to be made when the debt is not restructured and retaining the group of debts under Decision 780 and Circular $09^{3}$, some credit institutions may have lower CARs. In addition, raising capital is currently difficult because business outcomes of the system have not been very stable, making it difficult to mobilize capital from the existing shareholders as well as finding new partners. For smaller banks, the ability to raise capital will be more difficult due to the less attractive earnings of shares while profit is mainly allocated to restructuring activities and dealing with bad debt activities.

2. List of SOBs: Agribank, Vietinbank, Vietcombank, BIDV, CB Bank, GP Bank, Ocean Bank.

3. Source: The State Bank of Vietnam. 


\subsubsection{Asset Quality}

In 2017, the process of dealing with bad debts of the financial institutions was accelerated, especially in the last months of the year, thanks to the impact of Resolution 42/2017/QH14 resolving bad debts of credit institutions. Resolution 42/2017/QH14 solves a number of obstacles for the effective disposal of bad debts including measures to improve the lender's ability to enforce collateral in order to facilitate credit institutions to revoke mortgages and release bad debts and at the same time, create favorable conditions for bad debt transactions in the secondary market. From August 2017 to December 2017, the total bad debts handled by Resolution 42/2017/QH14 was around 83.46 trillion dong. This outcome was made possible by the State Bank of Vietnam's (SBV) initiation of the VAMC - an agency responsible for creating the market for trading bad debts. The SBV also forced some commercial banks to restructure so that they could resolve their bad debt problems. Accordingly, the Governor of the State Bank issued Directive 02 on dealing with bad debts and restructuring credit institutions. At the same time, the Strategy for Banking Development of Vietnam also identifies the target that by the end of 2020, the bad debt ratio of the whole banking system should be kept under 3\%.

\subsection{Performance Indicators}

\subsubsection{Profitability}

Business outcomes reached the highest level since 2012, with many banks posting a sharp increase in profit compared to the end of 2016. The total revenue of the whole system in 2017 rose by $52 \%$ compared to 2016 in the context of macroeconomic stability and positive economic growth. The income structure was improved at some CIs due to the trend of increasing the proportion of services. The profitability of the credit system in 2017 was higher than that of 2016 as the difference in revenue and expenditure of the credit institutions has increased significantly (52\%) while total assets and equity have increased more gradually (up by $17.6 \% \%$ and $11.5 \%$ compared to the end of 2016). ROA and ROE in 2016 were $0.74 \%$ and $10.25 \%$ (2016 were $0.56 \%$ and $8.6 \%$ ) respectively, with the highest rise in $\mathrm{JCBs}^{4}$.

While business results at many banks improved, some banks had disappointing financial results because the owners of these banks violated some regulations and were involved in some risky investments. In addition, although the profit targets including ROA, ROE of CIs were quite high and stable compared to the previous year, they were still lower compared to other countries in the region. The risk associated with decreasing profit of CIs is still high and so is the size of bad debts and potential bad debts in the banking system.

\subsubsection{Capital Adequacy Ratio}

The capital adequacy ratio (CAR) for CIs in 2017 was $12.23 \%$, down from $12.84 \%$ at the end of 2016, lower than the average of 12.9\% for the period 2011-2017. By the end of December 2017 , most of the CIs had complied with the safety ratios in their operations. Violators among CIs were troubled commercial banks and weak financial leasing companies and financial companies. In addition, if calculating the full amount of specific provisions is to be deducted when the debt is not restructured to keep the group of debts under Decision 780 and Circular 09, there will be a number

4. Source: SBV. 
of credit institutions with lower CAR ratio. Even though the CAR ratio of the system by the end of December 2017 was still higher than the SBV's minimum requirement (9\%) and at many CIs, the CAR was much higher than the average, the CAR has nonetheless been declining recently. In addition, many commercial banks have met the minimum requirement of capital adequacy under Circular 36 (over 9\%), but is still relatively low, at less than $10 \%$.

\subsubsection{Growth of Credit}

Credit growth has been stable in the past two years, mainly due to the continued recovery of the economy and stable interest rates. By the end of 2017, outstanding loans reached 6,509 trillion dong, an increase of $18.24 \%$ over 2016 . Credits increased at all banks and commercial banks which currently have a dominant market share (49.9\%) compared to the whole system. The ratio of credit/ GDP has increased rapidly in recent years and by the end of 2017 , it reached $130 \%$, indicating that total credit has continued to support positive economic growth.

\subsubsection{Liquidity}

The LDR ratio increased from $87.74 \%$ in 2016 to $90.23 \%$ in 2017 , of which the LDR of the SOBs was $94.02 \%$ and the LDR of the JCBs was $84.17 \%$. These are higher than the ceiling level set by the SBV because the CIs boosted lending activity at the beginning of the year. However, the liquidity of the system was maintained, thanks to the SBV's increase in money supply through the purchase of more than 7.5 billion USD in 2017. In 2017, although credit growth was faster than capital mobilization, the interest rate remained relatively stable. Interest rates on long-term deposits fluctuated slightly, increasing only at a few small and medium sized banks, in order to improve the capital structure to meet the requirements of Circular 06/2016/TT-NHNN on the ratio of short-term funds to medium and long-term loans. However, the regulation on the ratio of short-term capital used for medium and long-term lending applicable to the CIs in 2018 was set at $45 \%$ as stipulated in Circular 19/2017/TT-NHNN dated 28/12/2017. The amendment of Circular $36 / 2014 /$ TT-NHNN will reduce the long-term capital of CIs, thus reducing the pressure on capital costs of some banks, especially banks with high ratios.

\subsubsection{NPLs}

Credit quality improved as bad debt decreased significantly compared to 2016. However, the bad debt ratio remained high and the debt of group 5 (the potential capital loss) still accounts for a large proportion. In 2017, the bad debt process of credit institutions was accelerated, especially in the last months of the year. However, if the calculation had been more circumspect, the data for bad debts could even be higher because bad debts trading at market price is limited and the process of restructuring weak banks is slow. Credit institutions mainly deal with bad debts through various forms such as debt sale, collateral settlement, credit risk provision. 


\section{Data and Methodology}

\subsection{Description of the Applied Methods}

Stress-testing (ST) is a commonly used method by banking supervision agencies around the world. The biggest advantage of this method is that it provides forecasts and tests the banking/ banking system's resilience under unfavorable economic conditions. The hypothetical events (scenarios) are attached to the model to analyze their impacts on the financial situation of the bank/ banking system, especially impacts on bank profits and capital due to asset depreciation.

Table 1

Assumptions (Scenarios) of Stress Test in Some Countries

\begin{tabular}{|l|l|}
\hline Hong Kong & $\begin{array}{l}\text { Scenario from basic to stress level is based on: (1) GDP growth rate; (2) China's } \\
\text { GDP growth rate; (3) Interest rate; (4) Real estate prices. }\end{array}$ \\
\hline Indonesia & $\begin{array}{l}\text { (1) A shift in debt collection capacity to less than 20\%; (2) Interest rate increased } \\
\text { by } 100 \text { basis points; (3) Rupiah depreciates 20\% on forward contracts less than 3 } \\
\text { months; (4) Government bond yield down by 20\%; (5) Real GDP growth declines. }\end{array}$ \\
\hline Malaysia & $\begin{array}{l}\text { Macroeconomic indicators are comparable to the worst levels in history such } \\
\text { as the 1997 East Asian financial crisis; the 2001 dot-com bubble and the SARS } \\
\text { outbreak in 2003; External factors such as prolonged recession on global and } \\
\text { regional scale. }\end{array}$ \\
\hline Philippines & $\begin{array}{l}\text { Scenario from basic to stress level based on: (1) National GDP growth rate; (2) } \\
\text { Interest rate; (3) Inflation rate (4) Deposit growth rate; (5) Exchange rates (to } \\
\text { USD). }\end{array}$ \\
\hline Singapore & $\begin{array}{l}\text { Various macroeconomic shocks; shocks to the world economy; Estimation of } \\
\text { income and dividend payments during stress horizon. }\end{array}$ \\
\hline Chinese Taipei & $\begin{array}{l}\text { (1) Declining revenue of corporate borrowers (2) Declining real income of } \\
\text { household borrowers (3) Declining collateral value of real estate. }\end{array}$ \\
\hline Thailand & $\begin{array}{l}\text { Scenario from the basic to the stress level is based on: (1) National GDP growth } \\
\text { rate and its components; (2) Interest rate; (3) Inflation rate (core and headline) (4) } \\
\text { Exchange rate (to US dollar) (5) Crude oil price (6) GDP growth rate of trading } \\
\text { partners. }\end{array}$ \\
\hline
\end{tabular}


There are currently two approaches to conducting stress testing: the top-down approach and the bottom-up approach. The "top-down" approach is implemented by regulators, while the "bottomup" approach is implemented by the individual bank. The advantage of a top-down approach is that it is easier to implement than a bottom-up approach as the regulator simply synthesizes the data and consistently applies the scenario parameters. Therefore, it allows the regulator to compare bank's results with one another. However, according to Cihak (2007), the downside of a top-down approach is that the application of aggregate data may underestimate risk concentration and ignore interlinks between banks. Depending on the specific characteristics of the banking system, central banks may choose a top-down or bottom-up approach or a combination of both.

\section{Bank's Stress Test - Bottom-up Approach}

Stress testing is recognized as one of the international practices for risk management. The Basel Capital Accord II requires financial institutions, especially banks, to periodically test banks' resilience in different adverse situations. The Basel Committee also issued the minimum criteria that banks should meet under a stress test.

International experience shows that supervisory agencies often require banks to conduct periodic (6 month or 1 year) stress tests, especially for banks which may pose contagion risk. Banks are now required to conduct annual stress tests. On the side of regulatory agencies such as central banks and financial supervision agencies, they will be responsible for issuing regulations on ST and evaluating the performance of ST in banks.

\section{Bank's Stress Test - A Top-down Approach}

Most supervisory agencies also conduct ST at a systematic level to predict the vulnerability of the whole system as well for each bank group, for timely and effective intervention. The Fed and Bank of England perform ST and publish ST results to classify various banking groups based on their financial soundness.

\begin{tabular}{|c|c|c|}
\hline & Top-Down & Bottom-Up \\
\hline Subject & Central bank/Supervision agencies & $\begin{array}{l}\text { Each bank builds its own tools or uses } \\
\text { internal models }\end{array}$ \\
\hline Data & $\begin{array}{l}\text { Use aggregate data of each bank or } \\
\text { system-wide data }\end{array}$ & $\begin{array}{l}\text { Use bank's portfolio/business data, or } \\
\text { customer data of each individual bank }\end{array}$ \\
\hline Impact analysis & $\begin{array}{l}\text { Evaluate the impact of each scenario } \\
\text { on the portfolio of the whole system or } \\
\text { individuals, assess capital quality }\end{array}$ & $\begin{array}{l}\text { Evaluate impacts of the scenario on } \\
\text { financial situation of each customer, } \\
\text { then sum up to consider the impact on } \\
\text { bank's portfolio and capital. }\end{array}$ \\
\hline Advantage & $\begin{array}{l}\text { Use effectively when assessing credit } \\
\text { risk. } \\
\text { Allows bank comparison and assess } \\
\text { spillover effects. }\end{array}$ & $\begin{array}{l}\text { Due to bank's specific data, it could } \\
\text { well reflect the situation of liquidity } \\
\text { risk and market risk in each category. }\end{array}$ \\
\hline Disadvantage & $\begin{array}{l}\text { It does not clearly reflect risk status of } \\
\text { each bank }\end{array}$ & $\begin{array}{l}\text { Difficult to compare results of banks } \\
\text { together. }\end{array}$ \\
\hline
\end{tabular}

Source: Siregar (2011). 


\section{Application of the Stress Test in Assessing the Ability of Risk Resilience of Commercial Banks}

The top-down stress test approach is being applied to some developing countries (including Vietnam $^{5}$ ) by the FSAP Team of the World Bank (WB) and the International Monetary Fund (IMF). This model is based on the model of Cihak (2007) and Li Lian Ong et al. (2010). The model does not require data that is too detailed and or accumulated over a long range of time. It is therefore easy to implement and in accordance with the real conditions of data and technology of developing countries.

The WB/IMF Stress Test model uses balance sheet data, statistical reports and aggregated information from the Credit Information Center (CIC) with a sample of all commercial banks (excluding foreign bank branches, non-bank credit institutions) with total assets accounting for nearly $90 \%$ of total assets of the whole system. Different stress scenarios are used in the model to assess the ability to withstand credit, market, interbank, and liquidity risks as follows:

- Credit Risk: adjust the data by transferring the debt group with the assumption that banks did not classify debt properly, the value of the collateral is not properly assessed; analyze impact of macroeconomic factors (with variables: output gap, real interest rate and real effective exchange rate (REER)) on bad debt and thereby on capital by the Vector Auto Regression (VAR) model.

- Market Risk: analyze the impact of interest rate shocks and the VND depreciation on the capital through futures gap analysis and foreign currency performance based on the worst scenario determined by unfavorable movement of exchange rate and interest rates statistics in the past;

- Interbank Risk: analyze the impact of a bank in the event of a bank being unable to pay for loans/deposits from other banks;

- Liquidity Risk: analyze liquidity after five days of bank-run with assumed rates of withdrawal, asset utilization (high liquidity and high liquid assets).

In addition, through the impact assessment of shocks to capital, the model is able to determine the size of capital that needs to be injected into the banking system in the event of a crisis to ensure that all banks in the system meet the minimum capital adequacy requirement.

\subsection{The Suitability of the Chosen Specific Methods}

Stress tests consist of an assessment of a bank's resilience, measured by the sufficiency of its capital or liquidity in the face of shocks to risk factors. The tests can be based on single factor shocks (e.g., changes in CAR resulting from a large increase in NPLs or interest rates) or scenario analysis, including macroeconomic stress scenarios (e.g., increases in NPLs and decreases in CAR following severe, but plausible changes in macroeconomic variables). Stress tests normally cover the main risks to financial stability, namely: credit risk, market risk (e.g., interest rate risk, exchange rate risk), concentration risk, (interbank) contagion risk, and liquidity risk. The scope, depth and accuracy of the analysis of such risks are usually driven by data availability, capacity constraints (e.g., existing model-ware, know-how) and the complexity of the banking sector itself. In this study, we conducted a top-down test to assess the impact of D-SIBs on the performance of the banking system in Vietnam.

5. The model is applied under the framework of Financial Sector Assessment Program (FSAP) in Vietnam in 2013 to assess the resilience of the banking system to adverse shocks. 
The stress test uses data from 2017 audited consolidated financial statements of 15 banks identified as D-SIBs and hypothetical scenarios based on the real market and bank system conditions in Vietnam such as bad debt, cross ownership rate, exchange rate, interest rate, real estate price, etc.

\section{Empirical Part}

\subsection{Identification of D-SIBs}

\subsubsection{D-SIBs Identification Methodology}

Circular 08/2017/TT-NHNN dated 1 August 2017 on the submission and the procedures for banking supervision of the State Bank of Vietnam defines D-SIBs as credit institutions, branches of foreign banks that have systemic importance; providing the objectives of banking supervision by the degree of impact of various institutions on the system. Accordingly, credit institutions and branches of foreign banks are identified as systemically important when they have the ability to cause a negative impact on the entire system of credit institutions, foreign bank branches and/or when systemic risks disrupt the operation of the system of credit institutions, branches of foreign bank and the whole economy in case of insolvency.

We apply the approach developed by FSB, IMF, BIS (2009), BCBS 2011 and Zlatuse Komarkova et al. (2012), using static quantitative indicators for identifying D-SIBs in Vietnam with the aim of officially providing more stringent requirements for regulating and supervising CIs recognized in this category (D-SIBs) compared to other CIs in the future, thus addressing the systemic risks arising from the structure of "too big to fail", and "orderly exit of small weak banks" that are not systemically important. Based on the current level of development of the Vietnamese banking sector, we provide simpler quantitative indicators compared to the original studies. However, it still maintains the suitability and reliability for identifying D-SIBs in Vietnam.

\section{Principle}

The systematic importance of banks is assessed in two steps. Firstly, define quantitative scores using a set of indicators of scale, degree of alignment, and substitutability. And secondly, use qualitative assessments, monitoring information to supplement the quantitative assessment in the first step. Banks can be removed from or added to the list identified in step one.

\section{Quantitative Assessment}

The systematic importance of the banks in the sample was assessed according to the indexbased measurement method, based on the scores of the indicator groups: size, interconnectedness, substitutability.

i) Size. This is a primary measure of systemic importance. The larger the bank, the more likely it is that the sudden stopping of a service will be widespread and therefore the more likely it will be for the bank to disrupt the financial market and the banking system, and to the broader functioning of the economy. This measure looks at the overall size of banking activity in the system and economy and provides a precise measure of potential systemic impacts in the event of a bank collapse. The extent of loss from a bank's insolvency to the stability of its entire financial system and economy depends largely on the size of its assets and the amount of its 
services and the financing that the bank provides. A large-scale bank usually comes with a high degree of alignment, complexity and low replacement.

ii) Interconnectedness. This indicator represents the degree of association of a bank with other financial institutions that may give rise to external factors affecting the financial system and the domestic economy in Vietnam. Systemic risk can occur through the insolvency of a bank that has a significant impact on the financial system.

iii) Substitutability. This indicator assesses the systematic importance of the banks in its operation as a provider of infrastructure services. The bigger the bank, the harder it is to replace it, and the more likely it is that the risk will cause a disruption in the event of a bank failure. The level of importance of a bank's system increases as other credit institutions are less likely to provide similar services in the event that the bank ceases to operate.

The weighting and scores of the indicator groups for the whole sample are as follows:

Table 2

Weighting and Scores of Some Indicators

\begin{tabular}{|l|l|c|c|}
\hline Indicate & Individual Indicate & Weight & Score \\
\hline Size & Total Assets & $50 \%$ & 2 \\
\hline \multirow{5}{*}{ Interconnectedness } & $\begin{array}{l}\text { Total assets in the financial system } \\
\text { Include: } \\
- \text { Deposits at the SBV; } \\
- \text { Loans and deposits at other credit institutions; } \\
- \text { Securities issued by other credit institutions; } \\
- \text { Contribution of capital, long-term investment to } \\
\text { other CIs }\end{array}$ & $12.5 \%$ & 0.5 \\
\cline { 2 - 4 } & $\begin{array}{l}\text { Total debt assets in the financial system } \\
\text { Include: } \\
- \text { Debts owed by the Government and the SBV; } \\
- \text { Borrowing and receiving deposits from other } \\
\text { credit institutions. }\end{array}$ & $12.5 \%$ & 0.5 \\
\hline \multirow{2}{*}{ Substitutability } & $\begin{array}{l}\text { Deposits of customers } \\
\text { Lotal }\end{array}$ & $12.5 \%$ & 0.5 \\
\cline { 2 - 4 } & Loans to customers & $12.5 \%$ & 0.5 \\
\hline \multirow{2}{*}{ Total } & $100 \%$ & 4 \\
\hline
\end{tabular}

\section{Qualitative Assessment}

Based on the results of the quantitative scores, the State Bank will combine these with the qualitative assessment from the results of the inspection and supervision of D-SIB, taking into account the complexity of the bank. the number and size of branches, the number and size of subsidiaries, the level of complexity in the operation, the derivative transactions and the role and importance of the financial infrastructure, which includes the role of the payment system. 


\subsubsection{Identification of D-SIBs in Vietnam}

Based on the static quantification methodology with 3 categories: size, interconnectedness and replacement, we use the annual financial statement audited data of credit institutions as well as consider the complexity of banks through the number and size of branches, the number and size of subsidiaries, the complexity in operations and derivatives transactions of banks. We then calculate the systemic importance and identify the 15 D-SIBs in Vietnam.

Table 3 below represents the results obtained from the above methodology of identifying the 15 CIs as D-SIBs for Vietnam in 2017. The ranking and key system scores of each bank are shown below:

Table 3

The 15 D-SIBs in Vietnam

\begin{tabular}{|c|c|c|c|c|c|c|c|c|}
\hline \multirow[b]{3}{*}{ Rank } & \multirow[b]{3}{*}{ CIs } & \multicolumn{5}{|c|}{ Score of the Indicator Group } & \multirow{3}{*}{$\begin{array}{l}\text { Total } \\
\text { Scores }\end{array}$} & \multirow{3}{*}{$\begin{array}{l}\text { Total } \\
\text { Scores } \\
(\%)\end{array}$} \\
\hline & & \multirow{2}{*}{$\begin{array}{l}\text { Size } \\
\text { Total } \\
\text { Assets }\end{array}$} & \multicolumn{2}{|c|}{ Interconnectedness } & \multicolumn{2}{|c|}{ Substitutability } & & \\
\hline & & & $\begin{array}{l}\text { Total } \\
\text { Assets } \\
\text { to the } \\
\text { System }\end{array}$ & $\begin{array}{l}\text { Total } \\
\text { Liability } \\
\text { to the } \\
\text { System }\end{array}$ & $\begin{array}{l}\text { Deposits } \\
\text { from } \\
\text { Customers }\end{array}$ & $\begin{array}{l}\text { Loans to } \\
\text { Customers }\end{array}$ & & \\
\hline 1 & Bank 1 & 0.22 & 0.05 & 0.04 & 0.05 & 0.06 & 0.43 & 10.80 \\
\hline 2 & Bank 2 & 0.23 & 0.04 & 0.02 & 0.07 & 0.07 & $\mathbf{0 . 4 3}$ & 10.63 \\
\hline 3 & Bank 3 & 0.23 & 0.04 & 0.07 & 0.06 & 0.07 & 0.47 & 11.77 \\
\hline 4 & Bank 4 & 0.18 & 0.07 & 0.06 & 0.05 & 0.04 & 0.41 & 10.18 \\
\hline 5 & Bank 5 & 0.08 & 0.00 & 0.01 & 0.02 & 0.02 & 0.13 & 3.25 \\
\hline 6 & Bank 6 & 0.03 & 0.01 & 0.00 & 0.01 & 0.01 & 0.06 & 1.42 \\
\hline 7 & Bank 7 & 0.05 & 0.01 & 0.00 & 0.02 & 0.02 & 0.09 & 2.37 \\
\hline 8 & Bank 8 & 0.05 & 0.01 & 0.01 & 0.01 & 0.01 & 0.10 & 2.57 \\
\hline 9 & Bank 9 & 0.05 & 0.02 & 0.01 & 0.01 & 0.01 & 0.11 & 2.76 \\
\hline 10 & Bank 10 & 0.06 & 0.02 & 0.01 & 0.02 & 0.01 & 0.12 & 2.98 \\
\hline 11 & Bank 11 & 0.02 & 0.01 & 0.01 & 0.00 & 0.00 & 0.04 & 0.93 \\
\hline 12 & Bank 12 & 0.02 & 0.01 & 0.02 & 0.00 & 0.01 & 0.06 & 1.45 \\
\hline 13 & Bank 13 & 0.08 & 0.01 & 0.02 & 0.02 & 0.02 & 0.15 & 3.82 \\
\hline 14 & Bank 14 & 0.05 & 0.01 & 0.02 & 0.01 & 0.02 & 0.11 & 2.87 \\
\hline 15 & Bank 15 & 0.03 & 0.01 & 0.01 & 0.01 & 0.01 & 0.07 & 1.63 \\
\hline & Total & 1.39 & 0.31 & 0.31 & 0.38 & 0.39 & 2.78 & 69.42 \\
\hline
\end{tabular}




\subsection{Stress Testing D-SIBs}

\subsubsection{Data Adjustments}

Reported values of capital, collateral and loans by classification were adjusted to reflect the economic reality of the banking system before ST. The adjustments include:

Adjustment 1: An initial X\% haircut on regulatory capital is applied to all D-SIBs, reflecting indirect cross-ownership among banks, leading to "double-counting" of capital (Capital 1).

Adjustment 2: This adjustment relates to the re-classification of loans.

Adjustment 3: This adjustment relates to the treatment of collateral: first the implied value of collateral for each loan category is estimated based on the reported loan amount and the corresponding provision using the statutory provision rates of that loan category. Subsequently, a $\mathrm{Y} \%$ average haircut is applied to the implied collateral value of each bank, to account for collateral (mostly real estates) valuation deficiencies.

Finally, following these adjustments, the resulting "starting point" capital (Capital-2) is computed by deducting from the Capital-1 the additional provisions that would be obtained by applying the corresponding provisioning rates to the re-classified loan amounts, net of adjusted collateral, in each of the five loan categories.

\subsubsection{Results}

The following stress tests were carried out under the static balance sheet assumption to deal with credit risk, market (mainly interest rate and exchange rate) risks, concentration risks and liquidity risk.

For the group of 15 D-SIBs, borrowing and deposit-taking from the interbank in 2017 were in relatively small amounts in proportion to total assets for most of the banks. Contagion risks were assessed based on the interbank matrix which includes the net lending between banks in the system.

Scenario: This scenario assumes the default of each bank at a time for all of its interbank obligations and the impact on other banks. If the default of any bank for its interbank obligations implies the default of another bank within the system, then the second iteration should be calculated to assess the impact of the bank default on all other banks.

Through the assessment, it is found that the contagion risks are at a very low level. The impact of a bank default on its interbank obligations from other banks will stop from the first iteration without the contagion of insolvency on other banks in the interbank system.

We also use Bank for International Settlements (BIS) locational statistical data which covers individual countries and the amount outstanding of cross-border bank exposures between Vietnam and other countries. The reporting countries are required to report the credit exposures of their domestic banks to other countries in the country list and the amount outstanding of credit exposure from each reporting country to the other countries. From the list of countries reporting, there are only 12 countries out of 31 countries with reporting data. Based on this available data, we assessed that there is no impact from reporting countries on Vietnam. 
The following figures show the relationship between Vietnam and other reporting countries based on the data from BIS.

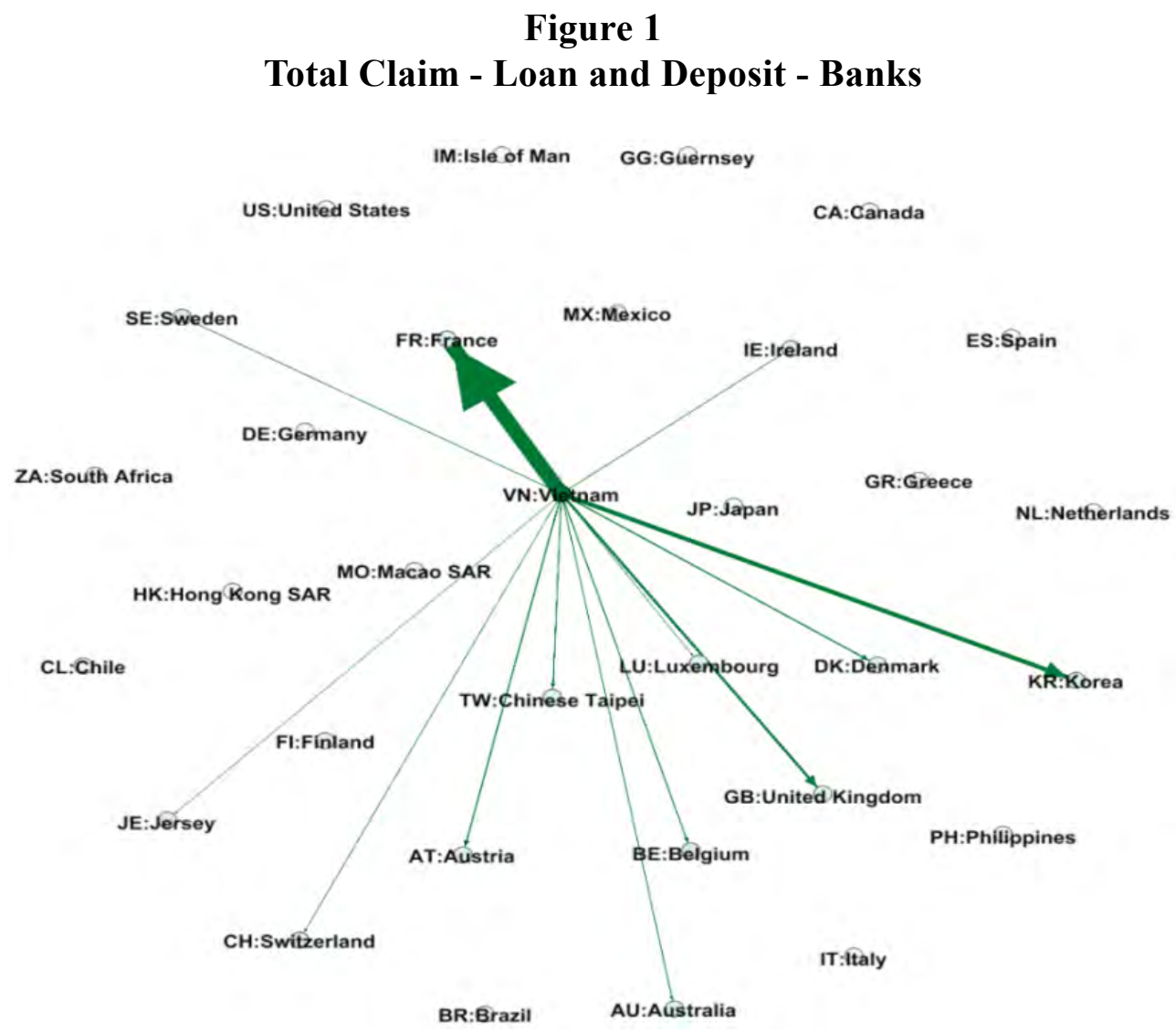

Figure 2

Total Claim - Non-conventional Bank

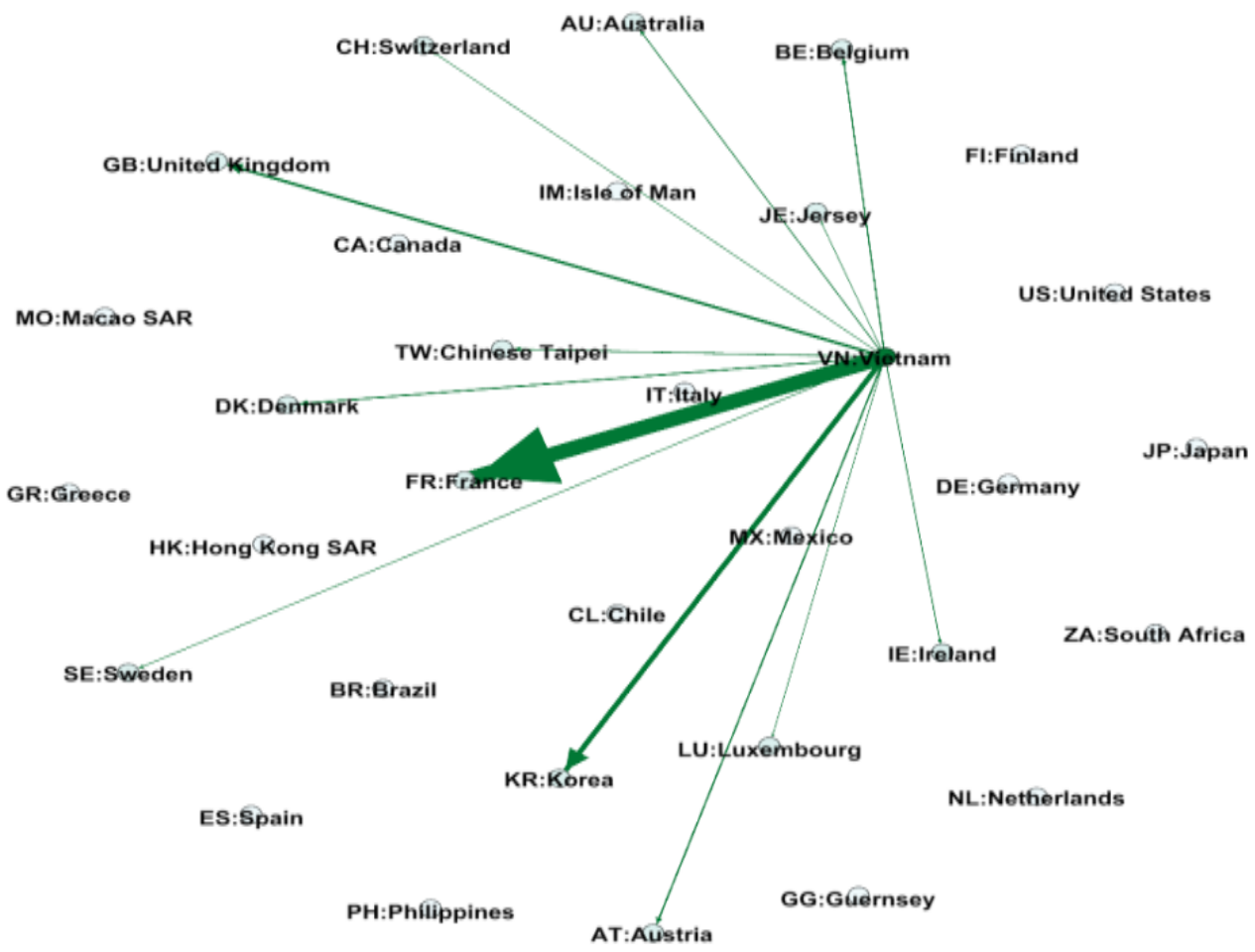




\section{Figure 3}

Total Claim - Loan and Deposit - Non-bank

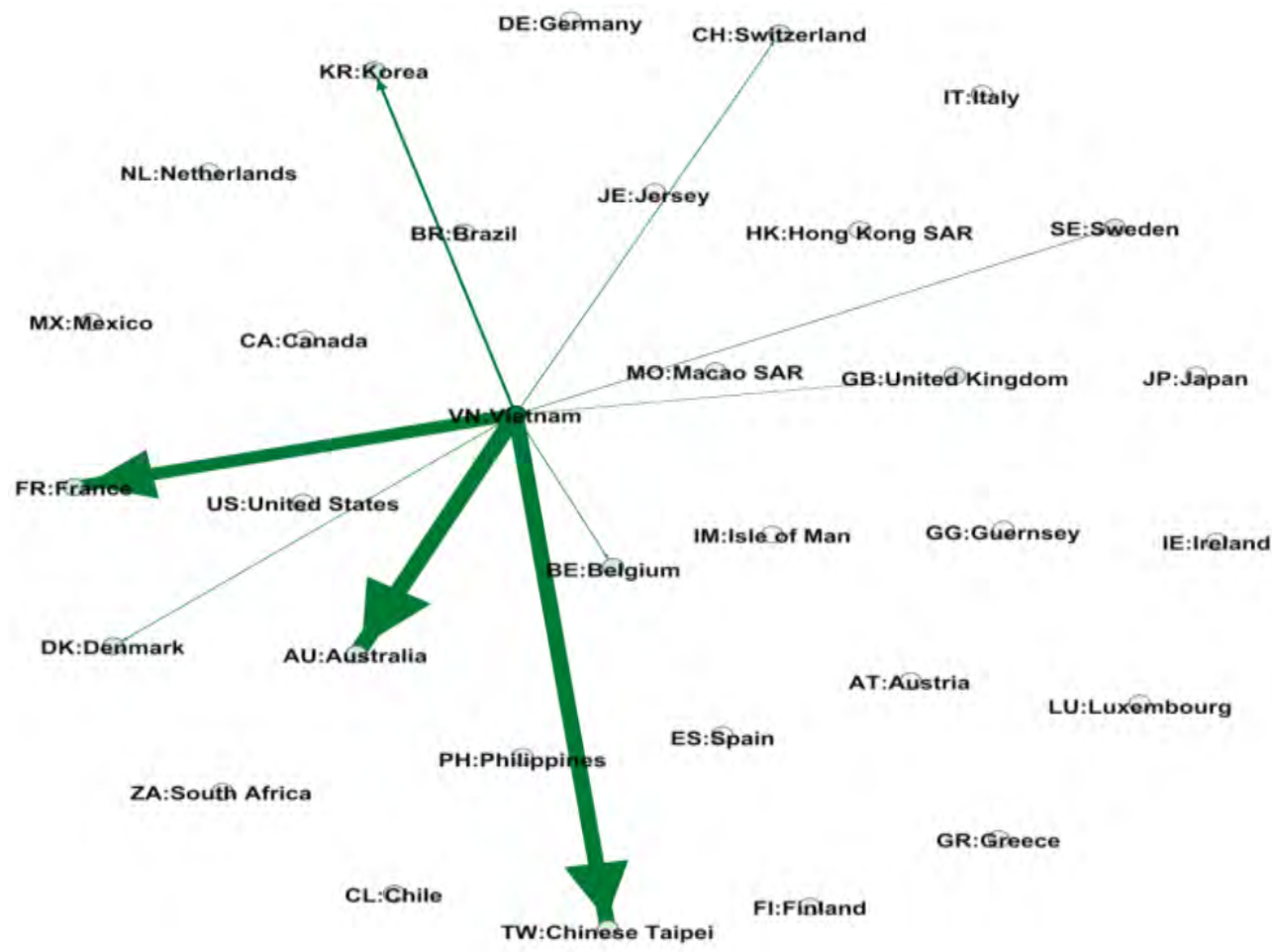

Figure 4

Total Claim - Non-conventional Non-banks

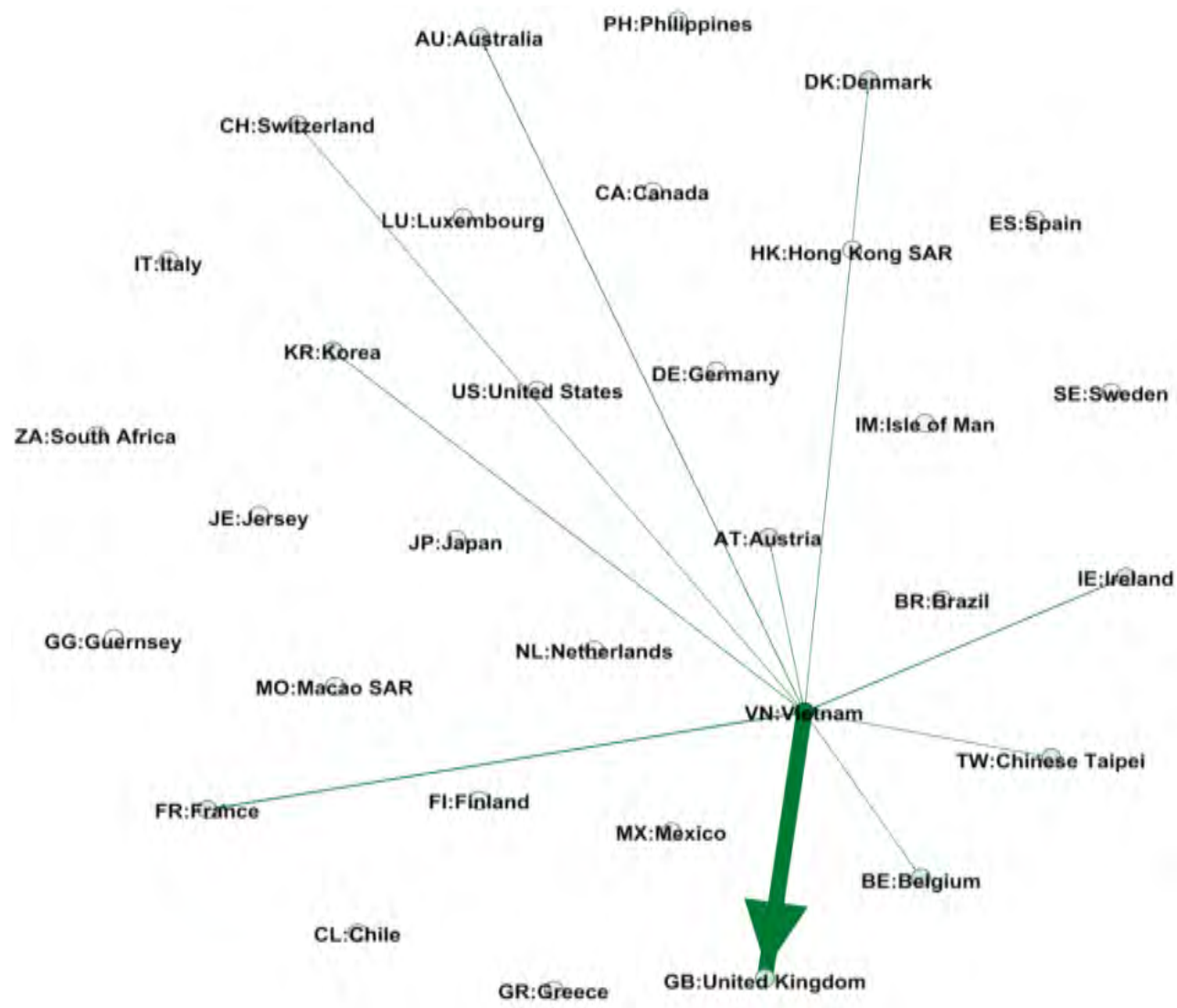




\section{Figure 5}

Total Liability - Loan and Deposit Banks

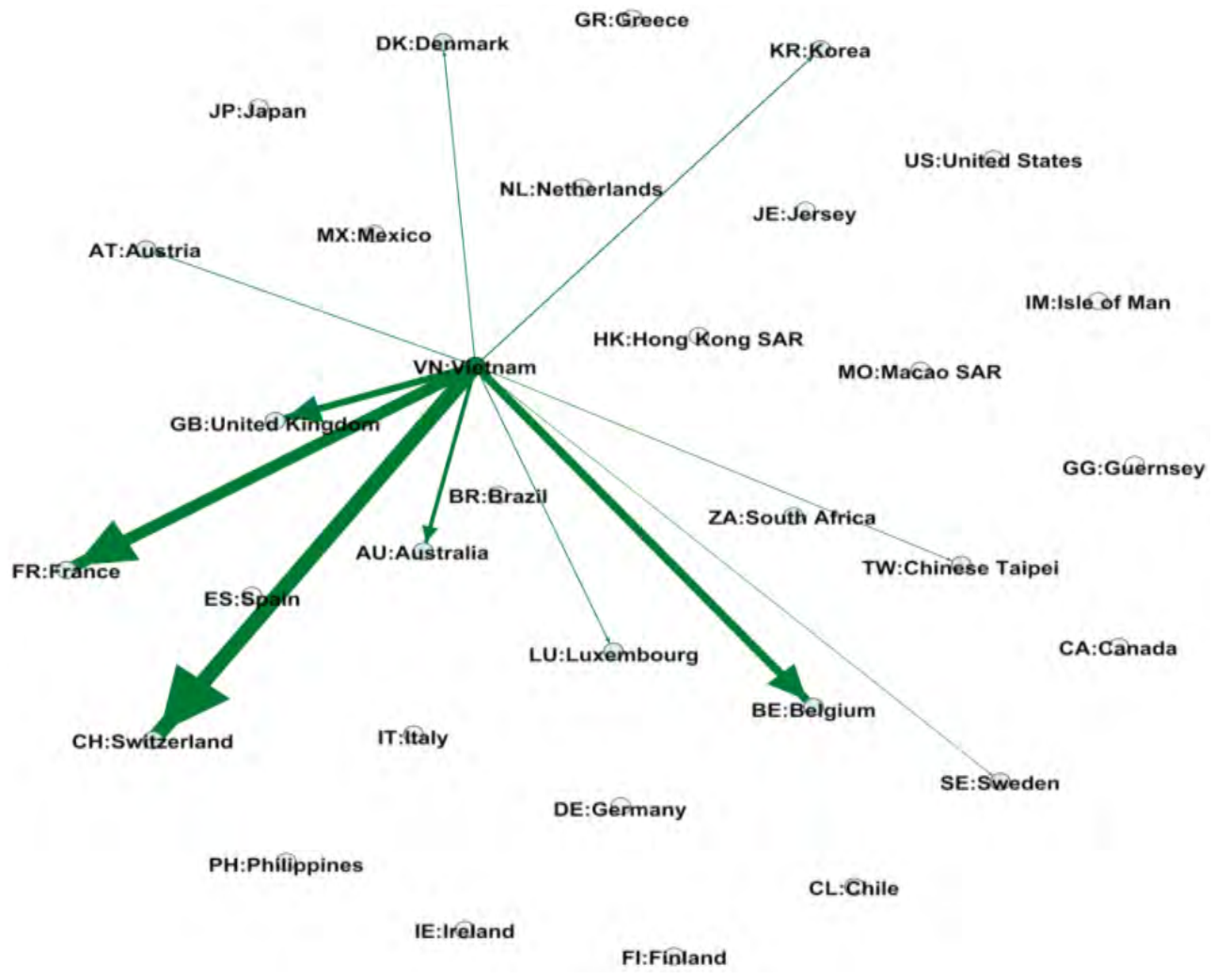

Figure 6

Total Liability - Non-conventional Banks

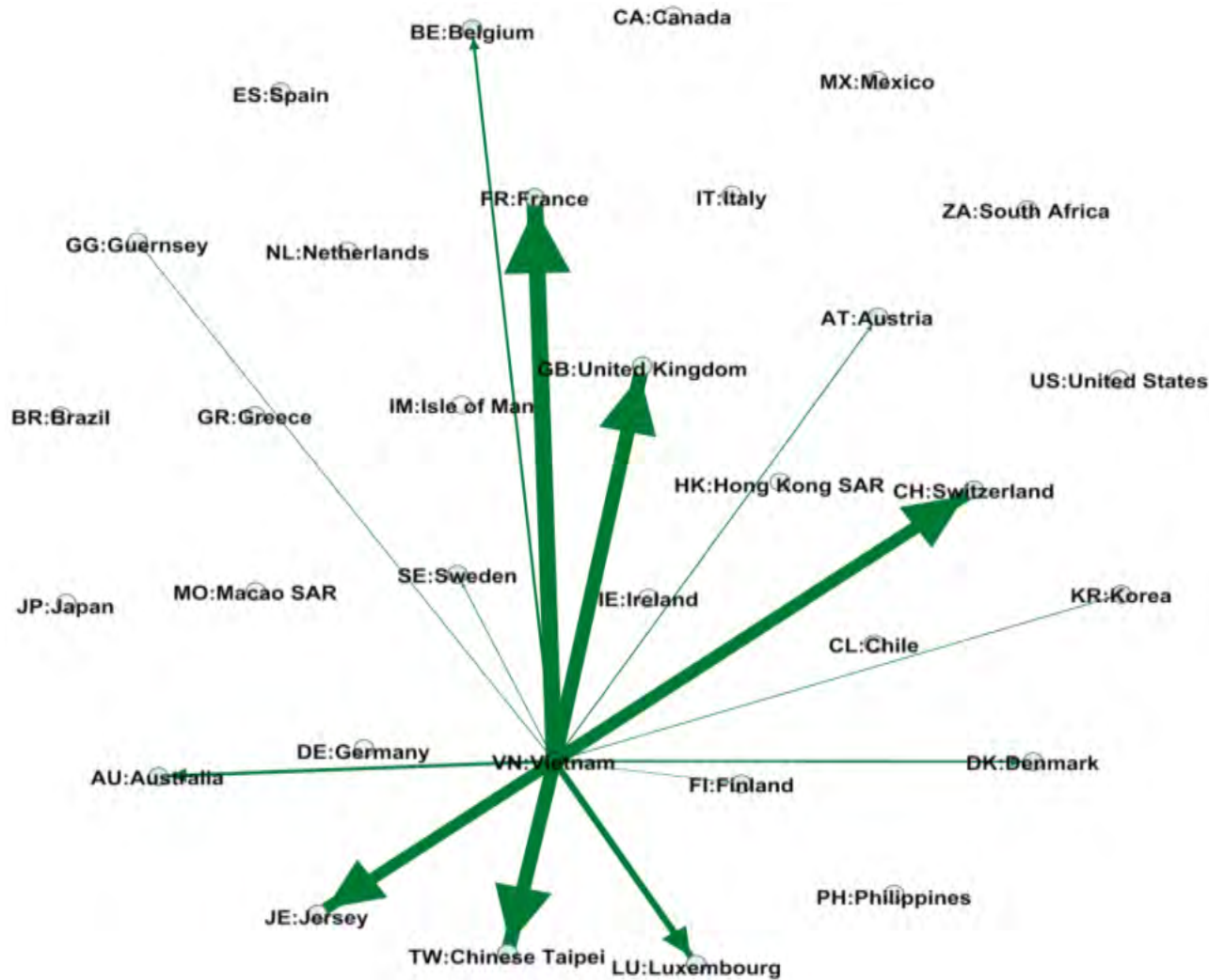




\section{Figure 7}

Total Liability - Loan and Deposit Non-banks

AT:AUstria ES:Spain
BR:Brazil
GB:United Kingdom

FI:Finland

GR:Greece

ZA:South Africa

IT:Italy

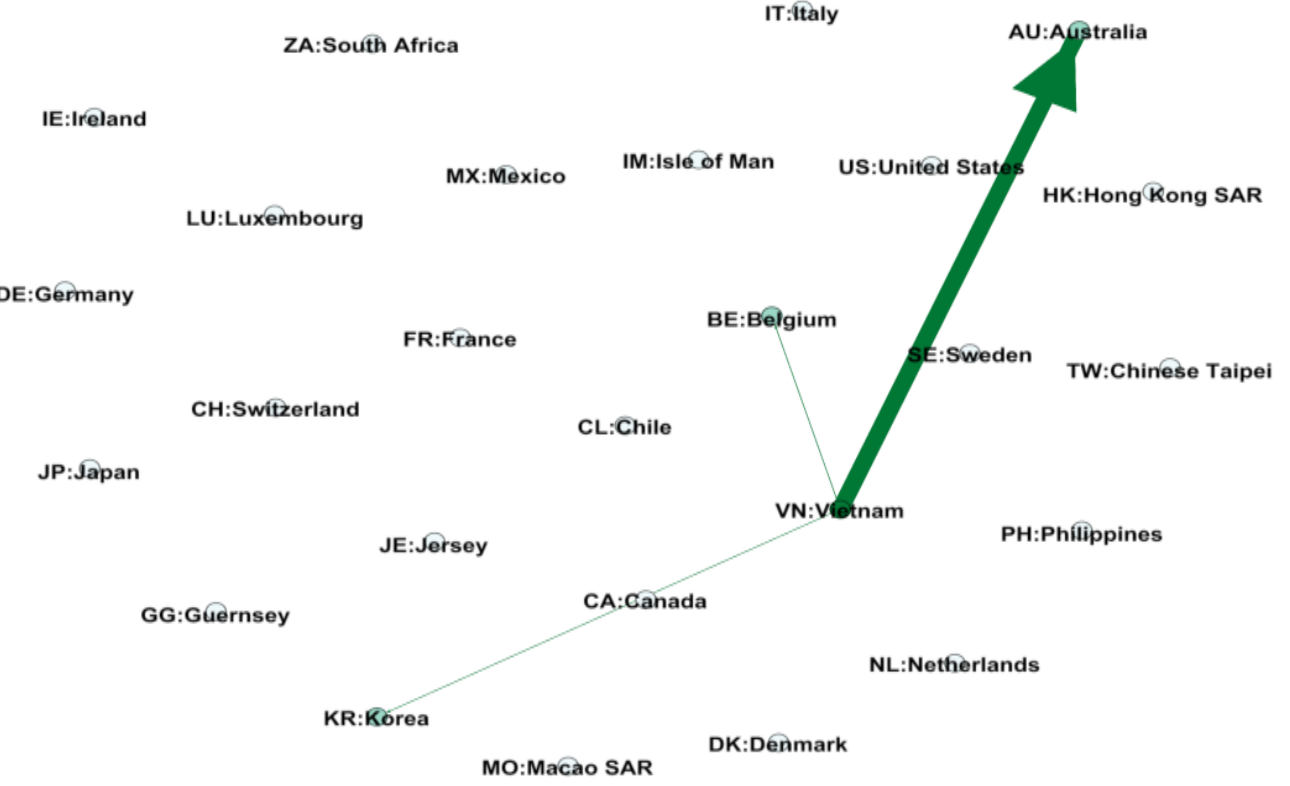

Figure 8

Cross-border Bank Exposure Network

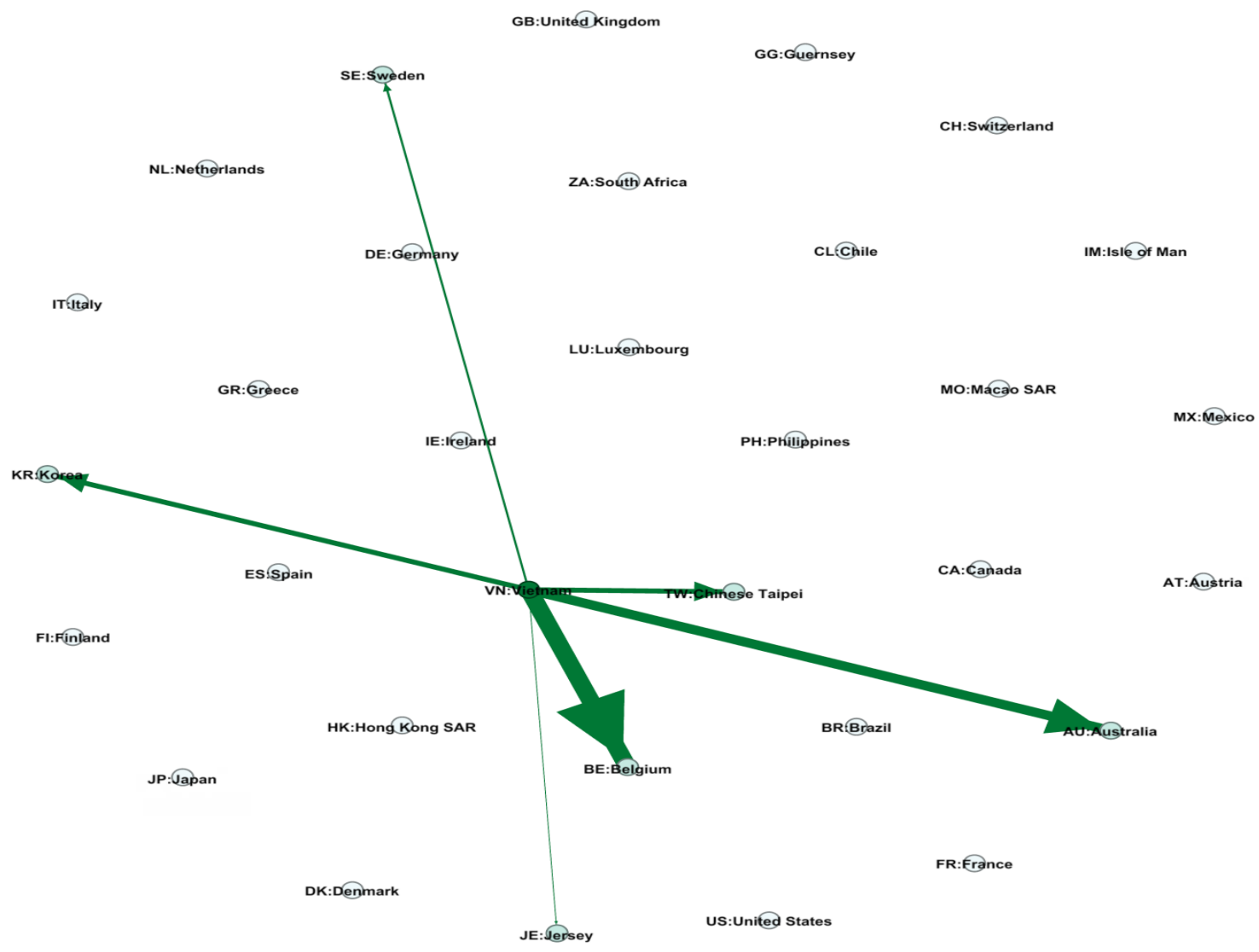


The figures are the network maps between Vietnam and other reporting countries based on the data from BIS. Figure 1 shows the total claim-loan and deposit-banks between Vietnam and reporting countries (Austria, Australia, Belgium, Brazil, Canada, Switzerland, Chile, Germany, Denmark, Spain, Finland, France, United Kingdom, Guernsey, Greece, Hong Kong, Ireland, Isle of Man, Italy, Jersey, Japan, Korea, Luxembourg, Macao SAR, Mexico, Netherlands, Philippines, Sweden, Chinese Taipei, United States, and South Africa). The connections between Vietnam and other countries are illustrated by the arrows. However, some countries are reporting with empty data. Also, with the data provided, the map indicates a one- way relationship between Vietnam with reporting countries and also between reporting countries.

\section{Conclusions}

In this paper, we examined the systemic risk for the Vietnam interbank market associated with the cross-border linkages between Vietnam and other countries. The empirical results from the contagion risk assessment for the 15 D-SIBs in Vietnam, show that there is very low level of contagion risk of one bank's default on its obligation with other banks from interbank linkages. Also, the impact from other countries on Vietnam with linkages are low and do not have any impact.

We also find that the network has low connectivity between Vietnam and other countries for banking activities. In this sense, the empirical analysis examines the relationship between cross-border links among banking systems and financial stability, taking the network structure into account. The result suggests that the effect of integration in international interbank markets on stability is unclear. The analysis has relevant policy implications as it reveals that the resilience of the banking system is affected both positively and negatively by interdependencies in the banking network. The main objective of policymakers should thus be to keep the benefits of international risk-sharing as well as geographical diversification gains while limiting fragility costs (Tonzer, 2013). 


\section{References}

BCBS, (2011), Global Systemically Important Banks: Assessment Methodology and the Additional Loss Absorbency Requirement, Basel Committee on Banking Supervision, November.

BCBS, (2011), Basel III: A Global Regulatory Framework for More Resilient Banks and Banking Systems.

BCBS, (2011b), "Assessment of the Macroeconomic Impact of Higher Loss Absorbency for Global Systematically Important Banks," BIS Publication, October.

BCBS, (2012a), A Framework for Dealing with Domestic Systemically Important Banks, Bank for International Settlement, October.

BCBS, (2012b), "Principles for the Supervision of Financial Conglomerates," BIS Publication, September.

Berg, S. A., (2011), "Systemic Surcharges and Measures of Systemic Importance," Journal of Financial Regulation and Compliance, 19(4), pp. 383-395.

Delpini, D.; S. Battiston; M. Riccaboni; G. Gabbi; F. Pammolli and G. Caldarelli, (2013), "Evolution of Controllability in Interbank Networks," Scientific Reports, 3 (1626), 1.

Drehmann, M. And N. Tarashev, (2011), "Systemic Importance: Some Simple Indicators," BIS Quarterly Review, March.

FSB, (2011), Policy Measures to Address Systemically Important Financial Institutions - Cannes Summit in November 2011.

FSB, (2010), Reducing the Moral Hazard Posed by Systemically Important Financial Institutions, FSB Recommendations and Time Lines, Financial Stability Board, October.

FSB, IMF, BIS, (2009), Guidance to Assess the Systemic Importance of Financial Institutions, Markets and Instruments: Initial Considerations, Financial Stability Board, International Monetary Fund and Bank for International Settlements, Report to G20 Finance Ministers and Governors, October.

IMF, (2010), "Systemic Risk and the Redesign of Financial Regulation," in: Global Financial Stability Report, April, pp. 63-90.

Kreis, Y. and D. Leisen, (2015), “A Structural Model of Bank Default Linkages,” Gutenberg School of Management and Economics, University of Mainz, Germany.

Monetary Authority of Singapore, (2015), MAS' Framework for Impact and Risk Assessment of Financial Institutions.

Moore, Kyle and Chen Zhou, (2012), Identifying Systemically Important Financial Institutions: Size And Other Determinants, April. 
Poledna, S. and S. Thurner, (2014), Elimination of Systemic Risk n Financial Networks by Means of a Systemic Risk Transaction Tax, University of Vienna.

PWC, (2011), Basel III and Beyond: Systemically Important Financial Institutions (SIFIs), November.

Tarashev, N.; C. Borio and K. Tsatsaronis, (2010), “Attributing Systemic Risk to Individual Institutions," BIS Working Paper, 308.

Tonzer, Lena, (2013), "Cross-Border Interbank Networks, Banking risk and Contagion,” FIW Working Paper, No. 129.

Upper, C., (2011), "Simulation Methods to Assess the Danger of Contagion in Interbank Markets," Journal of Financial Stability, 7(3), pp. 111-125.

U.S. Department of Justice and the Federal Trade Commission, (2010), Horizontal Merger Guidelines, U.S. Department of Justice.

Võ Trí Thành, et.al., (2013), Giám sát hệ thống tài chính, chỉ tiêu và mô hình định lượng, Báo cáo nghiên cứu RS - 03, Ủy ban Kinh tế của Quốc hội và UNDP tại Việt Nam.

Wong, J. and T. Fong, (2008), "Stress Testing Banks Credit Risk Using Mixture Vector Autoregressive Models," HKMA Working Paper, 13/2008.

Zlatuse, Komarkova; Václav Hausenblas and Jan Frait, (2012), "How To Identify Systemically Important Financial Institutions," Chapter Thematic Article 1 in CNB Financial Stability Report 2011/2012, 2012, pp 100-11. 